\title{
Studies on vegetation-, fire-, climate- and human history in the mid- to late Holocene - a contribution to protection and management of the forest-steppe-biome in the Mongolian Altai
}

\author{
Dissertation \\ zur Erlangung des mathematisch-naturwissenschaftlichen Doktorgrades \\ „Doctor rerum naturalium“ \\ der Georg-August-Universität Göttingen \\ im Promotionsprogramm Biologie \\ der Georg-August University School of Science (GAUSS)
}

vorgelegt von

Julia Unkelbach

aus Bonn

Göttingen, 2020 


\section{Betreuungsausschuss}

Prof. Dr. Hermann Behling, Abteilung für Palynologie und Klimadynamik, Albrecht-vonHaller-Institut für Pflanzenwissenschaften, Georg-August-Universität Göttingen

Prof. Dr. Erwin Bergmeier, Abteilung für Vegetationsanalyse und Phytodiversität, Albrecht-von-Haller-Institut für Pflanzenwissenschaften, Georg-August-Universität Göttingen

\section{Mitglieder der Prüfungskommission}

$\underline{\text { Referent: }}$

Prof. Dr. Hermann Behling, Abteilung Palynologie und Klimadynamik, Albrecht-vonHaller-Institut für Pflanzenwissenschaften, Georg-August-Universität Göttingen

\section{Korreferent:}

Prof. Dr. Erwin Bergmeier, Abteilung Vegetationsanalyse und Phytodiversität, Albrechtvon-Haller-Institut für Pflanzenwissenschaften, Georg-August-Universität Göttingen

\section{Weitere Mitglieder der Prüfungskommission:}

Jun.-Prof. Dr. Michaela Dippold, Abteilung Biogeochemie der Agrarökosysteme, Department für Nutzpflanzenwissenschaften, Georg-August-Universität Göttingen

PD Dr. Dirk Gansert, Abteilung Ökologie und Ökosystemforschung, Albrecht-von-HallerInstitut für Pflanzenwissenschaften, Georg-August-Universität Göttingen

PD Dr. Ina Meier, Abteilung Ökologie und Ökosystemforschung, Albrecht-von-HallerInstitut für Pflanzenwissenschaften, Georg-August-Universität Göttingen

Prof. Dr. Alexander Schmidt, Abteilung Geobiologie, Geowissenschaftliches Zentrum der Universität Göttingen, Georg-August-Universität Göttingen 
Für meine Eltern 


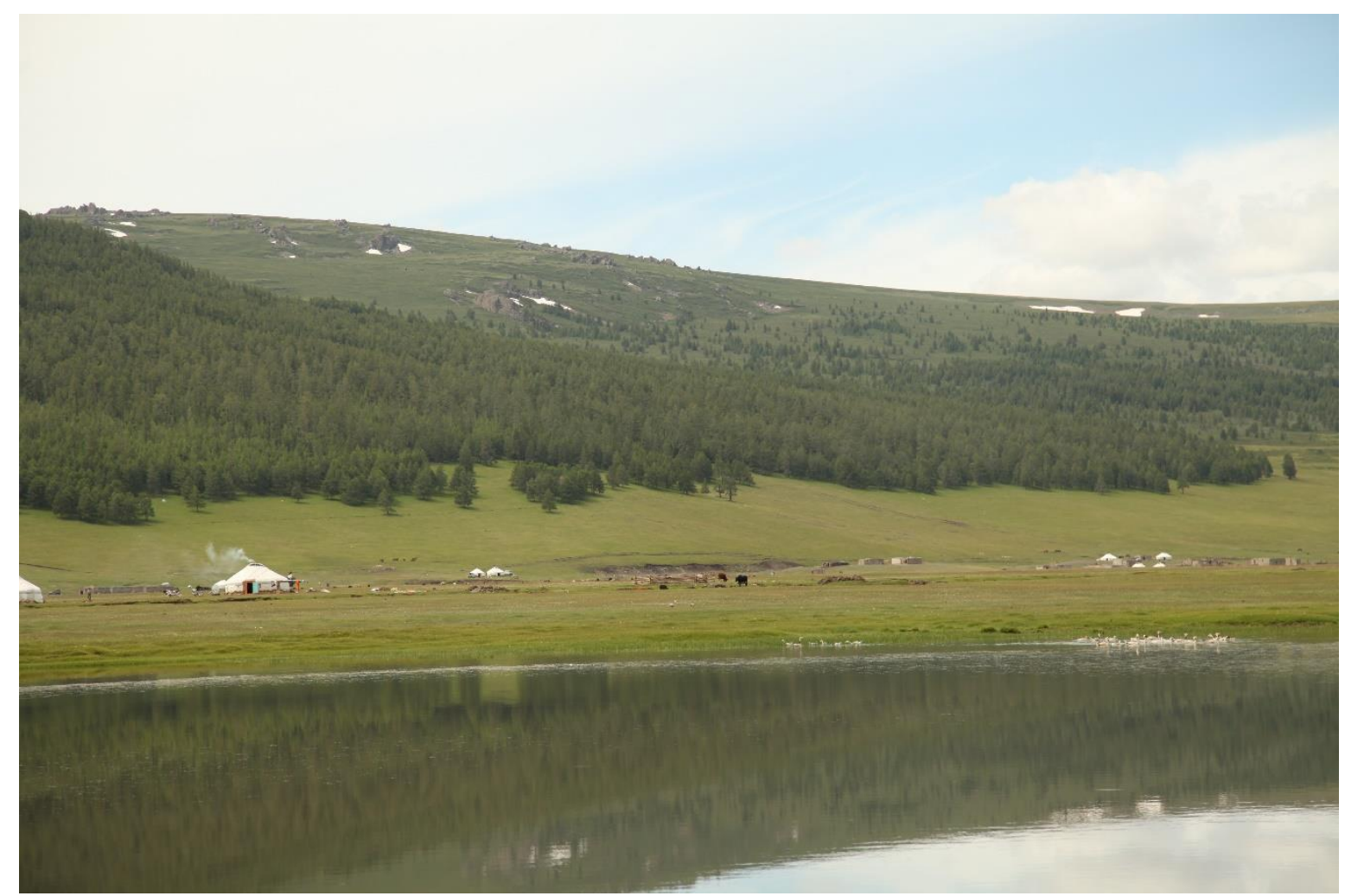

View of the forest-steppe-ecotone on the northern slopes of the Altai Mountains in 'Altai Tavan Bogd' National Park, Mongolia (Behling, 2016) 


\section{Acknowledgements}

\section{There are moments in fife, we need somebody who befieves more in you than yourseff..}

Over the last 4 busy years in Göttingen, I met many people who became valuable to me personally and contributed markedly to the accomplishment of my $\mathrm{PhD}$ work.

I am grateful to my supervisor, Hermann Behling, for giving me the opportunity to start a new chapter in my scientific career in Göttingen in 2015 and for always believing in me no matter what obstacles had to be overcome. I very much appreciated his continuous support in networking, field work and for always having the capacity to listen to questions and concerns. I also thank my co-supervisor, Erwin Bergmeier, for his scientific support and nice discussions. Many thanks go to Dirk Enters and Kaoru Kashima for contributing their knowledge of XRF-scanning and diatom analysis to my multiproxy studies and to Michael Klinge for providing data and efficient discussions about geomorphological and climatological processes in the Mongolian Altai.

My acknowledgement goes to the German Research Foundation (DFG) who financially supported my work (BE 2116/28-1).

I would like to thank all my colleagues and friends at the department for the nice time I had over the recent years. Especially Lyudmila Shumilovskikh for her valuable help with identification of NPP types and her time and effort reading my manuscript drafts as well as Sina Alizadeh and Daniela Piraquive Bermudez for their patience and assistance solving my (silly) beginner's problems with R. I am also grateful to Uta Nüsse-Hahne, who patiently provided an introduction to the laboratory routine and tirelessly assisted in sample preparation. Also, many thanks to Anggi Hapsari, Carolina Guarinello de Oliveira Portes, Christina Setyaningsih, Valentina Alvarez Barra and Lisa SchülerGoldbach for the pleasant working environment and always having a sympathetic ear for my insecurities, inquisitive work-related questions and happiness.

It was a pleasure meeting and working with all of you!

Finally, I would like to express my greatest gratitude to my parents, Regina and Udo Unkelbach by the very simple, but true statement: you know, that all this would never have been possible without you. My last very special thanks go to my partner, Carlo Schröder. Without your constant love, support and energy, I would never have survived this crazy journey. 



\section{Table of Contents}

List of Figures, Tables and Appendices.................................................. III

Acronyms............................................................................ VI

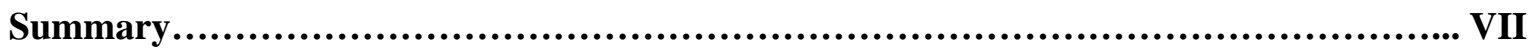

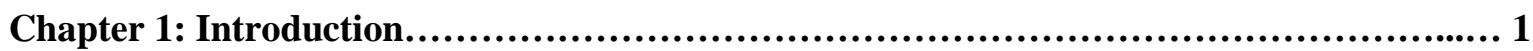

Thesis objectives: aims, outline and personal contributions............................... 1

Palynological and palaeoecological investigations in the Altai Mountains and adjacent regions

- state of knowledge.................................................................. 3

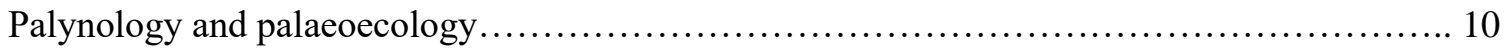

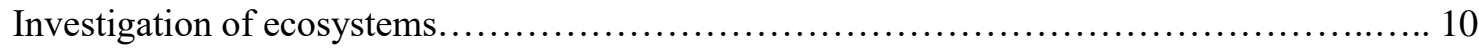

Multi-proxy approach........................................................... 11

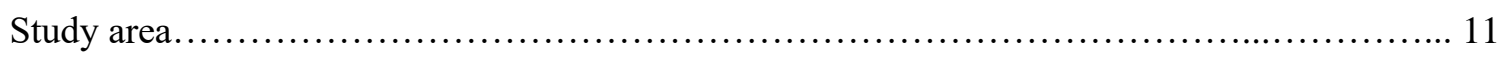

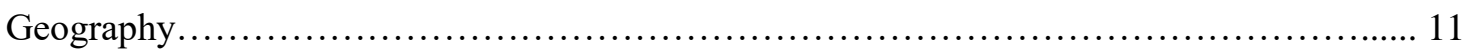

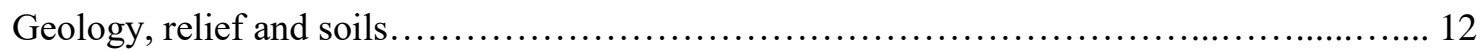

Modern climate...................................................................... 13

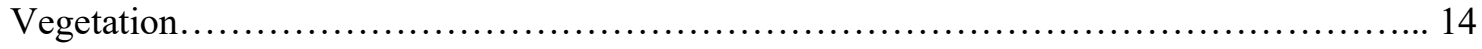

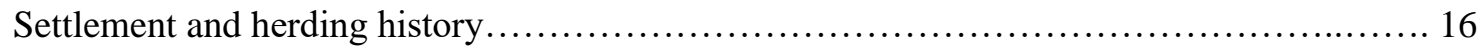

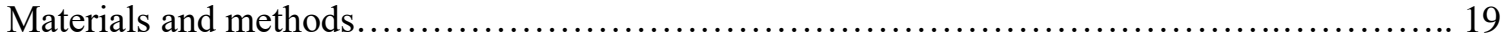

Chapter 2: Manuscript 1 Late Holocene vegetation, climate, human and fire history of the forest-steppe-ecosystem inferred from core G2-A in the 'Altai Tavan Bogd' conservation area

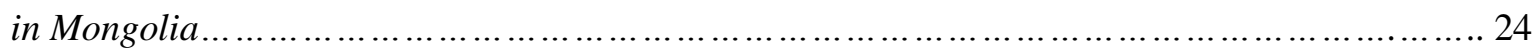

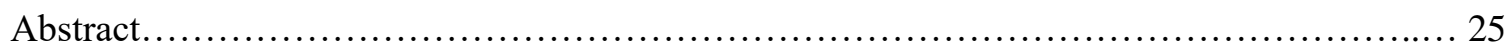

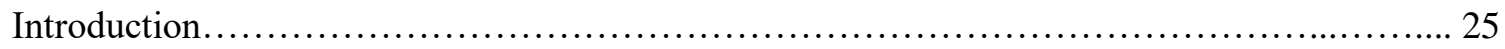

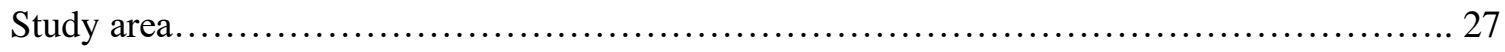

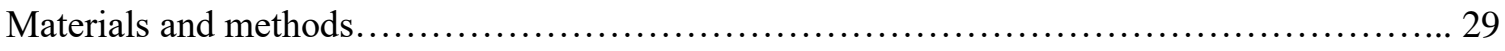

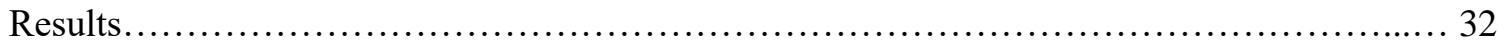

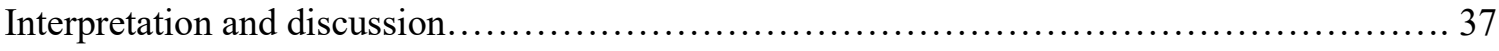

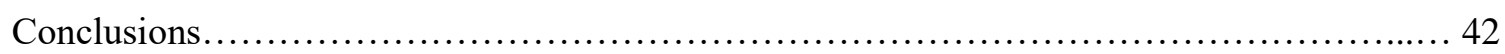

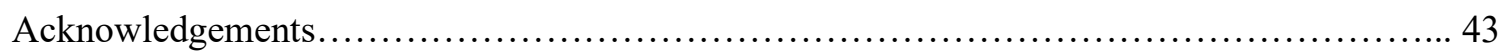

Chapter 3: Manuscript 2 Late Holocene (Meghalayan) palaeoenvironmental evolution inferred from multi-proxy-studies of lacustrine sediments from the Dayan Nuur region of Mongolia........ 44

Abstract.............................................................................. 45

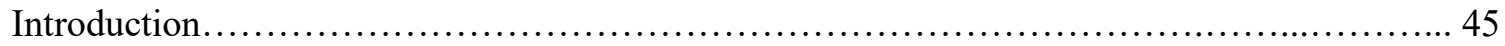

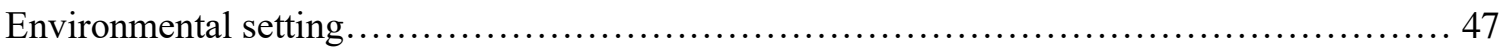

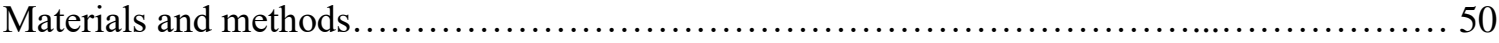


Results.

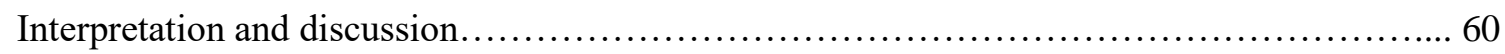

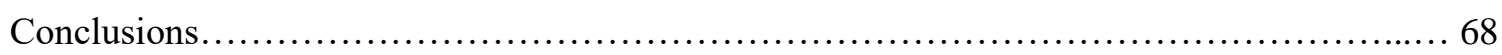

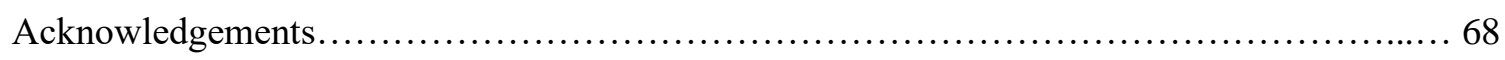

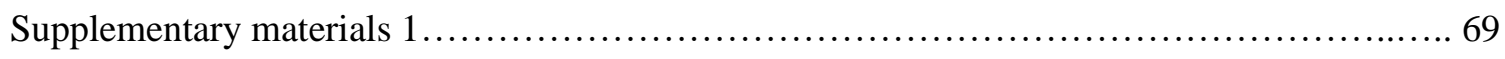

Chapter 4: Manuscript 3 Decadal high-resolution multi-proxy analysis to reconstruct natural and human induced environmental changes over the last 1,350 cal yr BP in the Altai Tavan Bogd

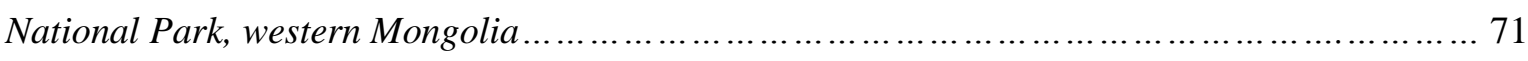

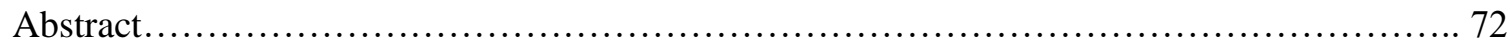

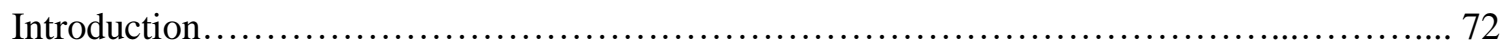

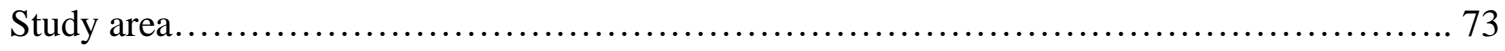

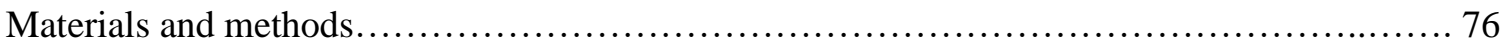

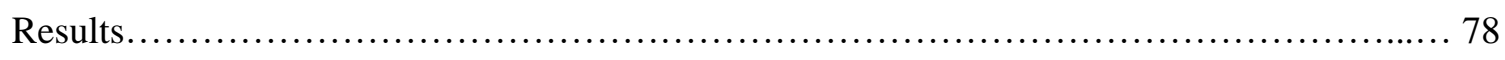

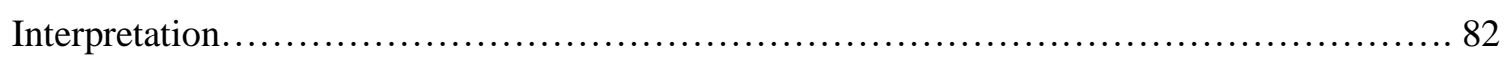

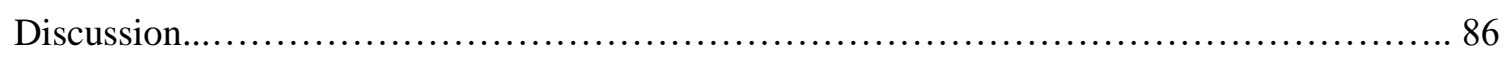

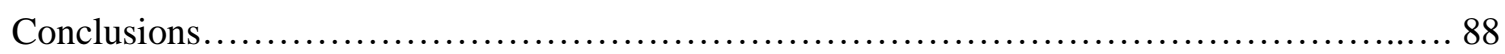

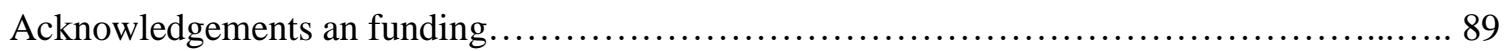

Chapter 5: Manuscript 4 Late-Holocene climate and land-use history in the Mongolian Altai

Mountains: combined evidence from palynological, macro-charcoal and tree-ring

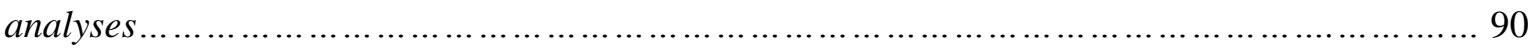

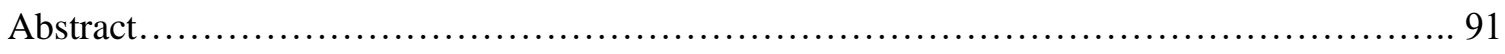

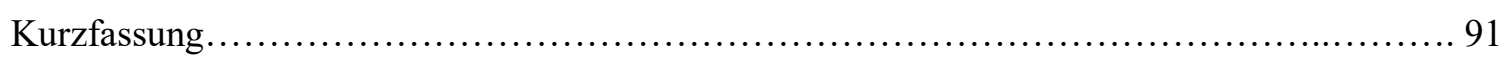

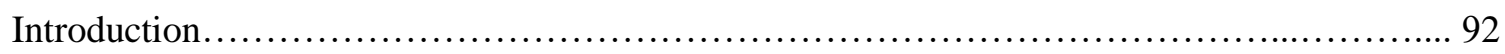

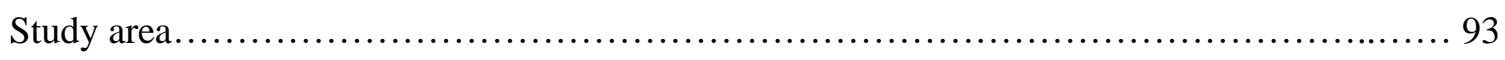

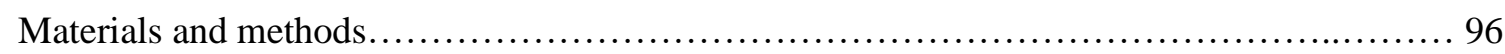

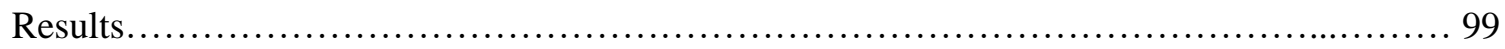

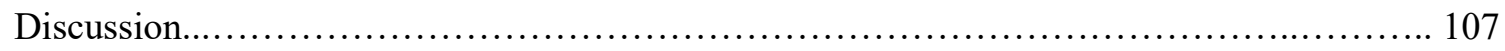

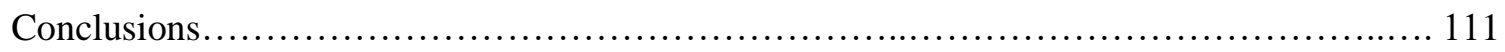

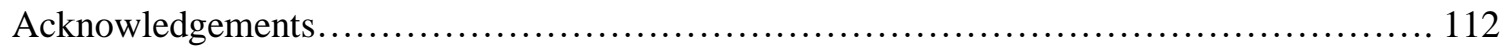

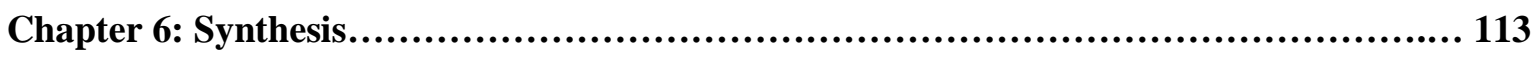

Palaeoenvironmental change in the Mongolian Altai since 4,310 cal yr BP.................. 113

Vegetation-, climate-, grazing- and fire dynamics.................................. 113

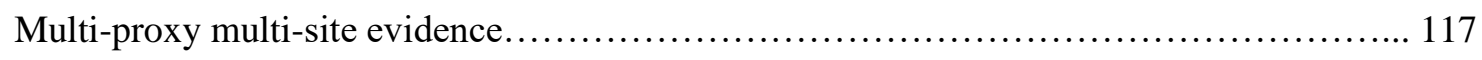

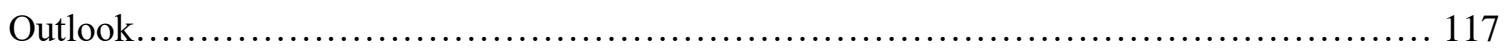

Implications for sustainable land use and conservation management..................... 117

Perspectives on future research................................................... 118 
Bibliography.

Appendix A Atlas of identified pollen-, spore-, non-pollen palynomorph taxa and macro-charcoal morphotypes. 138

Appendix B Detailed pollen, non-pollen palynomorph and diatom records..... 165 



\section{List of Figures, Tables and Appendices}

\section{Figures}

Fig. 1.1 Map of the mountainous regions (grey) within Central Asia showing the locations of the presented palynological and palaeoecological studies

Fig. 1.2 Topographic map showing the location of the Altai Tavan Bogd National Park within Central Asia

Fig. 1.3 Circulation systems influencing Central Asia and present-day limit of the summer monsoon

Fig. 1.4 Climate graph of Ulgii, Mongolia

Fig. 1.5 Altitudinal vegetation zones in the Mongolian Altai.

Fig. 1.6 Locations and characteristics of sites within the study area south of Dayan Nuur in the Altai Tavan Bogd National Park

Fig. 2.1 Map of the study area in the Mongolian Altai and its location within Mongolia

Fig. 2.2 Age-depth model of the sediment core G2-A

Fig. 2.3 Plate showing macro charcoal types from G2-A sediment core

Fig. 2.4 CHARAnalysis diagram presenting the interpolated charcoal counts, the background charcoal noise and the main fire events

Fig. 2.5 Percentage diagram presenting lithology and results of the palynological analysis of G2-A sediment core

Fig. 2.6 Diagram presenting pollen concentration in $\times 10^{4}$ counts per $\mathrm{cm}^{3}$, Artemisia to Chenopodiaceae ratio (A/C), Artemisia to Cyperaceae ratio (A/Cy), arboreal to nonarboreal pollen ratio (AP/NAP), cumulative macro charcoal counts in total (charcoal sum) and the main fire events suggested by CharAnalysis

Fig. 2.7 Diagram presenting charcoal results divided into wood, leaf, grass and other charcoal remains, the main fire events indicated by CharAnalysis software

Fig. 2.8 PCA of taxa

Fig. 2.9 PCA of subsamples

Fig. 3.1 Map showing the location of the Altai Tavan Bogd National Park within Central Asia and the location of core D3L6

Fig. 3.2 Detailed satellite map showing the location of coring site D3L6 in vicinity of Dayan Nuur

Fig. 3.3 BACON output diagram and the age-depth-model for lacustrine sediment core D3L6.

Fig. 3.4 Vegetation type and pollen ratio percentage diagram

Fig. 3.5 Macro-charcoal diagram

Fig. 3.6 Diatom percentage diagram including diatom concentration [valves/mg]

Fig. 3.7 XRF-scanning diagram of selected normalized proxies. 
Fig. 3.8 Summarized multi-proxy diagram of selected proxies and settlement periods in the Mongolian Altai

Fig. 3.9 XRF-scanning diagram of selected normalized proxies.

Fig. 3.10 Photos of selected unknown NPP types

Fig. 4.1 Detailed map showing the location of the 'Altai Tavan Bogd' National Park within Central Asia and the location of the coring site

Fig. 4.2 BACON output diagram and the age-depth-model for lacustrine core D1L1

Fig. 4.3 XRF-scanning results of core D1L1

Fig. 4.4 Diagram presenting macro charcoal and micro charcoal results of core D1L1

Fig. 4.5 Composite diagram of lithology, selected proxies and Mongolian Altai settlement periods

Fig. 5.1 Detailed topographic map showing the locations of cores $\operatorname{Tr} 5-2 \mathrm{~B}$ and $\mathrm{Ch}$ (red) within the area of investigation (Yamaat valley)

Fig. 5.2 BACON output diagram for core Tr5-2B and the age-depth-model

Fig. 5.3 BACON output diagram for core $\mathrm{Ch}$ and the age-depth-model

Fig. 5.4 Moisture indicators of core Tr5-2B

Fig. 5.5 Moisture indicators of core $\mathrm{Ch}$

Fig. 5.6 Macro-charcoal diagram of core Tr5-2B

Fig. 5.7 Macro-charcoal diagram of core $\mathrm{Ch}$

Fig. 5.8 Tree-ring chronologies of Larix sibirica from Lake Dayan, Mongolian Altai

Fig. 6.1 Multi-site trees and shrubs pollen sum

Fig. 6.2 Multi-site Sporormiella influx

Fig. 6.3 Multi-site macro charcoal influx

\section{Tables}

Tab. 1.1 Information on investigated palaeoecological sites from the Mongolian Altai and adjacent areas

Tab. 1.2 Brief overview of cultural/political periods in the Mongolian Altai from Early Bronze Age to present

Tab. 1.3 Detailed description of studied sites and sediment cores

Tab. 1.4 Detailed laboratory schedule for pollen analysis applied on Mongolian sediments in the research

Tab. 1.5 Detailed laboratory schedule for macro-charcoal analysis applied on Mongolian sediments in the research

Tab. 2.1 Radiocarbon dates from the G2-A core sediments

Tab. 3.1 A brief overview of the settlement history in western Mongolia

Tab. 3.2 Uncalibrated and calibrated radiocarbon dates of core D3L6 
Tab. 4.1 Uncalibrated and calibrated radiocarbon dates of core D1L1

Tab. 5.1 Uncalibrated and calibrated radiocarbon dates of cores Tr5-2B and $\mathrm{Ch}$

\section{Appendices}

App. A Atlas of pollen, spores, non-pollen palynomorphs and macro-charcoal morphotypes

App. B Detailed pollen and non-pollen palynomorph diagrams 


\section{Acronyms}

$\begin{array}{ll}\text { A or Art } & \text { Artemisia } \\ \text { ACE } & \text { after common era } \\ \text { AD } & \text { anno Domini } \\ \text { AP } & \text { arboreal pollen } \\ \text { BC } & \text { before Christ } \\ \text { BCE } & \text { before common era } \\ \text { BP } & \text { before present (present = AD 1950) } \\ \text { C or Che } & \text { Chenopodiaceae } \\ \text { cal yr } & \text { calibrated years } \\ \text { Cy } & \text { Cyperaceae } \\ \text { DZ } & \text { diatom zone } \\ \text { HdV } & \text { Hugo de Vries Laboratory, University of Amsterdam } \\ \text { LGM } & \text { Last Glacial Maximum } \\ \text { LIA } & \text { Little Ice Age } \\ \text { MWP } & \text { Medieval Warm Period } \\ \text { NAP } & \text { non-arboreal pollen } \\ \text { NPP } & \text { non-pollen palynomorphs } \\ \text { PZ } & \text { pollen zone } \\ \end{array}$




\section{Summary}

In this thesis, several sedimentological archives from Altai Tavan Bogd National Park are studied to reconstruct the vegetation-, fire-, climate- and human history of the forest-steppe biome in the Mongolian Altai. The research is carried out to improve the understanding of the dynamics and variability of this sensitive ecosystem and its unique biodiversity. Previous palynological or palaeoecological work from the Mongolian Altai is sparse, yet important for an implementation of sustainable land use as well as protection and management of the species-rich vegetation in the Altai region. The main goals of this research are to reconstruct past vegetation and to investigate the role and extent of climate, fire and anthropogenic impact on environmental change.

A multi-site approach of five environmental archives (lacustrine and peat) from different locations and elevations within the forest-steppe biome (below, within and above the forest belt) is applied to obtain as much information as possible. Multi-proxy analyses including palynological and sedimentological proxies (pollen, NPPs, charcoal, diatoms and XRF-scanning) were used on the radiocarbon dated sediment archives.

During the mid- and the beginning of the late Holocene $(4,300$ to $1,000(2,000)$ cal yr BP) the vegetation in the area was characterized by open coniferous forest and high-mountain steppe indicating rather warm and humid conditions. In the further course of the late Holocene, steppe communities expanded noticeably favoring a colder and more arid climate. During the last approx. 70 years an increase in tree and shrub vegetation indicates a warming climate and a higher availability of water due to permafrost and glacier degradation in the high mountains. Regarding the human history in the Mongolian Altai, the period from 2,000 to 1,000 cal yr BP represents a transition phase from hunters and gatherers to a nomadic herding lifestyle. Coprophilous fungi reconstructions show that grazing intensified around 1,000 cal yr BP, possibly also favoring the expansion of steppe. Highresolution data show that changes in human occupation due to political shifts and changing Mongolian settlements had an impact on the vegetation in the area, especially during Mongol Empire (744 to 582 cal yr BP). Regardless of specific settlement periods, short-term changes in climatic conditions favored shifts in grazing activities. In the Mongolian Altai, fires play a tangential role. However, at around 1,000 cal yr BP the fire frequency increased in accord with growing anthropogenic impact and climate aridity. An episode of low fire activity persists since around 150 cal yr BP.

Major local variances occurred regarding the time frame and extent of steppe expansion and grazing activities in the soil archive within the forest belt and with respect to the fire frequency in the peat archive above the upper forest line. The applied multi-proxy approach highlights the value of the reconstruction of several independent proxies to examine various aspects of an ecosystem in the same archive, despite of that the interpretation of results is challenging. Additionally, the multi-site study offers the best possibility to distinguish between local environmental signals and regional trends. 


\section{Chapter 1: Introduction}

\section{Thesis objectives: aims, outline and personal contributions}

Recently, considerable attention has been devoted to global warming discussions. The desire for a better understanding of present climate conditions to predict future scenarios has increased the interest in climate and environmental dynamics of the past. In this regard, the extent of anthropogenic influence to environmental change is widely discussed as well. Multi-proxy studies provide new insights into archives from all over the world and enable the reconstruction of various independent proxies within the same archive. This holistic examination of ecosystems and their response to climate change as well as the use of natural resources make a valuable contribution in the context of adaption strategies to global warming.

The vegetation of the forest-steppe biome in the Mongolian Altai is very sensitive and responds strongly to natural and anthropogenic changes. However, in this region in Central Asia palaeoarchives have rarely been studied (Brügger et al., 2018; Rudaya et al., 2008, 2009; Tarasov et al., 2000). More detailed investigations are needed to examine the response of forest and steppe communities to natural and anthropogenic variabilities during the Holocene.

This thesis is devoted to the research of detailed vegetation-, fire-, climate- and human history in the Mongolian Altai from the mid- to late Holocene. Environmental archives from different locations in the forest-steppe biome are radiocarbon dated and analyzed by using a multi-proxy approach as well as multivariate statistics. The aim is to gain a holistic view on present and past vegetation and environmental changes and the role of anthropogenic impact. Those changes are expressed by the reconstruction of several sedimentological and palynological proxies. Pollen analysis is applied to investigate the response of vegetation to climate, fire and human influences. A climate reconstruction for the mid- to late Holocene is intended to a certain extent. Non-pollen palynomorph (NPP) analysis is also used to reconstruct the grazing history, and charcoal analysis provides information about the fire frequency.

The focus is on the dynamics and stability of the forest and steppe vegetation, the role of fire in the past, erosion processes and the conditions for lake formation and lake level dynamics in the area. Firstly, the aim is to examine how natural the existing forest-steppe vegetation is and to focus on the driving forces of the environmental changes in Central Asia. Changes in the Mongolian Altai's forest-steppe ecosystem and plant diversity shall be detected in response to natural and anthropogenic environmental shifts. In the next step, the extent of these natural and anthropogenic impacts shall be quantified. Secondly, a combination of the multi-proxy records enables the examination of the temporal aspect of human impact. It shall be evaluated since when the Mongolian Altai is subject of human disturbance and to what extent different cultures inhabiting the area had an influence on the 
vegetation over time. It is desired to gain a better understanding of the natural or socio-economic driving factors for herding and grazing in this remote alpine area. Finally, this thesis shall give a perspective of future protection and management of the species-rich vegetation of the Mongolian Altai. One prerequisite for a successful implementation is to understand the dynamics of the forest boundary. In particular, the aim is to investigate which areas have once been covered by forests, if forest-steppe-changes proceeded continuously or if conditions favored abrupt changes between both stable ecosystems (forest and steppe).

The main part of the thesis is comprised of four manuscripts. Two published in international peerreviewed journals, one submitted and one in preparation. The complete versions of the pollen- and NPP diagrams are presented in Appendix B.

\section{Chapter 1: Introduction (pp. 1-23)}

The introduction deals with the state of knowledge of palynological and palaeoecological studies in the Altai Mountains and adjacent regions in Central Asia. The region under investigation is described in detail. Additionally, a general overview of applied methods is presented.

Chapter 2: Manuscript 1 (pp. 24-43)

In the first manuscript "Late Holocene vegetation, climate, human and fire history of the foreststeppe ecosystem inferred from core G2-A in the 'Altai Tavan Bogd' conservation area in Mongolia" (J. Unkelbach, Ch. Dulamsuren, G. Punsalpaamuu, D. Saindovdon, H. Behling, published in Vegetation History and Archaeobotany, 27(5), 665-677) the first pollen and macro-charcoal records (G2-A) inferred from a peat sequence south of Dayan Nuur in the Mongolian Altai are given. Foreststeppe and fire dynamics of the last 3,880 cal yr BP are reconstructed and discussed in the context of climate change. An initial estimate of a possible human impact on the environment is given based on the fire history. Subsampling, laboratory work, pollen and macro-charcoal counting, age-depthmodel, numerical analysis, analysis of results, preparation of figures and tables as well as writing and revising the manuscript were performed by myself.

Chapter 3: Manuscript 2 (pp. 44-70)

The second manuscript "Late Holocene (Meghalayan) palaeoenvironmental evolution inferred from multi-proxy-studies of lacustrine sediments from the Dayan Nuur region of Mongolia" (J. Unkelbach, K. Kashima, D. Enters, Ch. Dulamsuren, G. Punsalpaamuu, H. Behling, published in Palaeogeography, Palaeoclimatology, Palaeoecology 530, 1-14) deals with multi-proxy analyses (pollen, spores, NPP, charcoal, diatoms, XRF scanning) of a lacustrine sediment core (D1L1) from the same area in the Mongolian Altai. Holistic late Holocene (4,310 cal yr BP) palaeoenvironmental reconstructions are presented revealing an increased anthropogenic influence on the vegetation in the area for the last approx. 1,000 years. My personal contribution includes sample preparation, counting and analysis of results for pollen, spores, NPPs and charcoal data as well as age-depth-modeling, 
preparation of all figures and tables, and writing and revision of the manuscript (except XRFscanning sections).

Chapter 4: Manuscript 3 (pp. 71-89)

The third manuscript "Decadal high-resolution multi-proxy analysis to reconstruct natural and human induced environmental changes over the last 1,350 cal yr BP in the Altai Tavan Bogd National Park, western Mongolia" (J. Unkelbach, K. Kashima, G. Punsalpaamuu, L. Shumilovskikh, H. Behling, submitted to The Holocene) addresses the development of anthropogenic impact on the environment of Dayan Nuur area inferred from a multi-proxy-study of a high-resolution, lacustrine sediment record. Possible impacts of natural and political shifts on the herding and grazing habits of the nomadic population over the last 1,350 cal yr BP are discussed. Practical work for pollen, spore, NPP and charcoal analysis, preparation of the age-depth-model, all figures and tables as well as manuscript writing were performed by me.

Chapter 5: Manuscript 4 (pp. 90-101)

The desired aim of the fourth manuscript "Late-Holocene climate and land-use history in the Mongolian-Chinese border area, Altai Mountains: combined evidence from palynological, macrocharcoal and tree-ring analyses" (J. Unkelbach, Ch. Dulamsuren, H. Behling, in preparation) is to compare the vegetation and climate history inferred from two additional high-resolution pollen, spore, NPP and charcoal records (Ch and Tr5-2B) to dendrochronological climate data obtained from Larix sibirica trees in the same valley south of Dayan Nuur. The main part of the manuscript is supposed to deal with the comparison and discussion of the different climate reconstructions. My personal contribution was to perform pollen, spore, NPP and charcoal analysis including the preparation of respective figures and tables, establishment of the age-depth-model as well as writing the manuscript draft (except future dendrological sections).

Chapter 6: Synthesis (pp. 102-108)

The thesis concludes with a summary and synthesis of the multi-site investigation of environmental archives. Uncertainties as well as recommendations for future protection and management of the forest-steppe ecosystem are discussed.

\section{Palynological and palaeoecological investigations in the Altai Mountains and adjacent regions - state of knowledge}

Previous studies on the vegetation, climate, fire and settlement history in the Altai Mountains and surrounding areas are presented according to their spatial distribution in Fig. 1.1. These offer reconstructions ranging from the late Pleistocene $(22,600 \mathrm{cal}$ yr BP, e1 Achit Nuur) to present day (Tab. 1.1). Most studies cover the mid- and late Holocene (8,200 cal yr BP to present). 


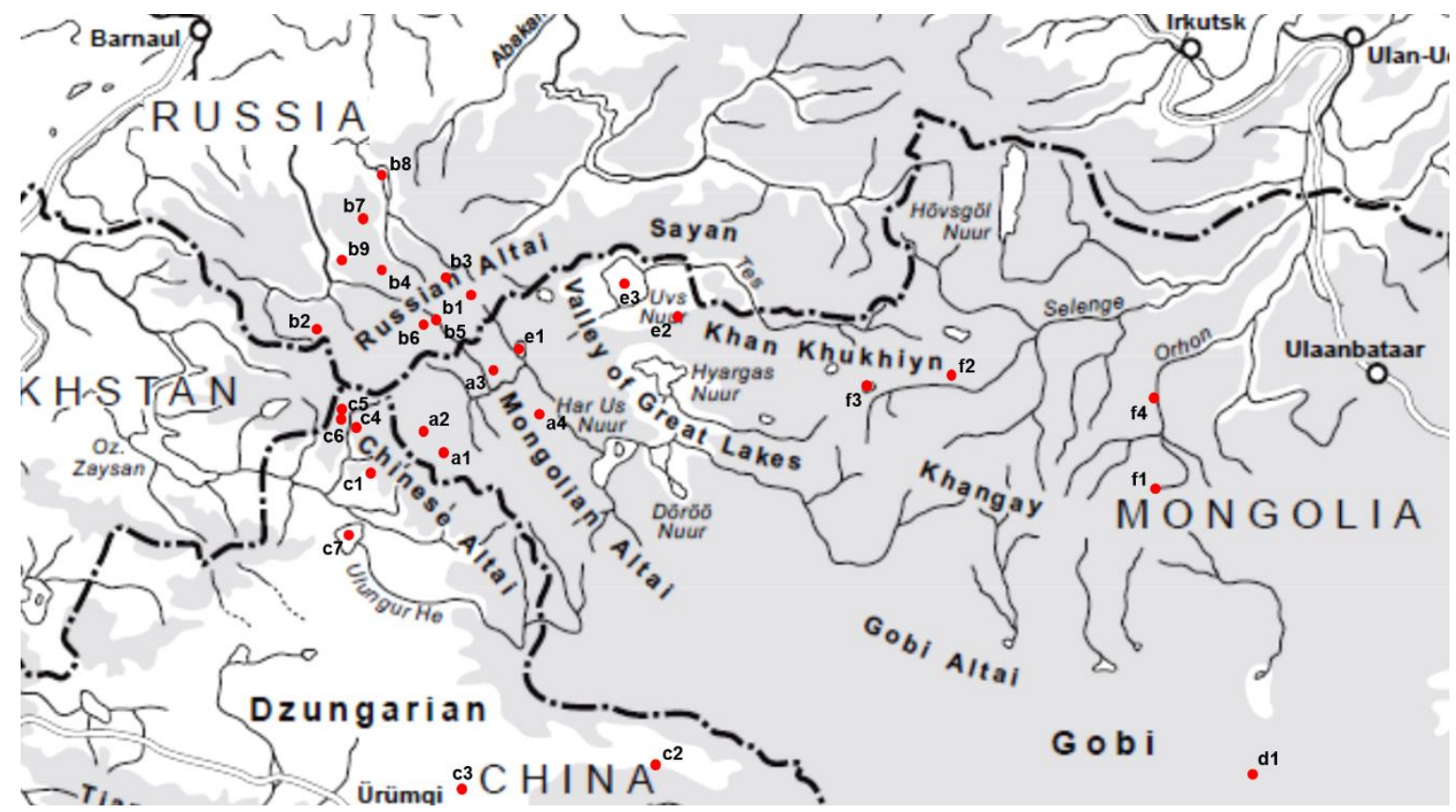

Fig. 1.1 Map of mountainous regions (grey) within Central Asia (after Klinge et al., 2003) showing the locations of the presented palynological and palaeoecological studies (red dots). Sites are grouped according to their region (a1-f4), numbers correspond to Tab. 1.1.

\section{Mongolian Altai}

The pioneer work of Tarasov et al. (2000) and Rudaya et al. (2009) were the first palynological records providing information on the vegetation and climate dynamics for the terminal late Glacial and the Holocene in the Mongolian Altai. Based on low resolution pollen, NPP and diatom data from Hoton Nuur (a2), both studies suggest a vegetation pattern dominated by steppe communities prior to $10,000(9,000)$ cal yr BP indicating a cold and dry climate. For the period from $10,000(9,000)$ to $5,000(4,000)$ cal yr BP, boreal forest expanded in the area, revealing an increase in precipitation and temperature during the early and mid-Holocene. After 5,000 $(4,000)$ cal yr BP, both records suggest a reversion to open vegetation types and drier climatic conditions. Both authors have not considered human impact as an important factor for forest reduction until recently.

Pollen and charcoal reconstructions of Tsambagarav Glacier (a4) ice core material by Brügger et al. (2018) are in accord with the general climatic trends reconstructed at Hoton Nuur. Brügger et al. (2018) dated the start of the irrecoverable forest decline to 3,750 cal yr BP followed by a fire maximum in response to increased dead biomass accumulation after the forest collapse.

Further palaeoecological studies in the Mongolian Altai were carried out by D'Arrigo et al. (2000) (a3) and Dulamsuren et al. (2014) (a1) providing climate information reconstructed from Larix sibirica tree rings. These studies demonstrate short-term temperature and moisture oscillations over the last approx. 400 years and generally wetter conditions due to the $20^{\text {th }}$ century climate warming since around 60 years ago. 


\section{Russian Altai}

There are plenty of pollen reconstructions carried out by Blyakharchuk et al. $(2004,2007)$ who documented the palaeoenvironmental history in the Russian Altai. Based on a study of three peat sequences (Kendegelukol (b4), Tashkol (b7) and Uzunkol (b9)), the history of vegetation and climate in the area can be described as follows: at the end of the late Glacial, before 15,500 cal yr BP, the distribution of forest and steppe suggests cold and rather dry climatic conditions. A short-term forest decline from 15,500 to 15,000 cal yr BP was followed by a more prominent forest increase revealing warmer but still dry conditions from 15,000 to 12,200 cal yr BP. After a transition phase $(12,200$ to $9,500 \mathrm{cal}$ yr BP), forest expanded markedly pointing to an increase in humidity. Since 7,700 cal yr $\mathrm{BP}$, the amount of forest in the Russian Altai declined irrecoverably indicating a stable period of cooler and more continental climate. Pollen data obtained from Akkol Lake (b1) and Grusha Lake (b3) confirm the results of the previous studies but reveal that the mid-Holocene forest decline occurred more than 2,500 years later (5,000 cal yr BP) as demonstrated in Blyakharchuk et al. (2004). Contrasting results are also presented by Schlütz and Lehmkuhl (2007). They date the start of the forest reduction and steppe expansion caused by climatic cooling at Kuray Range (b5) to 3,400 cal yr BP. In that area, the Tarkhata Valley record (b6) provides detailed information on the local human influence in the Russian Altai since 1,900 cal yr BP.

Further palynological and palaeoecological studies were carried out on Lake Teletskoye (b8) lacustrine sediments by Andreev et al (2007), Eichler et al (2011) and Sidorova et al. (2012). These studies provided high-resolution vegetation and climate reconstructions for the late Holocene highlighting the effect of the $20^{\text {th }}$ century global warming and the regional significance of vegetation changes. This is supported by temperature and precipitation reconstructions from Belukha Glacier (b2), indicating a gradual climate warming in the Russian Altai since AD 1850.

\section{Chinese Altai}

Over the last decade, Holocene environmental change was subject of numerous publications. The most extensive pollen record was established by Tao et al. (2010) providing detailed information on vegetation and climate history at Balikun Lake (c2) since 16,700 cal yr BP. In that generally arid area, vegetation cover varied from desert to steppe communities depending on general climatic trends. During the period from 16,700 to 8,900 cal yr BP, extremely dry conditions prevailed followed by an increasingly moister interval from 8,900 to 7,900 cal yr BP. In the period from 7,900 to 4,300 cal yr BP, steppe vegetation recovered suggesting a persisting precipitation increase. An extremely arid climate event from 4,300 to 3,800 cal yr BP is reconstructed from the desert steppe pollen dominance. From 3,800 to $530 \mathrm{cal}$ yr BP, moisture increased again. Tao et al. (2010) suggest that $530 \mathrm{cal}$ yr BP marks the beginning of a climate deterioration which continues to date. An et al. 
(2011) present similar pollen results revealing rather consistent vegetation and climate reconstructions. Contrasting trends were only observed over the last $530 \mathrm{cal} \mathrm{yr} \mathrm{BP}$, for which they suggest commencing humid conditions.

A recently published lacustrine sediment record from Kanas Lake (c4) presents a different perspective on the climate change during the Holocene. Huang et al. (2018) argued that climate shifted from extremely cold and dry conditions before $11,700 \mathrm{cal}$ yr BP to increasingly warm and humid lasting until 4,000 cal yr BP. For the whole period after 4,000 cal yr BP, they reconstructed a decrease in temperature and precipitation. A diatom record established by Lin et al. (2018) covering the last approx. 100 years complements the work of Huang et al. (2018) suggesting an increased influx of meltwater into Balikun Lake since around AD 1970.

Liu et al. (2009) provide a palaeoenvironmental record from Wulungu Lake (c7) spanning the last 9,550 cal yr BP corresponding to the reconstructions of Huang et al. (2018) in almost every detail. Further, two palynological studies were carried out on peat sequences. The Narenxia record (c5) published by Feng et al. (2017) extends beyond 11,500 cal yr BP and the Tielishan record (c6) studied by Zhang et al. (2016) spanning over the last 10,000 cal yr BP show more detailed discoveries of climate change during the Holocene. However, both studies reveal contrasting trends for most of the reconstructed periods. Especially for the last approx. 1,000 cal yr BP, Feng et al. (2017) disproved the reconstruction of a climate warming by Zhang et al. (2016) suggesting an interval of cooler conditions.

Discrepancies in data interpretation might have been caused by anthropogenic disturbance as suggested by Li et al. (2019) from Alahake Lake area (c1) for the last $790 \mathrm{cal}$ yr BP or by Tarasov et al. (2019) from Bosten Lake (c3).

\section{Gobi Altai}

Palynological and palaeoecological records from Gobi Altai are still sparse. There are plenty of recent sedimentological studies (e.g. Lehmkuhl et al., 2018) but only one pollen record published by Miehe et al. (2007). Palynological investigations were carried out on a peat sequence from Yolin Am (d1) covering more than the last 5,000 cal yr BP. Climate reconstructions revealed a warm and wet phase before 4,350 cal yr BP. From 4,350 to $850 \mathrm{cal}$ yr BP, warm conditions prevailed while the area was impacted by an increasingly dry climate and increasing nomadic activities. In the period from 850 to 350 al yr BP, temperature decreased but grazing impact on the vegetation intensified. After $350 \mathrm{cal}$ yr BP, aridity and temperature increased under a pronounced intensification of land use. 


\section{Valley of the Great Lakes}

The most extensive palaeoenvironmental study in the region was carried out by Grunert et al. (2000) on lake deposits and terrace formations around Uvs Nuur (e3) extending beyond 46,000 cal yr BP. Their broad reconstructions demonstrate that arid conditions prevailed in the Valley of the Great Lakes before 46,000 cal yr BP. Based on their geomorphological data, the period before the Last Glacial Maximum (LGM, 46,000 to 26,000 cal yr BP) was presumably influenced by wet and cool to cold climate conditions while the LGM (26,000 to 20,000 cal yr BP) itself was assumed to be characterize by extremely dry and cold climate. During the Late Glacial (20,000 to 11,500 cal yr BP), climatic conditions were marked by rising temperatures and increased precipitation, and this trend continued in the early Holocene from 11,500 to 5,000 cal yr BP. Contrasting trends were observed in the period from 5,000 to 3,000 cal yr BP (drier and colder conditions). After 3,000 cal yr BP, the late Holocene was still characterized by lower temperatures, but precipitation increased again. Over the last decades, a reconstructed lake level rise was attributed to increased meltwater inflow due to climate warming.

For the Holocene, contrasting climate reconstructions are reported from Achit Nuur (e1) and Bayan Nuur (e2). Especially for the mid-Holocene (6,500 to 3,000 cal yr BP) the palynological results of Gunin et al. (1999), Sun et al. (2013) and Tian et al. (2014) suggest markedly moister and warmer climatic conditions and a generally drier period for the late Holocene since 3,000 cal yr BP.

\section{Central Mongolia}

In Central Mongolia, Telmen Nuur (f3) has intensively been studied by Fowell et al. (2003), Peck et al. (2002) and Soninkhishig et al. (2003) in order to reconstruct climate information. The palynological record established by Fowell et al. (2003) and the moisture record obtained from sedimentological evidence by Peck et al. (2003) provide similar climatic patterns for Central Mongolia over the last approx. 7,000 cal yr BP. An initial arid period starting from 7,000 cal yr BP ended at around 4,500 cal yr BP due to increasing precipitation. The moisture maximum was reconstructed to the interval from 2,710 to $1,260 \mathrm{cal} \mathrm{yr}$ BP. A stable period was followed by a renewed increase in humidity after $680 \mathrm{cal}$ yr BP. Telmen Nuur diatom record presented by Soninkhishig et al. (2003) is sparse due to poor diatom preservation, hence it provides additional temperature information for the mid-Holocene interval from 6,230 to 5,520 cal yr BP. In that period, diatom data suggests a relatively warm climate compared to present-day conditions.

Further palynological studies were carried out on Ugii Nuur (f4) lacustrine sediments by Wang et al. (2009) covering the mid- and late Holocene. During the period prior to 7,880 cal yr BP, mild and semi-humid conditions prevailed. Increasingly dry and warm climate was reconstructed for the period from 7,880 to 3,170 cal yr BP. The interval from 3,170 to 1,600 cal yr BP was assumed to be 
increasingly cool and wet with a maximum in humidity at around 2,340 cal yr BP. The period after 1,600 cal yr BP is characterized by an increase in climate instability.

In the Orkhon Valley (f1), sedimentological and palynological analyses performed by Lehmkuhl et al. (2011) demonstrate that sedimentation in the area started in the Late Glacial at around 15,000 cal yr BP. At the end of the Late Glacial period and in the beginning of the Holocene the sediment composition was characteristic for arid conditions and indicated moister conditions for the midHolocene from 8,000 to 3,000 cal yr BP. For the late Holocene (3,000 cal yr BP to present), a continuous vegetation decrease was reconstructed based on palynological evidence. This vegetation reduction was assumed to be a result of intensified human impact as several ancient capitals were located in the area. After 600 calyr BP, anthropogenic impact decreased because of changing political powers and relocation of the capital.

Recent climatic trends in Central Mongolia were reconstructed by Jacoby and Baatarbileg (2003) based on dendrochronolgical data. The record from Solongotyn Daava (f2) suggests rather high temperatures for the period from $\mathrm{AD} 1450$ to $\mathrm{AD} 1800$ and markedly cooler conditions from $\mathrm{AD}$ 1800 to AD 1900. From AD 1900 to AD 2000, temperatures increased steadily. Precipitation oszillated from $\mathrm{AD} 1650$ to $\mathrm{AD} 1840$ and decreased in the following interval (AD 1840 to AD 1985). From AD 1985 to AD 2000, precipitation increased in correlation with temperature.

Tab. 1.1 Information on investigated palaeoecological sites from the Mongolian Altai and adjacent areas. Sites are grouped according to their region (a1-f4), numbers correspond to Fig. 1.1. Cha: charcoal, Dia: diatoms, NPP: non-pollen palynomorphs, Pol: pollen, Sed: Sedimentological parameters, Tre: tree-rings, XRF: XRF-data.

\begin{tabular}{|c|c|c|c|c|c|c|}
\hline No. & Site & Coordinates & $\begin{array}{l}\text { Elevation } \\
\text { (m a.s.l.) }\end{array}$ & Proxies & Time interval & Reference \\
\hline \multicolumn{7}{|c|}{ (a) Mongolian Altai } \\
\hline a1 & Dayan Area & $\begin{array}{l}48^{\circ} 15^{\prime} \mathrm{N} \\
88^{\circ} 54^{\prime} \mathrm{E}\end{array}$ & 2300 & Tre & $280 \mathrm{cal} \mathrm{yr} \mathrm{BP}$ & Dulamsuren et al. (2014) \\
\hline a2 & Hoton Nuur & $\begin{array}{l}48^{\circ} 40^{\prime} \mathrm{N}, \\
88^{\circ} 18^{\prime} \mathrm{E}\end{array}$ & 2083 & Pol & $>9070 \mathrm{cal} \mathrm{yr} \mathrm{BP}$ & Tarasov et al. (2000) \\
\hline $\mathrm{a} 2$ & Hoton Nuur & $\begin{array}{l}48^{\circ} 37^{\prime} 18^{\prime \prime} \mathrm{N}, \\
88^{\circ} 20^{\prime} 45^{\prime \prime} \mathrm{E}\end{array}$ & 2083 & $\begin{array}{l}\text { Pol, } \\
\text { NPP, } \\
\text { Dia }\end{array}$ & $>11500 \mathrm{cal} \mathrm{yr} \mathrm{BP}$ & Rudaya et al. (2009) \\
\hline a3 & Khalzan Khamar & $\begin{array}{l}49^{\circ} 55^{\prime} \mathrm{N} \\
91^{\circ} 34^{\prime} \mathrm{E}\end{array}$ & 2500 & Tre & $550 \mathrm{cal}$ yr BP & D'Arrigo et al. (2000) \\
\hline $\mathrm{a} 4$ & $\begin{array}{l}\text { Tsambagarav } \\
\text { Glacier }\end{array}$ & $\begin{array}{l}48^{\circ} 39.338^{\prime} \\
\mathrm{N}, \\
90^{\circ} 50.826^{\prime} \mathrm{E}\end{array}$ & 4130 & $\begin{array}{l}\text { Pol, } \\
\text { Cha }\end{array}$ & 5450 cal yr BP & Bruegger et al. (2018) \\
\hline
\end{tabular}

\section{(b) Russian Altai}

\begin{tabular}{|c|c|c|c|c|c|c|}
\hline b1 & Akkol Lake & $\begin{array}{l}50^{\circ} 15^{\prime} \mathrm{N}, \\
89^{\circ} 37^{\prime} 30^{\prime \prime} \mathrm{E}\end{array}$ & 2204 & Pol & $10000 \mathrm{cal} \mathrm{yr} \mathrm{BP}$ & Blyakharchuk et al. (2007) \\
\hline b2 & Belukha Glacier & $\begin{array}{l}49^{\circ} 48^{\prime} 26^{\prime \prime} \mathrm{N}, \\
86^{\circ} 34^{\prime} 43^{\prime \prime} \mathrm{E}\end{array}$ & 4062 & Sed & 171 cal yr BP & Sidorova et al. (2012) \\
\hline b3 & Grusha Lake & $\begin{array}{l}50^{\circ} 23^{\prime} \mathrm{N} \\
89^{\circ} 25^{\prime} \mathrm{E}\end{array}$ & 2413 & Pol & $15900 \mathrm{cal} \mathrm{yr} \mathrm{BP}$ & Blyakharchuk et al. (2007) \\
\hline b4 & Kendegelukol & $\begin{array}{l}50^{\circ} 30^{\prime} 20^{\prime \prime} \mathrm{N}, \\
87^{\circ} 38^{\prime} 30^{\prime \prime} \mathrm{E}\end{array}$ & 2050 & Pol & $15250 \mathrm{cal} \mathrm{yr} \mathrm{BP}$ & Blyakharchuk et al. (2004) \\
\hline
\end{tabular}




\begin{tabular}{|c|c|c|c|c|c|c|}
\hline b5 & Kuray Range & $\begin{array}{l}50^{\circ} 08^{\prime} 04^{\prime \prime} \mathrm{N}, \\
88^{\circ} 51^{\prime} 10^{\prime \prime} \mathrm{E}\end{array}$ & 2330 & Pol & 6500 cal yr BP & Schlütz and Lehmkuhl (2007) \\
\hline b6 & Tarkhata Valley & $\begin{array}{l}49^{\circ} 39^{\prime} 01^{\prime \prime} \mathrm{N}, \\
88^{\circ} 28^{\prime} 10^{\prime \prime} \mathrm{E}\end{array}$ & 2210 & Pol & $1900 \mathrm{cal} \mathrm{yr} \mathrm{BP}$ & Schlütz and Lehmkuhl (2007) \\
\hline b7 & Tashkol & $\begin{array}{l}50^{\circ} 27^{\prime} \mathrm{N}, \\
87^{\circ} 40^{\prime} 15^{\prime \prime} \mathrm{E}\end{array}$ & 2150 & Pol & $16300 \mathrm{cal} \mathrm{yr} \mathrm{BP}$ & Blyakharchuk et al. (2004) \\
\hline b8 & Teletskoye Lake & $\begin{array}{l}51^{\circ} 43^{\prime} \mathrm{N}, \\
87^{\circ} 39^{\prime} \mathrm{E}\end{array}$ & 434 & Pol & $900 \mathrm{cal} \mathrm{yr} \mathrm{BP}$ & Andreev et al. (2007) \\
\hline b8 & Teletskoye Lake & $\begin{array}{l}51^{\circ} 43^{\prime} \mathrm{N}, \\
87^{\circ} 39^{\prime} \mathrm{E} \\
\end{array}$ & 434 & $\begin{array}{l}\text { Pol, } \\
\text { Cha }\end{array}$ & 700 cal yr BP & Eichler et al. (2011) \\
\hline b8 & Teletskoye Lake & $\begin{array}{l}51^{\circ} 43^{\prime} \mathrm{N}, \\
87^{\circ} 39^{\prime} \mathrm{E}\end{array}$ & 434 & Sed & 171 cal yr BP & Sidorova et al. (2012) \\
\hline b9 & Uzunkol & $\begin{array}{l}50^{\circ} 29^{\prime} \mathrm{N}, \\
87^{\circ} 6^{\prime} 30^{\prime \prime} \mathrm{E}\end{array}$ & 1985 & Pol & $16200 \mathrm{cal} \mathrm{yr} \mathrm{BP}$ & Blyakharchuk et al. (2004) \\
\hline
\end{tabular}

(c) Chinese Altai

\begin{tabular}{|c|c|c|c|c|c|c|}
\hline $\mathrm{c} 1$ & Alahake Lake & $\begin{array}{l}47^{\circ} 41^{\prime} 18^{\prime \prime} \mathrm{N}, \\
87^{\circ} 34^{\prime} 16^{\prime \prime} \mathrm{E}\end{array}$ & 483 & $\begin{array}{l}\text { Pol, } \\
\text { Cha }\end{array}$ & 4700 cal yr BP & Li et al. (2019) \\
\hline $\mathrm{c} 2$ & Balikun Lake & $\begin{array}{l}43^{\circ} 40^{\prime} \mathrm{N}, \\
92^{\circ} 50^{\prime} \mathrm{E}\end{array}$ & 1575 & Pol & 9000 cal yr BP & An et al. (2011) \\
\hline c2 & Balikun Lake & $\begin{array}{l}43^{\circ} 40^{\prime} \mathrm{N}, \\
92^{\circ} 50^{\prime} \mathrm{E}\end{array}$ & 1575 & Pol & $16700 \mathrm{cal} \mathrm{yr} \mathrm{BP}$ & Tao et al. (2010) \\
\hline c3 & Bosten Lake & $\begin{array}{l}41^{\circ} 59^{\prime} 34^{\prime \prime} \mathrm{N}, \\
87^{\circ} 03^{\prime} 26^{\prime \prime} \mathrm{E}\end{array}$ & 1050 & $\begin{array}{l}\text { Pol, } \\
\text { NPP }\end{array}$ & $8540 \mathrm{cal} \mathrm{yr} \mathrm{BP}$ & Tarasov et al. (2019) \\
\hline $\mathrm{c} 4$ & Kanas Lake & $\begin{array}{l}48^{\circ} 43^{\prime 2} 23^{\prime \prime} \mathrm{N}, \\
87^{\circ} 01^{\prime} 22^{\prime \prime} \mathrm{E}\end{array}$ & 1365 & Pol & $13400 \mathrm{cal} \mathrm{yr} \mathrm{BP}$ & Huang et al. (2018) \\
\hline $\mathrm{c} 4$ & Kanas Lake & $\begin{array}{l}48^{\circ} 533^{\prime} 34^{\prime \prime} \mathrm{N}, \\
87^{\circ} 07^{\prime} 50^{\prime \prime} \mathrm{E}\end{array}$ & 1370 & $\begin{array}{l}\text { Dia, } \\
\text { XRF }\end{array}$ & $\sim 100$ cal yr BP & Lin et al. (2018) \\
\hline $\mathrm{c} 5$ & Narenxia Peat & $\begin{array}{l}48^{\circ} 48^{\prime} \mathrm{N} \\
86^{\circ} 54^{\prime} \mathrm{E}\end{array}$ & 1750 & Pol & $12240 \mathrm{cal} \mathrm{yr} \mathrm{BP}$ & Feng et al. (2017) \\
\hline c6 & Tielishan Peat & $\begin{array}{l}48^{\circ} 48^{\prime} 31^{\prime \prime} \mathrm{N}, \\
86^{\circ} 55^{\prime} 10^{\prime \prime} \mathrm{E}\end{array}$ & 1770 & Bio & 9665 cal yr BP & Zhang et al. (2016) \\
\hline c7 & Wulungu Lake & $\begin{array}{l}47^{\circ} 13^{\prime} \mathrm{N}, \\
87^{\circ} 15^{\prime} \mathrm{E} \\
\end{array}$ & 479 & Pol & 9550 cal yr BP & Liu et al. (2009) \\
\hline
\end{tabular}

\section{(d) Gobi Altai}

$\begin{array}{lllll} & & & & \text { Pol, } \\ \text { d1 } & \text { Yolin Am } & 103^{\circ} 26^{\prime} \mathrm{N}, & & \\ & & & \end{array}$

\section{(e) Valley of Great Lakes}

\begin{tabular}{lllcccc} 
& & $49^{\circ} 30^{\prime} \mathrm{N}$, & & & \\
e1 & Achit Nuur & $90^{\circ} 36^{\prime} \mathrm{E}$ & 1435 & Pol & $12500 \mathrm{cal} \mathrm{yr} \mathrm{BP}$ & Gunin et al. (1999) \\
\hline & & $49^{\circ} 30^{\prime} \mathrm{N}$, & & & & \\
e1 & Achit Nuur & $90^{\circ} 36^{\prime} \mathrm{E}$ & 1435 & Pol & $22600 \mathrm{cal} \mathrm{yr} \mathrm{BP}$ & Sun et al. (2013) \\
\hline & & $49.98^{\circ} \mathrm{N}$, & & & & \\
e2 & Bayan Nuur & $93.95^{\circ} \mathrm{E}$ & 932 & Pol & $15800 \mathrm{cal} \mathrm{yr} \mathrm{BP}$ & Tian et al. (2014) \\
\hline & & $50^{\circ} 20^{\prime} \mathrm{N}$, & & & & \\
e3 & Uvs Nuur & $92^{\circ} 50^{\prime} \mathrm{E}$ & 1100 & Sed & $46700 \mathrm{cal} \mathrm{yr} \mathrm{BP}$ & Grunert et al. (2000)
\end{tabular}

\section{(f) Central Mongolia}

\begin{tabular}{|c|c|c|c|c|c|c|}
\hline f1 & Orkhon Valley & $\begin{array}{l}47^{\circ} 13^{\prime} \mathrm{N}, \\
102^{\circ} 56^{\prime} \mathrm{E}\end{array}$ & 1600 & Pol & 2350 cal yr BP & Lehmkuhl et al. (2011) \\
\hline $\mathrm{f} 2$ & Solongotyn Dava & $\begin{array}{l}48^{\circ} 19^{\prime} \mathrm{N}, \\
98^{\circ} 59^{\prime} \mathrm{E}\end{array}$ & 2200 & Tre & 1150 cal yr BP & Jacoby and Baatarbileg (2003) \\
\hline f3 & Telmen Nuur & $\begin{array}{l}48^{\circ} 50^{\prime} \mathrm{N}, \\
97^{\circ} 20^{\prime} \mathrm{E}\end{array}$ & 1789 & Pol & 6090 cal yr BP & Fowell et al. (2003) \\
\hline f3 & Telmen Nuur & $\begin{array}{l}48^{\circ} 50^{\prime} \mathrm{N}, \\
97^{\circ} 20^{\prime} \mathrm{E}\end{array}$ & 1789 & $\begin{array}{l}\text { Pol, } \\
\text { Dia }\end{array}$ & 7110 cal yr BP & Peck et al. (2002) \\
\hline f3 & Telmen Nuur & $\begin{array}{l}48^{\circ} 50^{\prime} \mathrm{N}, \\
97^{\circ} 20^{\prime} \mathrm{E}\end{array}$ & 1789 & Dia & $6230 \mathrm{cal} \mathrm{yr} \mathrm{BP}$ & Soninkhishig et al. (2003) \\
\hline f4 & Ugii Nuur & $\begin{array}{l}47^{\circ} 46^{\prime} \mathrm{N} \\
102^{\circ} 46^{\prime} \mathrm{E}\end{array}$ & 1332 & $\begin{array}{l}\text { Pol, } \\
\text { Dia }\end{array}$ & 8660 cal yr BP & Wang et al. (2009) \\
\hline
\end{tabular}




\section{Palynology and Palaeoecology}

\section{Investigation of ecosystems}

Ecosystems consist of a network of interacting biotic (e.g. plants, animals, other organisms) and abiotic (e.g. rocks, sediments, temperature) constituents. In their ideal state, ecosystems are at equilibrium between internal and external driving factors. Each ecosystem constituent contributes to the constitution of the present-day environment (Birks and Birks, 2006). Palaeoecologists evaluate environments of the past (palaeoenvironments) by reconstructing the dynamics of ecosystems from biotic responses of proxy data (Guiot et al., 2009). Biotic proxy data can be derived from different natural archives (e.g. lake sediments, peat, trees, ice cores) and provide a record of changes over time in the characteristics of sediment and fossil organisms (Birks and Birks, 2006). As there is a high number of different biotic proxies, a specialist knowledge is required to identify and interpret the fossil material. In this regard, organisms are commonly investigated as whole groups: pollen, diatoms, ostracods, chironomids, etc. Ecological tolerances and biology of taxa indicate environmental preferences and, assuming similar present-day and past conditions, taxa serve as indicator species for the investigation of palaeoenvironments (Birks and Birks, 1980, 2006; Birks, 2003; Smol, 2002). In palaeoecology, it is particularly of interest to infer past habitat, vegetation distribution and climate about the time of deposition.

Pollen analysis is one valuable tool for the reconstruction of catchment and regional vegetation. Pollen assemblages reflect its composition and structure, and provide quantitative information of climate change over long time periods through intermediate vegetation reconstruction steps or transfer functions (e.g. Guiot et al., 2009; Telford and Birks, 2009). Pioneer work about the application of pollen in vegetation science was carried out by Lennart von Post (1884-1951). He published the first pollen diagrams (Fries, 1967) and taught of the principles of pollen analysis, methodology, pollen counting, statistics, presentation of results and problems in dating and interpretation. Knut Faegri and Johannes Iversen refined van Post's work and devoted their Textbook of Modern Pollen Analysis (1950) to him, which is still used as a standard reference in palynology today (Birks and Berglund, 2017).

However, pollen, as every other proxy, has its advantages as well as disadvantages. Although pollen analysis enables the possibility of identifying taxa occurrences and relative changes on a high resolution and allows the reconstruction of local and regional vegetation (depending on palaeoarchive quality and size), spatially accurate taxa reconstructions are still difficult (Nelle et al., 2010). Plant-climate interactions are not only affected by the non-stable atmospheric $\mathrm{CO}_{2}$ concentration, but pollen assemblages are also noisy in various other aspects. The pollen productivity cannot be directly presumed to be equal to the productivity of vegetation, because it varies over space and time (Sugita, 2007). Pollen grain transportation disturbs the assemblage and plant species are influenced by more than one climatic variable causing interpretation problems (Guiot et al., 2009). 
The effects of background pollen disturbance and percentage calculations result in non-linear pollenvegetation relationships (Sugita, 2007). Additionally, reconstructions based on just one single proxy may generally result in systematic errors (Sidorova et al., 2012).

\section{Multi-proxy approach}

A wider overview of the dynamics of present and past ecosystems can be derived from the investigations of as many proxies as possible (Smol, 2002). A multi-proxy approach applies several proxies simultaneously to extend the spatial scale and diminish the weaknesses of single proxies (Birks and Birks, 2006; Mann, 2002). Hence, each proxy reflects different aspects of the ecosystem and several proxies help to gain a holistic view on the reconstructed environment (Birks and Birks, 2006). Despite of that they have many advantages, successful multi-proxy studies reveal various methodological challenges such as different time-resolutions, possible contrasting results, high amounts of data, etc. (Sidorova et al., 2012). Hence, like in all palaeoenvironmental studies, it is necessary to address the following requirements: (1) formulate clear and relevant research questions, (2) chose investigation areas which will provide answers to the research aims, (3) take samples for different proxies at the same locations or levels in the same core, (4) data collections should be coordinated and stored efficiently, (5) create a reliable age-depth-model, (6) present numerous results clearly and apply numerical techniques for detecting similar patterns in all proxies, (7) interpret similarities and differences wisely and with regard to greater patterns (Birks and Birks, 2006).

\section{Study area}

\section{Geography}

The Altai Mountains are a sub-longitudinal mountain range in Central and East Asia with an extension of more than 2,100 km (Rudaya et al., 2009). They are subdivided into the Russian Altai in the North and West, the Chinese Altai in the Southwest and the Mongolian Altai in the East. The Mongolian Altai is bordered to the Southeast by the Gobi Altai and by the Valley of Great Lakes to the East and Northeast (Lehmkuhl et al., 2016). The Altai is the tallest and most extensive mountain range in Mongolia. The highest mountain massif is Kuiten Uul of Tavan Bogd, 4,374 m a.s.l. (Gunin et al., 1999).

The study area $\left(48^{\circ} 15^{\prime} \mathrm{N}, 88^{\circ} 48^{\prime} \mathrm{E}\right.$, Fig. 1.2$)$ is located in the province Bayan-Ulgii, south of Dayan Nuur close to the Chinese border. Other significant regional lakes are Hoton Nuur (11pprox.. $50 \mathrm{~km}$ distant), Kanas Lake $(145 \mathrm{~km})$ and Achit Nuur $(180 \mathrm{~km})$. The area is part of the Altai Tavan Bogd National Park, established in 1996. The National Park is situated at >2,000 m a.s.l., whereas the 
highest altitudes exceed 4,000 m. a.s.l. in the North and West (Lkhagvadorj et al., 2013). At present, the national park is divided into three zones, (1) a special conservation zone (19\% of the park), (2) a tourism zone (58\%) that is used for grazing and tourism and (3) a limited use zone (20\%) where traditional land use is allowed, tourism is not regulated and illegal hunting is tolerated (Beket and Knapp, 2012).

The closest town is Ulgii $\left(48^{\circ} 55^{\prime} \mathrm{N}, 8^{\circ} 56^{\prime} \mathrm{E}, 1,715 \mathrm{~m}\right.$ a.s.1.), located 12 pprox.. $120 \mathrm{~km}$ northeast of the study area.

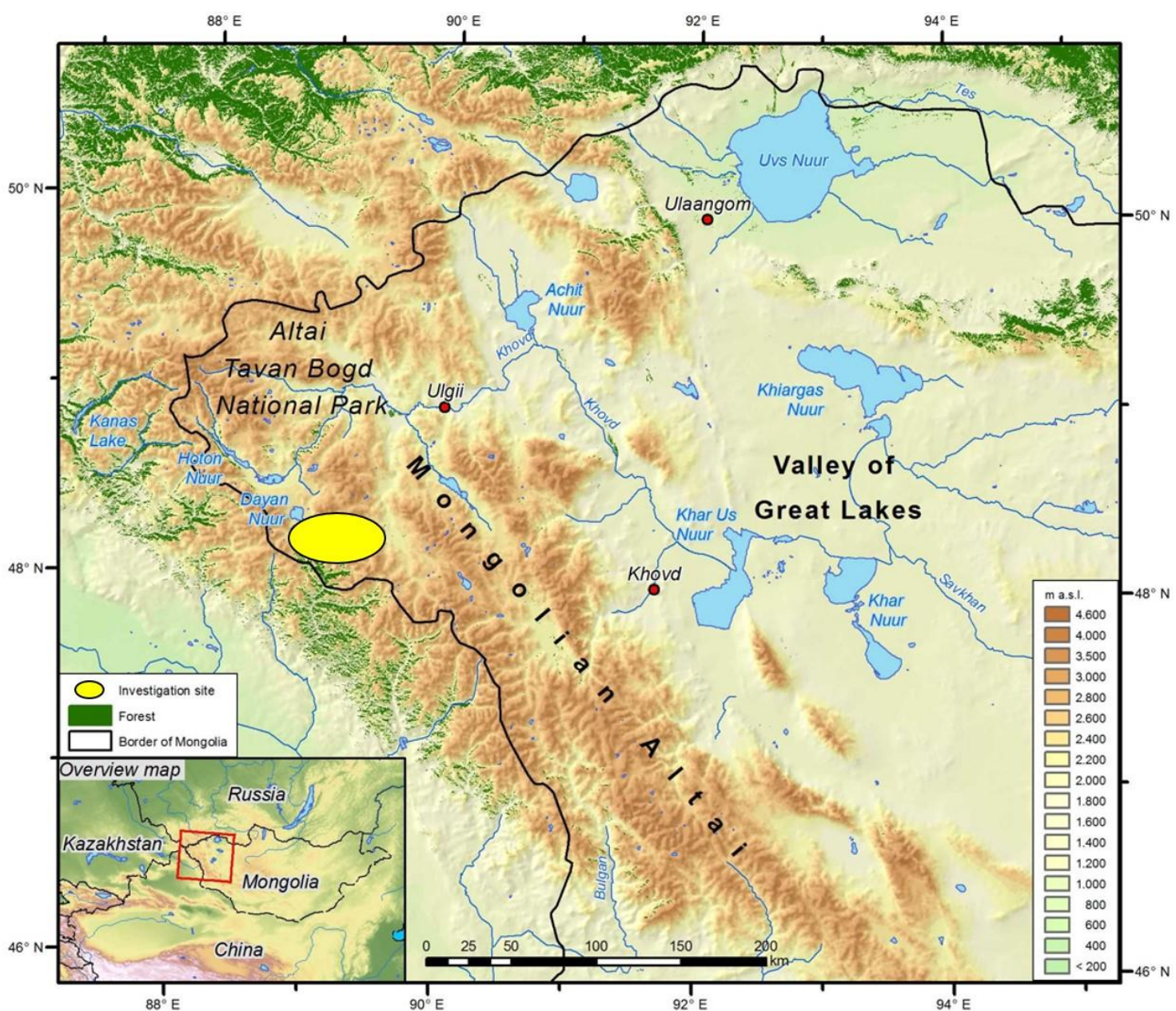

Fig. 1.2 Topographic map showing the location of the Altai Tavan Bogd National Park within Central Asia (overview map), the characteristics of the Altai Mountains and the location of investigation area (yellow oval).

\section{Geology, relief and soils}

The Altai Mountain relief started its present formation roughly around $5 \mathrm{Ma}$ ago because of the Indian and Eurasian continental plate collision (Jolivet et al., 2007). It developed under successive accretion of subduction complexes and continental fragments along the Precambrian Angara cratin 
south of Siberia. Precambrian assemblages form the basement of the orogen trending in accurate belts in NW-SE directions (Cunningham, 2005). Other major geological structures are N-S- or WNW-ESE-directed (Klinge et al., 2003). Paleozoic to Mesozoic intrusive structures occur, which range from not deformed plutons to severely deformed orthogneisses consisting of gabbroic to alaskitic granite rocks. Metamorphosed Precambrian assemblages are exposed at higher elevations, cut by Paleozoic or Mesozoic plutons in most locations. In some areas, rift deposits of Jurassic and Cretaceous clastic sediment sequences occur (Cunningham et al., 1996). Uplift processes in the Cenozoic resulted in the development of alluvial deposits along the mountain range margins and within several mountain basins (Cunningham, 2005). During the late Quaternary, older structures have been highly shaped by glaciation dynamics and erosion processes (Lehmkuhl et al., 2016). Hence, nowadays, the Altai Mountain ranges are characterized by flat summit plateaus of tens of kilometers length, large moraine ridges and systems of glaciofluvial terraces (Jolivet et al., 2007; Lehmkuhl et al., 2016).

Summits above 3,400 m a.s.l. are covered by bare rock deposits and plateau glaciers (Klinge et al., 2017). In the basins and on the slopes, pediments are composed of gravel and alluvial sediments as well as aeolian sand and loess-like material (Klinge et al., 2017; Lehmkuhl, 1997). Dominating soils in the area are leptosols (Dulamsuren et al., 2014).

Permafrost conditions prevail from the mountain plateaus to the basins. However, in lower elevations periglacial processes and permafrost distribution are limited by the low soil humidity (Klinge et al., 2017). Only forested areas are underlain by continuous permafrost.

\section{Modern climate}

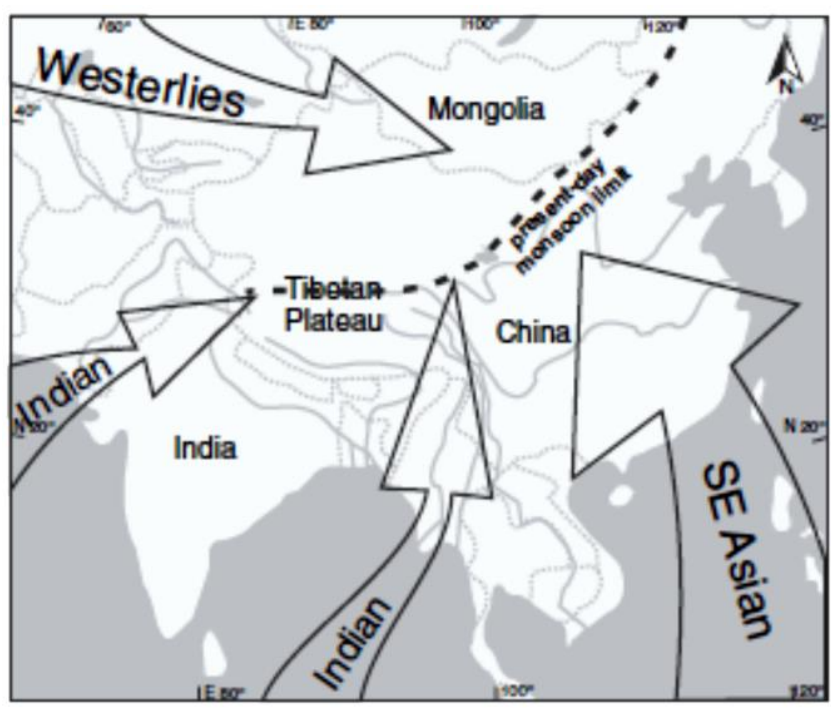

Fig. 1.3 Circulation systems influencing Central Asia and present-day limit of the summer monsoon (Herzschuh, 2006)
Climate in the Altai Tavan Bogd National Park is characterized by extreme continentality due to its specific topographic conditions and the great distance to the moisture sources of the Indian, Arctic and Pacific Oceans (Andreev et al., 2007). Nowadays, the only circulation system of Central Asia impacting western Mongolia is the westerlies (Fig. 1.3) (Herzschuh, 2006). However, most wet air masses arriving from the West are captured by the westernmost mountain ranges of the Altai. 
Whereas the Russian Altai receives more than $800 \mathrm{~mm}$ of mean annual precipitation, the rain shadow effect causes a reduction to $200 \mathrm{~mm}$ in the Southeast and down to $50 \mathrm{~mm}$ in the Valley of Great Lakes (Klinge et al., 2003).

The climate station of Ulgii is the closest source providing reliable climate data for the study area (Fig. 1.4). Average temperatures range from $-17.1{ }^{\circ} \mathrm{C}$ in January to $16.3{ }^{\circ} \mathrm{C}$ in July. A variation of $33.4{ }^{\circ} \mathrm{C}$ in average monthly temperatures is one indicator for the strongly continental climate. The other indicator is the low average precipitation of $114 \mathrm{~mm}$ per year. Most of the rainfall occurs during the short summer period from June to August (70-80\%). During the winter period (6 month), the area is covered by ice and snow (Chen et al., 2003).

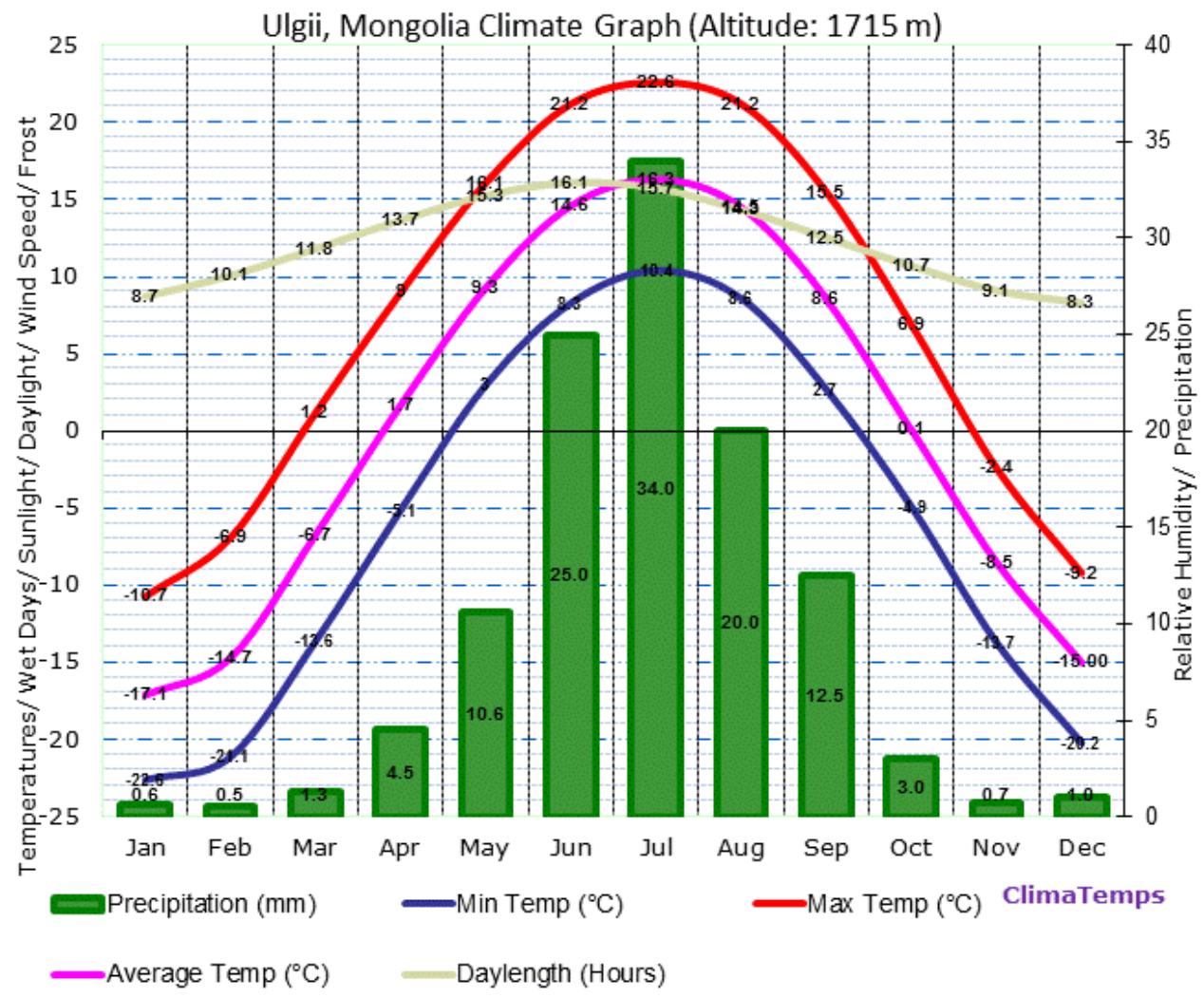

Fig. 1.4 Climate graph of Ulgii, Mongolia (http://www.ulgii.climatemps.com/, accessed 05 September 2017)

\section{Vegetation}

In the Mongolian Altai, gradients such as elevation and exposure, temperature and precipitation are the main drivers affecting vegetation composition, distribution and productivity (Rudaya et al., 2009). Precipitation is the main factor favoring a W-E-directed plant community pattern, whereas altitude determines the vertical range of vegetation distribution (Gunin et al., 1999). In the north- 
western part of the Mongolian Altai the altitudinal vegetation zones are described as follows (after Beket and Knapp, 2012):

I. High mountain zone/belt ((2,100) 2,700 to $4,374 \mathrm{~m}$ a.s.l.)

1. nival: regular snow cover, without vascular plants

2. subnival: lichen communities, fragments of petrophytes, cryophyte meadows and swamps

3. alpine: high mountain tundra, cryophyte grassland and subalpine shrubs

II. Mountain forest zone/belt (1,700 to 2,200 $\mathrm{m}$ a.s.l.)

divided into several sub-zones without distinctive boundaries

1. Sub-alpine open woodland

2. Coniferous forests with larch, spruce and pine

3. Forest-steppe complex, forests with shrubs and meadow steppes

III. Mountain steppe zone/belt (1,600 to 3,200 m a.s.1.)

high mountain cushion herb vegetation, cryo-xerophytic grassland, xerophytic shrubs and grass steppes

IV. Desert zone/belt (1,100 to $2,100 \mathrm{~m}$ a.s.l.)

Semi-desert and desert communities, occurs only depending in micro-climatic phenomenon (very warm and dry climate in intra-montane basins in the rain shadow of surrounding depressions)

In addition to the altitudinal vegetation zones (Fig. 1.5), there are some types of azonal vegetation such as water plant communities within/surrounding lakes and rivers, pioneer and floodplain vegetation, and shrubs associated with gravel banks in river valleys (Beket and Knapp, 2012). Forests and forest-steppes only occur on north-facing slopes as a result of less evapotranspiration. They usually grow on the upper parts of the mountain slopes or on the central parts if a high mountain zone is present (Dulamsuren et al., 2014). Summer temperature controls the upper tree growth limit, whereas moisture availability and human impact determine the lower limit (Klinge et al., 2003). Most forested areas are only composed of Siberian larch (Larix sibirica). In some areas close to the Chinese border Siberian pine (Pinus sibirica) and Siberian spruce (Picea obovata) add to the forest composition (Dulamsuren et al., 2014). In places where forest stands are missing and on south-facing slopes, the transition from mountain steppe communities to alpine grassland communities is continuous (Gunin et al., 1999). 


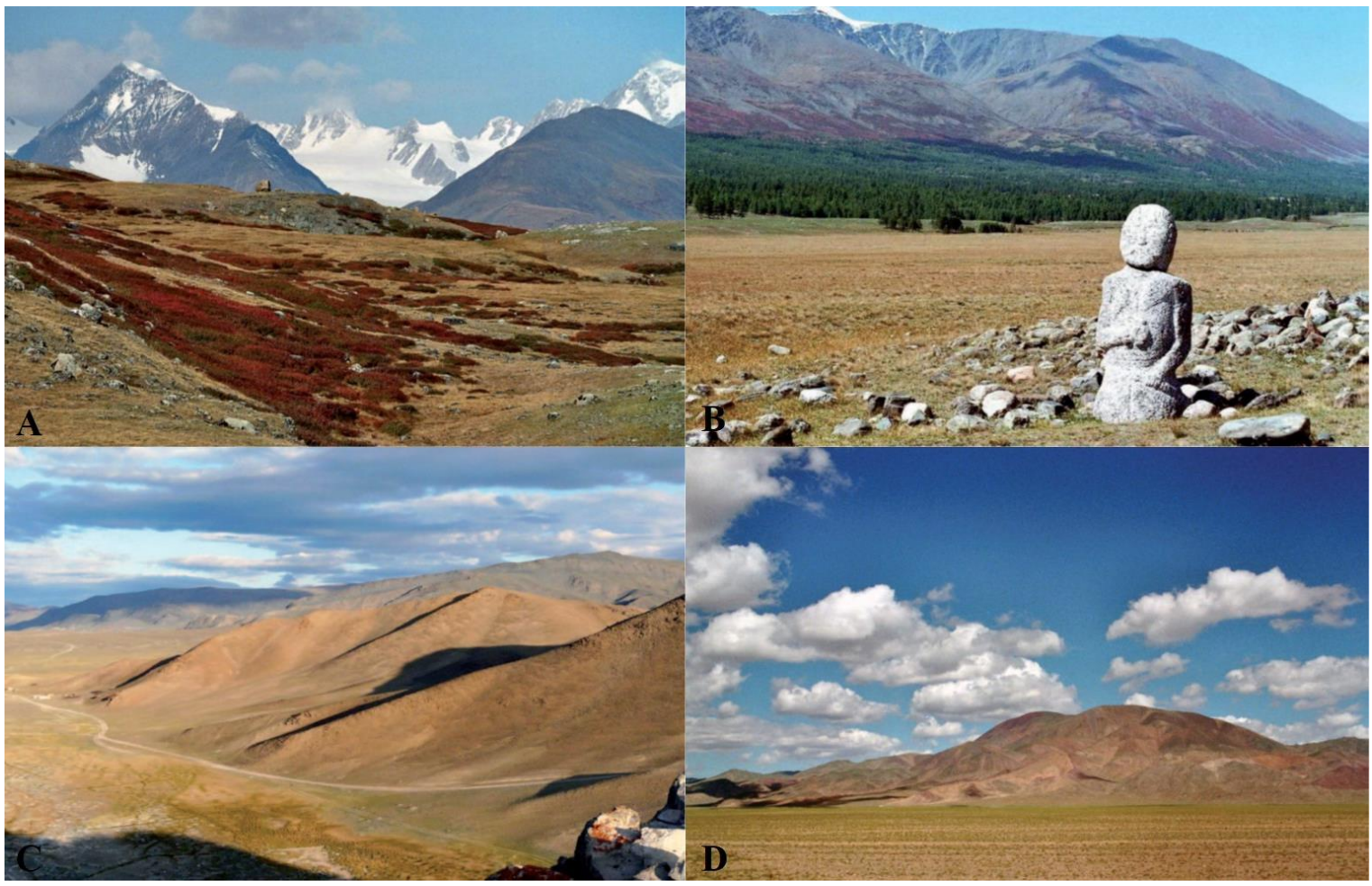

Fig. 1.5 Altitudinal vegetation zones in the Mongolian Altai. A: High mountain zone, vegetation complex of alpine Kobresia-grassland (brown) and subalpine Betula-shrubland (red), nival belt with peaks and glaciers in the background, B: Mountain forest zone, mountain steppe in the valley (brown), closed mountain forest belt on the lower slopes (green), forest line to the subalpine Betulashrubland (red), C: Mountain steppe zone, D: Desert zone, semi-desert with Anabasis brevifolia Stipa glareosa, Kraschennikovia ceratoides, Reaumuria soongorica (Beket and Knapp, 2012).

\section{Settlement and herding history}

The area of the current state of Mongolia has been inhabited by modern humans since the Upper Paleolithic (46,000-12,000 cal yr BP) (Tab. 1.2). Until the early/mid Bronze Age (before 4,450 cal yr BP), various gatherer-hunter-groups subsisted on forest and steppe. During late Bronze Age (3,450-2,650 cal yr BP) animal husbandry and mobile pastoralism developed within the Eurasian steppe and were introduced to multi-cultural Mongolian territory, most likely via Tuva in Southern Siberia (eg Fernández-Giménez et al., 2017; Houle, 2015; Miehe et al., 2009; Tumen, 2006). Those conclusions are drawn from bones of sheep, goats and horses found in excavated burials. Except of their mortuary behaviors, only very little is known about Mongolian Bronze Age cultures, such as their settlement patterns, subsistence practices and demographics to present day (Houle, 2015). Organizational forms of nomadic cultures and pastoral activities adjusted and stabilized throughout Terminal Bronze Age (2,650-2,350 cal yr BP). Mobile pastoralism expanded noticeably, increasing the pressure on the environment by intensified deforestation for new pasture grounds, firewood and building materials (e.g. burial chambers). Scythian and Pazyryk cultures of the Iron Age (2,3502,159 cal yr BP), were the first communities expanding their habitats into the sub-alpine and high- 
altitude steppe zones while practicing semi-sedentary herding (Chlachula, 2019). Under Xiongnu (2,159-1,795 cal yr BP), Xianbei (1,795-1,715 cal yr BP) and Rouran Empire (1,620-1,395 cal yr BP), new organizational forms established uniting pastoral activities of small-scale nomadic clans/cultures (Holcombe, 2013; Kradin, 2005; Park et al., 2017; Rogers, 2015). As a result of eastward Turkic expansions, a Turkic State established on Mongolian territory lasting from 1,395 to 1,150 cal yr BP. At this time, an agricultural herding society developed (Neolithic evolution), but due to climatic conditions, only pastoralism remained possible in the Mongolian Altai. Around 1,150 cal yr BP the Turks were pushed back and Khanates replaced the Turkic State. More traditions in pastoral economy developed: herders adapted to grazing patterns and summer/winter shelters (Fernández-Giménez, 1999; Fernández-Giménez et al., 2017).

Tab. 1.2 Brief overview of cultural/political periods in the Mongolian Altai from Early Bronze Age to present

\begin{tabular}{|c|c|c|}
\hline $\begin{array}{l}\text { Time period } \\
\text { (BC/AD) }\end{array}$ & $\begin{array}{l}\text { Time period } \\
\text { (cal yr BP) }\end{array}$ & Cultural/Political Period \\
\hline $2,500-1,500 \mathrm{BC}$ & $4,450-3,450$ & Early/Mid Bronze Age \\
\hline $1,500-700 \mathrm{BC}$ & $3,450-2,650$ & Late Bronze Age \\
\hline $700-400 \mathrm{BC}$ & $2,650-2,350$ & Terminal Bronze Age \\
\hline $400-209$ BC & $2,350-2,159$ & $\begin{array}{c}\text { Beginning of Early Iron Age } \\
\text { Scythian culture, Pazyryk culture }\end{array}$ \\
\hline $209 \mathrm{BC}-155 \mathrm{AD}$ & $2,159-1,795$ & Xiongnu Empire \\
\hline $155-235 \mathrm{AD}$ & $1,795-1,715$ & Xianbei Empire \\
\hline $330-555 \mathrm{AD}$ & $1,620-1,395$ & Rouran Empire \\
\hline $555-900 \mathrm{AD}$ & $1,395-1,050$ & Turkic State \\
\hline $900-1206 \mathrm{AD}$ & $1,050-744$ & Khaganates \\
\hline $1206-1368 \mathrm{AD}$ & $744-582$ & Mongol Empire \\
\hline $1368-1691 \mathrm{AD}$ & $582-259$ & Northern Yuan Dynasty \\
\hline $1691-1911 \mathrm{AD}$ & $259-39$ & Qing Dynasty \\
\hline $1911-1924 \mathrm{AD}$ & $39-26$ & Independence \\
\hline $1924-1960 \mathrm{AD}$ & 26 to -10 & $\begin{array}{c}\text { Mongolian People's Republic in Soviet } \\
\text { Union } \\
\text { (Centrally planned economy) }\end{array}$ \\
\hline 1960 - $1990 \mathrm{AD}$ & -10 to -40 & $\begin{array}{c}\text { Mongolian People's Republic in Soviet } \\
\text { Union } \\
\text { (Collective Period) }\end{array}$ \\
\hline $1990-2000 \mathrm{AD}$ & -40 to -50 & $\begin{array}{l}\text { Democracy } \\
\text { (Privatization) }\end{array}$ \\
\hline $2000 \mathrm{AD}$ to present & -50 to present & $\begin{array}{c}\text { Democracy } \\
\text { (Market Economy) }\end{array}$ \\
\hline
\end{tabular}


During Mongol Empire (744-582 cal yr BP), Mongol territory expanded massively, increasing the number of livestock (e.g. cows, sheep and horses) and, again, reorganizing pastoral activities. Political allies of the Great Khan controlled the pastures and from that time on, groups of herders were assigned to fixed territories including the possibility of wide-ranging seasonal migrations (Fernández-Giménez et al., 2017). The establishment of Northern Yuan Dynasty in Mongolia (582259 cal yr BP) sealed the disintegration of the Mongol Empire and reintroduced Tibetan Buddhism into Mongolia. Consequently, powerful Buddhist leaders were granted their own territories on which clans herded the monasteries' livestock for church wealth. Coordinated seasonal migrations were allowed under customary law of the steppe.

After Northern Yuan Dynasty was superseded by Qing Dynasty (259-39 cal yr BP) in Mongolia, Mongolian territory was divided into administrative areas (banners) ruled by a hereditary prince or religious leader. Herders were allowed to graze specific pasture areas but moving from one banner to another was permitted. Nomadic movements were also coordinated by the leader of the banner. Two to twelve households, respectively, formed a herding encampment traveling and camping together increasing the number of livestock per camp. In some areas, grazing was prohibited (Fernández-Giménez et al., 2017). In general, these nomadic herding regulations persisted until the Socialist Government of the Soviet Union established a centrally planned economy in Mongolia (26 to -10 cal yr BP). They only allowed herding of state-owned livestock and nomadic movements were restricted which led to a sharp decline in livestock population due to slaughter. From -10 to $-40 \mathrm{cal}$ yr BP, a form of specialized herding (one-species herding) in collectives was introduced. Collectives provided infrastructure for supplied transportation, veterinary service and water. Seasonal movements averaged four movements per year, while some areas were kept as emergency reserve pastures (Fernández-Giménez et al., 2017; Johnson et al., 2006). Under democracy (after -40 cal yr $\mathrm{BP})$, most state-owned livestock was privatized, whereas pastureland remained state property. These massive changes resulted in a short-term increase in animal population (Fernández-Giménez, 1999; Johnson et al., 2006). The establishment of a market economy in Mongolia since -50 cal yr BP, favors a rise in mining and service industries and a general decline in the number of nomadic herders and livestock-owning households. Persisting nomadic herders move from rural to more urban areas as a result of the development of regional production centers (State Farm approach) (Hirano and Batbileg, 2013 ;). Nowadays, approx. 80 nomadic clans ( $>400$ persons) inhabit the area around Dayan Nuur in summer, some live there the whole year. Their livestock includes goats, horses, sheep, yaks, and camels grazing on both forests and grasslands (Khishigjargal et al., 2013) 


\section{Materials and methods}

In this thesis, multi-site and multi-proxy research was carried out on five sediment cores of different lengths, sediment compositions and time intervals. All sediment cores were collected in the Altai Tavan Bogd National Park in an area of about $136 \mathrm{~km}^{2}$ south of Dayan Nuur. The maximum distance between two sites (cores Ch and D3L6) is approx. $22 \mathrm{~km}$.

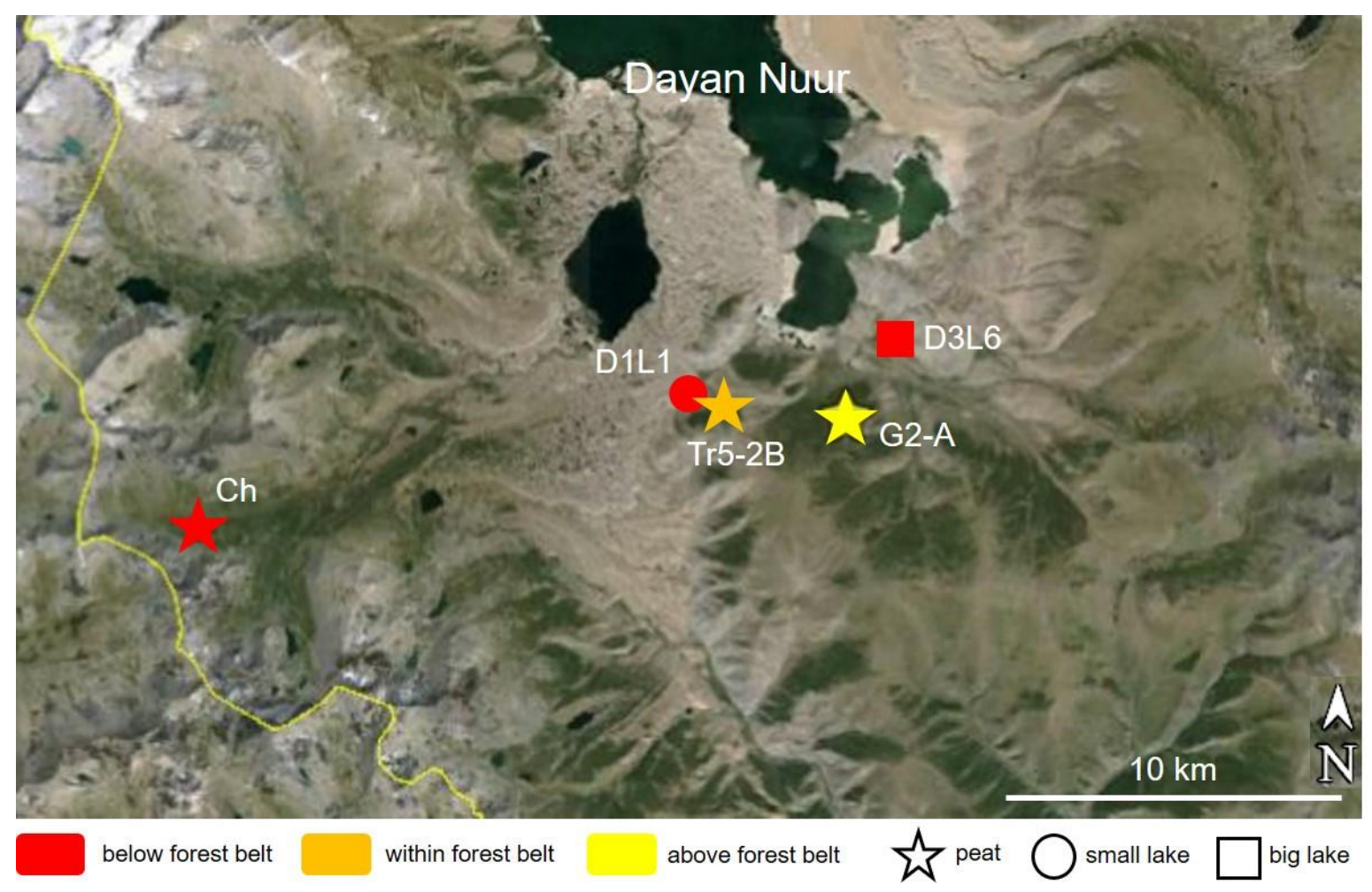

Fig. 1.6 Locations and characteristics of sites within the study area south of Dayan Nuur in the Altai Tavan Bogd National Park (modified from Google Inc., 2019 (accessed 03 August 2019)).

Cores were selected based on their location and characteristics to reflect a broad spectrum of features of the forest-steppe ecosystem in the Mongolian Altai. Archive locations and details are presented in Fig. 1.6 and Tab. 1.3.

The following five different archives were selected according to specific environmental criteria:

(1) Core D3L6 (big lake below lower forest boundary), wide catchment area reflects long-term regional changes at a lower elevation

(2) Core D1L1 (small lake below lower forest boundary), smaller catchment area compared to core D3L6 reflects more short-term local changes at a lower elevation

(3) Cores Ch, Tr5-2B and G2-A (peat core transect from below, within and above the forest boundary), smaller catchment area compared to lacustrine archives reflect local changes at different elevations and vegetation types 
Tab. 1.3 Detailed description of studied sites and sediment cores

\begin{tabular}{|c|c|c|c|}
\hline Name of site & Ch & D1L1 & D3L6 \\
\hline Synonym name & border core & small lake & big lake \\
\hline Location (latitude, & $48^{\circ} 12^{\prime} 57.76^{\prime \prime} \mathrm{N}$ & $48^{\circ} 15^{\prime} 26.94^{\prime \prime} \mathrm{N}$ & $48^{\circ} 16^{\prime} 22.18^{\prime \prime} \mathrm{N}$ \\
\hline longitude & $88^{\circ} 38^{\prime} 1.85^{\prime \prime} \mathrm{E}$ & $88^{\circ} 49^{\prime} 59.29^{\prime \prime} \mathrm{E}$ & $88^{\circ} 54^{\prime} 48.50^{\prime \prime} \mathrm{E}$ \\
\hline Altitude (a.s.l.) & $2,583 \mathrm{~m}$ & $2,312 \mathrm{~m}$ & $2,239 \mathrm{~m}$ \\
\hline Current vegetation & forest-steppe & dry mountain-steppe & dry mountain-steppe \\
\hline $\begin{array}{l}\text { Current location } \\
\text { within ecosystem }\end{array}$ & below forest belt & below forest belt & below forest belt \\
\hline Core type & peat & lake & lake \\
\hline Core length $(\mathrm{cm})$ & 33 & 135 & 94 \\
\hline Basal age (cal yr BP) & 320 & 1,350 & 4,310 \\
\hline Analyzed proxies & $\begin{array}{l}\text { pollen, NPP, micro } \\
\text { charcoal, macro- } \\
\text { charcoal }\end{array}$ & $\begin{array}{l}\text { pollen, NPP, micro } \\
\text { charcoal, macro- } \\
\text { charcoal, diatoms, } \\
\text { XRF data }\end{array}$ & $\begin{array}{l}\text { pollen, NPP, micro } \\
\text { charcoal, macro- } \\
\text { charcoal, diatoms, } \\
\text { XRF data }\end{array}$ \\
\hline Thesis chapter & 5 & 4 & 3 \\
\hline
\end{tabular}

\begin{tabular}{lll} 
Name of site & G2-A & Tr5-2B \\
\hline Synonym name & above treeline core & forest core \\
\hline $\begin{array}{l}\text { Location (latitude, } \\
\text { longitude }\end{array}$ & $\begin{array}{l}48^{\circ} 15^{\circ} 0.00^{\circ} \mathrm{N} \\
88^{\circ} 53^{\prime} 40.10^{\circ} \mathrm{E}\end{array}$ & $\begin{array}{l}48^{\circ} 15^{\prime} 12.00^{\circ} \mathrm{N} \\
88^{\circ} 50^{\prime} 19.06^{\circ} \mathrm{E}\end{array}$ \\
\hline Altitude (a.s.l.) & $2,430 \mathrm{~m}$ & $2,380 \mathrm{~m}$ \\
\hline $\begin{array}{l}\text { Current vegetation } \\
\text { Current location } \\
\text { within ecosystem }\end{array}$ & dry mountain-steppe & forest-steppe \\
\hline Core type & above forest belt & within forest belt \\
\hline Core length (cm) & 34 & peat \\
\hline Basal age (cal yr BP) & 3,880 & 38 \\
\hline & & 1,350 \\
\hline & $\begin{array}{l}\text { pollen, macro- } \\
\text { charcoal }\end{array}$ & $\begin{array}{l}\text { pollen, NPP, micro } \\
\text { charcoal, macro- } \\
\text { charcoal }\end{array}$ \\
Analyzed proxies & 2 & 5
\end{tabular}

Due to the advantages of multi-proxy analyses, several different proxies have been studied on the sediment material: pollen and spores, NPPs, micro and macro-charcoal, diatoms and XRF-data.

For palynological analysis (pollen, spores, NPPs), laboratory work was performed according to the detailed schedule in Tab. 1.4 taught by U. Nüsse-Hahne after Faegri \& Iversen (1989). Chemicals and sieves are used to break up and remove large amounts of inorganic and organic sediment components and color the remaining material to facilitate the identification of pollen grains and other palynomorphs under the light microscope. 
Tab. 1.4 Detailed laboratory schedule for pollen analysis applied on Mongolian sediments in the research (after Faegri and Iversen, 1989).

\begin{tabular}{|c|c|c|}
\hline $\begin{array}{l}\text { Chemicals/ } \\
\text { Methods }\end{array}$ & Steps & Purpose \\
\hline Markers & $\begin{array}{l}\text { - Addition of } 1 \text { tablet with Lycopodium } \\
\text { clavatum spores }\end{array}$ & $\begin{array}{l}\text { Concentration and } \\
\text { influx calculations }\end{array}$ \\
\hline HCl 10\% & $\begin{array}{ll}\text { - } & \text { Addition of } 4 \mathrm{ml} \mathrm{HCl} 10 \% \\
\text { - } & \text { Wait until tablet is fully dissolved } \\
\text { - } & \text { Mix with plastic stick } \\
\text { - } & \text { Centrifuge, discard supernatant in respective } \\
& \text { waste container } \\
\text { - } & \text { Addition of } 4 \mathrm{ml} \text { distilled water } \\
\text { - } & \text { Mix with vortexer } \\
\text { - } & \text { Centrifuge, discard supernatant } \\
\end{array}$ & $\begin{array}{l}\text { calcareous fraction } \\
\text { removal }\end{array}$ \\
\hline HF $40 \%$ & $\begin{array}{l}\text { - } \quad \text { Addition of } 4 \mathrm{ml} \mathrm{HF} 40 \% \\
\text { - } \quad \text { Mix carfully with plastic stick } \\
\text { - } \quad \text { Leave samples under fume cupboard overnight } \\
\text { - } \quad \text { Mix again carefully } \\
\text { - } \text { Centrifuge, discard supernatant in respective } \\
\text { - } \text { Additiontainer of } 4 \mathrm{ml} \text { distilled water } \\
\text { - } \quad \text { Mix with vortexer } \\
\text { - } \quad \text { repeat sample washing } 2 \text { times } \\
\end{array}$ & $\begin{array}{l}\text { silicate fraction } \\
\text { removal }\end{array}$ \\
\hline КОН $10 \%$ & $\begin{array}{l}\text { - } \text { Heat water bath to } 90{ }^{\circ} \mathrm{C} \\
\text { - } \\
\text { - } \text { Addition of } 4 \mathrm{ml} \text { potassium hydroxide } 10 \% \\
\text { - } \text { Put into water bath for } 10 \mathrm{~min} \\
\text { - } \text { Centrifuge, discard supernatant in respective } \\
\text { - } \text { waste container } \\
\text { - } \text { Addition of } 4 \mathrm{ml} \text { distilled water } \\
\text { - } \quad \text { Centrifuge, discard supernatant }\end{array}$ & $\begin{array}{c}\text { Organic matter break } \\
\text { up and humic acid } \\
\text { removal }\end{array}$ \\
\hline Sieving & $\begin{array}{ll}\text { - } & \text { Wet sieve with } 120 \mu \mathrm{m} \text { mesh } \\
\text { - } & \text { Centrifuge, discard supernatant }\end{array}$ & large fraction removal \\
\hline $\begin{array}{c}\text { Erdtman's } \\
\text { acetolysis } \\
\left(\mathrm{CH}_{3} \mathrm{COOH}\right) \\
\text { and } \\
\left.\mathrm{CH}_{3} \mathrm{CO}\right)_{2} \mathrm{O} \\
+\mathrm{H}_{2} \mathrm{SO}_{4}\end{array}$ & $\begin{array}{l}\text { - } \text { Addition of } 4 \mathrm{ml} \text { acetic acid } \\
\text { - } \quad \text { Mix with vortexer } \\
\text { - } \text { waste container } \\
\text { - } \text { ratio of } 1: 9 \\
\text { - } \text { Addition of } 4 \mathrm{ml} \text { of mixture } \\
\text { - Mix with vortexer } \\
\text { - Put into water bath of } 90^{\circ} \mathrm{C} \text { for } 10 \mathrm{~min} \\
\text { - } \quad \text { Centrifuge, discard supernatant in respective } \\
\text { - } \text { Addition of } 4 \mathrm{ml} \text { distilled water } \\
\text { - Mix with vortexer } \\
\text { - Centrifuge, discard supernatant } \\
\text { - repeat sample washing until water is clean }\end{array}$ & $\begin{array}{l}\text { dehydrogenation, } \\
\text { cellulose removal and } \\
\text { coloring }\end{array}$ \\
\hline
\end{tabular}




\begin{tabular}{lll}
\hline & $\bullet$ & Wet sieve with $5 \mu \mathrm{m}$ mesh \\
Sieving & $\bullet$ & Transfer material to Eppendorf tube by \\
& disposable syringe for storage
\end{tabular}

Charred particles of $<125 \mu \mathrm{m}$ are referred to as microscopic (micro) charcoal (e.g. Clark, 1990; Whitlock and Millspaugh, 1996) and counted in the same preparations as the palynomorphs. However, it must be considered that the palynological laboratory procedure favors charcoal particle fragmentation. Hence, micro charcoal results should be interpreted as general trends rather than reliable data (Biagioni, 2015).

The preparation of macroscopic (macro) charcoal (>125 $\mu \mathrm{m}$ ) samples was carried out following the procedure of Stevenson and Haberle (2005) taught by Dr. S. Biagioni. A detailed schedule is presented in Tab. 1.5. Employing this method, chemicals are used to break up organic matter, remove humic acid and bleach the remaining fraction. The process simplifies the separation of charred particles from organic material due to its resistance to hydrogen peroxide. Wet sieving is conducted to remove the microscopic fraction $(<125 \mu \mathrm{m})$.

Macro-charcoal samples are counted using a bionocular dissecting microscope. Inspired by the methods presented by Umbanhowar and McGrath (1998) and Mustaphi and Pisaric (2014), all charred macroscopic fragments are assigned to one of the following morphological groups: (A) wood-type, (B) leaf-type, (C) grass-type charcoal or (D) others by visual inspection (see Appendix A3). (D) others include roots, mosses, seeds and all unidentifiably small particles.

Diatom analysis and XRF scanning have been conducted on two of the investigated sediment cores (D1L1 and D3L6). Performing those analyses in the laboratory were not part of my personal work and are therefore not explained in detail here. Descriptions of respective laboratory work and counting methods are presented in the materials and methods sections in chapters 3 and 4 . 
Tab. 1.5 Detailed laboratory schedule for macro-charcoal analysis applied on Mongolian sediments in the research (after Stevenson and Haberle, 2005).

Chemicals/Methods

Steps

Purpose

- Addition of 5-10 $\mathrm{ml}$ potassium hydroxide $10 \%$

- Mix with plastic stick

- Leave samples under fume cupboard

КОН $10 \%$ overnight (approx. 24 hours)

- Mix with plastic stick

- After sediment settled: pipe out potassium hydroxide with plastic pipette

Organic matter

break up and

humic acid

removal

- Discard supernatant in respective waste container

- Addition of 5-10 ml hydrogen peroxyde

- Mix with plastic stick

bleaching of

- If solution foams, make sure no particles are

organic material

$\mathrm{H}_{2} \mathrm{O}_{2}$ 4-6\% transported out of the vial

- Leave samples under fume cupboard overnight (approx. 24 hours), same amount of time for all samples

- Wet sieve with $125 \mu \mathrm{m}$ mesh

- Wash under gentle water flux to avoid particle fragmentation

in remaining

fraction

Sieving

Storage

- Discard supernatant in respective waste container

- Use water to wash the coarse fraction back into the vial small fraction

removal

sample

conservation

- Store in water until counting 


\title{
Chapter 2:
}

\section{Manuscript 1}

\section{Late Holocene vegetation, climate, human and fire history of the forest- steppe ecosystem inferred from core G2-A in the 'Altai Tavan Bogd' conservation area in Mongolia}

\author{
Julia UnKelbach ${ }^{1}$, ChOIMAa DULAMSUREN ${ }^{2}$, GAADAN PUNSALPAAMUU ${ }^{3}$, DAVAAdORJ \\ SAINDOVDON $^{3}$, HERMANN BEHLING $^{1}$
}

\footnotetext{
${ }^{1}$ University of Goettingen, Department of Palynology and Climate Dynamics, Albrechtvon-Haller Institute for Plant Sciences, Untere Karspüle 2, 37073 Goettingen, Germany, email: Julia.unkelbach@biologie.uni-goettingen.de

${ }^{2}$ University of Goettingen, Department of Plant Ecology, Albrecht-von-Haller Institute for Plant Sciences, Untere Karspüle 2, 37073 Goettingen, Germany

${ }^{3}$ Department of Biology, Mongolian State University of Education, Baga Toiruu-14, 210648 Ulaanbaatar, Mongolia
}

Published in:

Vegetation History and Archaeobotany, 27(5), 665-677

DOI https://doi.org/10.1007/s00334-017-0664-5 


\begin{abstract}
The 'Altai Tavan Bogd' conservation area, located between 2,000 and 4,000 m a.s.l. in the northwestern part of the Mongolian Altai, is a montane forest-steppe ecosystem which has developed under extreme continental and alpine climatic conditions and is very sensitive to natural variations. Nomadic peoples have influenced the area due to grazing, logging of trees and fire for a long time. To reconstruct the dynamics of this unique forest-steppe ecosystem for the last 4,000 years under the influence of climatic changes and/or nomads, palynological and macro-charcoal analyses of the radiocarbon dated core G2-A have been performed. Between 3,880 and 2,610 cal BP the vegetation was represented by a mixture of rather open forests and non-forested high mountain steppe areas suggesting a moist and warm climate similar to the present conditions. Macro-charcoal analysis reveals three main fire events, which are probably of anthropogenic origin. In the period from 2,610 to $550 \mathrm{cal} \mathrm{BP}$ a decrease in precipitation and temperature is suggested by a higher representation of herbaceous species, retreating open forests and an increase in macro-charcoal concentration. Since $550 \mathrm{cal}$ BP the forest spread out again, whereas the composition of trees differs from the period between 3,880 and 2,610 cal BP. It is characterized by the shrubs Betula rotundifolia and Juniperus indicating a more open forest, which is probably related to human activities. The advancing upper forest line and a higher plant diversity reveals that the conditions changed to a more humid climate again, lasting until present.
\end{abstract}

\title{
Introduction
}

The conservation area 'Altai Tavan Bogd' is located in the northwestern part of Mongolia, where the southernmost extensions of the boreal forest merge into the Mongolian steppe. In this area, the forest growth is stretched to its natural limits in several aspects. The cold-continental climate conditions, especially the aridity and low summer temperatures, enable only a very short growing season, limiting the forest expansion in higher elevations (upper forest boundary) (Sommer and Treter, 1999). The low summer temperatures in combination with harsh winters and the deforestation by the inhabitants constrains the forest expansion into the plain (lower forest boundary). The amount of precipitation is the most important factor controlling vegetation distribution (Gunin et al., 1999). Under these extreme conditions, a small arboreal zone evolved with Larix sibirica as the most common tree species (Dulamsuren et al., 2014). Changes in the microclimate of this ecosystem may lead to shifts in the location of the forest boundary and the composition of the forests as well as their reduction and expansion (Sommer and Treter, 1999). In the past, these changes have not only been caused by climatic fluctuations but also by land use. 
For the last 2,000-3,000 years, various nomadic peoples have inhabited the Mongolian Altai (Fernandez-Gimenez, 1999; Schlütz and Lehmkuhl, 2007). Changes in political structures as a consequence of the occupation of the Mongolian Altai under different rulers has led to shifts in land use and animal husbandry through time. Different approaches, especially to grazing activities, are connected to the Mongol Empire (AD 1206-1690), the Manchu Rule (AD 1691-1911), Early Communism (AD 1924-1959) and the breakup of the Soviet Union in the 1990s (FernandezGimenez, 1999). Although the region has only been sparsely populated, the response of the flora to human impact is rather sensitive (Hilbig, 1995). Further investigations are needed to detect similarities between historical data and changes in the vegetation composition.

Palaeoecological data derived from environmental archives in the transition zone from coniferous forest to mountain steppe can provide detailed information on environmental changes. Palynological studies allow a detailed reconstruction of the former vegetation and forest boundaries as well as climatic changes in general. In combination with these studies, analysis of charcoal remains permits determination of the anthropogenic influence on the region.

Several recent studies in the Mongolian and Russian Altai focused on the reconstruction of vegetation and climate based on data obtained from lake records (Kalugin et al., 2005; Andreev et al., 2007; Rudaya et al., 2008, 2009; Wang et al., 2009, 2011). Tarasov et al. (2000), Rudaya et al. (2008, 2009, 2016) and Rudaya and Li (2013) implemented detailed palynological and geochemical analyses of sediments from Lake Teletskoye (Russian Altai) and Hoton-Nur Lake (Mongolian Altai, approx. 30 $\mathrm{km}$ distant from the new study site 'Altai Tavan Bogd' presented here) revealing general climatic trends and changes in precipitation for the last 10,700 cal year BP. According to these studies the regional climate was rather dry prior to 10,700 cal year BP, followed by a marked increase in precipitation in the early and mid-Holocene and a return to a precipitation level of 250-300 mm/year after 5,000 years BP. However, so far, no palynological or macro-charcoal studies have been implemented in the conservation area 'Altai Tavan Bogd'.

Hence not much is known about the human impact on the vegetation and fire history from this part of the Altai Mountains. The studies by Dulamsuren et al. (2014) focus on the response of tree-ring width to climate warming, while Lkhagvadorj et al. (2013) investigated today's nomadism in the Mongolian Altai under a changing economy and warming climate. Some publications on adjacent areas are supplemented by results from other proxies such as diatoms (Rudaya et al., 2009), chironomid remains (Ilyashuk and Ilyashuk, 2007) and tree rings (D'Arrigo et al., 2001; Zhang et al., 2003; Dulamsuren et al., 2014).

Available palaeoecological studies indicate that the coniferous forest in the Mongolian Altai and adjacent areas has been established from 9,000 to 6,000 cal BP under the influence of a moister and warmer climate (Herzschuh, 2006; Schlütz and Lehmkuhl, 2007; Tao et al., 2010). At that time, the expansion of the steppe communities was limited to the southern exposed mountain slopes and 
intermontane drought islands. Between 6,000 and 4,900 cal BP the climate became more continental which caused an expansion of steppe and a decline of the coniferous forest. This trend intensified over the last 3,000 years (Schlütz and Lehmkuhl, 2007; Rudaya et al., 2008). The evaluation of the vegetation indicates a high variability between dry and moist periods (Chenlemuge et al., 2013; Tian et al., 2013). The results of Wang et al. $(2009,2011)$ of pollen and diatom records from Ugii Nuur basin in Central Mongolia verify the interpretation of a warmer and drier mid-Holocene $(6,000-3,000$ cal BP) in Mongolia. However, these results are contradicted by Schwanghart et al. (2009), who indicate wetter conditions around the same basin between 8,000 and 4,000 cal BP.

In this paper, results of a detailed pollen and macro-charcoal analysis of deposits from a small basin on a hilltop close to Lake Dayan Nuur in the Mongolian Altai Mountains are presented. Pollen ratios are used to determine palaeoclimatic and palaeovegetational information from pollen assemblages. Furthermore, the macro-charcoal record resembles the fire history of the Lake Dayan Nuur region in the conservation area 'Altai Tavan Bogd'. By excluding the charcoal background signal, a detection of local main fire events is provided.

Based on these results, the aim is to reconstruct the dynamics of the forest-steppe ecosystem in the Mongolian Altai during the last about 4,000 cal BP. In order to gain new insights into the environmental and climatic changes as well as human impact by nomads in the Altai region, the results will be used to investigate how natural the existing vegetation is and to what extend the dynamics of the forest boundaries together with the forest and steppe vegetation of the past can be reconstructed. These findings will be important for sustainable use as well as protection and management of the species-rich vegetation in the 'Altai Tavan Bogd' conservation area and other regions. This kind of study is the first one in the Mongolian Altai.

\section{Study area}

The study area is located in the Mongolian part of the Altai Mountains (Fig. 2.1), a sub-longitudinal mountain range in Central and East Asia with an extension of more than 2,100 km (Rudaya et al., 2009). It is situated in western Mongolia south of Lake Dayan Nuur in the province Bayan-Ulgii that has an area of 45,700 $\mathrm{km}^{2}$. The area is part of the Tavan Bogd National Park, established in 1996, and located at $>2000 \mathrm{~m}$ a.s.l. The highest elevations reach up to a maximum of 4,000 $\mathrm{m}$ a.s.l. in the western and the northern part of the region (Lkhagvadorj et al., 2013).

Due to the specified topographic setting and its large distance to the moisture sources of the Indian and the Pacific Ocean, the Mongolian Altai is characterized by an extreme continental climate (Andreev et al., 2007). Winters are severely cold with mean annual temperatures of $-21.2 \pm 3.4{ }^{\circ} \mathrm{C}$ in the village of Altai $\left(48^{\circ} 17^{\prime} \mathrm{N}, 89^{\circ} 31^{\prime} \mathrm{E}, 2,150 \mathrm{~m}\right.$ a.s.l.). Summers are accordingly chilly with mean 
annual July temperatures of $12.9 \pm 1.1{ }^{\circ} \mathrm{C}$ that provide a short vegetation period. The annual precipitation of only $120 \pm 26 \mathrm{~mm}$ implies the extreme aridity (Lkhagvadorj et al., 2013).

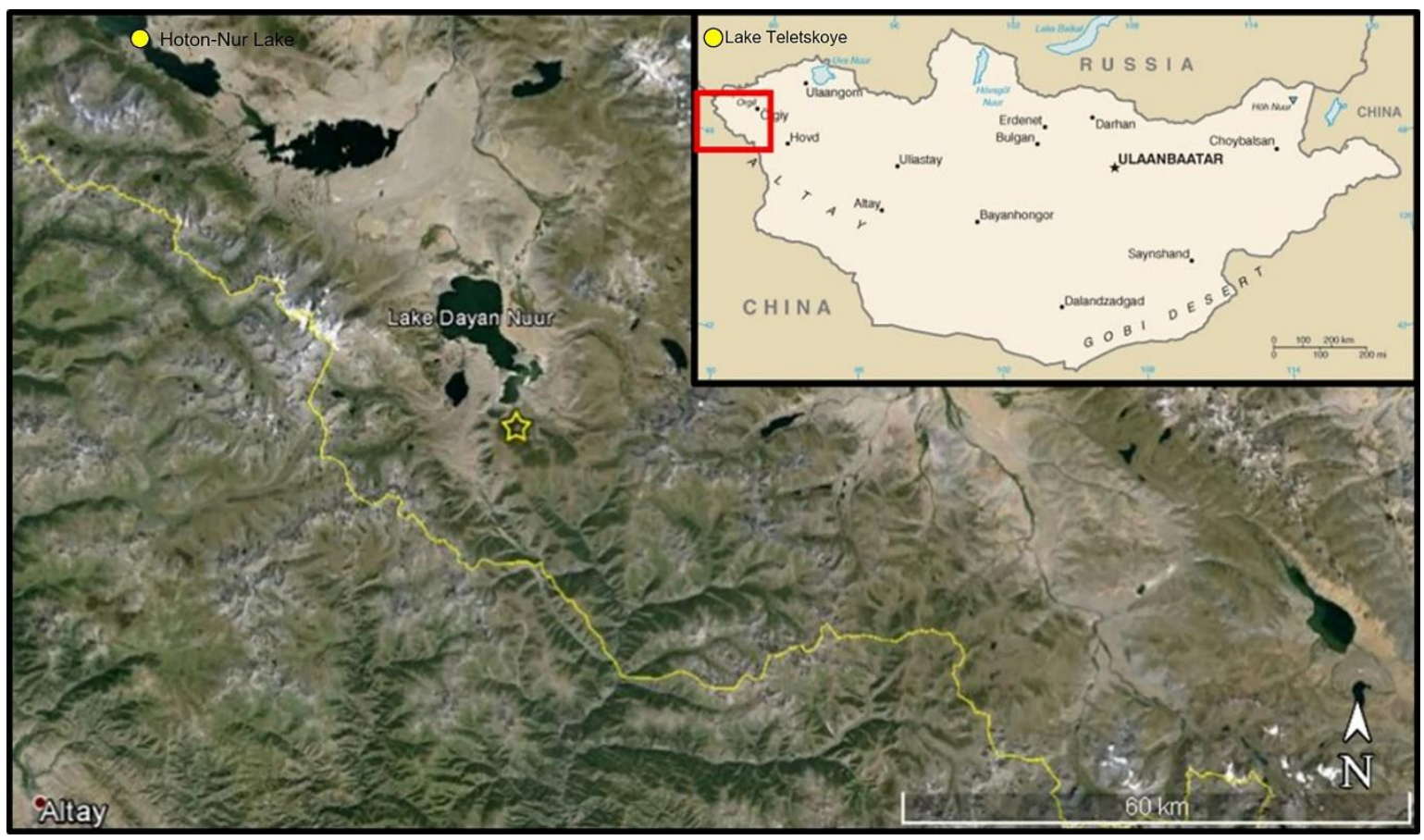

Fig. 2.1 Map of the study area in the Mongolian Altai (earth.google.com) and its location within Mongolia (http://www.laenderservice.de). The yellow star indicates the location of the G2-A coring site $\left(48^{\circ} 15^{\prime} 3.00^{\prime \prime} \mathrm{N}, 88^{\circ} 53^{\prime} 40.10^{\prime \prime} \mathrm{E} ; 2,490 \mathrm{~m}\right.$ a.s.l.), the two yellow circles indicate the location of the two comparison sites Lake Teletskoye and Hoton-Nur Lake.

The vegetation in this part of the Mongolian Altai is strongly connected with the relief and the annual precipitation. Those special conditions create a specific mosaic vegetation cover characterized by the development of high mountain steppes as well as a discontinuous coniferous forest belt in between. In the 'Altai Tavan Bogd' conservation area it is dominated by alpine steppe vegetation mainly consisting of Cyperaceae, especially Kobresia, Artemisia and Chenopodiaceae (Schlütz and Lehmkuhl, 2007; Dulamsuren et al., 2014) as well as Festuca lenensis, Oxytropis oligantha and Potentilla nivea. On mountain slopes occur open larch forests composed of Larix sibirica, Picea obovata, Pinus sibirica, Betula rotundifolia and Salix glauca (Rudaya et al., 2008). The vegetation surrounding the study site provides rather open forests of Larix sibirica at the upper forest limit. Trees of Picea obovata and Pinus sibirica do not occur in the forests in the study area, but at a distance of about $10 \mathrm{~km}$ from the coring site.

This province is one of the lowest populated regions in Mongolia. Only few of its 93,000 inhabitants live in small villages, the remainder (> 90\%) are pastoral nomads (Soma, 2014). 


\section{Materials and methods}

A $49 \mathrm{~cm}$-long sediment core (G-2 A) was obtained by use of a Russian corer from a very small round peat bog formation of around $2 \mathrm{~m}$ in diameter located on top of a hill $2 \mathrm{~km}$ south of Lake Dayan Nuur. The coring site $\left(48^{\circ} 15^{\prime} 0.00^{\prime \prime} \mathrm{N}, 88^{\circ} 53^{\prime} 40.10^{\prime \prime} \mathrm{E}\right)$ is situated at $2,490 \mathrm{~m}$ a.s.l. at the upper forest line. The sediment core was photographed for lithological description and wrapped in plastic for conservation. Subsequently, it was transported to the Department of Palynology and Climate Dynamics at Georg-August-University of Göttingen in Germany and stored in darkness in a cold room at $4{ }^{\circ} \mathrm{C}$.

Tab. 2.1 Radiocarbon dates from the G2-A core sediments

\begin{tabular}{cccc} 
Laboratory Code & Depth $(\mathbf{c m})$ & Type of Material & C $^{\mathbf{1 4}}$ Age (yr BP) \\
\hline \hline Poz-81590 & 14 & Bulk sediment & $1660 \pm 30$ \\
\hline Poz-81592 & 23 & Bulk sediment & $2530 \pm 30$ \\
\hline NTUAMS-2014 & 34 & Bulk sediment & $3067 \pm 12$
\end{tabular}

\section{Radiocarbon dating and age-depth-modelling}

Three bulk sediment samples were sent for radiocarbon dating, due to the lack of larger organic or charred macro remains in the sediment core G2-A. One sample was sent to AMS ${ }^{14} \mathrm{C}$ Dating Facility at National Taiwan University in 2015 and two to Poznan Radiocarbon Laboratory, Poland, in 2016 (Tab. 2.1). Ages were calibrated using IntCal13 (Reimer et al., 2013) and an age-depth-model was established with BACON version 2.2 (Blaauw and Christen, 2011) (Fig. 2.2). The ages of the pollen zones have been interpolated.

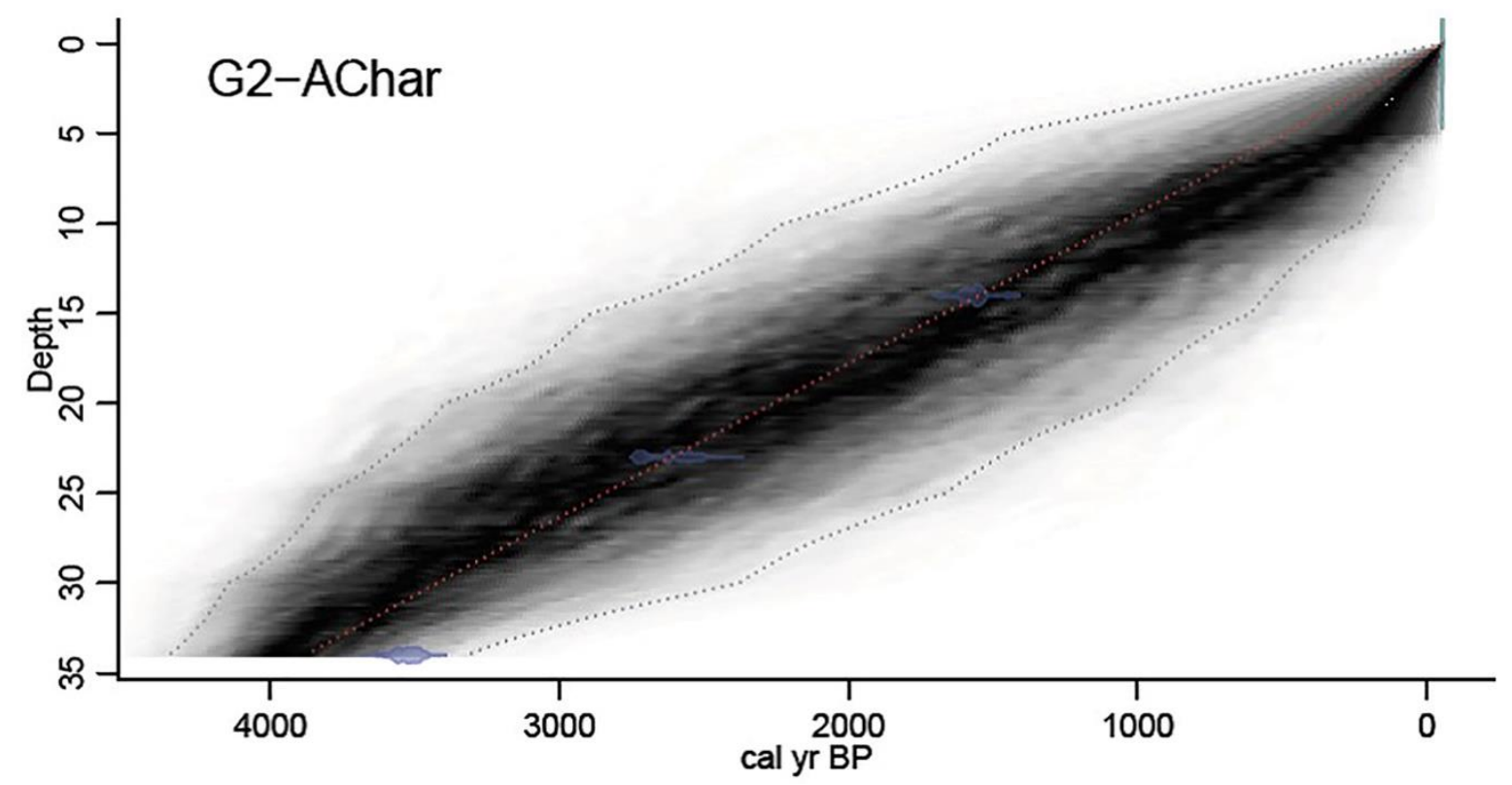

Fig. 2.2 Age-depth model of the sediment core G2-A. 


\section{Palynological analysis}

For the fossil pollen record 20 samples of $0.25 \mathrm{~cm}^{3}$ were taken in intervals of $1-2 \mathrm{~cm}$ along the core G2-A down to a depth of $34 \mathrm{~cm}$. All samples were processed using the standard method with $10 \%$ $\mathrm{HCl}, 10 \% \mathrm{KOH}, 40 \% \mathrm{HF}$ and acetolysis (Fægri and Iversen, 1989). Before this procedure, a tablet of Lycopodium spores was added to each sample as an exotic marker to calculate pollen concentrations.

Pollen and spores were identified based on the reference collection of Mongolian pollen and spore taxa at the Department of Palynology and Climate Dynamics, established by Gaadan Punsalpaamuu (Mongolian State University of Education, Ulaanbaatar), the online pollen database PalDat, hosted by the Society for the Promotion of Palynological Research in Austria, and other relevant literature and pictures (Beug, 2004; Murad, 2011). All samples were counted up to a terrestrial pollen sum of 300 in the upper part $(0-14 \mathrm{~cm})$ and of 200 in the middle part $(16-34 \mathrm{~cm})$ due to lower content and poor pollen preservation at greater depths. Below the depth of $34 \mathrm{~cm}$ only very few and mostly damaged pollen grains or only grain fragments were visible in the samples. On that account, the segment from 34 to $49 \mathrm{~cm}$ was not analyzed.

Pollen percentages and concentrations were calculated based on the sum of Lycopodium spores together with a pollen sum consisting of arboreal and herbaceous pollen grains per sample and plotted against core depth. In the diagram, all types are grouped into trees and shrubs, herbs and ferns. Within the groups, they were arranged according to their family affiliations and chronological occurrence. Subsequently, the ratios of arboreal pollen (AP) to non-arboreal pollen (NAP), Artemisia to Chenopodiaceae (A/C) and Artemisia to Cyperaceae (A/Cy) were calculated for further inspection. Especially in arid and semi-arid regions, where the climate is highly continental (cold winters and dry summers) and vegetation density and productivity are limited by the availability of water, Artemisia and Chenopodiaceae are the most common taxa to be used as a moisture indicator. Chenopodiaceae require less water during the growing season and have less demanding habitat requirements than Artemisia (Herzschuh, 2007; Zhao et al., 2012).

The program TILIAGRAPH was used for data illustration (Grimm, 1991). A cluster analysis on the pollen assemblage via CONISS (Grimm 1987) was performed to establish pollen zones (PZ). 


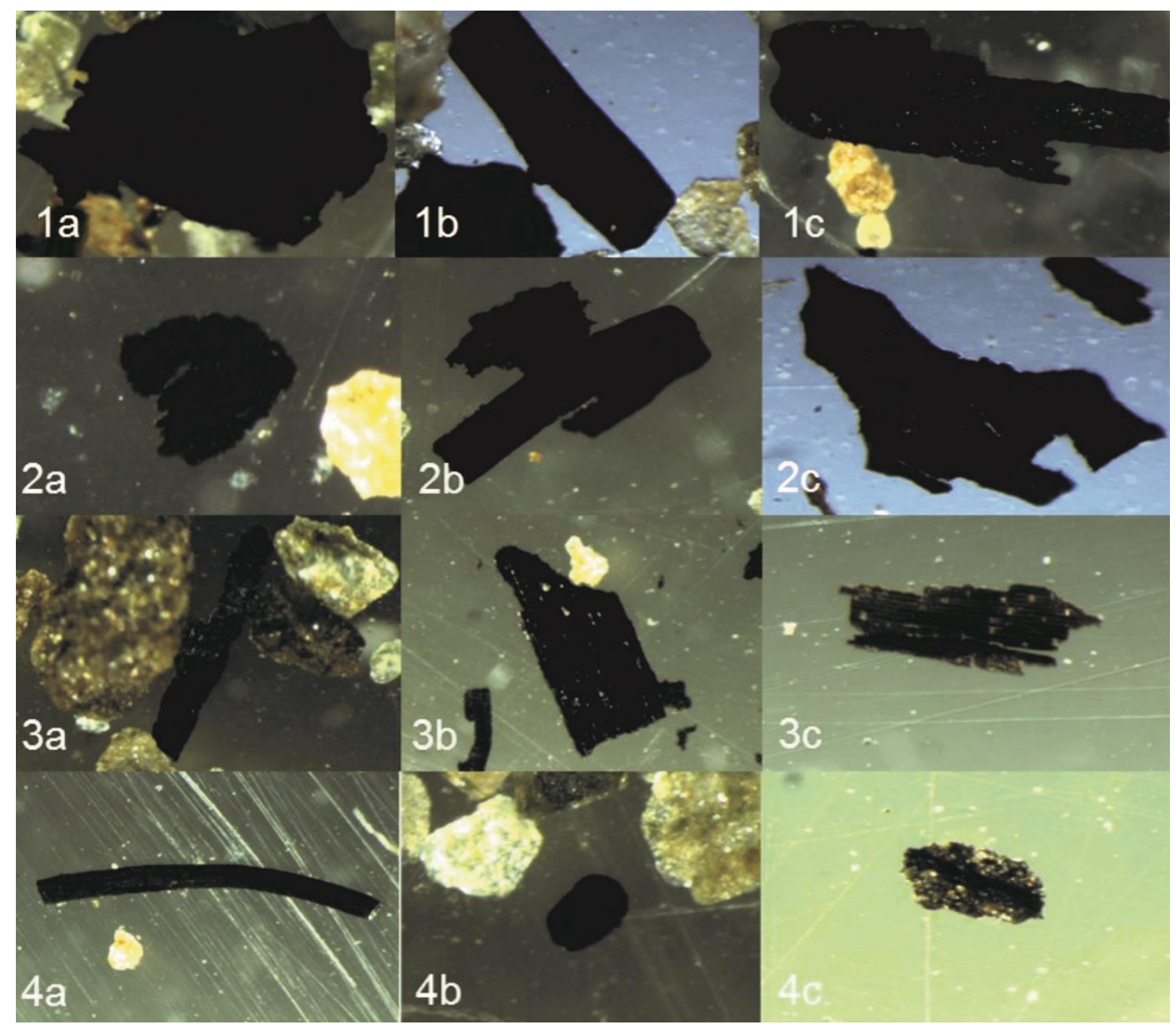

Fig. 2.3 Plate showing macro-charcoal types from G2-A sediment core: 1 wood type, 2 leaf type, 3 grass type, 4 other types: $4 \mathrm{a}$ root type, $4 \mathrm{~b}$ seed type, $4 \mathrm{c}$ moss type.

\section{Macro-charcoal analysis}

For charcoal analysis, $1 \mathrm{~cm}^{3}$ samples were taken along the core $\mathrm{G} 2-\mathrm{A}$ at intervals of $0.5 \mathrm{~cm}$ up down to a depth of $35 \mathrm{~cm}$ (70 samples). All samples were processed according to the method of Stevenson and Haberle (2005) with $10 \% \mathrm{KOH}$ and $6 \% \mathrm{H}_{2} \mathrm{O}_{2}$. Wet sieving during the preparation procedure was conducted carefully with low water pressure to ensure little particle fragmentation in the course of the treatment.

Charred fragments $(>150 \mu \mathrm{m})$ were counted under a binocular dissecting microscope. According to the examples in Umbanhowar and McGrath (1998) and Mustaphi and Pisaric (2014), all charred material was divided into four different types: wood, leaf, grass and others (including roots, mosses, seeds and very small fragments, which could not be assigned correctly) (Fig. 2.3). In all samples, comparatively many charcoal particles could be identified. Results are depicted in terms of charcoal particles concentration per $\mathrm{cm}^{3}$. 


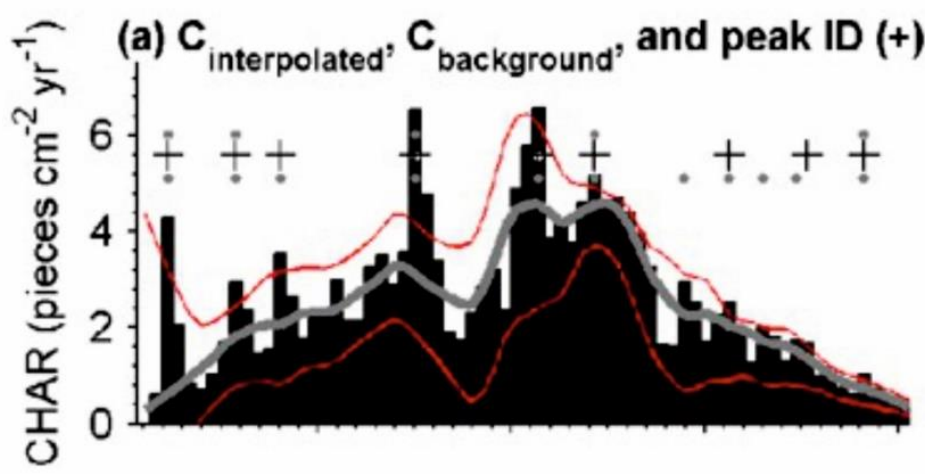

Fig. 2.4 CHARAnalysis diagram presenting the interpolated charcoal counts $\left(\mathrm{C}_{\text {interpolated }}\right)$, the background charcoal noise $\left(\mathrm{C}_{\text {background, }}\right.$ grey line) and the main fire events (peak ID, + ).

Charcoal data was analysed by CharAnalysis version 1.1 (Higuera et al., 2009) to separate background charcoal from the charcoal record in order to detect main fire events. The inserted data (depth, ages, sample volumes and sums of charcoal counts per sample) were converted to charcoal accumulation rates CHAR $\left(\mathrm{cm}^{-2}\right.$ year $\left.{ }^{-1}\right)$ with an interpolation to the median sample resolution of this record (58 years). The varying low-frequency charcoal CHAR $_{\text {background }}$ was calculated by the use of a lowess smoother, which is robust to outliers over a 500-year interval. Locally defined peaks within this interval were estimated by subtracting $\mathrm{CHAR}_{\text {background }}$ from CHAR and peak identification via base threshold values on a noise distribution determined by a Gaussian mixture model. The fire frequency and fire return intervals were smoothed over 1,000 years. A significant peak was recognized if the minimum charcoal count within a 75-year period prior to a peak had a $<5 \%$ chance of coming from the same Poisson distribution as the maximum charcoal count associated with the peak. A CHAR peak represents a fire episode of one or more large fire events in the catchment of core G2-A within a 58-year interval (Higuera et al., 2009; Mustaphi and Pisaric, 2014) (Fig. 2.4).

\section{Numerical analysis}

A Principal Component Analysis (PCA) was performed to investigate interdependencies among the identified taxa in the 20 subsamples of core G2-A. PCA on a basis of square root transformation and covariance matrices of taxa was realized in RStudio version 1.0.136 (RStudio Team, 2016) using Vegan package version 2.0-10 (Oksanen, 2013). For reasons of clarity and comprehensibility, rare taxa with a share of $<1 \%$ in every subsample were excluded.

\section{Results}

\section{Lithology}

Based on visual inspection the sediment core G-2 A mainly consists of dark brownish clayey and silty organic rich sediments, partly with fine horizontal laminations. It can be subdivided into four 
sedimentary units that are separated by colour and organic content. The lowermost part $(49-37.5 \mathrm{~cm})$ consists of mostly inorganic, homogenous and sparsely laminated dark brown sediment with many small stones. The second part $(37.5-20.5 \mathrm{~cm})$ is characterized by a lighter brown colour with slightly lighter laminations with low organic content. The third part $(20.5-8.5 \mathrm{~cm})$ is composed of the same dark brown and homogenous sediment as the lowermost part, but of higher organic content. The uppermost part $(8.5-0 \mathrm{~cm})$ is a humus layer of dark brown colour and largely disturbed by sizeable roots.

\section{Chronology and sedimentation rate}

The chronology of the core record G2-A is based on three AMS radiocarbon dates (Tab. 2.1). As the vegetation cover of the coring site was intact, the core top should have an age of 2014 (year of coring). The dated base of the analysed $34 \mathrm{~cm}$-long core segment is 3,880 cal BP. The chronology indicates a low average sedimentation rate of $0.088 \mathrm{~mm} / \mathrm{year}$ at the coring site and the age-depth modelling with BACON did not suggest any major changes in the sedimentation rate for the $34-\mathrm{cm}$ interval of core G2-A (Fig. 2.2).

\section{Palynological results}

In total 41 different pollen and spore taxa could be identified: 10 arboreal, 30 herbaceous and 1 spore taxa (Fig. 2.5, Appendix B1). The pollen concentration of core G2-A ranges from 14,500 in the lowermost part to 268,420 grains per $\mathrm{cm}^{3}$ in the upper part (Fig. 2.6). In general, the pollen spectra are characterized by herbaceous pollen with a representation of $>80 \%$, corresponding to the modern natural setting of the area, and a marked dominance of Cyperaceae and Poaceae. The amount of arboreal pollen is relatively low and varies from 5 to $22 \%$. Spores are very rare and occur generally at core depths between 6 and $24 \mathrm{~cm}$. A CONISS cluster analysis on all pollen grains suggests three pollen zones $(\mathrm{PZ})$.

PZ 1 (34-23 cm core interval; 6 samples; 3,880-2,610 cal BP)

A characteristic feature of the first $\mathrm{PZ}$ is the relatively high representation and diversity of arboreal pollen (up to 22\%; 10 taxa present) where Larix sibirica values rise up to $11 \%$. Pinus sibirica, Picea obovata and Ephedra fragilis are present. Despite Cyperaceae (45-65\%) and Poaceae (10-13\%), Artemisia, Chenopodiaceae and Rosaceae show the highest percentages among the non-arboreal pollen taxa. Other herbaceaeous taxa, e.g. Liliaceae, Rumex, Gentiana barbata and Chichorioideaetype, are present in lower concentrations. Single spores of Polypodium are present in the sample at $24 \mathrm{~cm}$. 
The AP/NAP ratio shows relatively high values $(0.11-0.33)$. A/C ratio values range from 0.81 to 1.86, whereas the A/Cy ratio (0.05-0.12) is far smaller because of the higher representation of Cyperaceae in the record.

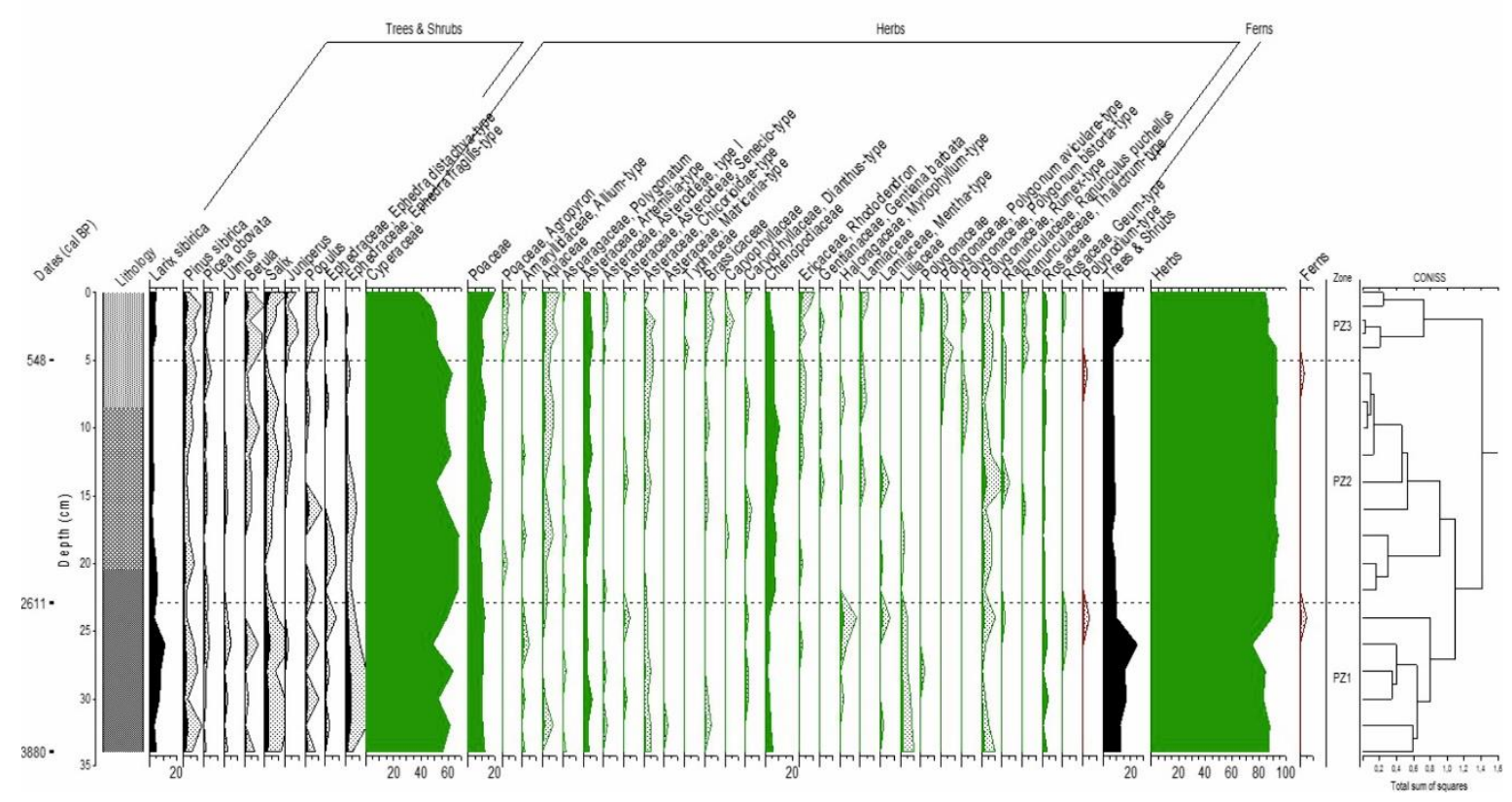

Fig. 2.5 Percentage diagram presenting lithology and results of the palynological analysis of G2-A sediment core using TILIA/TILIAGRAPH software (Grimm, 1991) and the pollen zones supported by CONISS (Grimm, 1987).

\section{PZ 2 (23-5 cm core interval; 9 samples; 2,610-550 cal BP)}

Herbaceous taxa increase slightly up to $90-95 \%$. Arboreal pollen proportions decrease to 5-9\%, mainly due to a steadily decline of Larix sibirica, Ulmus and Ephedra fragilis. Among the herbaceous pollen the percentages of Artemisia stabilize, while the representations of Cyperaceae, Poaceae, Apiaceae, Chenopodiaceae and Rumex increase markedly and the proportion of Liliaceae and Rosaceae is lower. Single spores of Polypodium are present in one sample at $6 \mathrm{~cm}$ depth.

The AP/NAP ratio generally decreases to values between 0.06 and $0.10 . \mathrm{A} / \mathrm{C}$ ratio values decrease as well and range between 0.29 and 1 , whereas the $\mathrm{A} / \mathrm{Cy}$ ratio remains roughly constant varying between 0.03 and 0.1 .

PZ 3 (5-0 cm core interval; 5 samples; 550 cal BP - present)

The transition to PZ 2 is marked by a decrease in herbaceous pollen to $86 \%$. The share of the arboreal pollen rises to $8-14 \%$, mostly due to an increase in Larix sibirica, Pinus sibirica, Betula and Juniperus. In this context, a marked decline in the representation of Cyperaceae (from 53 to $38 \%$ ) is 
noteworthy. Additionally, the percentages of Poaceae, Apiaceae, Artemisia, Brassicaceae and Thalictrum reach their maxima. There is an increase in the diversity of the herbaceous pollen. Agropyron, Typhaceae, Caryophyllaceae and Polygonum aviculare occur in this zone only.

PZ 3 shows an increase in the AP/NAP ratio to values from 0.08 to 0.18 . The $\mathrm{A} / \mathrm{C}$ ratio increases as well and ranges from 1.05 to 1.50 . Concurrently, there is a marked increase in the $\mathrm{A} / \mathrm{Cy}$ ratio $(0.10$ $0.14)$.

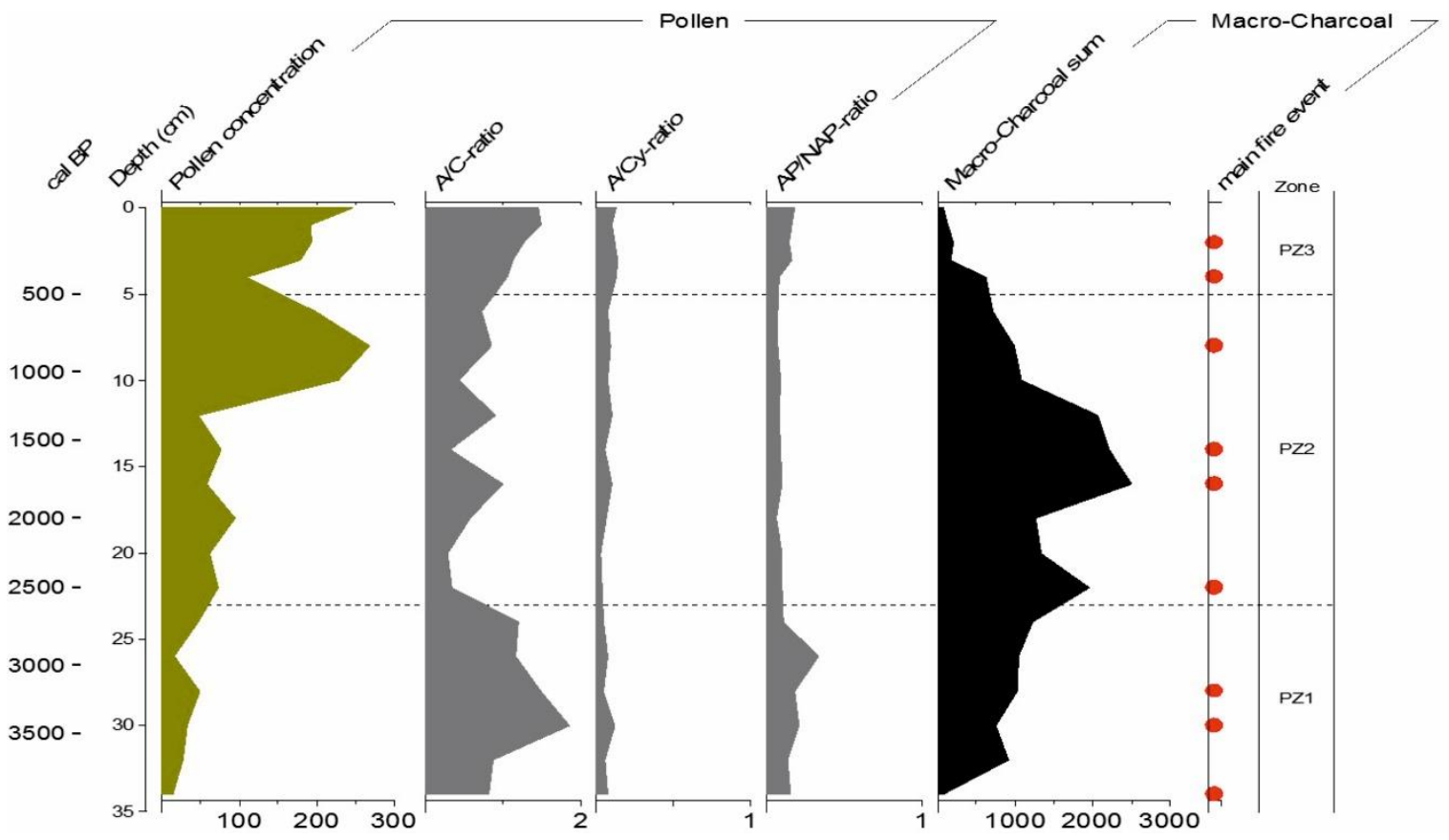

Fig. 2.6 Diagram presenting pollen concentration in $\times 10^{4}$ counts per $\mathrm{cm}^{3}$, Artemisia to Chenopodiaceae ratio (A/C), Artemisia to Cyperaceae ratio (A/Cy), arboreal to non-arboreal pollen ratio (AP/NAP), cumulative macro-charcoal counts in total (charcoal sum) and the main fire events suggested by CharAnalysis (Higuera et al., 2009). Diagram was constructed with TILIA/TILIAGRAPH software (Grimm, 1991).

\section{Macro-charcoal results}

The charcoal record has an average time resolution of 56 years per sample. Charred material is present in all samples along core G2-A (Fig. 2.7). Relatively high charcoal concentrations are found especially in PZ 2 from 22 to $14 \mathrm{~cm}$ in the middle part of the record. Comparatively low concentrations are mainly observed in PZ 1 from 5 to $0 \mathrm{~cm}$. CHARAnalysis software suggests 9 main fire events in the catchment: two in PZ 3 (178 cal bp; 468 cal BP), four in PZ 2 (874; 1,570; 1,860; 2,498 cal BP) and three in PZ 1 (3,194; 3,426; 3,774 cal BP). 


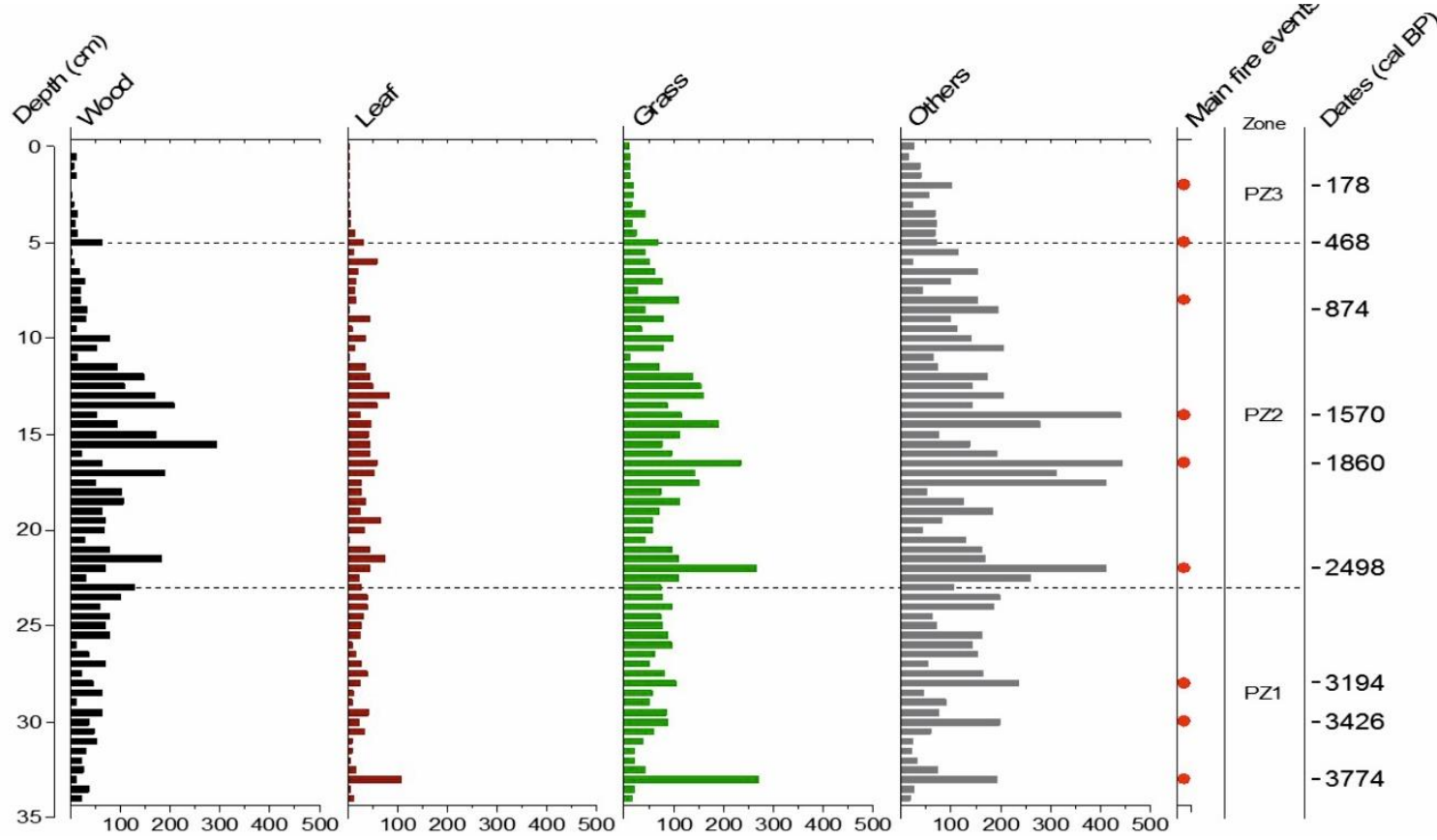

Fig. 2.7 Diagram presenting charcoal results divided into wood, leaf, grass and other charcoal remains, the main fire events indicated by CharAnalysis software (Higuera et al. 2009) and the three pollen zones according to CONISS (Grimm, 1987). Diagram was constructed with TILIA/TILIAGRAPH software (Grimm, 1991).

Regarding the four different morphotypes, it is noticeably that charred roots, mosses and seeds or very small charcoal particles are the most frequent fraction ( $44 \%$ of charcoal counts in total). Charred leaves $(10 \%)$ are rarer than wood $(20 \%)$ and grass particles (26\%). In general, the proportions of the quantities in the different fractions seem to correlate. The same peaks are often visible in all four morphological groups.

The composition of the charcoal material only changes little through time. At greater depths, grass material is more frequent than wood, especially in PZ 2 between 22 and $14 \mathrm{~cm}$. At the top of the record $(5-0 \mathrm{~cm})$ both fractions show almost equal values.

\section{Numerical results}

The PCA is comprised of 30 taxa in the 20 subsamples of the period from 3,880 cal BP to present time (Figs. 2.8, 2.9). PC1 (2.0993) captures $33 \%$ of the total variance (6355) in the dataset and PC2 (1.1453) comprises $18 \%$. The first axis divides the taxa into arid species (negative end) and alpine species (positive end) (Fig. 2.8). The arboreal species (especially Larix sibirica, Salix, Ulmus and Populus) at the positive end of the second axis (PC2) are separated by their ordination from steppe species (e.g. Chenopodiaceae, Cyperaceae and Rumex) at the negative end. Poaceae, Asteraceae types and Pinus sibirica show an intermediate orientation on both axes. Pollen subsamples are 
clustered according to their PZs within the plot along both axes (Fig. 2.9). Samples of PZ1 (sit15sit20) show comparatively high values on both axes, samples of PZ2 (sit6-sit14) cluster at the negative end of PC2 and all samples of PZ3 (sit1-sit5) show low values on the first axis.

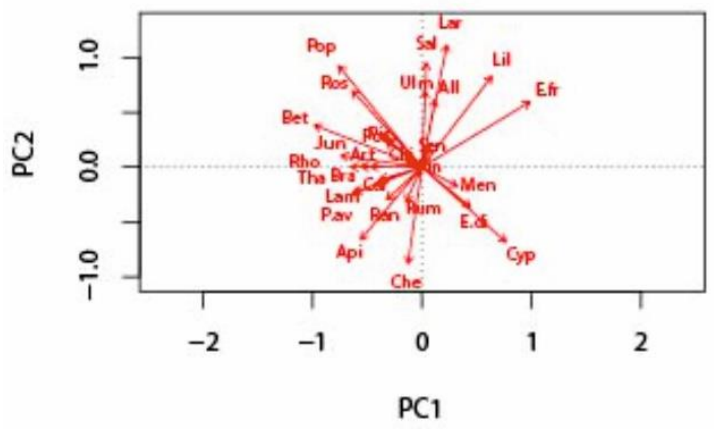

Fig. 2.8 PCA of taxa, Lar: Larix sibirica, Pin: Pinus sibirica, Pic: Picea obovata, Ulm: Ulmus, Bet: Betula, Sal: Salix, Jun: Juniperus, Pop: Populus, E-di: Ephedra distachya-type, E-fr: Ephedra fragilis-type, Cyp: Cyperaceae, Poa: Poaceae, Art: Artemisia, Sen: Senecio-type, Chi: Chicorioideae-type, All: Allium, Car: Caryophyllaceae, Api: Apiaceae, Bra: Brassicaceae, Che: Chenopodiaceae, Rho: Rhododendron, Lam: Lamiaceae, Men: Mentha-type, Lil: Liliaceae, P-av: Polygonum aviculare-type, Pbi: Polygonum bistorta-type, Rum: Rumex, Ran: Ranunculaceae, Tha: Thalictrum, Ros: Rosaceae.

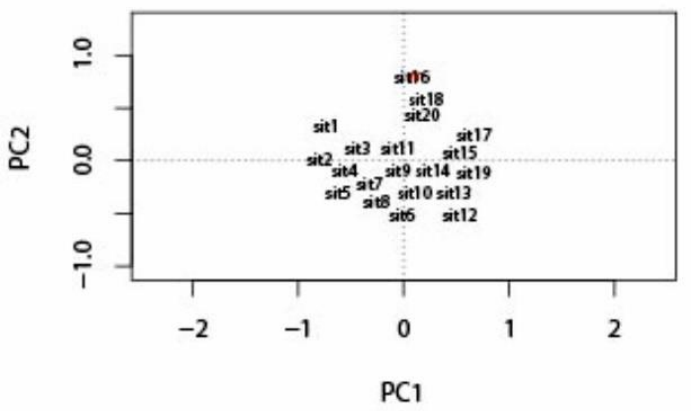

Fig. 2.9 PCA of subsamples, sit1-sit20: pollen samples 1-20.

\section{Interpretation and discussion}

Only minor changes in the sedimentation rate can be observed in the record, with slightly higher values in PZ 1 and PZ 3 (Fig. 2.2). The established chronology suggests a continuous sedimentation without any interruption. This is also supported by the lithology and pollen record, which do not indicate any gaps or interruptions. The low pollen concentration in the record from 3,880 to ca. 1,300 cal BP in PZ 1 (Fig. 2.5), could have been caused by poorer pollen preservation (Havinga, 1967), due to increased decomposition because of the warmer and moister climate. However, this contradicts the relatively high representation of arboreal pollen during this period. The cause of the increase in the pollen concentration (Fig. 2.6) in the upper core part $(10-0 \mathrm{~cm})$ is not clear, but might 
be related to a higher pollen productivity due to wetter and warmer climatic conditions, or due to peat growth and the development of locally wetter conditions favouring better pollen preservation. For the interpretation of the pollen record it needs to be considered that today, within a radius of about $50 \mathrm{~m}$ around the coring site, the vegetation consists only of herbaceous plants, and within a radius of up to $500 \mathrm{~m}$ there are only few trees, almost entirely Larix sibirica, with a few Salix, Juniperus and Betula shrubs. This situation in combination with the poor pollen production of Larix sibirica (Ekberg and Eriksson, 1966) leads to a high representation of herbaceous species. Other trees, such as Pinus and Picea, are present in the record due to long-distance transport over several kilometres. The ecological differences between arboreal species (e.g. Larix sibirica, Salix, Ulmus and others) and arid steppe species are evident from the PCA (Fig. 2.8). Especially on the second axis, both groups show opposite ordinations due to their different water requirements.

In the late Holocene from 3,880 to 2,610 cal BP (PZ 1) the pollen spectra reflect the dominance of herbaceous vegetation rich in Cyperaceae and Poaceae above the upper forest line (Fig. 2.5).

However, during this period the proportion of arboreal pollen is relatively high. Larix sibirica, in particular, has the highest occurrence of the whole record in this period. According to Liu et al. (1999) and Herzschuh (2007) the relatively high AP/NAP ratios (0.11-0.33) can be attributed to the presence of a mixture of open forests or small areas of forest and non-forested steppe-zones. Despite the much higher occurrence of Larix sibirica, this is roughly comparable to the modern vegetation cover (core top samples) in the study area. The absence of heliophilous Juniperus shrubs, which can be seen as an indicator of open forests (Hilbig, 1995), compared to the more recent period (PZ 3) where Juniperus was common, suggests that the forests in the study region were more closed. Ephedra fragilis is usually strongly linked to aridity (Hilbig, 1995). The occurrence of this small shrub suggests vegetation of an open character in the study area, growing perhaps on eroded slopes or on exposed rocks (Rudaya et al., 2008).

The A/C ratio (0.9-1.9) points to forest or forest-steppe vegetation during this period (Fig. 2.6). The evaluation of the ratio results in this study is based on the classification according to El-Moslimany (1990), Herzschuh (2007) and Liu et al. (1999). Although Zhao et al. (2012) argue that the application of this ratio is limited to steppe, steppe desert and desert areas, and requires Artemisia and Chenopodiaceae percentages of more than $45-50 \%$ of the pollen sum in each sample, the A/C results in this paper should be considered as a trend. In addition, the A/Cy (Artemisia to Cyperaceae) ratio (0.05-0.12) reflects alpine steppe vegetation (Herzschuh, 2007). These extremely low values are attributed to the abundance of some species of Cyperaceae, such as Kobresia, in all samples of core G2-A, a distinctive occurrence of the dry mountain steppe vegetation in Mongolia (Hilbig, 1995; Kürschner et al., 2005; Schlütz et al., 2007).

In this context, Andreev et al. (2007) also took into consideration that high representations of Cyperaceae in pollen records from dry areas in Mongolia should not be considered directly as an 
indicator of humidity, but of cooler temperatures and a possible expansion of cold adapted sedge/grass steppe-tundra vegetation. The relatively high proportions of Larix sibirica, Pinus sibirica and Salix as well as the presence of Rosaceae and Liliaceae point to a rather humid and slightly warmer climate (Hilbig, 1995). However, the values of the A/C ratio (> 1) emphasize the suggestion of humid conditions as in forests or forest-steppes (0.5-1.7 according to El-Moslimany (1990)). Additionally, the macro-charcoal record displays an average charcoal concentration with increasing values (Figs. 2.6, 2.7). In this regard, a rather humid episode at the beginning is indicated that changes to drier conditions at the end of this period.

Admittedly, it is possible to detect a few relationships between climate and fire history in the area, but to solely interpret the fire history with regard to human activities is inherently difficult. It is, for instance, not possible to connect a pollen increase/decrease after changes in the fire frequency with agricultural activities, because the cold and arid climate does not permit the practice of agriculture in the Mongolian Altai at that elevation (Gunin et al., 1999). Nevertheless, there are a few hypotheses concerning human impact on fires in the area that need to be verified by means of additional proxies. Non-pollen palynomorphs, e.g. coprophilous fungi, could be a more valuable indicator of the presence of humans and their interactions with the environment (van Geel et al., 2003). Studies of this character are already scheduled. The interpretations below regarding the fire history derived from macro-charcoal should be taken as possible but not confirmed scenarios.

The reconstruction of the fire frequency in combination with the climatic conditions indicates that the three main fire events in the first half of this period might be of anthropogenic origin, because of the distinct peaks in relation to the adjacent macro-charcoal samples (Higuera et al., 2007). This may point to the assumption of the presence of early settlers or nomadic peoples in the 'AltaiTavan Bogd' conservation area even before 3,000 cal BP. This has not yet been inferred from other records, e.g. in the Russian Altai (Schlütz and Lehmkuhl, 2007; Rudaya et al., 2008). These suggestions correlate with the results by Schlütz et al. (2007) regarding the great expansion of Kobresia mats due to grazing activities by domesticated yaks in connection with nomadic migration. Kobresia mats are generally more resistant to grazing and trampling than other species in the area (Wesche et al., 2005), which could enhance intense grazing activities around the coring site since the beginning of the record. It might also be an explanation for the high occurrence of Cyperaceae in this record compared to other studies in the Mongolian Altai (Tarasov et al., 2000; Rudaya et al., 2008), the Russian Altai (Schlütz and Lehmkuhl, 2007; Rudaya et al., 2016) and Central Mongolia (Wang et al., 2009).

The second period between 2,610 and 550 cal BP (PZ 2) is characterized by markedly lower proportions of arboreal species while the proportions of herbaceous taxa are the highest of the whole record.

The AP/NAP ratio (0.06-0.1) also reflects an expansion of the herbaceous vegetation around the coring site. Tree growth was even more limited, and the forest line might have been more distant 
from the coring site than in the previous period. However, larger amounts of wood-type charcoal in this period (Fig. 2.7) do not support this suggestion of a reduction in vegetation cover and a retreat of the forest line. It should be considered that errors in the identification of the wood-type charcoal cannot completely be excluded (Umbanhowar and McGrath, 1998; Mustaphi and Pisaric, 2014). In the steppe, an increase in Chenopodiaceae, Artemisia and Poaceae is notable (Fig. 2.5). According to Liu et al. (1999) the very low A/C values $(<0.2)$ can be attributed to a non-forested steppe zone, whereas El-Moslimany (1990) suggests a transition from forest or forest-steppe to a semiarid steppe for the local vegetation cover. These trends are corresponding to a regional precipitation change and a possible onset of a cooler climate in the area (Herzschuh, 2007).

Furthermore, the decreasing values of the $\mathrm{A} / \mathrm{C}$ ratio (0.3-1) point to a change in the moisture conditions as well (e.g. Zhao et al., 2012). Also, the even lower values of the A/Cy ratio (0.03-0.1) support the assumption of an onset of a cooler period in this part of the Mongolian Altai (Herzschuh, 2007). In this period, the macro-charcoal record generally displays a very high charcoal concentration (Figs. 2.6, 2.7), which also favours a more arid period, but the concentration tends to decline during the latter part of this time interval. The reconstruction of the frequency and intensity of the fires might also favour the assumption of arid climate conditions, where fires can spread more easily (Umbanhowar et al., 2009).

In particular, the continuous occurrence of high amounts of charcoal from 2,000 to 1,250 cal BP may lead to the conclusion that these fires might be of natural origin. However, the three reconstructed main fire events at about 2,500,1,860 and 1,570 cal BP still need to be treated with care because of their intensity in contrast to their adjacent time intervals (Higuera et al., 2007). Further inspection of non-pollen palynomorphs might also be useful to gain a final insight into its origin.

The suggestions of an opening of the forests and a retreating forest line in this period correlate with the results from Schlütz et al. (2008) regarding the additional development of steppes caused by the initial pressure of use in this part of the late Holocene.

The third late Holocene period from 550 cal BP to today (PZ 3) is distinguished by a renewed increase in the arboreal pollen proportions similar to the first period. According to Liu et al. (1999), based on the higher AP/NAP ratio (0.08-0.18) in this period, the vegetation cover tends to revert from nonforested steppe zones to a mixture of high mountain steppe and rather open forests. The composition of the arboreal pollen indicates a trend towards heliophilous species (e.g. Betula, Juniperus). At the same time, the proportion of drought-resistant species in the assemblage (Ephedra fragilis, E. distachya) decreases, possibly due to a denser arboreal vegetation cover than in the previous interval. This trend points to an approaching forest line and forests that are more open than in the first period. Moreover, the comparably low charcoal concentration (Figs. 2.6, 2.7) might indicate a reduction of vegetation cover serving as fuel for fires in the region as Umbanhowar et al. (2009) suggested. The 
abundance of Juniperus and Betula in this period in this intensively grazed environment can also be explained by its unsuitability for grazing animals (Earle, 2015).

In this context, the occurrence of Polygonum aviculare may indicate a more intense land use, because it is a secondary cultivation indicator and resistant to trampling (Jäger, 2011). Re-emerging taxa such as Agropyron, Typhaceae, Thalictrum or Caryophyllaceae point to a greater diversity among the nonarboreal species and a better access to water resources (Hilbig, 1995).

The A/C ratio (1.05-1.5) again points to conditions that are more humid (El-Moslimany, 1990). The slight rise in the $\mathrm{A} / \mathrm{Cy}$ ratio (0.1-0.14) reinforces the assumption of moister conditions similar to those before 2,610 cal BP. Additionally, it favours the presumption of a marginal increase in temperature (Herzschuh, 2007). Moreover, the macro-charcoal record presents a very low charcoal concentration, which may also generally point to a more humid episode.

The reconstruction of fire frequency in combination with the climatic conditions might indicate that both main fire events at 470 and $180 \mathrm{cal} \mathrm{BP}$ are possibly of anthropogenic origin. The small number of charcoal fragments suggests rather two small local fires by nomads than extended regional fires (Higuera et al., 2007; Umbanhowar et al., 2009). This might reflect the general changes as well in the political structures of animal husbandry management and the grazing practices of the inhabitants of the area correlating with changes in the land use system (Fernandez-Gimenez, 1999), possibly using less fire. Unfortunately, the time resolution of the samples in this period does not allow any detailed comparisons between the political periods in the Mongolian Altai and the fire history. It is noticeable, however, that both small fire events occurred during the Mongol Empire (cal AD 1480) and the Manchu Rule (cal AD 1770), respectively (Fernandez-Gimenez, 1999). Presumably, in these periods the use of fire as a source of warmth, for cooking, and for deforestation to maintain more space for grazing, was a more common tool than in modern times.

The data reveal that during the last approx. 4,000 years not only climate was an important factor for environmental changes in the 'Altai Tavan Bogd' conservation area, but possibly also human activities to some degree. Palynological data generally suggest three major periods of a changing climate from more humid and warm (3,880-2,610 cal BP) to more arid and rather cold (2,610-550 cal BP) and eventually to slightly more humid and warm again, lasting until the present (Fig. 2.5). These results show some similarities to pollen data from the Hoton-Nur basin (Tarasov et al., 2000; Rudaya et al., 2008), also located in the Mongolian Altai. At this site, there have also been shifts from forest-steppe to steppe visible for the last 9,000 years. In contrast to our site, there was already a major decrease in precipitation at around 4,000 cal BP, but resulting in the establishment of arid steppe vegetation and also the retreat of forest communities around the lake. Nevertheless, a correlation of both records shows at least a similar recovery of the open forest landscape at around 500 cal BP (Tarasov et al., 2000). Another reconstruction by Rudaya et al. (2008) at Hoton-Nur arrived at a different result, especially for the period between 3,000 and 2,000 cal BP. At that time, 
the proportion of arboreal pollen was still comparably high and decreased continuously after 2,000 cal BP. A 1,738-year tree-ring record by D'Arrigo et al. (2001) from the Tarvagastay Mountains in western central Mongolia offers a very high time resolution and shows comparably small temperature oscillations for this period. The results support the assumption of a slightly increasing temperature in the study area, especially since $550 \mathrm{cal}$ BP.

Palynological data from Wulungu Lake in northern Xinjiang, China, located between the Chinese Altai Mountains and the Jungger Basin show a similar temporal zonation but reveal entirely opposite climatic trends. At that site climate changed from more humid and colder (4,200-560 cal BP) to even colder and drier conditions (from $560 \mathrm{cal}$ BP to today) (Liu et al., 2008). These results are supported by a palynological record from Balikun Lake, Xinjiang, China, located southeast of the Chinese Altai Mountains (Tao et al., 2010), and a 2,326-year tree-ring record from Quinhai-Tibetan Plateau at a comparable elevation at about 3,500 m a.s.l. (Zhang et al., 2003).

Another markedly different climatic reconstruction of the past 4,300 years is presented from the Lake Teleskoye record in the Russian Altai (Rudaya et al., 2008, 2009, 2016), where, for example, the maximum of mountain taiga coverage is visible from 3,500 cal BP and only interrupted by short cooling events (Rudaya et al., 2016). In general, this site is characterized by higher precipitation and the absence of steppe communities, which makes it difficult to compare with our data. These spatial differences may lead to the conclusion that small-scale variations and regional influences on the climatic trends occurred in the 'Altai Tavan Bogd' study area.

However, as mentioned before, comparisons with records from close to our study area are difficult because of the availability of data with a similar time resolution and vegetational setting. Further investigations are needed to verify regional and local climate signals in our analysis. The same holds true for the charcoal record.

\section{Conclusions}

The palaeoecological analyses of core G2-A display the vegetation, climate, fire and human history in the forest-steppe ecosystem south of Lake Dayan Nuur in the conservation area "Altai Tavan Bogd', Mongolian Altai, for the past 3,880 years. The reconstruction of pollen, pollen ratios and charcoal suggest a mixture of open forests and high mountain steppe vegetation in this area since 3,880 cal BP. In the second period from 2,610 to 550 cal BP the steppe vegetation expanded noticeably, which points to a decrease in precipitation and possibly lower temperatures. At about 550 cal BP the reconstruction demonstrates a recovery of the open forest landscape at the cost of the steppe vegetation cover, and a rise in plant diversity. This trend can both be attributed to an increase in temperature and precipitation to modern values and less use of fire. The fire history documents 
that an intensification of pastoralism and deforestation by the inhabitants might have taken place. This reflects a possible importance of the local anthropogenic influence on environmental changes in the conservation area 'Altai Tavan Bogd' around Lake Dayan Nuur. The interpretation of the human impact on the fire history in this study must be discussed cautiously, because there is more evidence (e.g. from non-pollen palynomorphs) needed to get more solid results. This record is the first vegetation and climate reconstruction for the period from 4,000 cal BP in this part of the Mongolian Altai inferred from pollen and macro-charcoal. Sites from neighbouring areas, northern Mongolian Altai (Tarasov et al., 2000; Rudaya et al., 2008) or Russian Altai (Andreev et al., 2007; Rudaya et al., 2009) show different time resolutions but are consistent with the general climatic trend inferred from this record.

\section{Acknowledgements}

This research project (AZ: BE 2116/28-1) was funded by the German Science Foundation (DFG) and carried out at Georg-August-Universität Göttingen, Germany. We are grateful to the team of G. Punsalpaamuu from the Mongolian State University of Education, Ulaanbaatar, and U. Beket from Bayan-Ulgii for their kind help in the field work. U. Nüsse-Hahne is thanked for her help in the laboratory work. Lyudmila Shumilovskikh is thanked for reading the manuscript. Additionally, we want to thank two anonymous reviewers for their helpful comments and kind advice. 


\title{
Chapter 3:
}

Manuscript 2

\section{Late Holocene (Meghalayan) palaeoenvironmental evolution inferred from multi-proxy-studies of lacustrine sediments from the Dayan Nuur region of Mongolia}

\author{
Julia UnKelbach ${ }^{1}$, KaORu Kashima ${ }^{2}$, Dirk EnTERS ${ }^{3,4}$, ChOImaA DUlamsuren $^{5,6}$, \\ GAADAN PUNSALPAAMUU ${ }^{7}$, HERMANN BEHLING $^{1}$
}

${ }^{1}$ Department of Palynology and Climate Dynamics, Albrecht-von-Haller Institute for Plant Sciences, University of Goettingen, Untere Karspüle 2, 37073 Goettingen, Germany

${ }^{2}$ Department of Earth and Planetary Sciences, Kyushu University, 744 Motooka, Nishi-ku, Fukuoka 819-0395, Japan

${ }^{3}$ Institute of Geography, University of Bremen, GEOPOLAR, 28359 Bremen, Germany

${ }^{4}$ Lower Saxony Institute for Historical Coastal Research, 26382 Wilhelmshaven, Germany

${ }^{5}$ Department of Plant Ecology, Albrecht-von-Haller Institute for Plant Sciences, University of Goettingen, Untere Karspüle 2, 37073 Goettingen, Germany

${ }^{6}$ Applied Vegetation Ecology, University of Freiburg, Tennenbacher Str. 4, 79106 Freiburg, Germany

${ }^{7}$ Department of Biology, Mongolian State University of Education, Baga Toiruu-14, 210648

Ulaanbaatar, Mongolia

Published in:

Palaeogeography, Palaeoclimatology, Palaeoecology 530, 1-14

DOI https://doi.org/10.1016/j.palaeo.2019.05.021 


\begin{abstract}
The 'Altai Tavan Bogd' National Park, located between 2,000 $\mathrm{m}$ and 4,000 $\mathrm{m}$ a.s.l. in the northwestern part of the Mongolian Altai, is a forest-steppe ecosystem in Central Asia which is noticeable because of its extreme continental and high-altitude conditions. Its vegetation is very sensitive to environmental changes and impact by nomadic people. To reconstruct the dynamics of this foreststeppe ecosystem, a broad approach was taken employing multi-proxy analyses including the analysis of pollen, spores, non-pollen palynomorphs, charcoal and diatoms, as well as XRF scanning of a lacustrine sediment core of a small and shallow lake located south of Dayan Nuur. Five radiocarbon dates indicate a record spanning the last 4,375 years.

Between 4,310 and 1,040 cal yr BP, the vegetation was characterized by a mixture of alpine meadow and moist true steppe communities as well as forested areas with Larix sibirica, Pinus sibirica and Picea obovata stands. Starting around 2,350 cal yr BP, a substantially greater and/or denser forest occurrence can be inferred. A marked forest decline after 1,040 cal yr BP and the loss of Pinus sibirica and Picea obovata near the study area proceeded in accordance with a significantly higher abundance of large herbivores and a strong indication of nomadic people in the area as inferred from coprophilous fungi. One period of markedly increased fire activity is found from 640 to $550 \mathrm{cal} \mathrm{yr}$ BP. For the latest Holocene period, the records of non-pollen palynomorphs and diatoms suggest a rise of the lake water level. These contrasting trends of forest decline despite higher water availability may reflect the considerable human impact of the nomadic population and their cattle on the ecosystem in the 'Altai Tavan Bogd' National Park and Central Asia in general.
\end{abstract}

\title{
Introduction
}

The 'Altai Tavan Bogd' National Park (Fig. 3.1) is situated in the Mongolian Altai Mountains. As many parts of continental Central Asia, the area is influenced by extreme climatic conditions which create a unique vegetation mosaic, mainly composed of dry steppe, meadow steppe and forests. The annual precipitation rate as well as the grazing activity due to pastoral nomads, is an important factor controlling the vegetation pattern (Gunin et al., 1999).

Past palaeoenvironments have been rarely studied in the Mongolian Altai Mountains despite their importance for understanding the vegetation and settlement history in Central Asia. Forest-steppe ecotones are generally sensitive to climate and anthropogenic influence and little palaeoecological knowledge about their dynamics in the Altai Mountains has been derived so far. There are studies carried out at Dayan Nuur (Unkelbach et al., 2018), Hoton Nuur basin (Rudaya et al., 2008, 2009; Tarasov et al., 2000) and Tsambagarav glacier (Brugger et al., 2018). At Hoton Nuur basin, pollen and diatom records represent the last $11,500 \mathrm{cal}$ yr BP. Studies by Rudaya et al. $(2008,2009)$ and 
Tarasov et al. (2000) reconstructed a warmer and moister period with an extensive forest expansion before 6,500 cal yr BP and a forest reduction as well as drier and colder conditions for the late Holocene (since ca. 3,800 cal yr BP). However, both latter studies admitted certain limitations concerning time resolution and dating quality in their studies. On a local scale, pollen and macrocharcoal reconstructions of a small peat bog by Unkelbach et al. (2018) suggested warmer and more humid conditions from at least 3,880 to 2,610 cal yr BP. Findings showing a decrease in the forest vegetation and an increase in macro-charcoal particles imply a climatic change to drier and colder conditions, but also land-use intensification from 2,610 to $550 \mathrm{cal}$ yr BP. Since $550 \mathrm{cal} \mathrm{yr} \mathrm{BP}$ a steady recovery of the forests could be attributed to a rise in temperature and annual precipitation. Based on an ice core analysis, Brugger et al. (2018) identified more periods of forest expansion, contradiction and forest recoveries during the late Holocene in the Altai. However, the role of human impact on the late Holocene vegetation has only been considered in Central Asian environmental studies in a few cases.

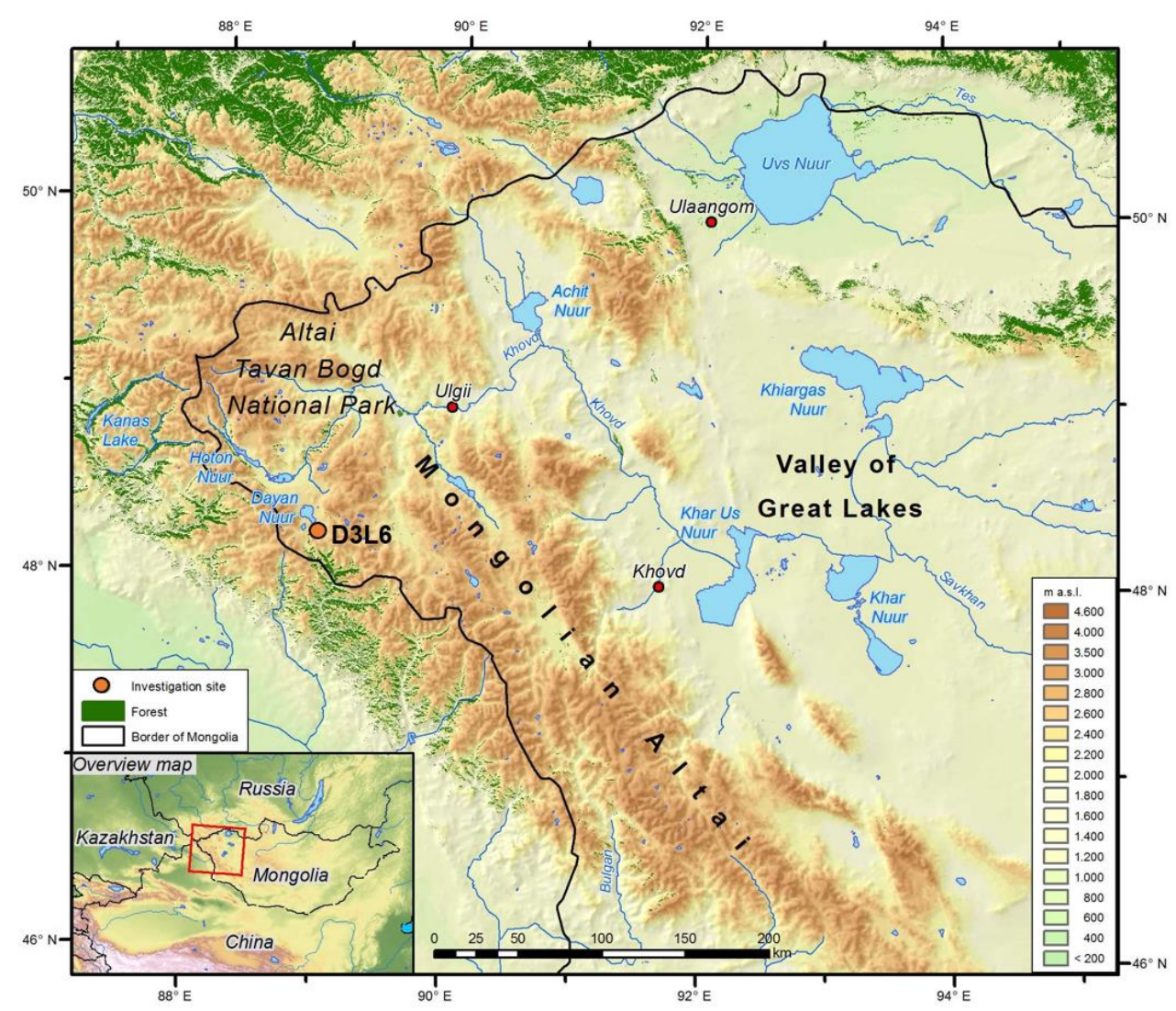

Fig. 3.1. Map showing the location of the Altai Tavan Bogd National Park within Central Asia (overview map) and the location of core D3L6 (orange dot). Forest distribution (green): modified from Klinge et al. (2018). Source: Digital Elevation Model based on Shuttle Radar Topography Mission, projection: UTM Zone 46, map created with ArcGIS version 10.6.1. 
In this paper, we aim to contribute to a better understanding of the driving forces of the environmental changes in Central Asia. Studies using a wide set of independent proxies to identify detailed environmental changes are still rare. Our multi-proxy approach enables the analysis of palynological parameters (pollen, spores, non-pollen palynomorphs), and additional parameters (macro-charcoal, diatoms, XRF-data). Our objectives are to detect changes in the Mongolian Altai's forest-steppe ecosystem and plant diversity in response to natural (climatic) and anthropogenic environmental shifts. In the next step, we aim to quantify the extent of these natural and anthropogenic impacts. Additionally, we want to focus on the dynamics and stability of the forest and steppe vegetation, the role of fires in the past and the conditions for lake formation and lake level dynamics in the area.

\section{Environmental setting}

\section{Relief and climate}

The Altai Mountains are an active intraplate and intracontinental orogen within the Indo-Eurasia deformation field in Central Asia. They cover 170,000 $\mathrm{km}^{2}$ over four different countries (Russia, Kazakhstan, Mongolia and China) and are subdivided accordingly into the Russian Altai, in the northern and western part; the Chinese Altai, in the South; and the Mongolian Altai, in the eastern part. In the Southeast, the Mongolian Altai borders the Gobi Altai and the Valley of Great Lakes in the East (Lehmkuhl et al., 2016). In Mongolia, the Altai is the tallest and most extensive mountain range (Gunin et al., 1999). The alpine relief exhibits steep U-shaped valleys trending mostly in N-Sdirections (western and southern Mongolian Altai) and several large mountain massifs, partly shaped by glacial erosion and separated by intermontane basins (eastern Mongolian Altai) (Lehmkuhl et al., 2016). The highest elevation in the area is the Tavan Bogd, 4,370m a.s.l. In these altitudes the mountain massifs are covered by bare rock debris and glaciers. In general, the geological structures are formed by siliceous rock, including schists and granites. In the alpine belt, continuous permafrost conditions prevail, whereas in the basins permafrost is discontinuous. The dominating soils are leptosols (Klinge et al., 2017). Fluvial systems serve as internal drainage systems towards the basins of the Valley of the Great Lakes. Most of the eroded sediment is deposited in its valleys or closed basins (Cunningham, 2005).

Due to these specific topographic conditions and the large distance to the Indian, Arctic and Pacific Oceans as moisture sources, the Mongolian Altai is characterized by extreme continentality (Andreev et al., 2007). The westernmost mountain ranges of the Altai capture the wet air masses transported by the westerlies. The rain shadow effect causes a reduction to $300 \mathrm{~mm}$ in the southeast and to 50 $\mathrm{mm}$ in the Valley of the Great Lakes, in contrast to the northwestern parts of the Altai (Russia), which receive $>800 \mathrm{~mm}$ of annual precipitation. Most of the rainfall (70-80\%) occurs during the short 
summertime (June to August). For the city of Ölgii $\left(48^{\circ} 55^{\prime} \mathrm{N}, 89^{\circ} 56^{\prime} \mathrm{E}\right)$ at an elevation of about 1,700 $\mathrm{m}$ a.s.l., the mean annual precipitation is $114 \mathrm{~mm}$ and the mean annual air temperature is $0.3{ }^{\circ} \mathrm{C}$. The monthly mean temperatures range from $-16.8{ }^{\circ} \mathrm{C}$ in January to $16.4{ }^{\circ} \mathrm{C}$ in July (AM Online Projects, 2018). Dry weather with temperature inversions and extremely cold air in the mountain basins (Klinge et al., 2003) with expectedly minor snowfall prevailing in winter.

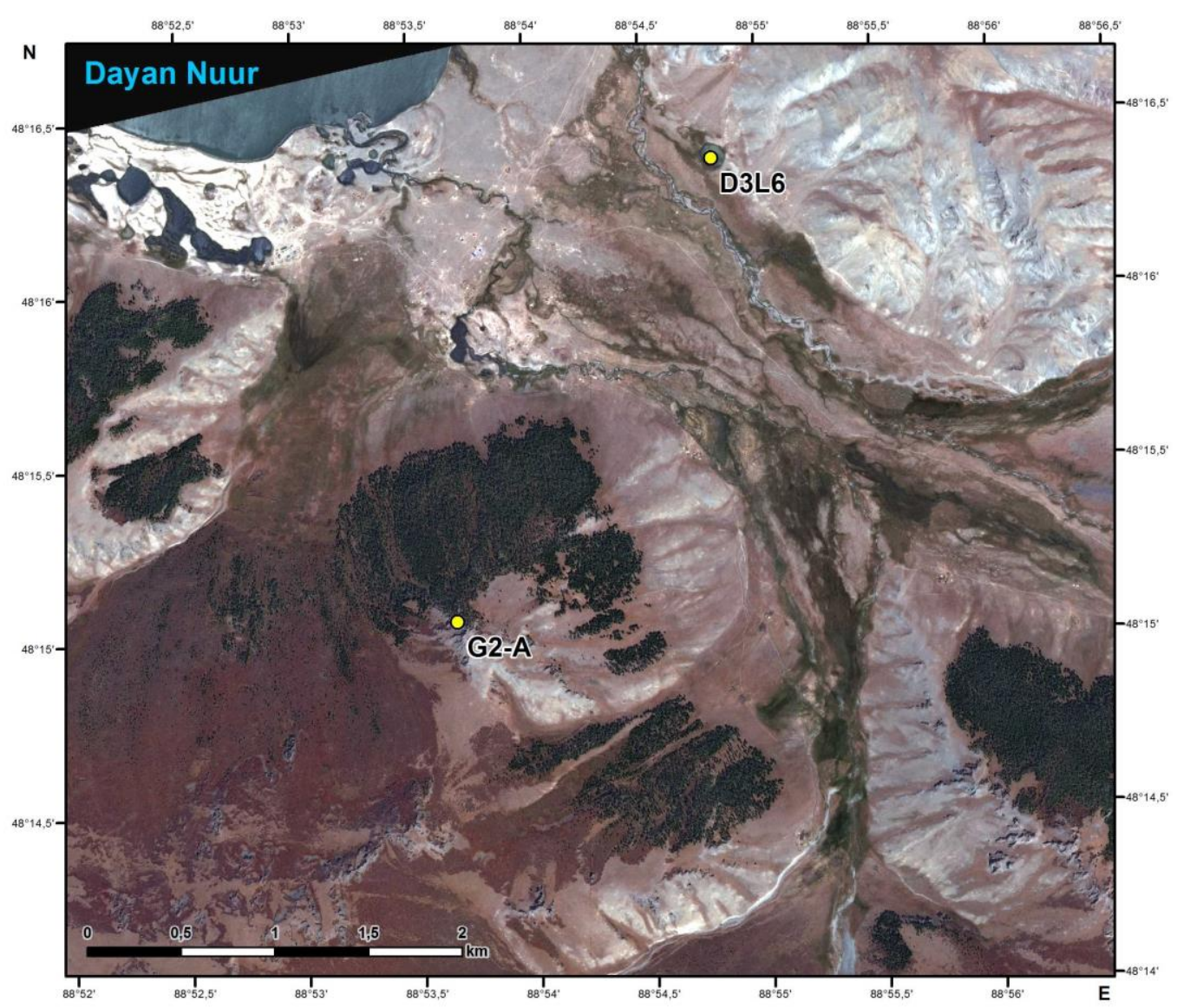

Fig. 3.2. Detailed satellite map showing the location of the coring site D3L6 $\left(48^{\circ} 16^{\prime} 22.18^{\prime \prime} \mathrm{N}\right.$, $88^{\circ} 54^{\prime} 48.50^{\prime \prime} \mathrm{E}, 2,450 \mathrm{~m}$ a.s.1.) in the vicinity of Dayan Nuur. Core G2-A $\left(48^{\circ} 15^{\prime} 0.00^{\prime \prime} \mathrm{N}, 88^{\circ} 53^{\prime}\right.$ $\left.40.10^{\prime \prime} \mathrm{E}\right)$ was added from Unkelbach et al. (2018). Source: Sensor Spot 7 (09/02/2014), map created with ArcGIS version 10.6.1.

\section{Vegetation}

In the Mongolian Altai elevation and precipitation are the driving factors for the vegetation distribution. Precipitation controls W-E-directed vegetation patterns, whereas elevation determines the vertical zonation of plant communities (Gunin et al., 1999). Consequently, the slopes in the western parts of the Mongolian Altai are dominated by alpine meadow steppes, forb grass steppe, dry mountain steppe and small forested areas. In the eastern parts, only dry steppe and semi-deserts make for comparatively sparse vegetation (Neuffer et al., 2003). At the lower slopes, forb-grass 
steppes and dry mountain steppes merge into cold mountain steppes. On southern foothills, desert steppes occur at the mountain base (Gunin et al., 1999).

Meadow steppes with Kobresia and Carex formations in combination with cushion plant communities comprise most of the Mongolian Altai area. Their vegetation composition differs greatly, merging locally with small spots of Juniperus sabina, Betula rotundifolia and Salix glauca (Gunin et al., 1999; Rudaya et al., 2008). Forested areas only occur on the wettest north-facing slopes between 2,000 and 2,500 $\mathrm{m}$ a.s.l. in the upper and central parts of the mountains (Gunin et al., 1999). In the basins and on the toe slopes, forest growth is prevented by temperature inversions in wintertime (Neuffer et al., 2003) and presumably by prolonged human disturbance through tree logging and livestock grazing (Hauck et al., 2012). Forests consist of larch trees (Larix sibirica), occasionally mixed with pine (Pinus sibirica) and spruce (Picea obovata) (Gunin et al., 1999).

Tab. 3.1. A brief overview of the settlement history in western Mongolia (Fernández-Giménez, 1999; Fernández-Giménez et al., 2017; Gonzaléz-Ruiz et al., 2012; Khishigjaral et al., 2013; Lkhagvadorj et al., 2013; Tumen, 2006; van Geel et al., 2004).

\begin{tabular}{|c|c|c|c|}
\hline $\begin{array}{l}\text { Time period } \\
\text { (BC/AD) }\end{array}$ & $\begin{array}{l}\text { Time period } \\
\text { (cal yr BP) }\end{array}$ & $\begin{array}{c}\text { Political/Cultural } \\
\text { structure }\end{array}$ & $\begin{array}{c}\text { Possible } \\
\text { environmental } \\
\text { impact }\end{array}$ \\
\hline $3,550-1,350 \mathrm{BC}$ & $5,500-3,300 \mathrm{BP}$ & Bronze Age & $\begin{array}{l}\text { hunting/fishing, } \\
\text { pastoralism first } \\
\text { introduced }\end{array}$ \\
\hline $1,350-850 \mathrm{BC}$ & $3,300-2,800 \mathrm{BP}$ & Late Bronze Age & $\begin{array}{l}\text { transition to } \\
\text { specialized } \\
\text { pastoralism }\end{array}$ \\
\hline $850-450 \mathrm{BC}$ & $2,800-2,400 \mathrm{BP}$ & $\begin{array}{l}\text { Early Iron Age } \\
\text { Scythian }\end{array}$ & $\begin{array}{c}\text { expansion of mobile } \\
\text { pastoralism }\end{array}$ \\
\hline $450 \mathrm{BC}-150 \mathrm{AD}$ & $2,400-1,800 \mathrm{BP}$ & Xiongnu & mass migration \\
\hline $150-550 \mathrm{AD}$ & $1,800-1,400 \mathrm{BP}$ & Turk & Turkish invasions \\
\hline $550-1150 \mathrm{AD}$ & $1,400-800 \mathrm{BP}$ & Chinese & Chinese invasions \\
\hline $1206-1368$ AD & $744-582 \mathrm{BP}$ & Mongol Empire & $\begin{array}{l}\text { fixed territories for } \\
\text { nomads, wide- } \\
\text { ranging seasonal } \\
\text { migrations }\end{array}$ \\
\hline $1691-1924 \mathrm{AD}$ & $259-26 \mathrm{BP}$ & $\begin{array}{c}\text { Manchu Colonial Period } \\
\text { and Autonomy }\end{array}$ & $\begin{array}{l}\text { reorganization of } \\
\text { territories, grazing } \\
\text { prohibited in some } \\
\text { areas }\end{array}$ \\
\hline $1924-1959$ AD & 26 to $-9 \mathrm{BP}$ & Early Communism & $\begin{array}{c}\text { sharp decline in } \\
\text { livestock population }\end{array}$ \\
\hline $1960-1990 \mathrm{AD}$ & -10 to $-40 \mathrm{BP}$ & Collective Period & $\begin{array}{l}\text { specialized herding } \\
\text { in collectives }\end{array}$ \\
\hline 1991 - 1999 AD & -41 to $-49 \mathrm{BP}$ & Privatization & $\begin{array}{c}\text { increase of cattle, } \\
\text { overgrazing and } \\
\text { forest threats }\end{array}$ \\
\hline $2000 \mathrm{AD}$ to present & -50 to present & Market Economy & $\begin{array}{c}\text { decline in number of } \\
\text { herders }\end{array}$ \\
\hline
\end{tabular}




\section{Settlement history}

Starting with early human occupation of the mountain regions in Central Asia from the Middle Palaeolithic (Tumen, 2006) and the introduction of cattle breeding in the Late Neolithic (late 3rd millennium BCE) (Volkov, 1995), the Mongolian Altai has been influenced by various nomadic tribes (Ėnkhtör et al., 2018). Diverse cultural and political structures have led to changes in land use and animal husbandry over time. A brief overview about the settlement history in western Mongolia is given in Table 3.1.

\section{Material and methods}

Field work was conducted in 2016 in the 'Altai Tavan Bogd' National Park, Bayan-Ölgii province, located $110 \mathrm{~km}$ southwest of Ölgii (Fig. 3.1). The coring site $\left(48^{\circ} 16^{\prime} 22.18^{\prime \prime} \mathrm{N}, 88^{\circ} 54^{\prime} 48.50^{\prime \prime} \mathrm{E}, 2,450\right.$ $\mathrm{m}$ a.s.1.) is an approximately round lake of around $150 \mathrm{~m}$ in diameter and $2.5 \mathrm{~m}$ max. water depth, located southeast of Dayan Nuur (Fig. 3.2). It is situated in a depression between hills and a flat floodplain with a little stream about $1 \mathrm{~km}$ from the lake. The lake has no river inflow or outflow. Today's vegetation surrounding the lake is mainly composed of dry and meadow steppe species such as Cyperaceae, Poaceae, Artemisia and Chenopodiaceae. About $2 \mathrm{~km}$ southwest of the lake few small stands of Larix sibirica are spread out across the area. Pinus sibirica and Picea obovata trees are not present near the lake, but close to the border of China at a distance of about $10 \mathrm{~km}$ and $15-20 \mathrm{~km}$, respectively (Beket, 2009).

In 2016, two core sections of $94 \mathrm{~cm}$ total length (D3L6) were obtained from the center of the lake using a Russian peat corer. They were transferred to the University of Göttingen, Germany, for further analyses and stored at $4{ }^{\circ} \mathrm{C}$ under dark conditions.

Tab. 3.2. Uncalibrated and calibrated radiocarbon dates of core D3L6. Calibration was performed using the Northern Hemisphere terrestrial calibration curve IntCal13 (Reimer et al., 2013).

\begin{tabular}{ccccc}
$\begin{array}{c}\text { Laboratory } \\
\text { Code }\end{array}$ & $\begin{array}{c}\text { Depth } \\
\text { (cm) }\end{array}$ & $\begin{array}{c}\text { Type of } \\
\text { Material }\end{array}$ & C $^{\mathbf{1 4}}$ Age (yr BP) & $\begin{array}{c}\text { calibrated C14 Age } \\
\text { (cal yr BP +/- 16) }\end{array}$ \\
\hline \hline Poz-93840 & 27 & Bulk sediment & $480 \pm 30$ & $451 \pm 30$ \\
\hline Poz-93932 & 55 & Bulk sediment & $735 \pm 30$ & $710 \pm 30$ \\
\hline Poz-93845 & 71 & Bulk sediment & $1105 \pm 30$ & $1036 \pm 30$ \\
\hline Poz-93766 & 84 & Bulk sediment & $2310 \pm 30$ & $2235 \pm 30$ \\
\hline Poz-85952 & 94 & Bulk sediment & $4045 \pm 30$ & $4309 \pm 30$
\end{tabular}




\section{Radiocarbon dating and age-depth-modelling}

As there were no plant remains in the core, five bulk samples (approx. $3 \mathrm{~cm}^{3}$ each sample) were selected for radiocarbon dating based on changes in lithology and pollen composition. These radiocarbon dates were measured at the Poznan Radiocarbon Laboratory, Poland, in 2017, using an accelerator mass spectrometer (AMS). The age-depth-model was established with standard settings of BACON version 2.2 (Blaauw and Christen, 2011) in RStudio version 3.3.3 (RStudio Team, 2016) for which the Northern Hemisphere terrestrial calibration curve IntCal13 of Reimer et al. (2013) was employed.

\section{Palynological analysis}

In total, 48 samples of $0.5 \mathrm{~cm}^{3}$ sediment material were taken continually at $2 \mathrm{~cm}$ intervals along core D3L6. They were prepared using the standard pollen preparation method of Faegri and Iversen (1989) including $10 \% \mathrm{HCl}, 10 \% \mathrm{KOH}, 40 \% \mathrm{HF}$ and acetolysis. All samples were sieved twice during the process to reduce overly coarse $>120 \mu \mathrm{m}$ and $<10 \mu \mathrm{m}$ fine material. Exotic marker spores (Lycopodium clavatum) were added for concentration $\left(\mathrm{grains} / \mathrm{cm}^{3}\right.$ ) and influx (grains $/ \mathrm{cm}^{2} / \mathrm{yr}$ ) calculations. The identification of pollen and spores was based on the reference collection of Mongolian pollen and spores at the Department of Palynology and Climate Dynamics, University of Göttingen (Germany) and relevant literature (Beug, 2004; Demske et al., 2013; Murad, 2011; Willard et al., 2004). All samples were counted to a terrestrial pollen sum of 300 pollen grains. Spores and aquatic pollen taxa were excluded from the pollen percentage sum. To obtain additional palaeoecological information, non-pollen palynomorphs (NPP) were counted. Identification of NPPs was based on Demske et al. (2013), Shumilovskikh et al. (2015) and van Geel (1978). New NPPtypes were introduced using lake code (D3L6) with a number and described morphologically in the Supplementary Material. If possible, they were added to the specific taxonomic group. NPP counts were presented in relation to the pollen sum. Pollen and NPP percentages, concentrations and influx were calculated based on the sum of Lycopodium clavatum spores.

For further interpretation, the ratios of arboreal to non-arboreal pollen (AP/NAP) and Artemisia to Chenopodiaceae (A/C) were calculated. Especially in highly continental climates (arid and semi-arid regions) with dry summers and cold winters the vegetation density and productivity are limited by the availability of water. In these regions, Artemisia and Chenopodiaceae are the most common species that are used as a moisture indicator (Fowell et al., 2003). Artemisia requires more water during the growing season and demands higher habitat requirements than Chenopodiaceae (Herzschuh, 2007; Zhao et al., 2012). Additionally, pollen of Artemisia and Chenopodiaceae species were distinguished based on their size and separated between $<20 \mu \mathrm{m}$-types and $>20 \mu \mathrm{m}$-types. The 
ratios $\mathrm{A}_{\text {big }} / \mathrm{A}_{\text {small }}$ and $\mathrm{C}_{\mathrm{big}} / \mathrm{C}_{\text {small }}$ were calculated to discover changes in the species' composition (Davis and Shafer, 2006; Schlütz and Lehmkuhl, 2007).

The software packages TILIA and TILIAGRAPH (Grimm, 1991) were used to illustrate pollen and NPP data. CONISS was applied to perform a square root transformation of the pollen data and to establish pollen zones (PZ) by statistical subdivision (Grimm, 1987).

3.3 Micro and macro-charcoal analysis

In total, 188 samples of $0.5 \mathrm{~cm}^{3}$ were taken in seamless intervals of $0.5 \mathrm{~cm}$. Following the method established by Stevenson and Haberle (2005), the samples were processed using $10 \% \mathrm{KOH}$ and $4 \%$ $\mathrm{H}_{2} \mathrm{O}_{2}$ and wet sieving to reduce particle fragmentation. Macro-charcoal fragments ( $\left.>150 \mu \mathrm{m}\right)$ were recorded using a binocular dissecting microscope. As presented by Unkelbach et al. (2018), all recorded particles were separated into four taxonomic types: wood, leaf, grass and others (e.g. small roots, moss and unidentifiably small particles). The results were illustrated in terms of total counts per sample. Additionally, the macro-charcoal influx was calculated. Software package TILIAGRAPH (Grimm, 1991) was used to visualize macro-charcoal data.

Furthermore, micro-charcoal particles were counted in the same samples as pollen and NPPs. Microcharcoal concentration and influx were calculated. They are used as an additional proxy for paleofire history (Whitlock and Larsen, 2001) and for comparison with macro-charcoal data.

\section{Diatom analysis}

In total, 48 samples of $2 \mathrm{~cm}$ intervals were taken along the core D3L6 at the same depths as the pollen samples. For preparation, about $10 \mathrm{mg}$ of material was taken from each sampled layer and stirred gently with pure water to avoid destroying diatom valves and chrysophyte cysts. The samples were dried on a heater at $70{ }^{\circ} \mathrm{C}$ and observed by SEM (scanning electron microscope) and through a light microscope.

SEM observation was conducted under $10 \mathrm{kV}$ without vacuum deposition using a low vacuum pressure SEM (Phenom Pro). After SEM observation, the samples were mounted in the high refractive material (Mount Media, Wako Pure Chemical Industries, Ltd.). Diatoms and chrysophyte cysts were counted by a light microscope $(\times 1000)$ using oil emersion lenses. At least, 200 valves and cysts were counted in each sample. In samples of a very low diatom and chrysophyte cysts abundance, counting was stopped before reaching 200 valves.

Diatom species were identified using Krammer and Lange-Bertalot (1986, 1988, 1991a, 1991b) and Watanabe (2005). Diatoms were grouped into (a) epiphytic, (b) plankton, (c) benthos, (d) saline according to their ecological indication. Despite the core being taken from a currently freshwater lake, saline species were found in the samples. Chrysophyte cysts were counted as well, but not classified into species, because species level identification of chrysophytes is very difficult only by 
observation of their cysts. Software package TILIAGRAPH (Grimm, 1991) was used to visualize diatom data.

\section{XRF-scanning analysis}

XRF-scanning was conducted with an ITRAX XRF-core scanner, COX analytical systems (Croudace et al., 2006) at the University of Bremen, Germany. Both sediment core sections were scanned for the detection of major and trace elements with a Cr-tube using a step size of $0.5 \mathrm{~mm}$ and a count time of $10 \mathrm{~s}$ for each step. Tube settings were set to $30 \mathrm{kV}$ voltage and $50 \mathrm{~mA}$ current for both sections. Semi-quantitative element data was obtained for $\mathrm{Si}, \mathrm{S}, \mathrm{K}, \mathrm{Ca}, \mathrm{Ti}, \mathrm{Mn}, \mathrm{Fe}, \mathrm{Br}, \mathrm{Rb}, \mathrm{Sr}$ and Zr. XRF scanning data were normalized by coh-radiation to reduce matrix effects and averaged to $5 \mathrm{~mm}$ intervals.

\section{Results}

\section{Lithology}

Lake core D3L6 mainly consists of dark brownish organic rich gyttja. It can be subdivided into four lithological units (I-IV) based on visual inspection. The lowermost unit $(94-92 \mathrm{~cm})$ is composed of a blackish dark-brown silty mud. Unit II $(92-76 \mathrm{~cm})$ mainly consists of a brownish pale gray mud, followed by unit III $(76-68 \mathrm{~cm})$, a rather thin layer composed of brownish sandy silt with many small enclosed pebbles. The uppermost unit $(68-0 \mathrm{~cm})$ is composed of homogenous dark-brown silty sediments, with small and thin rootlets in the uppermost $10 \mathrm{~cm}$.

\section{Chronology and sedimentation rate}

The chronology of the D3L6 record is established based on five AMS radiocarbon dates (Table 3.2). The age of the core top (sediment surface) is used with the year of coring (2016 CE). The base of the $94 \mathrm{~cm}$-long core was dated and calibrated to $4,310 \mathrm{cal} \mathrm{yr} \mathrm{BP}$. For the first $27 \mathrm{~cm}$, the model suggests a sedimentation rate of $0.52 \mathrm{~mm} / \mathrm{yr}$ and of $1.08 \mathrm{~mm} / \mathrm{yr}$ for the interval between 27 and $55 \mathrm{~cm}$ core depth. A sedimentation rate of $0.49 \mathrm{~mm} / \mathrm{yr}$ was calculated for the section from 55 to $71 \mathrm{~cm}$, and a rate of $0.11 \mathrm{~mm} / \mathrm{yr}$ between 71 and $84 \mathrm{~cm}$. For the lowermost section $(84-94 \mathrm{~cm})$, the age-depthmodel suggests a sedimentation rate of $0.05 \mathrm{~mm} / \mathrm{yr}$ (Fig. 3.3). Visual examination showed consistently compact and dense sediments along the core. No further calibration of sedimentation rate was necessary. 

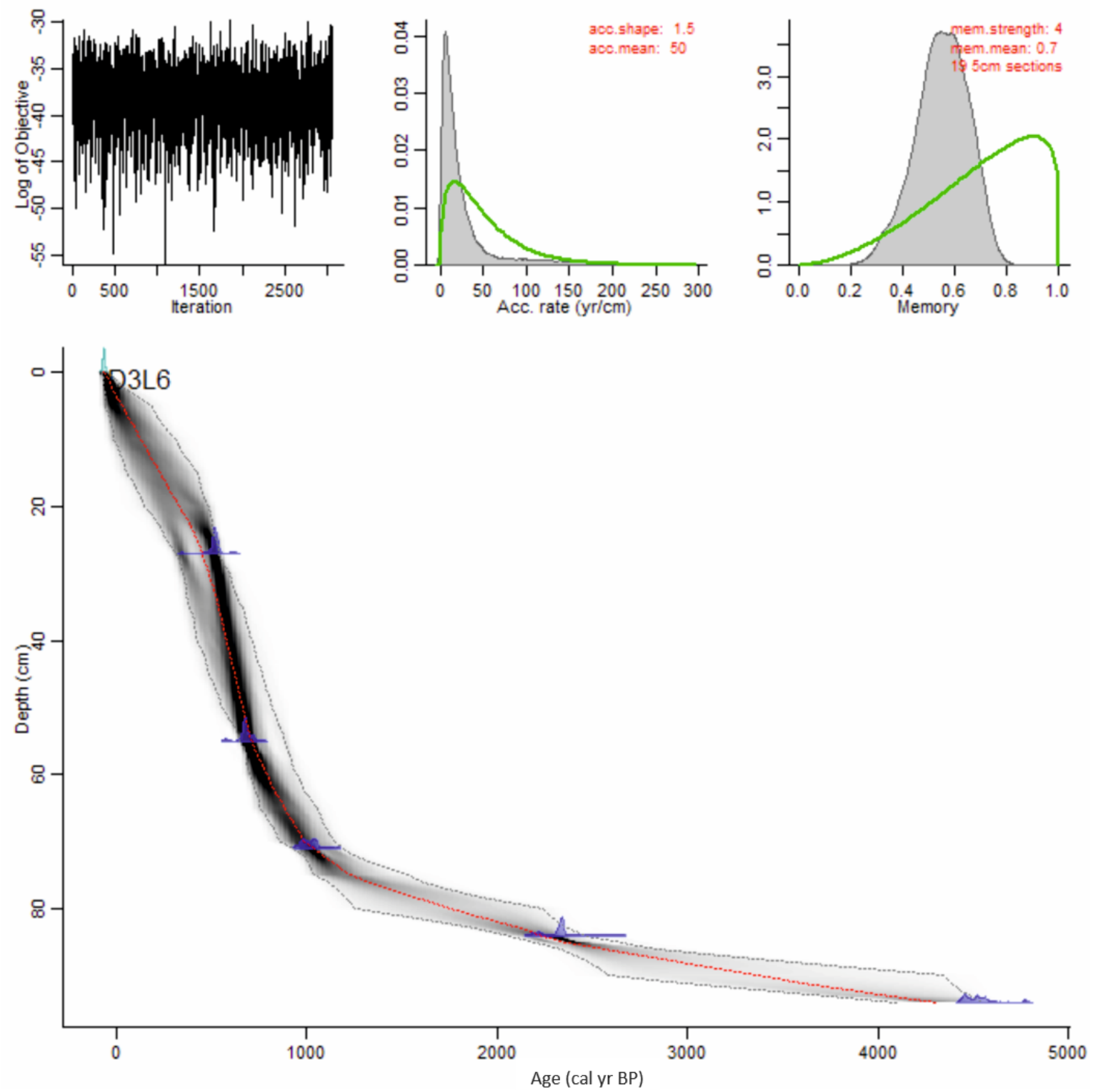

Fig. 3.3. BACON output diagram. Upper parts show the Markov chain Monte Carlo (MCMC) iterations (left), and the prior (green) and posterior (grey) distributions for the accumulation rate (middle) and memory (right). Bottom part shows the calibrated 14C dates (blue) and the age-depthmodel for lacustrine sediment core D3L6.

\section{Pollen results}

The palynological diagram (Fig. 3.4 and Appendix B2) is divided in two local pollen zones (PZ) with five sub-zones (PZ Ia, PZ Ib, PZ IIa, PZ IIb and PZ IIc). The pollen record has an average resolution of 273 years per sample for PZ I and of 31 years per sample for PZ II. At this site, both pollen zones are dominated by herbaceous species (55-93\%) where Cyperaceae (16-41\%) and Poaceae (13-29\%) are abundant. Artemisia (4-23\%) and Chenopodiaceae (1-22\%) are constantly present in lower concentrations. 
The lower zone PZ I (94-71 cm; 4,310-1,040 cal yr BP) is characterized by a relatively high abundance of coniferous species: Larix sibirica (4-15\%), Pinus sibirica (3-12\%) and Picea obovata (4-17\%). Betula (0-4\%) and Ephedra shrubs (0-3\%) occur frequently. In PZ Ia (94-85cm; 4,3102,350 cal yr BP), Artemisia, Ranunculaceae and especially Myriophyllum (up to 20\%) are very frequent. PZ Ib (85-71 cm; 2,350-1,040 cal yr BP) is characterized by an increase in coniferous taxa and Ephedra distachya and Ephedra fragilis. The proportion of Artemisia decreases slightly, while the Chenopodiaceae percentages are constant. Pollen concentration and influx are low. The AP/NAP $(0.1-0.8)$ and $\mathrm{A} / \mathrm{C}(0.5-3.3)$ ratios are generally high, whereas the sample at $72 \mathrm{~cm}$ differs from the other samples with its markedly high A/C value (6.5). The size ratios of Artemisia (0-2.5) and Chenopodiaceae (0-6) show low variations.

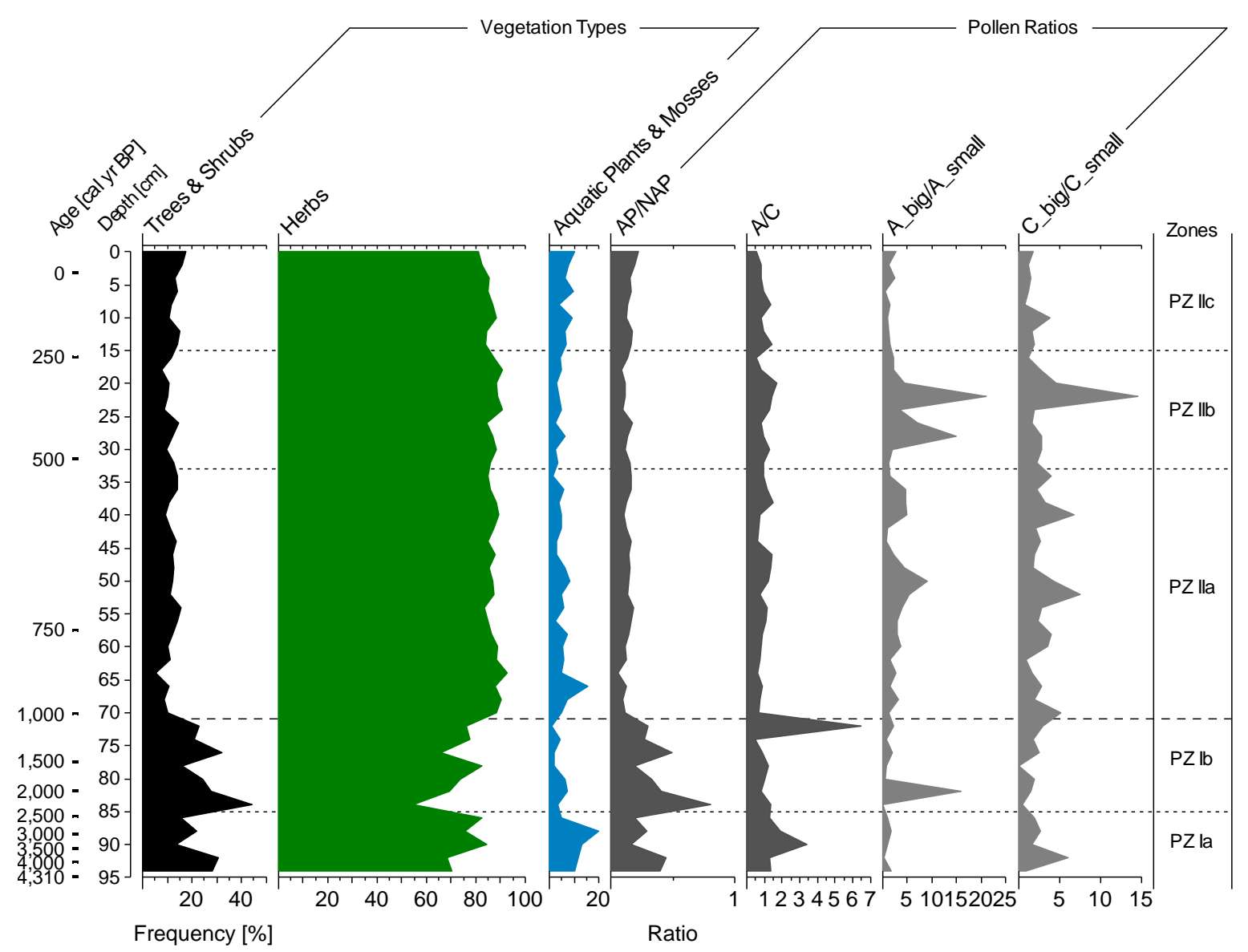

Fig. 3.4. Vegetation type and pollen ratio percentage diagram. Ratios: arboreal pollen to non-arboreal pollen (AP/NAP), Artemisia to Chenopodiaceae (A/C) and the bigger Artemisia and Chenopodiaceae types to the smaller Artemisia and Chenopodiaceae types (A_big/A_small and C_big/C_small).

In the upper pollen zone PZ II (71-0 cm; 1,040 cal yr BP to present), percentages of Larix sibirica, Pinus sibirica and Picea obovata decrease to a minimum of $2 \%, 0.5 \%$ and $1 \%$, respectively. Percentages of most herbaceous species increase markedly, e.g. Artemisia (>7\%), Chenopodiaceae 
$(>9 \%)$ and Caryophyllaceae $(>0.5 \%)$ or occur frequently for the first time, e.g. Apiaceae, Brassicaceae and Violaceae. Shrubs of Salix, Juniperus and Populus are present. In PZ IIa (71-33 cm; 1,040-510 cal yr BP), Artemisia and Chenopodiaceae show their highest values. Both taxa decrease in PZ IIb (33-15 cm; 510-240 cal yr BP), while Cyperaceae, Polygonaceae and Ranunculaceae increase. Betula, Salix and Ulmus reach their maxima in PZ IIc (15-0 cm; 240 cal yr BP to present). Additionally, a marked increase in pollen concentration and influx is visible in PZ II. Both AP/NAP (0.1-0.2) and A/C (0.6-1.7) ratios decrease. The frequency variations of $\mathrm{A}_{\text {big }} / \mathrm{A}_{\text {small }}$ and $\mathrm{C}_{\text {big }} / \mathrm{C}_{\text {small }}$ are more pronounced than before, especially in PZ IIb.

4.4 Non-pollen palynomorph results

The non-pollen palynomorph percentage diagram is represented in Appendix B3. It depicts all encountered NPP types, which have already been described in literature, and 12 of the most common unknown types in core D3L6 (Supplementary materials 1). In total, 96 NPP types were recorded, of which only $44(46 \%)$ could be identified reliably. All new types were assigned provisionally to the 12 different taxonomic groups. NPP assemblages are dominated by algae (10-410\%), mainly HdV$128(7-396 \%)$ and Botryococcus (0-29\%) as well as the fungus Glomus (4-76\%). Spores of almost all other fungi types, microfossils, animal and plant remains are rather frequent, soil fungi and testate amoebae are rather rare. The zonation is consistent with the pollen results; hence no different expression is introduced.

The assemblage of PZ I is markedly dominated by algae species, e.g. HdV-128 (70-396\%), Botryococcus (2-29\%) and Pediastrum (1-8\%). Glomus (16-76\%) is abundant. Saprophilous fungi (12\%), plant parasites (7\%) and other fungi (28\%) reach their maximum. At the transition from PZ Ia to PZ Ib, single peaks of Sordaria type A (up to 12\%), Dictisporium (11\%) and Chaetomium (7\%) exist. At the same time, Sporormiella is introduced and becomes frequent. In PZ Ib, all four species of coprophilous/saprophilous fungi occur simultaneously and are almost consistently present since that time. Whereas the non-pollen palynomorph concentration is rather low at the beginning of the record, two major peaks are visible in the middle section (approx. 1.3 million species per sample) and the uppermost part of PZ Ib (approx. 1.0 million species per sample).

In PZ II, the percentages of HdV-128 and Botryococcus decrease to a minimum of $7 \%$ and $0.5 \%$. Zygnemataceae, Spirogyra and Debarya occur. Percentages of Glomus, saprophilous and other fungi decrease as well. Coprophilous, coprophilous/saprophilous fungi and plant parasites are frequent, showing minor maxima. In PZ IIa, microfossils and testate amoebae were found. The non-pollen palynomorph concentration decreases slightly from around 0.25 million species per sample in PZ IIa to around 0.05 million in PZ IIc. 


\section{Charcoal results}

The macro-charcoal record has an average resolution of 71 years per sample for PZ I and of 8 years per sample for PZ II. Charred macro particles are present in almost all samples along core D3L6 (Fig. 3.5). Macro-charcoal is abundant especially in PZ Ia from 4,310 cal yr BP to 2,350 cal yr BP and decreases afterwards. In PZ IIa, one minor peak of charcoal particles can be observed between 640 and $550 \mathrm{cal}$ yr BP. Very low concentrations are found from $340 \mathrm{cal}$ yr BP to today (PZ IIb and IIc). In contrast, the macro-charcoal influx is generally low within the whole record, but the peak between 640 and 550 cal yr BP is still distinct.

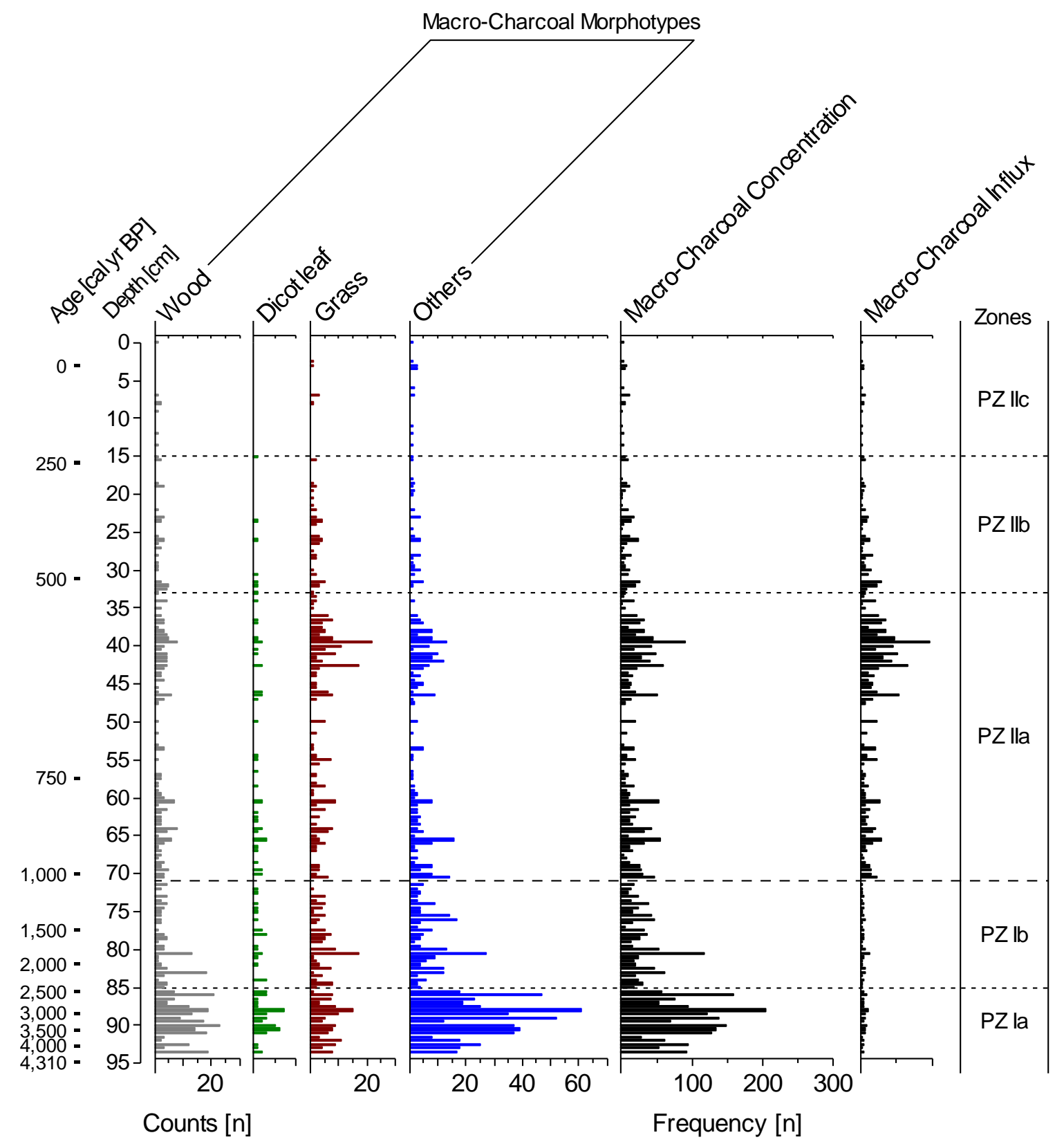

Fig. 3.5. Macro-charcoal diagram. Total charred particles are divided into wood, dicot leaf, grass and other charcoal fragments. Macro-charcoal concentration [particles/cm3] and macro-charcoal influx [particles/cm $2 / \mathrm{yr}$ ] have been calculated using the sum of total charcoal counts. 
With respect to the four different morphotypes, charred mosses, seeds, fine roots and unidentifiable particles are the most abundant fraction (47\% of total macro-charcoal counts). Charred grass particles (24\%) are more frequent than wood (23\%) and leaves (5\%). Generally, the peaks in the record seem to correlate at least in the proportions of three of the four morphological groups: wood, grass and other macro-charcoal particles. The composition of the macro-charcoal material shows only minor changes within the record. At the beginning of PZ Ia, charred wood material is more abundant than grass, and in PZ II the abundance of charred grass material is higher.

The micro charcoal record (Appendix B2) shows slightly different results. In PZ I, the maximum of charcoal fragments cannot be observed in PZ Ia, but in PZ Ib. In PZ II, the concentration decreases markedly, but, in contrast to the macro-charcoal record, not constantly. A minor decrease in the micro charcoal concentration is detected in PZ IIb. The micro charcoal influx is markedly lower in PZ I, but generally consistent with the concentration in PZ II.

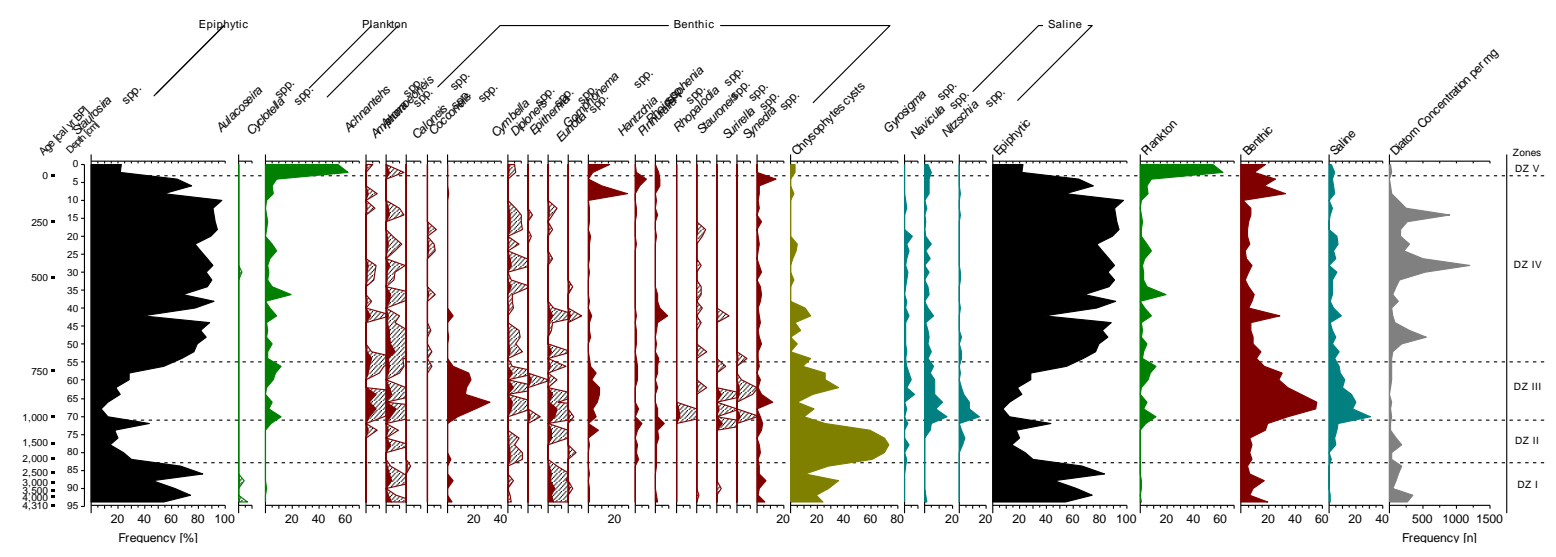

Fig. 3.6. Diatom percentage diagram including diatom concentration [valves/mg]. Samples are grouped into 5 diatom zones (DZ) by visual inspection.

\section{Diatom results}

Core D3L6 can be divided into five diatom zones (DZ) according to the distribution of diatoms and chrysophytes cysts (Fig. 3.6). The first zone, DZ I (94-84 cm; 4,310-2,230 cal yr BP), is characterized by Staurosira spp. (54-83\%) and chrysophytes cysts (11-36\%). The diatom concentration varies from 558 valves to 3,480 valves per mg sediment. In DZ II ( $84-70 \mathrm{~cm} ; 2,230$ 990 cal yr BP), Staurosira spp. (13-44\%) and chrysophytes cysts (10-73\%) are abundant. More benthic species (e.g. Achnanthes spp., Gomphonema spp. and Hantzschia spp.) are introduced. Benthic (6-35\%) and saline proportions (1-31\%) increase slightly at the end of this period. The diatom concentration decreases. Benthic species (11-56\%) are abundant in DZ III (70-54 cm; 990$700 \mathrm{cal}$ yr BP), e.g. Cocconeis spp. and Gomphonema spp. Chrysophytes cysts (5-36\%) decrease 
while saline species Gyrosigma spp. (1-7\%), Navicula spp. (2-13\%) and Nitzschia spp. (1-8\%) reach their maxima. A markedly low diatom concentration (70-310 valves per mg sediment) can be observed. In DZ IV (54-2 cm; 700 to -26 cal yr BP), epiphytic species Staurosira spp. increase markedly and are dominating (38-97\%). Benthic (1-33\%) and saline species (1-10\%) decrease as well as chrysophytes cysts (1-15\%). The diatom concentration increases markedly in this period up to 12,000 valves per $\mathrm{mg}$ sediment. DZ V $(2-0 \mathrm{~cm} ;-26 \mathrm{cal}$ yr BP to present) is characterized by a marked decrease of Staurosira spp. (22\%) and an abundance of plankton species Cyclotella spp. (54$62 \%)$. Additionally, another increase in the diatom concentration can be observed $(<330$ valves per mg sediment).

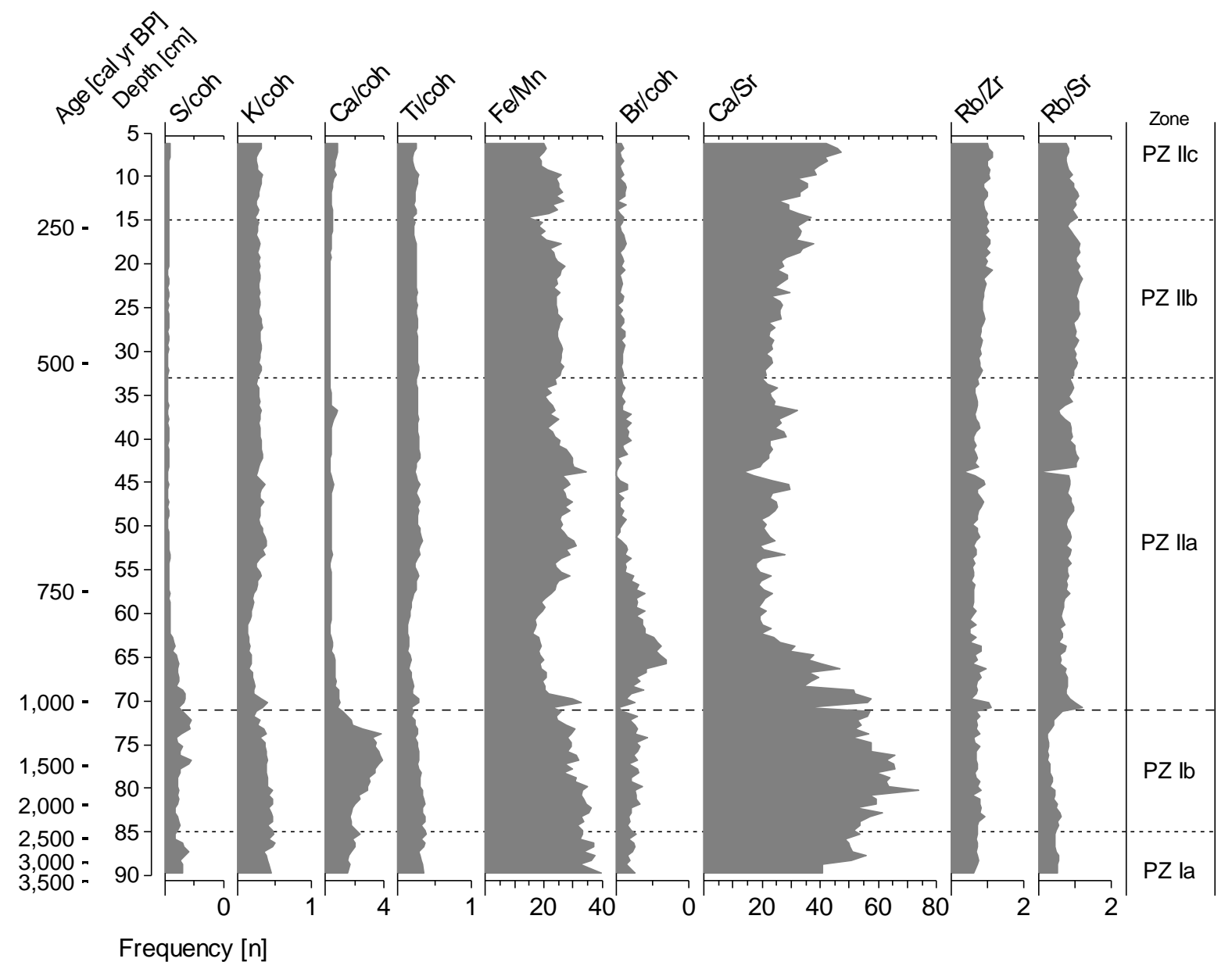

Fig. 3.7. XRF-scanning diagram of selected normalized proxies.

\section{XRF-scanning results}

Due to a very fluid consistency of the sediments at the top of core D3L6 no XRF scanning data could be obtained for the uppermost $6 \mathrm{~cm}$ (55 cal yr BP to present) (Fig. 3.7). The records of potassium (K) and titanium (Ti) show a very similar development with maximum values at the base of the core, 
minimum values between 70 and $58 \mathrm{~cm}(990-760 \mathrm{cal} \mathrm{yr} \mathrm{BP})$ and stable, intermediate values in the upper $50 \mathrm{~cm}$. In contrast, calcium (Ca) has a pronounced maximum between 82 and $73 \mathrm{~cm}$ core depth (2,000-1.130 cal yr BP). Then, Ca values decrease rapidly to very low values between 70 and $6 \mathrm{~cm}$ (990-50 cal yr BP). The calcium/strontium ( $\mathrm{Ca} / \mathrm{Sr}$ ) ratio likewise shows high values above 50 in the oldest sediments, but a more gradual decrease between 68 and $62 \mathrm{~cm}(950-830 \mathrm{cal} \mathrm{yr} \mathrm{BP})$ to values of around 20. While almost no sulfur (S) could be detected in the upper $62 \mathrm{~cm}$, increased values and several peaks appear in the $\mathrm{S}$ record below $62 \mathrm{~cm}$ core depth. The record of bromine $(\mathrm{Br})$ has a marked peak between 66 and $62 \mathrm{~cm}(910-830 \mathrm{cal}$ yr BP), whereas values are low in sediments below and above. In core D3L6, the iron/manganese (Fe/Mn) record closely follows the siliciclastic proxies $\mathrm{K}$ and $\mathrm{Ti}\left(\mathrm{r}^{2}=0.75\right.$ between $\mathrm{K}$ and $\left.\mathrm{Fe} / \mathrm{Mn}\right)$ with high values between 90 and $70 \mathrm{~cm}(3,330-990 \mathrm{cal} \mathrm{yr}$ $\mathrm{BP}$ ), a broad minimum at around $62 \mathrm{~cm}$ and fluctuating intermediate values between 50 and $6 \mathrm{~cm}$ (670-50 cal yr BP).

\section{Interpretation and discussion}

\section{Vegetation since the end of the mid-Holocene}

From 4,310 to 2,350 cal yr BP (PZ Ia) the landscape south of Dayan Nuur in the 'Altai Tavan Bogd' National Park was dominated by alpine meadow and moist steppe communities such as Artemisia, Cyperaceae and Ranunculaceae. Many modern-day shrub and herbaceous taxa did not yet occur in this period. A higher representation of Pinus sibirica and Picea obovata with a steady share of Larix sibirica as a short-distance pollen distributor (Savina and Burenina, 1981) could be observed. Hence, it suggests not only the local presence of Larix sibirica, but also the occurrence of Pinus sibirica and Picea obovata stands much closer to the coring site in comparison to recent time. A much higher representation of the forest can be inferred compared to the modern setting. At present, Pinus sibirica and Picea obovata occur in a forested area in up to $20 \mathrm{~km}$ distance (Beket, 2009) with a similar amount of both taxa (Unkelbach, unpublished data). The higher AP/NAP and A/C ratios confirm a larger forested area. A comparison of those ratios with results by Liu et al. (1999) for Inner Mongolia (China) and El-Moslimany (1990) for the continental Middle East also supports our interpretation. Hence, the $\mathrm{A} / \mathrm{C}$ ratio values in the Mongolian Altai are consistently low due to the general open character of forests as Herzschuh (2007) ascertained for Inner Mongolia.

According to the increasing proportion of arboreal pollen, the forest started to expand after 2,350 cal yr BP until 1,040 cal yr BP (PZ Ib). The occurrence of Ephedra distachya and the rising percentages of Ephedra fragilis point to an increased expansion of dry ruderal habitats (Gunin et al., 1999). The expansion of dry steppe takes place at an expense of the more water-requiring herbs, e.g. Cyperaceae. This points to a contradictive repression of alpine meadow communities not only by forested areas 
but also by dry mountain steppe. Increasing AP/NAP and A/C values feature these uncommon processes.

The period from 1,040 to 510 cal yr BP (PZ IIa) is characterized by major vegetation changes. One aspect is the abrupt and simultaneous retreat of Pinus sibirica and Picea obovata as well as the decline of Larix sibirica and Betula stands. From that time on, the forest near the coring site is only composed of Larix sibirica trees. The introduction of Juniperus and Populus shrubs and the increased representation of Salix and Ulmus indicate a higher diversity and an opening of the forests. Their rather low representations in the pollen diagram suggest only local presence in the "Altai Tavan Bogd' National Park. In this period, a marked increase of herbaceous ruderal plants, e.g. Artemisia and Chenopodiaceae, and the introduction of new species, e.g. Apiaceae, Brassicaceae and Rubiaceae, point to newly created open habitats. The high representations of Poaceae, a decrease of Cyperaceae and a reduced $\mathrm{A} / \mathrm{C}$ ratio show that the proportion of dry mountain steppe appears to have increased further.

In the period from 510 to 240 cal yr BP (PZ IIb), alpine meadow communities replaced the dry mountain steppe in parts of the area, as demonstrated by the increased shares of Cyperaceae, Polygonaceae and Ranunculaceae. The extent of forest distribution persisted. The period from 240 cal yr BP to present time (PZ IIc) is characterized by an opening of the forests and a slight recovery of the Larix sibirica stands in the area. Pinus sibirica and Picea obovata were further repressed while the shares of open forest indicators (Betula, Salix, Juniperus) increased. Another expansion of dry mountain steppe occurred from around 100 cal yr BP onwards, indicated by a decrease in the representation of Artemisia and an increase of Poaceae.

\section{Grazing since the end of the mid-Holocene}

Among the NPP, coprophilous fungi are significant indicators for detecting the presence of large herbivores and their grazing pressure in the course of pastoralism (e.g. Davis et al., 1984; Burney et al., 2003; Raper and Bush, 2009). Initial occurrence of the Sordaria-type and Sporormiella dung fungi suggest that the inhabitants of the study area started to change their lifestyle habits from hunting and gathering to pastoralism at around 2,350 cal yr BP, at the time of Xiongnu (Table 1). After a transition phase, Sporormiella spores became markedly more plentiful at around 1,040 cal yr BP in the period of Chinese invasions to Mongolia and occurred continuously since that time. A peak in the Sporormiella record (PZ IIa) coincides with the abrupt decrease of arboreal pollen and the expansion of steppe communities starting from 1,040 cal yr BP. Trampling and grazing of the animals diminished the number of saplings, reduced the forested areas and interfered with their recovery (Hauck et al., 2012; Khishigjargal et al., 2013). Instead, ruderal herbaceous plants became prevalent. 
Hence, even lower numbers of animals may have a major impact on the vegetation composition and expansion in the area.

\section{Fire since the end of the mid-Holocene}

The macro-charcoal record enables to detect climate-fire-vegetation linkages and prehistoric human practices (e.g. Clark and Royall, 1995; Pitkänen and Huttunen, 1999; Umbanhowar et al., 2009; Wick and Möhl, 2006). From 4,310 to 1,040 cal yr BP, the fire frequency is assumed to be very low. After $1,040 \mathrm{cal}$ yr BP, the influx started to increase slightly. A fire activity maximum is visible from 640 to $550 \mathrm{cal}$ yr BP during the period of the Mongol Empire (Table 3.1). It could be attributed to the increased formation of dead biomass under drier and probably warmer conditions at that time (Eichler et al., 2011). After 550 cal yr BP, the fire frequency decreased steadily. From 240 cal yr BP to present time, the very low number of charred particles suggests rare fires in the area starting at the time of Manchu Colonial Period and Autonomy. Despite of the peak from 640 to $550 \mathrm{cal}$ yr BP, it can be inferred that fire generally played a minor role in forming the landscape of the "Altai Tavan Bogd' National Park over the recorded last 4,375 years.

Brugger et al. (2018) provided information on a correlation of dry periods indicated by the herbaceous pollen composition (e.g. A/C ratio) and a decrease in arboreal taxa with a following maximum of micro charcoal. This phenomenon was explained by dead trees originating from the dry period serving as fuel for the later forest fires. In our data, there is a peak in the $\mathrm{A} / \mathrm{C}$ ratio (Fig. 5) shortly before the transition from PZ Ib to PZ IIa indicating a dry period. In Fig. 3.4, a decline of trees and shrubs can be observed during this transition. However, a maximum in the macro-charcoal influx (Fig. 3.5) occurs shortly after the beginning of PZ IIa. The sequence of events proceeds exactly as described by Brugger et al. (2018). Umbanhowar et al. (2009) explained that overgrazing reduces biomass and consequently the fuel for fire. Thus, they concluded that low charcoal content in lake sediments serves as an indirect proxy for increased grazing pressure. A relation of decreased fire frequency with increased grazing activity after 1,040 cal yr BP (PZ II) can be inferred from our data.

\section{Lake level since the end of the mid-Holocene}

Epiphytic diatom species and the presence of chrysophytes cysts suggest the existence of a small and shallow pond starting from 4,310 until 2,230 cal yr BP (DZ I). The period from 2,230 to $990 \mathrm{cal}$ yr BP (DZ II) is characterized by a dominance of chrysophytes cysts indicating a lower water level compared to the modern setting. An extensive wetland spread along the lake shore and possibly the lake dried up seasonally. Gyrosigma acuminatum and Nitzschia frustulum suggest an increasing electric conductivity of the lake water. After 990 until $700 \mathrm{cal}$ yr BP (DZ III) the occurrence of 
planktonic diatom species and the increasing representation of benthos species point to a water level rise. At the beginning of this period, a very shallow freshwater pond was newly formed. The distinct maximum of Cocconeis sp. indicates relatively high values of $\mathrm{pH}$, oxygen and a eutrophic state (Van Dam et al., 1994). A further increase in some saline species leads to a maximum of inferred electric conductivity from 990 to 870 cal yr BP. In the subsequent period from 700 to -26 cal yr BP (DZ IV) the further dominance of Staurosira construens suggests a further rise of the water level. The water depth of the lake is assumed to have been around $1 \mathrm{~m}$, or slightly less. Over the recent decades $(-26$ cal yr BP to present, DZ V) the abundance of plankton species features a drastic increase in the lake level. Today, the water depth is measured at $250 \mathrm{~cm}$. A rise of $>150 \mathrm{~cm}$ in about 75 years was most probably caused by the degradation of permafrost and glaciers due to climate warming at the beginning of the $21^{\text {st }}$ century from 2006 to 2016 , as has also been pointed out by Walther et al. (2017).

\section{Erosion since the end of the mid-Holocene}

$\mathrm{K}$ and Ti commonly serve as siliciclastic indicators (Kylander et al., 2011; Unkel et al., 2014). The records of these elements show a period of increased erosion between 3,500 and 1,000 cal yr BP (PZ I) despite very low sedimentation rates. During this period, the influx of minerogenic matter into the lake was relatively high, probably caused by increased precipitation and surface inflow. Likewise, the elevated amounts of sulfur prior to ca. $800 \mathrm{cal}$ yr BP may point to a reduced mixing of the lake, perhaps caused by higher water levels and a stratified water body during this time. As the distribution of sulfur is closely linked to the redox cycles of Fe (e.g. Davison, 1988), high concentrations of sedimentary sulfur usually indicate the occurrence of Fe-sulfides under reducing conditions that might have developed in a deeper, stratified water body. During this time, the high Ca content also indicates the presence of $\mathrm{Ca}$-carbonates and the high $\mathrm{Ca} / \mathrm{Sr}$ ratio suggests an allochthonous source. In marine environments, high $\mathrm{Ca} / \mathrm{Sr}$ ratios have been found in detrital carbonates (e.g. Hodell et al., 2008). However, Sr can also be found in feldspars (Kylander et al., 2011) and the different trends of the $\mathrm{Ca}$ and $\mathrm{Ca} / \mathrm{Sr}$ record may be caused by in-situ precipitation of carbonates. The differential solubility and mobility of $\mathrm{Mn}$ and Fe under changing redox conditions have also been utilized as a palaeo-redox indicator at the sediment-water interface (e.g. Haberzettl et al., 2006). Increasing Fe/Mn-ratios may indicate the onset of reducing conditions (Wersin et al., 1991). However, this interpretation is often challenged by a variety of other factors such as geochemical focusing (Schaller and Wehrli, 1996) or the incorporation of Mn and/or Fe into carbonates (e.g. Stevens et al., 2000). For lake D3L6 the strong correlation between the Fe/Mn and the siliciclastic indicators $\mathrm{K}$ and $\mathrm{Ti}$ suggests considerable amounts of "redox-insensitive" Fe or Mn bound in silicate rocks, impeding the use of this ratio as redox proxy. 
At ca. 800 cal yr BP (PZ II), rainfall dropped to very low levels and according the reduced $\mathrm{K}$ and Ti values, almost no allochthonous material was washed into lake D3L6 for 200 years. In this period, $\mathrm{Br}$ reaches a maximum. $\mathrm{Br}$ is bound to organic matter (e.g. Kalugin et al., 2013); this confirms a period of stable conditions under a drier climate with autochthonous organic matter as the dominant sediment component. The appearance of saline diatom species suggests a lower lake-level, but the $\mathrm{Ca}$ record is surprisingly low although the precipitation of autochthonous carbonates could be expected.

Intermediate levels of soil erosion due to increased precipitation started again at around $600 \mathrm{cal} \mathrm{yr}$ $\mathrm{BP}$ but the lake level does not seem to have risen high enough to develop a stratified water body for a longer period. Likewise, the Ca record does not show considerable changes. Apparently, no detrital carbonates were transported into the lake. The observed vegetation changes in the catchment of the lake had seemingly no impact on the sedimentation processes. It is likely that sedimentation in lake D3L6 was then being dominated by persistent human impact which overpowered climatic factors.

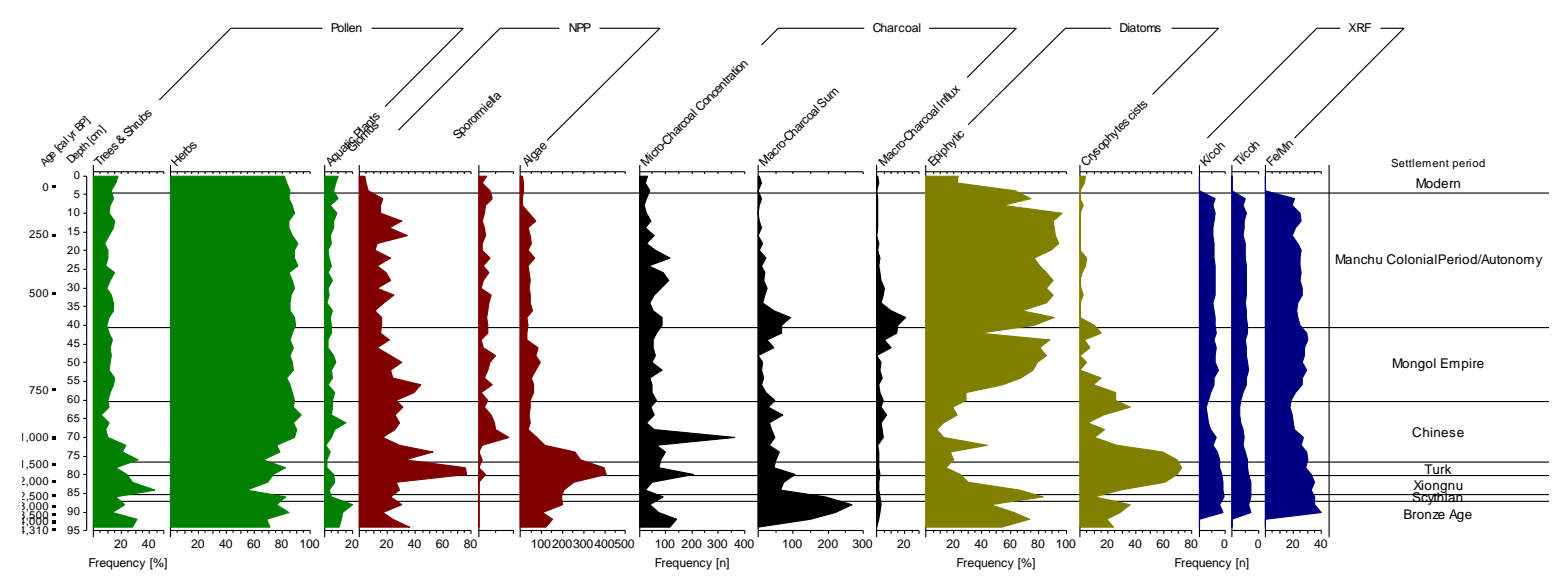

Fig. 3.8. Summarized multi-proxy diagram of selected proxies and settlement periods in the Mongolian Altai.

\section{Driving factor of the environmental changes}

A composite diagram of selected proxies is illustrated in Fig. 3.8. According to the pollen data, the period from 4,310 to 2,350 cal yr BP (PZ Ia) was characterized by rather humid and cold conditions in the Mongolian Altai. Compared with present time the annual precipitation was presumably slightly higher, as the then greater representation of coniferous trees in the area indicates. It is additionally assumed that the extreme continental conditions, especially the very low winter temperatures, were not as distinct as nowadays. For this period, diatom data suggest an increase in water availability, which is consistent with the climate reconstructions from pollen data (Fig. 3.8). In the period from 2,350 to 1,040 cal yr BP (PZ Ib) humid climate still prevailed. But an increase in temperature after 2,350 cal yr BP featured the expansion of forests and inhabiting areas of sparse vegetation with steppe 
communities. The temperature rise might have also facilitated evaporation and caused the lake's drying up.

At around 1,040 cal yr BP (PZ II), marked changes in plant diversity and the amount of biomass occurred in the Mongolian Altai. One possible scenario could be a climate change to more continental (dry and cold) conditions. Probably at that time, the temperature extremes between summer and winter developed. But in contrast to the findings by Andreev et al. (2007) in the Russian Altai, there is no evidence of the Medieval Warm Period at around 750 to $550 \mathrm{cal} \mathrm{yr}$ BP in our record. Another contradiction is the renewed water level rise indicated by the diatom record since $990 \mathrm{cal} \mathrm{yr}$ BP. The nearly simultaneous rise in water availability and the disappearance of trees in the area represent opposite climate signals.

According to the pollen and diatom record, moisture increased slightly within the cold phase between 510 and $240 \mathrm{cal}$ yr BP. A marked increase of Chenopodiaceae and a slight decrease in the representation of Larix sibirica correspond with the beginning of the Little Ice Age in the Altai Mountains from around 370 to $110 \mathrm{cal} \mathrm{yr} \mathrm{BP}$ found by Andreev et al. (2007). After that, the annual temperature started to increase gradually, and this tendency of climate warming persists. Summer temperatures increased over the last decades (Syromyatina et al., 2015) favoring permafrost degradation and water level rise.

But what caused the contrasting results at around 1,040 cal yr BP? The most likely scenario is the intensification of human land-use, possibly induced by slightly wetter conditions. An increase in the number of cattle as well as an expansion of tree logging for firewood are the likely factors for the observed decline of natural forests despite favorable climatic conditions. This interpretation is supported by the almost simultaneous changes seen in our proxy data. If those shifts had been caused solely by climatic signals, diatoms and NPPs would have responded more quickly than the forests surrounding the lake. Hence, our findings demonstrate a strong correlation between corresponding changes in the vegetation composition and the increased impact on the landscape by pastoral nomads in the area during the period of Chinese invasions into Mongolia starting at around 1400calyrBP (Table 1). Tree logging and grazing caused a decline of natural forests and favored the establishment of steppe vegetation.

Minor changes in the steppe composition over the last 1,000 years can possibly also be attributed to an intensification or reduction of human activities in this part of the Mongolian Altai. Our data reveal intensified periods of human impact from around 1,000 to 880 cal yr BP during the Chinese invasions, from 680 to $650 \mathrm{cal} \mathrm{yr}$ BP during the Mongol Empire and from 75 to $15 \mathrm{cal} \mathrm{yr} \mathrm{BP}$ at the transition from Autonomy to Early Communism. An increase of more open forests after $240 \mathrm{cal}$ yr BP started at the beginning of Manchu Colonial Period (259 BP). The minor forest recovery from 15 cal yr BP to present might either be attributed to the general decline in livestock population as a 
consequence of soviet policies (Early Communism) or to increased water availability due to permafrost degradation under a warming climate.

\section{Comparison with other records}

Our data reveal environmental changes in the Dayan Nuur region since the end of the mid-Holocene. Particularly advantageous is the large number of independent proxies, the analysis of coprophilous fungi as another indirect indicator for grazing activities, and the high resolution of samples. They indicate a trend from larger and more densely forested areas since the start of the record at 4,310 cal yr BP until the beginning of steppe expansion from ca. 1,040 cal yr BP. Pollen results coincide with findings by Unkelbach et al. (2018) from peat core G2-A at a small mire in approx. $3 \mathrm{~km}$ distance from core D3L6. The general trend from a rather humid and warm climate with greater forested areas (3,880-2,610 cal yr BP) to a decrease in the forest vegetation because of much drier and cooler conditions $(2,610-550$ cal $\mathrm{yr}$ BP) and a recovery of forests in accordance with increasing precipitation and temperature since $550 \mathrm{cal} \mathrm{yr} \mathrm{BP}$ are consistent with the data inferred from core D3L6. Here, too, the decline of forests corresponds with the intensified inhabitation of the area by nomadic peoples. But, a deviation of $>1500$ years compared to findings from core G2-A seems remarkable on such a local scale. However, it needs to be considered that coprophilous fungi have not been analyzed for core G2-A in our previous study. Additionally, the core for this study was obtained at a markedly lower elevation than core G2-A (approx. $150 \mathrm{~m}$ higher, upper forest boundary). The deviation of vegetation recovery after the cold and dry period starting from $550 \mathrm{cal}$ yr BP to 510 cal yr BP (G2-A), respectively, is considerably smaller. A comparison with the two Holocene studies from the Hoton-Nuur basin, $50 \mathrm{~km}$ northwest of our coring site, reveal greater differences. In the first pollen and diatom record, Tarasov et al. (2000) found a shift from wetter to drier climatic conditions at around 3,900 cal yr BP. Rudaya et al. $(2008,2009)$ dated the beginning of a gradual increase of aridity to $6,500 \mathrm{cal} \mathrm{yr} \mathrm{BP}$ caused by a diminution of forests. A possible climatic cooling was only ascertained to a period from 2,900 to 1,200 cal yr BP. However, both studies recognized certain limitations concerning time resolution and sample quality. Pollen analysis of the Hoton-1 core studied by Tarasov et al. (2000) has an average time resolution of approx. 600 years per sample and each pollen sample contained 5-10 cm sediment material to reconstruct general trends. The average time resolution of the Hoton-2 core studied by Rudaya et al. $(2008,2009)$ is approx. 145 years per sample, in marked contrast to 31 years per sample for PZ II in our research. In the lowermost part of core Hoton-2, only presence/absence of pollen taxa could be expressed due to low pollen content. Neither Tarasov et al. $(2000)$ nor Rudaya et al. $(2008,2009)$ found any evidence of significant human impact in the region until recent times, whereas in our data anthropogenic influences due to animal husbandry and deforestation are present for $>2000$ years. A similar 
palynological research is presented by Sun et al. (2013) from Achit Nuur, $200 \mathrm{~km}$ northeast of our coring site. From 6,400 to $1,600 \mathrm{cal}$ yr BP, the authors reconstructed an expansion of taiga in higher elevations and found a maximum in herbaceous taxa from 1,600 cal yr BP to present. The pollen assemblage of Achit Nuur core suggested a relatively warm climate over the last 5,000 years and wet conditions for the period from $6,400 \mathrm{cal}$ yr BP to $1,600 \mathrm{cal} \mathrm{yr}$ BP proceeding to dry conditions from $1,600 \mathrm{cal}$ yr BP to present. Again, limitations concerning low sample resolution and dating quality for the last 1,600 cal $\mathrm{yr}$ BP were discussed. Despite the fact that the pollen-based climate reconstructions show temporarily similar results compared to our record, similarly to Hoton-Nuur research, anthropogenic impact on the environment was understated. The ice core studies from Tambagarav Mountain in the Mongolian Altai (Brugger et al., 2018) reveal forest expansions from 4,950 to $4,750 \mathrm{cal} \mathrm{yr} \mathrm{BP}, 4,350$ to $4,050 \mathrm{cal} \mathrm{yr} \mathrm{BP}$ and 3,850 to 3,750 cal yr BP and a forest decline starting from 3,750 cal yr BP. The deviation to our reconstructed beginning of forest decline is remarkable. But it needs to be considered that ice cores depict vegetation changes on a considerably more regional scale than cores of lacustrine sediment. On a more regional scale, two contrasting environmental reconstructions are presented in the Lake Teletskoye record (Russian Altai Mountains). Rudaya et al. (2016) suggest a maximum of mountain taiga coverage in combination with a warm and humid climate starting from around 3,500 cal yr BP, only interrupted by a short cooling event. An additional reconstruction of Lake Teletskoye pollen and NPP data by Andreev et al. (2007) for the last 1,000 years shows climatic shifts of the last millennium in a higher resolution. But it needs to be considered that much higher precipitation and a markedly higher proportion of arboreal taxa characterize this Russian Altai site. Tian et al. (2013) presented a high-resolution multiproxy record from Khuisiin Nuur in the southeastern Khangai Mountains (Central Mongolia). Palynological reconstructions revealed generally lower percentages of arboreal taxa compared to the Mongolian Altai records for the last 1,200 years. At this site, a forest maximum occurred from 1,000 to $475 \mathrm{cal} \mathrm{yr} \mathrm{BP}$, indicating wetter and warmer conditions than in previous and subsequent times. Differences to our data can be explained by different moisture sources. Dayan Nuur area in the Altai Mountains is only dominated by the westerlies, whereas the Khangai Mountains were also under the influence of the Asian summer monsoon from the East. Palynological data from the Chinese Altai Mountains show an opposite climatic trend. At Lake Wulungu, northern Xinjiang, climate changed from colder and more humid conditions $(4,200-560 \mathrm{cal} \mathrm{yr} \mathrm{BP})$ to drier, but even colder (560 cal yr BP to present) (Liu et al., 2008). These results are partly supported by Huang et al. (2018). Their review of 14 long-term records from the Altai Mountains (e.g. Lake Kanas) reveals more humid and warm conditions at the end of the mid-Holocene and a forest decline in the late Holocene. The significance of human impact on the environment is discussed, but a climatic cooling with an increase in humidity from 4,000 cal yr BP to today is considered as the driving factor for Central Asian environmental change rather than the influence of nomadic people. 


\section{Conclusions}

This paper aimed to examine the environmental variations in the 'Altai Tavan Bogd' National Park, Mongolian Altai, over the last 4,375 years with special regard to the extent of natural and anthropogenic influences on the environmental changes since the end of the mid-Holocene of Central Asia. Markedly larger and denser forest areas with Larix sibirica, Pinus sibirica and Picea obovata occurred in the study area and were strongly reduced after 1,040 cal yr BP. First evidence of a change from hunters and gatherers to nomadic activities can be inferred from the Sordaria- and Sporormiella-type coprophilous fungi in the NPP record at around 2,350 cal yr BP. Intensified local grazing activities might have caused the intense forest reduction and steppe expansion at around 1,040 cal yr BP. Since $15 \mathrm{cal}$ yr BP, Larix sibirica forest recovers to some degree, probably as a result of a decline in livestock population or permafrost degradation due to global climate warming. This multi-proxy approach shows significant vegetation and environmental changes at around 1,040 cal yr BP in all pollen, non-pollen palynomorph, charcoal, diatom and XRF-scanning records. Those changes lead to contradictive reconstructions of climate signals under concurrent occupation of the area by nomads. Hence, small-scale variations, regional climatic trends and the local human settlement may have a greater impact on the 'Altai Tavan Bogd' study area than large-scale climate patterns during approximately the last 1,000 years. For a more detailed reconstruction of the anthropogenic impact on the environment during the various settlement periods in Mongolia, further investigations at a higher spatial scale and temporal resolution are necessary. In particular, in these settings NPPs are a valuable tool to show human impact on forest-steppe ecosystems, which has rarely been studied in Central Asia.

\section{Acknowledgements}

We are grateful for the assistance of the team at the Mongolian State University of Education, Ulaanbaatar (Mongolia), and D. Saindovdon for their help in the fieldwork. We thank Katharina Schildt and Jutta Groll for polishing the English and Sandra Brügger for fruitful discussions of Mongolian palaeoecology. We acknowledge Dr. Lyudmila Shumilovskikh for her valuable help in identifying and interpreting non-pollen palynomorphs and we thank an anonymous reviewer for constructive remarks that substantially improved the manuscript. The research was funded by the DFG, German Science Foundation, (BE 2116/28-1) and carried out at University of Goettingen, Germany. 


\section{Supplementary materials 1}

Descriptions of selected unknown NPP types:

Tr5-2B-A: (Plate I, A)

probably fruiting body of fungus, roundish, multicellular, cells irregularly shaped, thin walled, perithecium approx. $50 \times 45 \mu \mathrm{m}$, beige.

Tr5-2B-C: (Plate I, B)

probably fruiting body of fungus, roundish with hole in centrum, multicellular, cells irregularly shaped, thick-walled, perithecium approx. 135x $90 \mu \mathrm{m}$, dark brown.

Tr5-2B-1: (Plate I, C)

probably fungal spore, assemblage of 8-10 loosely connected cells (possibly ascospores), pale, approx. 20 x $15 \mu \mathrm{m}$, psilate, thick-walled, no apertures observed.

D3L6-36: (Plate I, D)

probably fungal spore, ascospores ellipsoid to rectangular, slightly curved, unequally 4-celled, pale, approx. $30 \times 12 \mu \mathrm{m}$, psilate, thick-walled, constricted at the septa, slit-shaped aperture.

D3L6-77: (Plate I, F)

probably fungal spore, ascospores ellipsoid to rectangular, equally 2-celled, dark brown, approx. 32 x $20 \mu \mathrm{m}$, verrucate, thin-walled, constricted at the septum, septum thick, slit-shaped apertures.

Tr5-2B-11: (Plate I, H)

probably fungal spore, prolate cylindric form, composed of numerous asymmetric cells, transversal and longitudinal septa, irregular pattern, approx. 80 x $20 \mu \mathrm{m}$, cells up to $20 \times 15 \mu \mathrm{m}$, psilate, thinwalled, cells with pores and anulus.

D3L6-1: (Plate I, J)

probably fungal spore, ascospore ellipsoid, 1-celled, dark brown, approx. $28 \times 22 \mu \mathrm{m}$, psilate, thickwalled, no apertures visible.

D3L6-34: (Plate I, L)

probably fungal spore, assemblage of 9 irregular connected cells, irregular septa, middle-brown, approx. 40 x $25 \mu \mathrm{m}$, cells up to $10 \times 10 \mu \mathrm{m}$, psilate, thick-walled, no apertures observed.

D3L6-21 (Plate I, E)

probably microfossil, hyaline, approx. $20 \times 10 \mu \mathrm{m}$, transparent to slightly yellow, 8-12 acanthaceous protuberances, protuberances $2-3 \mu \mathrm{m}$.

D3L6-49: (Plate I, G)

probably egg of Arthropoda species, spherical, yellow to brownish, approx. 90 x $90 \mu \mathrm{m}$, distinct scabrate ornamentation, thick-walled.

D3L6-65: (Plate I, I) 
probably cocoon of arthropoda species, oval cylindric form with rounded ends, equilateral, 3-celled each side, separated by thin septum, dark brown, approx. 50 x $40 \mu \mathrm{m}$, psilate to scabrate, open each end.

\section{D3L6-56 (Plate I, K)}

trilete spore, probably fern, yellow, approx. 70 x $55 \mu \mathrm{m}$, surface covered with tubercles, trilete scar indistinct.

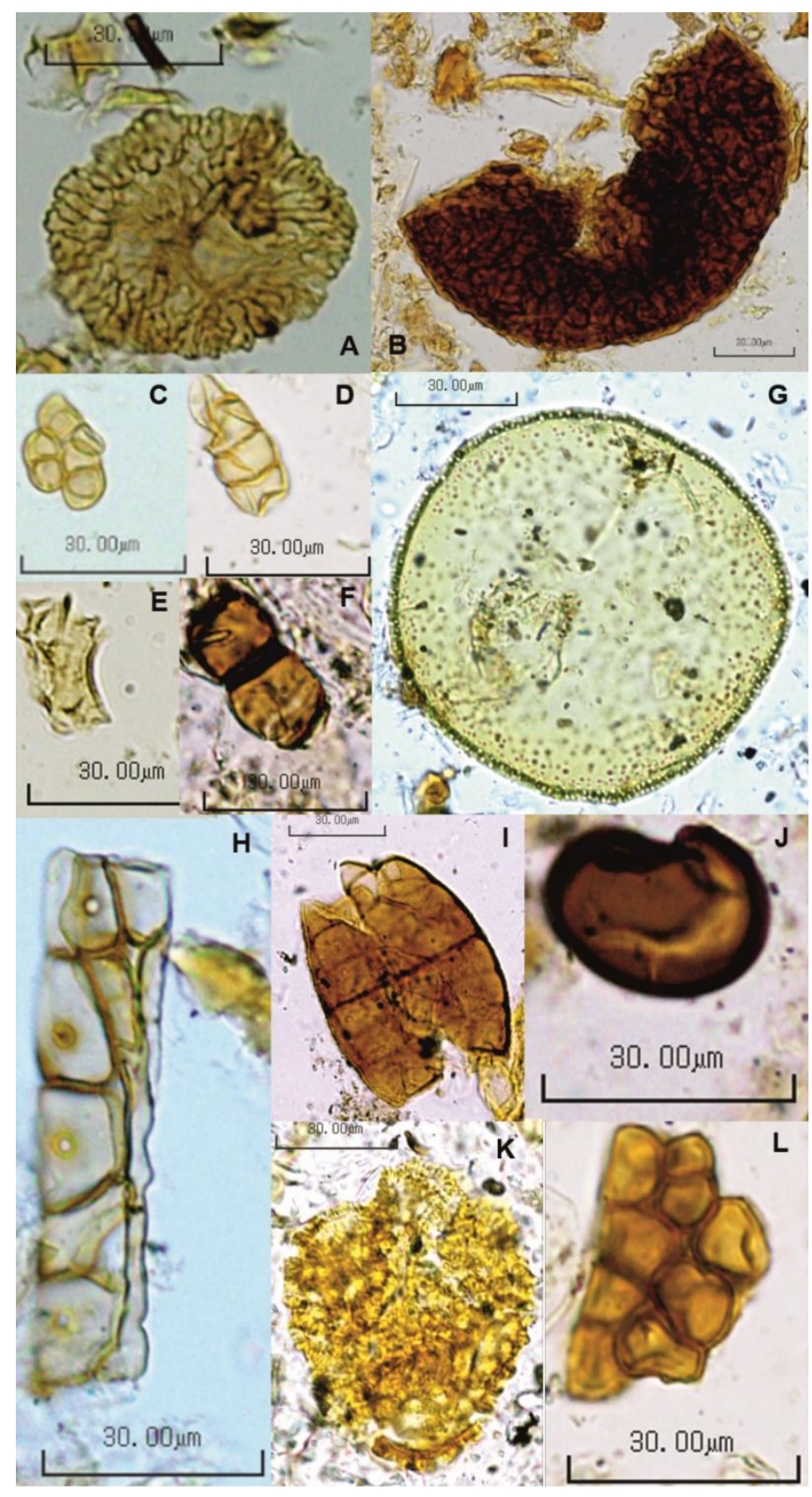

Fig. 3.9. Photos of selected unknown NPP types. A: Tr5-2B-A, probably fruiting body, fungi, B: Tr5-2B-C, probably fruiting body, fungi, C: Tr5-2B-1, probably fungi, D: D3L6-36, probably fungi, E: D3L6-21, probably microfossil, F: D3L6-77, probably fungi, G: D3L6-49, probably animal remain, H: Tr5-2B-11, probably fungi, I: D3L6-65, probably animal remain, J: D3L6-1, probably fungi, K: D3L6-56, probably plant spore, L: D3L6-34, probably fungi. 


\title{
Chapter 4:
}

Manuscript 3

\section{Decadal high-resolution multi-proxy analysis to reconstruct natural and human-induced environmental changes over the last 1,350 cal yr BP in the Altai Tavan Bogd National Park, western Mongolia}

\author{
JULIA UnKELBACH ${ }^{1}$, KAORU KASHIMA ${ }^{2}$, GAADAN PUNSALPAAMUU ${ }^{3}$, LYUDMILA \\ SHUMILOVSKIKH $^{1}$, HERMANN BEHLING ${ }^{1}$
}

\footnotetext{
${ }^{1}$ Department of Palynology and Climate Dynamics, Albrecht-von-Haller Institute for Plant Sciences, University of Goettingen, Untere Karspüle 2, 37073 Goettingen, Germany

${ }^{2}$ Department of Earth and Planetary Sciences, Kyushu University, 744 Motooka, Nishi-ku, Fukuoka 819-0395, Japan

${ }^{3}$ Department of Biology, Mongolian State University of Education, Baga Toiruu-14, 210648 Ulaanbaatar, Mongolia
}

Published in:

The Holocene

DOI https://doi.org/10.1177/0959683620908662 


\begin{abstract}
The 'Altai Tavan Bogd' National Park in the north-western part of the Mongolian Altai, Central Asia, is located in a forest-steppe ecosystem. It occurs under the influence of extreme continental and montane climate and is sensitive to natural and anthropogenic impacts. High-resolution $(<20$ years per sample) multi-proxy data of pollen, non-pollen palynomorphs (NPPs), macro-charcoal, diatoms, and XRF scanning from radiocarbon-dated lacustrine sediments reveal various environmental changes and the impact of different settlement periods for the late-Holocene. From 1,350 to $820 \mathrm{cal}$ yr BP (AD 600-1130), the distribution of grass steppe indicates a climate similar to present-day conditions. Rapid improvements of climatic conditions (e.g. increased rainfall events) possibly favored a recovery of forest-steppe encouraging nomadic movements into alpine areas. In the period from 820 to $400 \mathrm{cal}$ yr BP (AD 1130-1550), the decline of forested areas suggests an increasingly drier and possibly colder climate. Some political shifts during the Mongol Empire (744-582 cal yr BP; AD 1206-1368) favored variations in nomadic grazing habits. After $400 \mathrm{cal} \mathrm{yr}$ BP (AD 1550), moisture and temperature increased slightly, and from ca. 40 cal yr BP (AD 1910) to present, annual temperature continued to increase more markedly favoring an additional water availability due to permafrost degradation. Diatom data suggest several intervals of increased water availability in all periods which might have caused erosion due to heavier rainfall events or increased snow melt. Immediately after most of these high-water intervals, NPP data reveal periods of increased grazing activities in the area.
\end{abstract}

\title{
Introduction
}

Vegetation and climate change in Central Asia have received considerable attention over the last few years (e.g. Herzschuh et al., 2009; Huang et al., 2018; Klinge and Sauer, 2019; Rudaya et al., 2016, 2009; Tarasov et al., 2013; Zhang and Feng, 2018), but the extent of human impact on the environment during the mid- and late Holocene or by forced changes in human practices due to climate change have rarely been discussed in this context (Bruegger et al., 2018; Rudaya et al., 2009). Some palynological records (e.g. Rudaya et al., 2008; Tarasov et al., 2000; Zhang and Feng, 2018) are not taking any account of anthropogenic influence, focusing only on general climatic trends. However, the human-environment relationship has been described by Fernández-Giménez et al. (2017) for the last 30 years by a review of vegetation and cultural changes for Mongolia and adjacent areas, by Pederson et al. (2014) for Central Mongolia at the time of the Mongol Empire (744-582 cal yr BP), and by Lehmkuhl et al. (2011) during the last 2,300 years in the Orkhon valley (Central Mongolia). Other available archeological studies (e.g. Holcombe, 2014; Kradin, 2005; Park et al., 2017; Schmidt and Seguchi, 2016) focus on population and origin history, technologies, rise of power, or burial rituals, but only very little is known about nomadic herding and moving practices 
before modern times. Humans have always been dependent on developing strategies in adaptation to changing environments. This is of particular importance in Mongolia, because its economy is still notably reliant on pastoralism and the availability of natural resources (Lkhagvadorj et al., 2013; Ykhanbai et al., 2004). Hence, nomadic pastoralists have developed strategies for economic and environmentally friendly herding over millennia (Chlachula, 2018). Even though nomads reduce their impact on the environment to bare necessities, the forest sustains damage by trampling saplings and tree-logging (Khishigjargal et al., 2013). Especially the forest-steppe ecosystems of Central Asia are strongly dependent on moisture and temperature and sensitive to natural and anthropo-genicinduced changes (e.g. D’Arrigo et al., 2000; Gunin et al., 1999; Miehe et al., 2009). Our study area in the Altai Tavan Bogd National Park (Fig. 4.1), Mongolian Altai Mountains, is a representative location to investigate vegetation responses to environmental changes as well as human impact. This remote mountain area (2,000-2,500 $\mathrm{m}$ a.s.l.) is inhabited by nomadic tribes (Afanasievo) since the middle Bronze Age (e.g. Kovalev and Erdenebaatar, 2009; Vadetskaya, 1986), who are dependent on natural resources to present-day. Hence, the work presented here is an enhancement of other midto late Holocene reconstructions from Dayan Nuur region (Unkelbach et al., 2018, 2019). Both previous studies reveal a forest decline since $2,610 \mathrm{cal}$ yr BP (core G2-A, upper forest boundary) and 1,040 cal yr BP (core D3L6, lower forest boundary), respectively. These vegetation changes are attributed to increased anthropogenic impact rather than climate change. Building on this, we conduct a decennial-scale multi-proxy analysis of pollen, spores, non-pollen palynomorph (NPP), charcoal, diatoms, and XRF-scanning data from another lake core to attain a more detailed insight into the human-climate-vegetation dynamics in the 'Altai Tavan Bogd' National Park in this paper. Based on the high-resolution reconstructions of forest-steppe fire, lake level, and erosion dynamics, we aim to quantify an extent of natural and anthropogenic impacts on the environment. We want to gain a better understanding of the driving factors for herding and grazing in this remote area, and therefore, address the following questions: (1) Did human occupation of the area have a significant impact on vegetation changes? and (2) What are the natural or socio-political drivers for changes in herding and grazing activities in the area since 1,350 cal yr BP?

\section{Study area}

\section{Environmental setting}

The Altai Mountains (Fig. 4.1), an active intraplate and intracontinental orogen, are subdivided into the Russian Altai in the northern and western part, the Chinese Altai in the south, and the Mongolian Altai in the eastern part. The Mongolian Altai borders the Gobi Altai in the southeast and the Valley of Great Lakes in the northeast and east (Lehmkuhl et al., 2016). The Tavan Bogd peak, 4,370 m 
a.s.l., is the highest elevation in the area. The mountain massifs are covered by bare rock debris and glaciers in higher altitudes. In the area, discontinuous permafrost occurs in the alluvial plains in the basins, in peats, and in the periglacial belt of the high mountains. In the mountain forest-steppe belt permafrost occurs in forest areas on north-facing slopes, whereas it is absent on the south-facing slopes with steppe vegetation (Klinge et al., 2017). Because of the huge distance to the Indian, Arctic, and Pacific Oceans as moisture sources and these specific topographic conditions, the Mongolian Altai is characterized by extreme continental climate (Andreev et al., 2007). The westernmost ranges of the Altai Mountains capture the wet air masses transported by the westerlies.

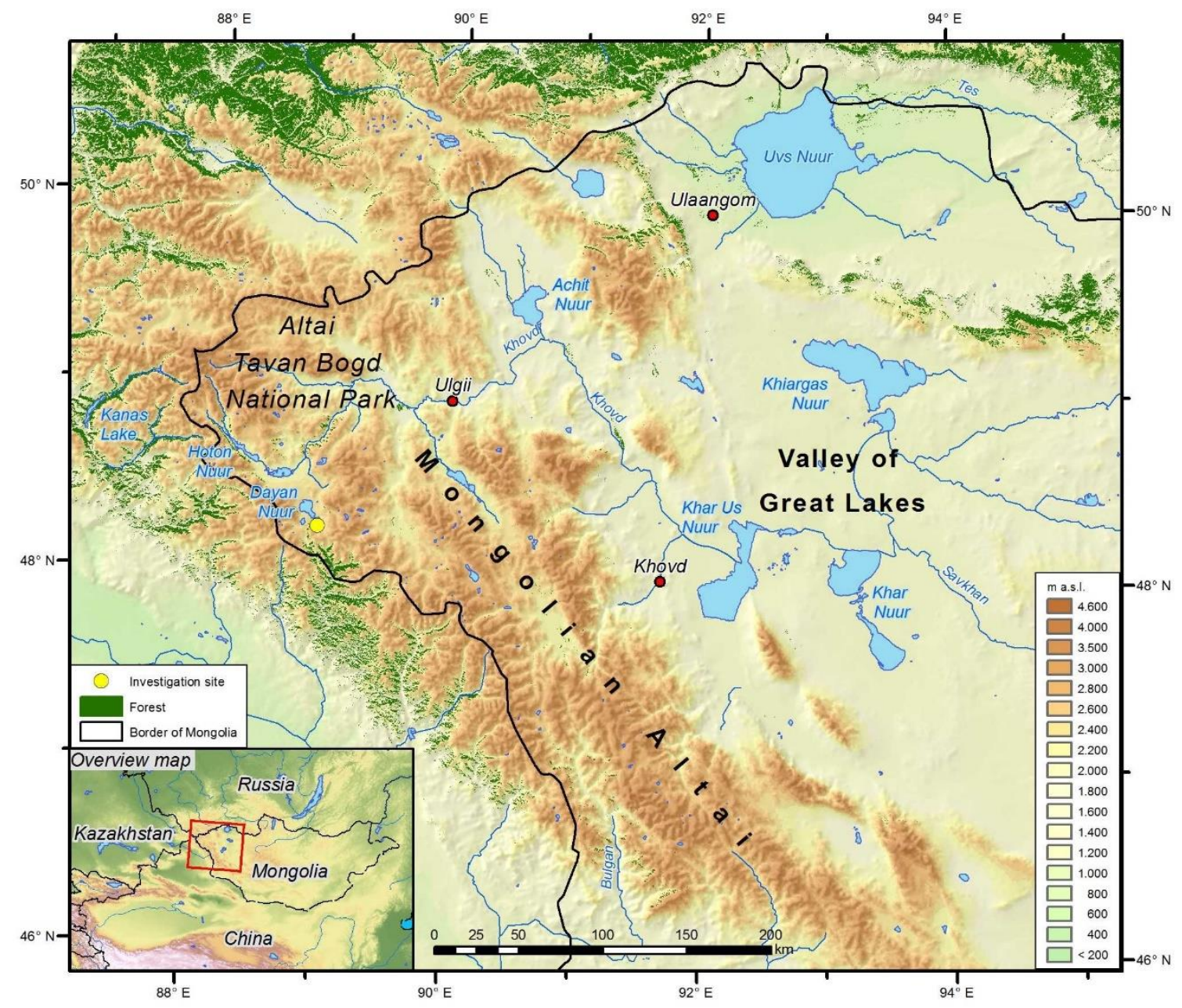

Fig. 4.1 Detailed map showing the location of the 'Altai Tavan Bogd' National Park within Central Asia (overview map) and the location of the coring site (yellow dot). The DEM is based on SRTM. Projection: UTM Zone 46. Forest distribution (green): modified from Klinge et al. (2018).

Whereas the Russian Altai receives more than $800 \mathrm{~mm}$ annual precipitation, in the southeast the rain shadow effect causes a reduction to $300 \mathrm{~mm}$ and to $50 \mathrm{~mm}$ in the Valley of the Great Lakes. In the city of Ulgii, about $1,700 \mathrm{~m}$ a.s.l., the mean annual temperature is $0.3^{\circ} \mathrm{C}$ and the annual precipitation 
averages $114 \mathrm{~mm}$. Monthly average temperatures range from $-16.8^{\circ} \mathrm{C}$ in January to $16.4^{\circ} \mathrm{C}$ in July (AM Online Projects, 2019). During the short summer season from June to August, $70-80 \%$ of the rainfall occurs.

In the Mongolian Altai elevation, temperature and precipitation are the driving factors determining the vegetation composition and distribution. Precipitation determines the latitudinal zonation of plant communities, whereas elevation induces the vertical (or altitudinal) zonation of vegetation patterns (Gunin et al., 1999). The north-facing slopes in the western parts of the Mongolian Altai are dominated by alpine meadow steppes, forb grass steppe, dry mountain steppe, and smaller forested areas (e.g. Hilbig, 1995; Beket, 2009). On south-facing slopes, desert steppes are found at the mountain base and trees are absent (Gunin et al., 1999). In the study area, 2,000-2,500 $\mathrm{m}$ a.s.l., vegetation is mainly composed of dry and meadow steppe dominated by Poaceae, Cyperaceae, Chenopodiaceae, and Artemisia. In short distance to the lake open forest stands of Larix sibirica, with shrubs of Betula and Juniperus occur on the north-facing mountain slopes.

\section{Settlement and grazing history of the Mongolian Altai}

The area of the current state of Mongolia has been inhabited by humans since the Upper Paleolithic (46,000-12,000 cal yr BP) (Tumen, 2006). Until the early/middle Bronze Age (before 4,450 cal yr BP), gatherer-hunter groups subsisted on forest and steppe. During middle Bronze Age, animal husbandry and mobile pastoralism developed within the Eurasian steppe and were introduced to Mongolian territory by the Afanasievo culture around 4,700 cal yr BP. The Afanasievo were the first known culture herding sheep and goats, and using copper (Dirksen et al., 2007; Frachetti, 2012). Organizational forms of nomadic cultures and pastoral activities adjusted and stabilized throughout terminal Bronze Age (2,650-2,350 cal yr BP) and under changing Empires of the Iron Age (2,350744 cal yr BP). Herding traditions of Turkic and Chinese origin favored transitions to mobile pastoralism. Herders adapted to grazing patterns and summer/winter shelters (Fernández-Giménez, 1999; Fernández-Giménez et al., 2017). During the Mongol Empire (744-582 cal yr BP), Mongol territory expanded noticeably, increasing the number of livestock. From that time on, groups of herders were assigned to fixed territories including the possibility of wide-ranging seasonal migrations (Fernández-Giménez et al., 2017). In general, these herding organizations persisted until the Socialist Government of the Soviet Union established their centrally planned economy in Mongolia (AD 1924-1990). They only allowed herding of state-owned livestock, and nomadic movements were restricted which led to a sharp decline in livestock population due to slaughter and later a return to one-species herding (Fernández-Giménez et al., 2017; Johnson et al., 2006). Under democracy (after AD 1990), state-owned livestock was privatized leading to a short-term increase in animal population. The establishment of a market economy in Mongolia since AD 2000 favors a rise 
in mining and service industries and a general decline in the number of nomadic herders (FernándezGiménez, 1999; Hirano and Batbileg, 2013; Johnson et al., 2006).

\section{Material and methods}

The coring site $\left(48^{\circ} 15^{\prime} 27.13^{\prime \prime} \mathrm{N}, 88^{\circ} 49^{\prime} 59.32^{\prime \prime} \mathrm{E} ; 2312 \mathrm{~m}\right.$ a.s.1.) is a small round freshwater lake of $20 \mathrm{~m}$ in diameter and $2.7 \mathrm{~m}$ of maximum water depth, located in the 'Altai Tavan Bogd' National Park (Fig. 4.1). Lake D1L1 is situated in a depression below the forest belt without any river inflow or outflow, sur-rounded by other small lakes. Three laminated sections were obtained by a Russian Corer in the center of the lake in 2016 using a wooden platform on two rubber boats. The collected core starts from the rocky lake base, is measured to $135 \mathrm{~cm}$, and could be recovered in three overlapping 50-cm long sections. The core was transported to the University of Gottingen and stored under dark conditions at $4{ }^{\circ} \mathrm{C}$ for further analysis. Five bulk samples of approx. $2 \mathrm{~cm}^{3}$ were obtained for AMS radiocarbon dating (Table 4.1) along the core based on significant changes in lithology or pollen composition. Radiocarbon samples were analyzed at Poznan Radiocarbon Laboratory, Poland. An age-depth model was performed with BACON version 2.2 (Blaauw and Christen, 2011) in RStudio version 3.4.4 (RStudio Team, 2019) using standard settings and the Northern Hemisphere terrestrial calibration curve IntCal13 by Reimer et al. (2013). Core D1L1 was sampled $\left(0.5 \mathrm{~cm}^{3}\right)$ for palynological analysis at 2-cm intervals along the core (68 subsamples). Each subsample is $1-\mathrm{cm}$ thick. Chemical preparation included $10 \% \mathrm{HCl}, 10 \% \mathrm{KOH}, 40 \% \mathrm{HF}$, and acetolysis (Faegri and Iversen, 1989). Spores of Lycopodium clavatum were added as an exotic marker to calculate concentrations $\left(\mathrm{grains} / \mathrm{cm}^{3}\right.$ ) and influx (grains $/ \mathrm{cm}^{2} / \mathrm{yr}$ ). To reduce overly fine and coarse material, all subsamples were sieved twice (10- $\mu \mathrm{m}$ and $120-\mu \mathrm{m}$ mesh width). Pollen and non-pollen palynomorph (NPP) analyses were carried out in the Department of Palynology and Climate Dynamics at the University of Goettingen. Pollen and spores were identified based on relevant literature (Beug, 2004; Demske et al., 2013) and the reference collection of Mongolian pollen and spores of the Department. All subsamples were counted to a pollen sum of 300 . The pollen sum includes trees, shrubs, and herbaceous plants, while aquatic plants, moss, and fern spores were excluded. For further investigations, pollen ratios (AP/NAP, Artemisia/Chenopodiaceae and Artemisia/Cyperaceae) were calculated as moisture indicators (Herzschuh, 2007; Zhao et al., 2012). NPPs were identified according to Van Geel (1978, 2001), Van Geel et al. (2011), Shumilovskikh et al. (2015), and the NPP database (Shumilovskikh, 2018). They were counted with special regard to coprophilous fungi, which serve as an indirect indicator for the presence of large herbivores (e.g. Burney et al., 2003; Raper and Bush, 2009). NPP percentages are presented in relation to the terrestrial pollen sum of $100 \%$. 
Subsamples for diatom analysis were taken at the same 2-cm intervals as the palynological samples. About $10 \mathrm{mg}$ of material was taken from each sample and stirred with distilled water to avoid destruction of diatom valves and chrysophyte cysts. Slides were dried on a heater at $70^{\circ} \mathrm{C}$. The identification of diatom species is based on Krammer and Lange-Bertalot (1986, 1988, 1991a, 1991b) and Watanabe (2005). According to their ecological preferences, diatoms were classified into (1) epiphytic, (2) planktonic, (3) benthic, and (4) saline.

Tab. 4.1 Uncalibrated and calibrated radiocarbon dates of core D1L1. Calibration was performed using the Northern Hemisphere terrestrial calibration curve IntCal13 (Reimer et al., 2013).

\begin{tabular}{ccccc}
$\begin{array}{c}\text { Laboratory } \\
\text { Code }\end{array}$ & $\begin{array}{c}\text { Depth } \\
(\mathbf{c m})\end{array}$ & $\begin{array}{c}\text { Type of } \\
\text { Material }\end{array}$ & C $^{\mathbf{1 4}}$ Age (yr BP) & $\begin{array}{c}\text { calibrated C } \\
\text { (cal BP +/- 16) }\end{array}$ \\
\hline \hline Poz-93767 & 51 & Bulk sediment & $405 \pm 30$ & $465 \pm 30$ \\
\hline Poz-101220 & 82 & Bulk sediment & $830 \pm 30$ & $736 \pm 30$ \\
\hline Poz-85951 & 107 & Bulk sediment & $975 \pm 30$ & $894 \pm 30$ \\
\hline Poz-101221 & 118 & Bulk sediment & $1060 \pm 30$ & $973 \pm 30$ \\
\hline Poz-93933 & 135 & Bulk sediment & $1585 \pm 30$ & $1353 \pm 30$
\end{tabular}

Chrysophyte cysts were not identified on species level to avoid classification mistakes. All valves of each sample were counted. Based on that, diatom percentages, concentrations, and influx were calculated for further interpretation.

XRF scanning was performed using an ITRAX XRF core scanner, COX analytical systems (Croudace et al., 2006), at Bremen University, Germany. All three sediment core sections were scanned to detect major and trace elements with a Cr-tube using a 0.5-mm step size and a 10-s count time for each step. Settings of the tube were set to $30-\mathrm{kV}$ voltage and 50-mA current for all sections. Semi-quantitative element data were obtained for Si, S, K, Ca, Ti, Mn, Fe, Br, Rb, Sr, and Zr. XRFscanning data were normalized by coh-radiation to reduce matrix effects.

For macro-charcoal analysis, subsamples $\left(0.5 \mathrm{~cm}^{3}\right)$ were taken in evenly spaced $0.5-\mathrm{cm}$ intervals along the core. All 271 sub-samples were processed using $10 \% \mathrm{KOH}$ and $4 \% \mathrm{H}_{2} \mathrm{O}_{2}$ following the method of Stevenson and Haberle (2005). Wet sieving was conducted to reduce particle fragmentation. Particles $(>125 \mu \mathrm{m})$ were counted under a binocular dissecting microscope and divided into four taxonomic groups (wood, leaf, grass, others) as presented in Unkelbach et al. (2018). The results are expressed in terms of the total number of charred particles per subsample. Macro-charcoal concentration per $\mathrm{cm}^{3}$ and influx per $\mathrm{cm}^{2}$ were calculated. In addition, microcharcoal fragments $(>5 \mu \mathrm{m})$ were counted in the same subsamples as pollen, spores, and NPPs for comparison with macro-charcoal results. TILIA and TILIAGRAPH (Grimm, 1991) were used to visualize multi-proxy data. CONISS was performed on the pollen data to calculate pollen zones (PZ) 
by square root transformation of the pollen percentages and a stratigraphically constrained cluster analysis (Grimm, 1987).
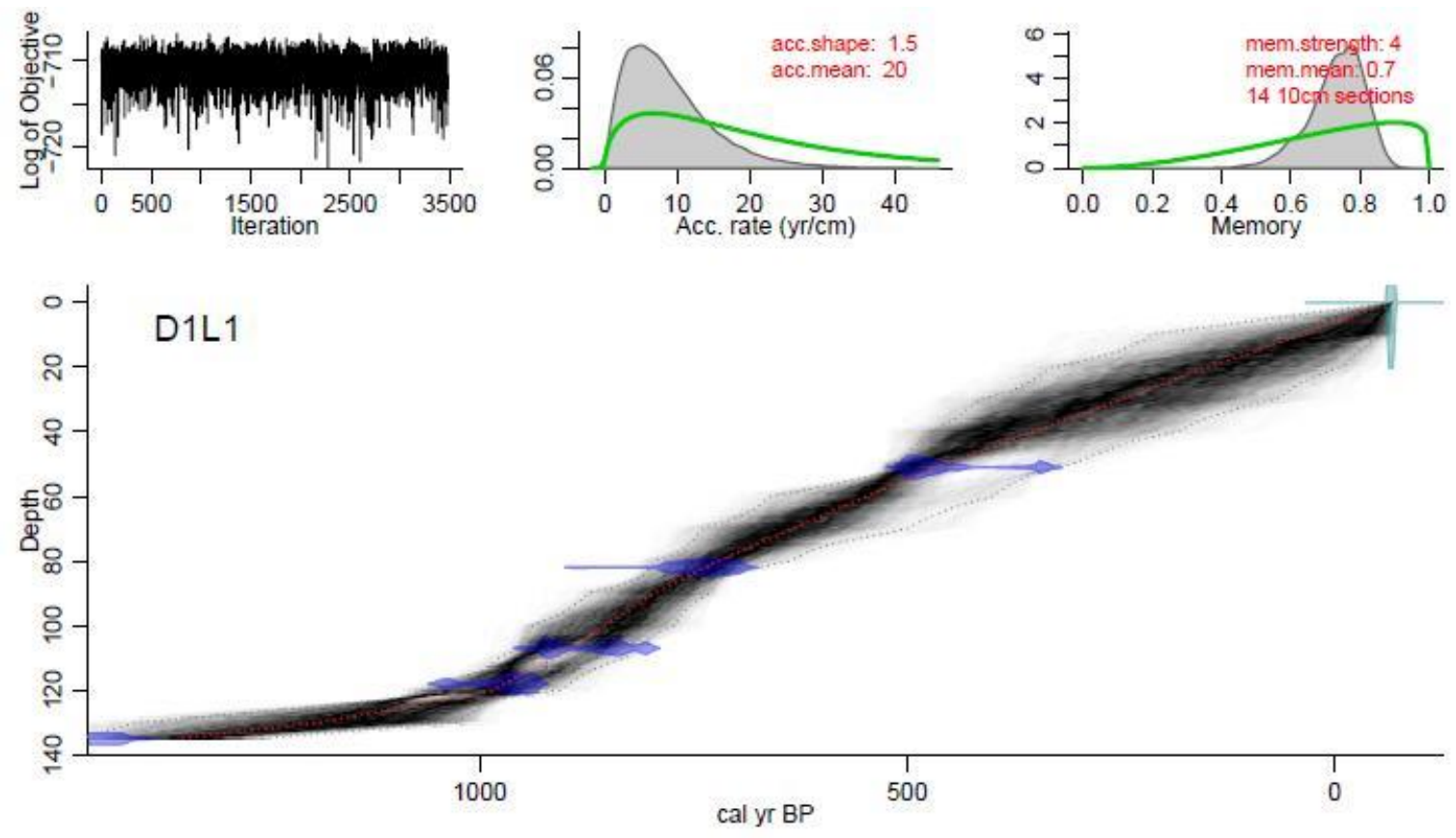

Fig. 4.2 BACON output diagram. Upper figures show the Markov chain Monte Carlo (MCMC) iterations (left), and the prior (green) and posterior (grey) distributions for the accumulation rate (middle) and memory (right). Bottom figure shows the calibrated 14C dates (blue) and the age-depthmodel for lacustrine core D1L1.

\section{Results}

\section{Lithology, chronology and sedimentation rate}

The sediments of core D1L1 can be divided lithologically into five units. The basal sediment layer (135-132 cm) consists of dark brown, sandy organic material (gyttja) above rocky under-ground. The following sediment layer $(132-127 \mathrm{~cm})$ comprises gray sand, poor in organic material. The unit from 127 to $111 \mathrm{~cm}$ is characterized by several dark brown and medium brown sandy organic rich gyttja layers. The adjoining unit $(111-49 \mathrm{~cm})$ consists of laminated layers of either medium and dark brown gyttja or pale white silty sediment. The uppermost unit $(49-0 \mathrm{~cm})$ is characterized by dark brown sandy gyttja layers with several slightly lighter brown laminations. The core base $(135 \mathrm{~cm})$ was calibrated to $1,350 \mathrm{cal} \mathrm{yr}$ BP. The core surface is considered to correspond to the year of field work in 2016. The age-depth model (Fig. 4.2) indicates no gaps in the sediment core. The calculated sedimentation rate is $0.45 \mathrm{~mm} / \mathrm{yr}$ for the lowermost section. For the section from 118 to $107 \mathrm{~cm}$, the model indicates a sedimentation rate of $1.39 \mathrm{~mm} / \mathrm{yr}$. For the section from 107 to $82 \mathrm{~cm}$, the 
sedimentation rate is 1.58 and $1.51 \mathrm{~mm} / \mathrm{yr}$ for the interval between 82 and $51 \mathrm{~cm}$. For the uppermost $51 \mathrm{~cm}$, the sedimentation rate is $0.96 \mathrm{~mm} / \mathrm{yr}$.

\section{Palynological results}

In total, 63 pollen and spore types and 110 NPP could be identified in core D1L1. According to CONISS, the palynological diagram (Appendices B4 and B5) is divided into three local PZs. The pollen record has an average time resolution of 26 years per sample for PZ I, 17 years per sample for PZ II, and 20 years per sample for PZ III. Pollen spectra throughout the diagram are dominated by herbaceous taxa (83-95\%), such as Cyperaceae (7-35\%), Poaceae (12-33\%), Artemisia (8-33\%), and Chenopodiaceae (8-28\%) pollen.

The lowermost PZ I (135-95 cm; 1,350-820 cal yr BP, AD 600-1130) is characterized by relatively high pollen proportions of Larix sibirica (2-6\%). Cyperaceae reveal low proportions (9-28\%) while Poaceae (13-33\%) and Chenopodiaceae percentages (10-28\%) are high. The proportion of aquatic plants is generally low. Only one fern spore occurs at $112 \mathrm{~cm}$. Sordaria occurs frequently, and Sporormiella sporadically starting from 126-cm core depth. In PZ I, the pollen influx is rather low with two marked peaks at 118 and $128 \mathrm{~cm}$. AP/NAP ratio (0.06-0.19) is generally high with only slight variations. Art/Che (0.46-2.58) and Art/Cy (0.33-3.26) ratios vary markedly with maxima at the same depths $(134,124$, and $110 \mathrm{~cm})$.In PZ II (95-45 cm; 820-400 cal yr BP, AD 1130-1550), percentages of Larix sibirica decrease to a minimum (1-3\%). Among the herbaceous taxa Artemisia (11-33\%) and Polygonum persicaria (2-8\%) percentages increase, while Chenopodiaceae $(<12 \%)$ decrease. The distribution of cryophilic species (e.g. Cortusa) is more frequent.

At the beginning of PZ II, there is an increase in the proportion of aquatic plants (2-4\%), but from $64 \mathrm{~cm}$ their percentages decrease $(<2 \%)$. Fern spores are missing. Sporormiella spores are more frequent with a maximum of $11 \%$ at $76 \mathrm{~cm}$. A general increase in pollen concentration and influx is visible. AP/NAP ratio (0.02-0.14) decreases, while both Art/Che (0.89-3.36) and Art/Cy (0.48-2.26) ratios increase.

The uppermost PZ III (45-0 cm; 400 cal yr BP (AD 1550) to present) is featured by an increase of Larix sibirica (up to 4\%). Betula (2-3\%), Pinus, Picea, and Cyperaceae increase, while the proportion of Artemisia shows lower values (8-23\%). Fern and moss spores are more present at the end of this period. Sporormiella (1-4\%) is abundant accompanied by Sordaria. Pollen concentration and influx values tend to be double in PZ III. A gradual increase in the AP/NAP ratio (0.07-0.19) is visible while Art/Che (0.58-3.00) and Art/Cy (0.24-1.72) ratios decrease markedly. 


\section{Diatom results}

Beside chrysophyte cysts, 36 diatom species could be identified in record D1L1. In general, the diatom assemblage is dominated by benthic (22-100\%) and epiphytic (1-68\%) types, while no diatoms were found in the samples from 132 to $128 \mathrm{~cm}$. The diagram can be divided into four diatom zones (DZs) according to visual inspection (Appendix B6). In DZ I (135-99 cm; 1,350-850 cal yr BP, AD 600-1100), epiphytic (up to 68\%) and benthic (up to 85\%) species are abundant, while crysophyte cysts increase. Planktonic species (3-18\%) occur from 120 to $110 \mathrm{~cm}$. The diatom concentration varies from 44 valves to 1224 valves per mg sediment. DZ II $(99-45 \mathrm{~cm}$; 850-400 cal yr BP, AD 1100-1550) is dominated by benthic species (up to 83\%). Epiphytic taxa decrease markedly. Four distinct peaks in the proportions of planktonic species can be observed at 82, 74, 68, and $46 \mathrm{~cm}$, corresponding to maxima in the diatom concentration and influx. In DZ III $(45-15 \mathrm{~cm}$; 400-90 cal yr BP, AD 1550-1860), epiphytic species (10-52\%) increase markedly while benthic species decrease. One peak in planktonic taxa is found at $32 \mathrm{~cm}$. From $27 \mathrm{~cm}$, diatom concentration decreases markedly. DZ IV (15-0 cm; 90 cal yr BP (AD 1860) to present) is dominated by benthic (up to $79 \%$ ) species with a decreased role of epiphytic species (6-37\%). Saline species and Crysophyte cysts decrease. Minor proportions of plank-tonic frustules are observed at 10 and $0 \mathrm{~cm}$. Diatom concentration is stable at around $150-400$ valves per mg sediment.

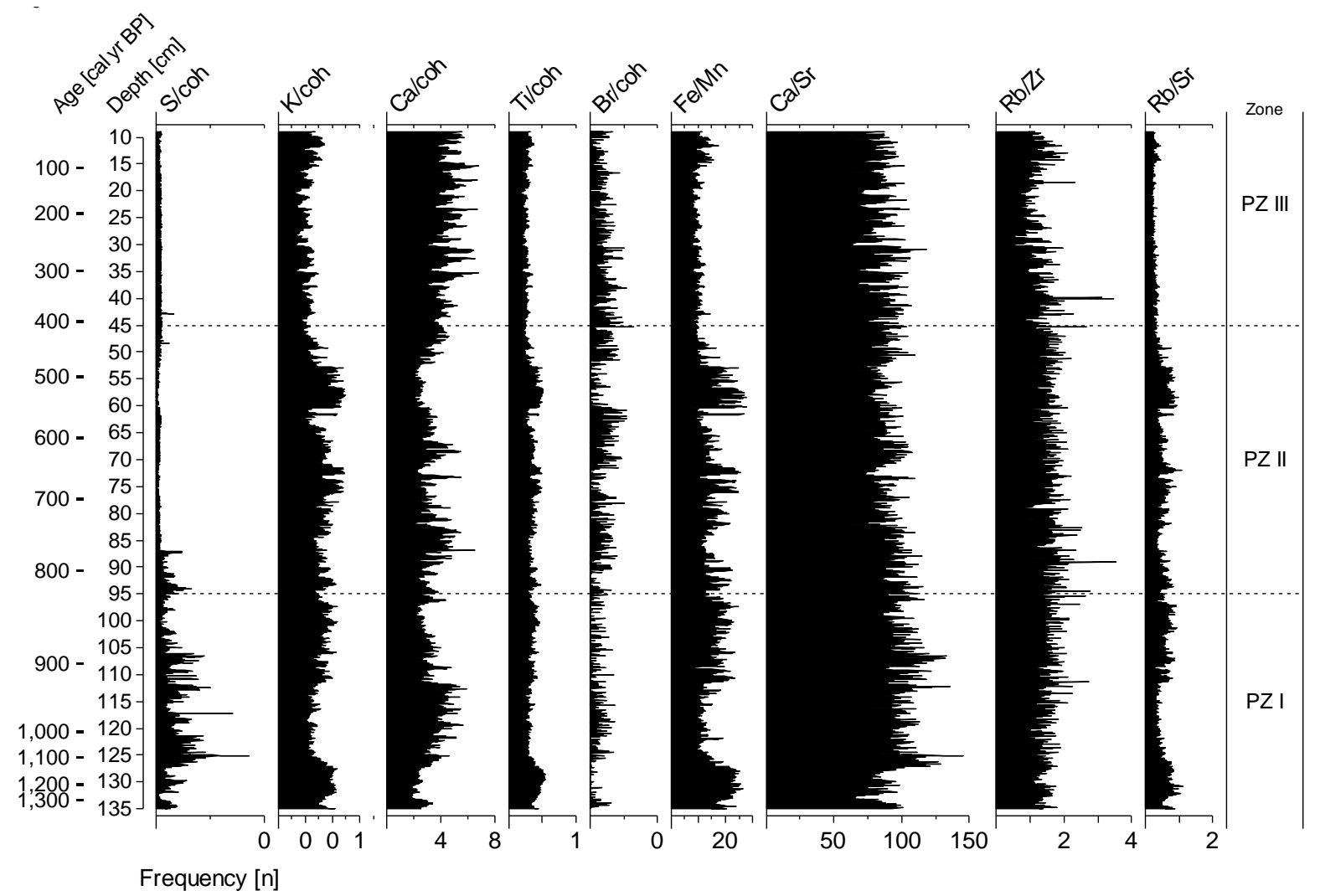

Fig. 4.3 XRF-scanning results of core D1L1. PZ I - III are added from Appendix B4 for comparison. 


\section{XRF-scanning results}

For the upper $9 \mathrm{~cm}$ ( 5 cal yr BP (AD 1945) to present), no XRF data could be obtained due to fluid sediment consistency at the top of the uppermost core section (Fig. 4.3). The potassium (K), titanium (Ti), iron/manganese $(\mathrm{Fe} / \mathrm{Mn})$, and rubidium/strontium $(\mathrm{Rb} / \mathrm{Sr})$ ratio records demonstrate similar trends with maxima at the core base from 132 to $126 \mathrm{~cm}$ and from 62 to $52 \mathrm{~cm}$, intermediate values from 126 to $62 \mathrm{~cm}$, and slightly lower values from $52 \mathrm{~cm}$ to the top. Calcium $(\mathrm{Ca})$, in general, shows an opposite pattern. Ca values have maxima from 126 to $112 \mathrm{~cm}, 87$ to $66 \mathrm{~cm}$, and in the upper 45 $\mathrm{cm}$, whereas Ca decreases to rather low values from 132 to $126 \mathrm{~cm}$ and from 62 to $52 \mathrm{~cm}$. In contrast, the calcium/strontium $(\mathrm{Ca} / \mathrm{Sr})$ ratio shows low values below $126 \mathrm{~cm}$ and stable higher values above. In the core section from 135 to $87 \mathrm{~cm}$, increased values of sulfur (S) with several peaks could be detected while its values decrease to a stable minimum for the upper $87 \mathrm{~cm}$. The bromine $(\mathrm{Br})$ record has higher values between 87 and $62 \mathrm{~cm}$ and for the uppermost $52 \mathrm{~cm}$. Br values are rather low from 135 to $87 \mathrm{~cm}$ and from 62 to $52 \mathrm{~cm}$. The rubidium/zirconium (Rb/Zr) ratio shows steady values with two distinct maxima at 87 and $38 \mathrm{~cm}$.

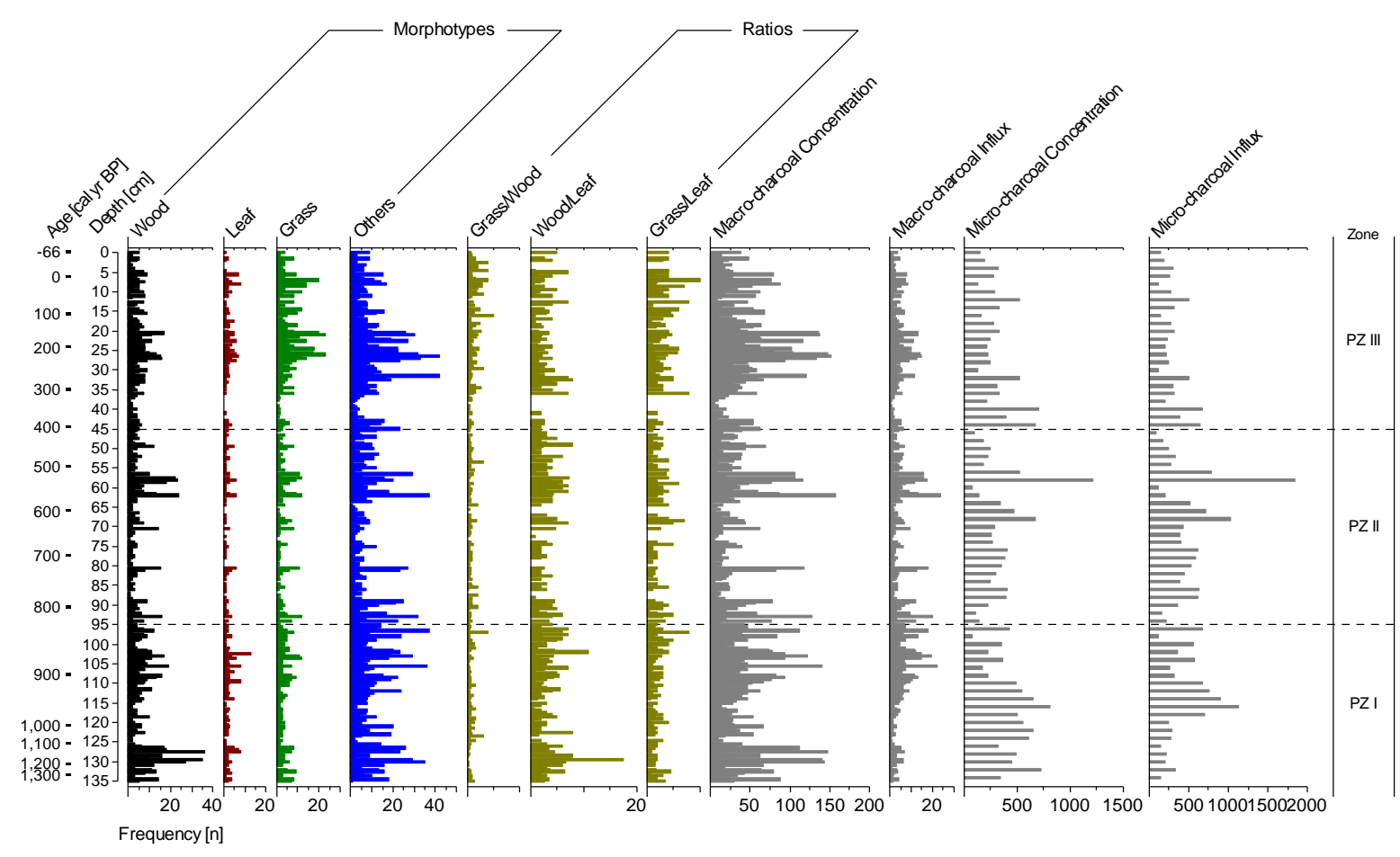

Fig. 4.4 Diagram presenting macro-charcoal and micro charcoal results of core D1L1. Macrocharcoal analysis includes the breakdown of results into different morphotypes, ratios as well as concentration [particles $/ \mathrm{cm}^{3}$ ] and influx [particles $/ \mathrm{cm}^{2} / \mathrm{yr}$ ]. Micro charcoal results are only depicted in terms of concentration [particles $/ \mathrm{cm}^{3}$ ] and influx [particles $/ \mathrm{cm}^{2} / \mathrm{yr}$ ]. 


\section{Charcoal results}

The macro-charcoal record has an average time resolution of 7 years per sample for PZ I, of 4 years for PZ II, and of 5 years per sample for PZ III. Abundant charred material is found in all sub-samples along the record (Fig. 4.4). With respect to the macro-charcoal influx, four peaks (periods of increased fire activity) can be observed: (1) from 112 to $88 \mathrm{~cm}$ (930-780 cal yr BP, AD 1020-1170), (2) from 81 to $80 \mathrm{~cm}(730-720 \mathrm{cal} \mathrm{yr} \mathrm{BP}, \mathrm{AD} 1220-1230)$, (3) from 63 to $57 \mathrm{~cm}(570-520 \mathrm{cal} \mathrm{yr}$ BP, AD 1380-1430), and (4) from 31 to $21 \mathrm{~cm}$ (260-160 cal yr BP, AD 1690-1790). Comparably low charcoal influx is found below $112 \mathrm{~cm}(1,350-930 \mathrm{cal}$ yr BP, AD 600-1020), from 80 to $63 \mathrm{~cm}$ (720-570 cal yr BP, AD 1230-1380), and from 5 to $0 \mathrm{~cm}$ (-10 cal yr BP (AD 1960) to present).In terms of the four different morphotypes, the most abundant charcoal fraction is other charred particles such as rootlets, seeds, mosses, or unidentifiably small material (46\% of macro-charcoal sum). Charred wood material (26\%) occurs more frequently than grass (20\%) and leaf (8\%). In general, trends in these four morphological groups seem to be consistent along the whole record. From the morphotype ratios it can be inferred that charred material shows minor changes in PZ I and PZ II but diversifies slightly in PZ III. The grass/wood and grass/leaf ratios increase in the uppermost period while the wood/leaf ratio shows lower values. The micro-charcoal record (Fig. 4.4) is generally consistent with the macro-charcoal results. In PZ I, the maximum of micro-charcoal influx is from 118 to $110 \mathrm{~cm}$ (970-910 cal yr BP, AD 980-1040). In PZ II, the maximum at $58 \mathrm{~cm}$ (530 cal yr BP, AD 1420) correlates with the macro-charcoal findings. A decrease in micro-charcoal material can be observed in PZ III.

\section{Interpretation and discussion}

\section{Regional vegetation and climate changes}

From 1,350 to $820 \mathrm{cal}$ yr BP (PZ I), the landscape in the study area of the Altai Tavan Bogd National Park was characterized by steppe, mainly composed of grasses, Artemisia and Chenopodiaceae. Close to the study site, the forest was composed of Larix sibirica with open habitat shrubs such as Betula and Juniperus (Appendix B4). Like nowadays, Pinus sibirica and Picea obovata did probably not occur in the forests nearby. Compared with the modern setting, a similar distribution of forest can be inferred. The recon-structed vegetation composition suggests relatively dry but rather warm climatic conditions. A low annual precipitation is inferred. After $820 \mathrm{cal}$ yr BP (PZ II), the decreasing proportions of trees and shrubs suggest an expansion of Artemisia steppe at the cost of Larix forest. The increase in cryophilic (cold steppe) species may also suggest a decrease in temperature whereas dry conditions prevailed. The period from $400 \mathrm{cal}$ yr BP to present (PZ III) is characterized by a slow, gradual recovery of Larix forest and an expansion of the moist steppe, as indicated by the 
higher distribution of Cyperaceae. Both taxa point to an increase in moisture, and steppe expansion to a possible decrease in temperature, leading to down-ward movement of the tree line. These changes correspond to the 'Little Ice Age' (LIA; 420 to 160 cal yr BP; Andreev et al., 2007), which apparently affected the vegetation in the study area. The occurrence of more shrub species such as Betula and Salix as well as ferns and mosses points to moister soil conditions after ca. 60 cal yr BP. We conclude that annual temperature increased favoring permafrost degradation.

\section{Grazing dynamics}

For reconstruction of the grazing activities in the area, we use coprophilous fungal spores Sporormiella and Sordaria-type. The consistent occurrence of coprophilous fungi suggests nomadic settlement close by the study area since the beginning of the recorded period. From 1,350 to $820 \mathrm{cal}$ yr BP (PZ I), Sporormiella and Sordaria-type spores occurred sparsely, indicating a grazing pressure on the vegetation. After 820 cal yr BP (PZ II), coprophilous fungi became more abundant. Especially the increase in the Sporormiella coincides with the decrease of arboreal pollen (e.g. Larix) and the expansion of steppe (Appendix B4). At that time, the number of tree saplings might have been severely reduced due to trampling and grazing by an increased number of animals, or due to treelogging and forest mismanagement which interfered forest recovery (Hauck et al., 2012; Khishigjargal et al., 2013). The distinct maximum in the Sporormiella record at around $690 \mathrm{cal}$ yr BP occurs during the Mongol Empire (744-582 cal yr BP) and might be related to the westward expansion of the Mongol territory. From $400 \mathrm{cal}$ yr BP to present (PZ III), the coprophilous fungi increased further. However, the increasing arboreal pollen percentage suggests that the grazing pressure is compensated by an increasing moisture.

\section{Lake dynamics}

Established DZs are similar to the suggested PZs by CONISS. An additional DZ from 90 cal yr BP to present indicates more prominent changes within the lake's condition than suggested by its surrounding vegetation. The abundance of epiphytic diatom species (Appendix B6) indicates the formation and existence of a shallow freshwater pond from 1,350 to 850 cal yr BP(DZ I). Temporary increases in saline species indicate a rise of electric conductivity (e.g. Navicula cincta and Nitzschia frustulum) in the lake water in these periods as a result of either erosion into the lake or a temporal increase in temperature (Bhateria and Jain, 2016). In the period from 850 to $400 \mathrm{cal} \mathrm{yr}$ BP (DZ II), the benthic-dominated diatom assemblages together with Crysophyte cysts indicate a lower water level. At the beginning of this period (840-740 cal yr BP), a maximum in benthic species Synedra ulna (alkaliphilous, eutrophilous) indicates high $\mathrm{pH}$ values and nutrient richness at that time 
(Whitmore, 1989). From 400 to $90 \mathrm{cal}$ yr BP (DZ III), a shallow pond reformed. The subsequent period from $90 \mathrm{cal}$ yr BP to present (DZ IV) is characterized by an abundance of epiphytic and benthic species indicating the prevalence of the small shallow lake. During this period, higher values of oxygen and $\mathrm{pH}$ as well as a low electric conductivity can be inferred from a distinct increase in some benthic (e.g. Cocconeis placentula and Gomphonema sp.) and a decrease of saline species (e.g. Navicula sp. and Nitzschia sp.). Both favor a eutrophic lake state (Van Dam et al., 1994). Long-term fluctuations in the lake level were interrupted by several short phases of higher lake levels, indicated by distinct peaks in the planktonic species proportion (Appendix B6). These peaks occurred around 980, 920, 720, 620, 580, 410, 280, 200, and $40 \mathrm{cal} \mathrm{yr} \mathrm{BP}$ and over the last 20 years. Planktonic species' abundance correlates with maxima in diatom concentration and influx at all stages. This correspondence demonstrates the temporarily improved conditions of diatom growth during high lake levels. A higher water level might either be caused by an increasing snowfall during winter season, more intense rainfall during summer, or increasing permafrost melting. A long-term precipitation increase is neither supported by the diatom assemblage nor by the vegetation reconstruction from the pollen assemblage (Appendix B4).

At the beginning of the record, the increased amount of S (Fig. 4.3) may indicate a reduced mixing of the lake from 1,350 to $770 \mathrm{cal}$ yr BP (PZ I), probably due to water body stratification. After 770 cal yr BP (PZ II and PZ III), S decreased to a constant minimum pointing to enhanced lake water mixing. The siliciclastic indicators $\mathrm{K}$ and Ti (e.g. Kylander et al., 2011; Unkel et al., 2014) show two periods of elevated erosion from 1,250 to 1,110 cal yr BP and between 570 to $470 \mathrm{cal} \mathrm{yr} \mathrm{BP}$. During both periods, the minerogenic influx into the lake was rather high. Based on the diatom data, the lake level was rather low during both periods excluding an increased precipitation or surface inflow. Probably due to the sparse vegetation cover and generally low precipitation, erosion was caused by aeolian processes. However, $\mathrm{Ca}$ and $\mathrm{Ca} / \mathrm{Sr}$ records show opposite trends. From 1,250 to 1,110 cal yr $\mathrm{BP}$ and from 570 to $470 \mathrm{cal} \mathrm{yr} \mathrm{BP}$, the lower $\mathrm{Ca}$ contents indicate a reduced presence of $\mathrm{Ca}$ carbonates, yet the high $\mathrm{Ca} / \mathrm{Sr}$ ratio suggests an allochthonous source for the whole record. After 400 cal yr BP (PZ III), the influx of allochthonous material decreased according to the reduced $\mathrm{K}$ and $\mathrm{Ti}$ values. Br, an element bound to organic matter (e.g. Kalugin et al., 2013), increases in this period, indicating a sediment composition dominated by autochthonous organic matter under stable climatic conditions. High $\mathrm{Ca}$ values suggest increased precipitation of autochthonous carbonates. Comparing the diatom and XRF data, the results for lake dynamics seem to be complementary. The diatom record suggests more stages of higher lake levels than siliciclastic elements indicate. Erosion processes in the area over the last $1350 \mathrm{cal} \mathrm{yr} \mathrm{BP}$ can be described as a combination of wind (under extremely dry conditions) and water (unusual heavy rainfall and surface runoff) erosion. Both processes might have produced siliciclastic white sediment layers (Fig. 4.5). An increase in moisture 
conditions leading to the development of denser vegetation hinders erosion processes and causes higher lake levels.

\section{Fire dynamics}

Based on the macro-charcoal influx (Fig. 4.4), the fire frequency is in general assumed to be rather low in the study area. However, four periods of increased fire activity occurred in the period from 930 to $160 \mathrm{cal}$ yr BP. With respect to the palynological results (Appendix B4), the first strong fire period (930-780 cal yr BP, PZ I) is linked to the initial period of increased forested areas during the Medieval Warm Period (MWP; 1,030-730 cal yr BP). In many cases fire intensity and frequency in grasslands are dependent on fuel sources, whereas fuel is strongly linked to net primary productivity which is directly dependent on temperature and precipitation (Umbanhowar et al., 2009). In addition, the fire maximum could be attributed to increased human activities during the time of Khaganates (Fig. 4.5) under a warmer and more humid climate that attracted more people to settle in the area. The second fire maximum (730-720 cal yr BP; PZ II) occurred at the end of the MWP during the Mongol Empire. A comparison with the Sporormiella record (Appendix B5) suggests that the same reasons apply for this short period: Improved climatic conditions favored nomadic activities around the study site. At the beginning of the Northern Yuan Dynasty, the third period of increased fire activity (570-520 cal yr BP; PZ II) is found. This period is characterized by a drier and colder climate. An increased formation of dead biomass as a fuel for fire or an increased import of charred material into the lake caused by wind erosion can be inferred as observed by Bruegger et al. (2018) at Tsambagarav glacier (Mongolian Altai Mountains) and Eichler et al. (2011) at Belukha glacier in the Russian Altai. This assumption is supported by the presence of a white erosion layer in the sediment from 62 to $56 \mathrm{~cm}$ and the absence of planktonic diatoms in these core depths (Fig. 4.5). The last period of increased fire activity (260-160 cal yr BP; PZ III) occurred under increasing humidity at the beginning of Qing Dynasty. It is highly likely that a correlation between more attractive pastures in the higher elevations of the Mongolian Altai and increased population has contributed to the higher amount of fire evidence in the study area. Over the last decades (ca. 40 years), nomads still settle in the area, but reduce the use of fire to a minimum to prevent environ-mental destruction (oral communication with locals, 2016).

\section{Discussion}

Our data reveal grazing activities during the entire 1,350 cal yr BP. Based on changing amount in spores of coprophilous fungi, pasture intensity varied through time. In the Mongolian Altai, the extent 
of anthropogenic impact on the environment by pastoral land use over time is influenced by a variety of external factors such as climate, political powers, or social structures (Unkelbach et al., 2019). In the discussion, we present a multi-proxy composite diagram of the core lithology, the most representative proxies for environmental changes, and a compilation of grazing indicators and the settlement history since 1,350 cal yr BP (Fig. 4.5) and discuss an influence of socio-economic and climatic factors on herding activities and pasture.

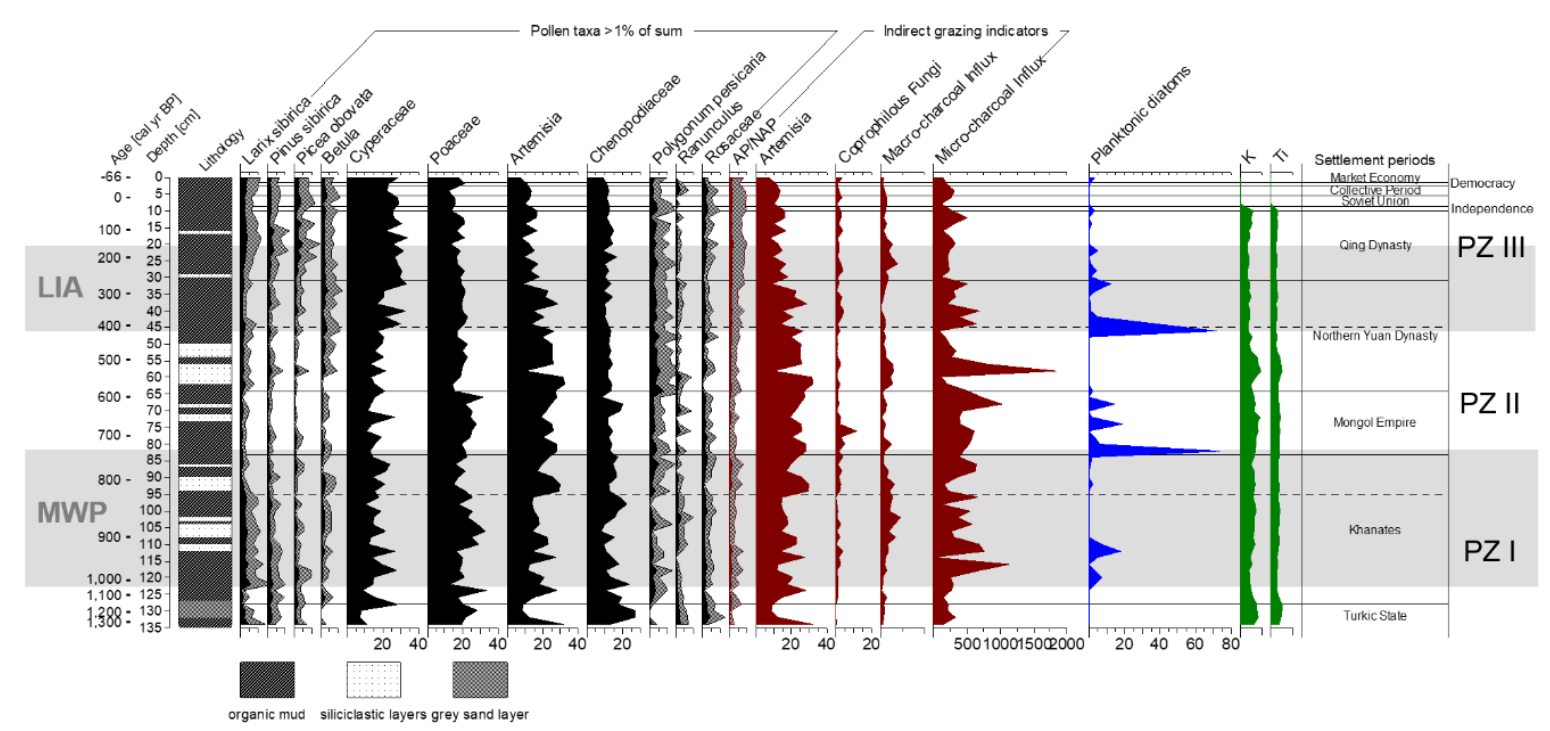

Fig. 4.5 Composite diagram of lithology, selected proxies and settlement periods in the Mongolian Altai. Pollen zones (PZ I-PZ III) are separated by dashed lines, MWP (Medieval Warm Period 1,030$730 \mathrm{cal} \mathrm{yr} \mathrm{BP}$ ) and LIA (Little Ice Age, 420-160 cal yr BP) are highlighted in gray.

\section{Long-term climate and vegetation changes}

Forest-steppe dynamics in the Altai Tavan Bogd National Park during the last 1,350 years correspond in general to the climate changes. The MWP (1,030-730 cal yr BP; Kalugin et al., 2005) is well represented in the assemblage by an increase in Larix and aquatic pollen taxa. After 820 cal yr BP, spread of Artemisia steppe point to dry climate conditions, causing upward movement of the Larix tree line. During the LIA, moist steppe developed leading to the recovery of larch forests close to the site. The D1L1 record is an enhancement of other reconstructions from Dayan Nuur region (Unkelbach et al., 2018, 2019). Both other studies reveal a forest decline due to increased anthropogenic impact since 2,610 cal yr BP (core G2-A, upper forest boundary) and 1,040 cal yr BP (core D3L6, lower forest boundary), respectively. Temporal discrepancies may be attributed to lower sample resolution, elevation differences, or rather local signals. In addition, our findings are in accord with Bruegger et al. (2018) who suggest that moisture is a more important factor for forest preservation than temperature in the Altai Mountains. However, the lack of paleoenvironmental 
multi-proxy studies on a comparable temporal resolution in the area hampers a reliable comparison on the regional scale. Due to the specific geographical situation of our study site in the high mountains, climatic and anthropogenic impacts on the environment can entirely differ from those in several hundred kilometers distance. A review of climatic and environmental developments of western Mongolia by Klinge and Sauer (2019) refers to these strong discrepancies in the reconstructions of different authors based additionally on diverse methodologies and differing potentials of the archives. Huang et al. (2018) dated the beginning of an increased human impact caused by climate warming of the MWP in the Chinese Altai (about $150 \mathrm{~km}$ distant to our study site) to approx. 1,400 cal yr BP. Consistencies regarding the extent of climatic influences on settlement processes, especially during the Mongol Empire, were already noticed. Fernández-Giménez et al. (2017), Pederson et al. (2014), and Lehmkuhl et al. (2011) attribute the expansion of Mongol political power and altering nomadic pastoralism to a period of high rainfall and persistently warm climate during the 13th century, whereas Miehe et al. (2007) see a connection between pronounced human influence and cold-dry climate in the Gobi Altai at that time.

\section{Short-term events and grazing dynamic around the lake}

Coprophilous fungi grow on dung of domesticated and wild animals (e.g. Doveri, 2004). Independent on the dung source, transitions in pastoral intensity might lie in changing climatic conditions. Planktonic diatom data and siliciclastic sediment laminations indicate that these transitions seem to be related to lake water level variations (Fig. 4.5). Based on the correlation of sediment stratigraphy with planktonic diatom and coprophilous fungal spore representations, most of the increases in grazing indicators around the study site occurred after the formation of white sediment layers or temporary lake level rises. The availability of water due to increased soil moisture had positive effects on the vegetation cover and pasture conditions attracting more animals in the area. An increase in soil moisture might have been caused by increased precipitation of snow, and a higher accumulation of meltwater during summer or a decrease in temperature which would have decreased the evapotranspiration pressure. Similar results were recently described for the early Holocene in northeastern Europe. Stivrins et al. (2019) demonstrated increase in large herbivore density during relatively stable climatic and environmental conditions, suggesting that herbivores did not constantly live at high densities around one lake but rather were dynamic and moved/migrated according to their needs. In case of Mongolia, nomad herding practices request an adaptation to the local environment, what consequently implies a selection of pasture locations. The correlation applies to all settlement periods from Khanates to Qing Dynasty (1,150-40 cal yr BP) and during Market Economy ( -50 cal yr BP to present), in which short-term climatic variations occur. Over the last $1,350 \mathrm{cal} y \mathrm{BP}$, nomadic herding and grazing practices including the increase in number of livestock, 
grazing different pastures, and moving to different areas did often change in accordance with natural events. Lake level changes reflect the humidity conditions in the region. Humidity is a major influencing factor for pasture conditions, to which changes in anthropogenic impact seem to be directly related in the area.

\section{Socio-political impact on pastoral activities}

One main driver for changes in herding and grazing habits is assumed to be the changing leadership in the area during the his-tory of Mongolian territory. Since the beginning of the sediment record, various political powers of different origin (Turks, Chinese, Mongols) had a marked impact on nomadic activities in our study area. To encipher impact of these groups on pastoral intensity, we compare changes in grazing indicators with a preceding transition of settlement periods. For the Khaganate period (1,150-744 cal yr BP), no correlation between herding changes due to settlement transition and grazing indicators can be inferred. The increasing grazing activity might be attributed to visible occupation of this remote area by nomads starting at around 1,040 cal yr BP (Unkelbach et al., 2019). At the beginning of the Mongol Empire (744-582 cal yr BP), the human impact increases markedly, probably in accordance with westward nomadic migrations. Arboreal species decrease to a minimum in this period (Fig. 4.5) indicating a landscape shaped by humans. For Northern Yuan Dynasty period (582-259 cal yr BP), only a minor correlation is detected. The amount of coprophilous fungi stabilizes at a lower level, while the increasing number of charred materials can rather be attributed to natural erosion processes (570-470 cal yr BP; Fig. 4.5) than changing human impact. For the Qing Dynasty and Independence (259-26 cal yr BP), amounts of coprophilous fungi and macro-charcoal might have increased very likely due to a higher livestock number at the beginning of this period. Immediately upon takeover by the Soviet Union (Socialist Government and Collective Period, 26 to -40 cal yr BP), a sharp decrease in coprophilous fungal spores indicates the decline in number of cattle and possible restrictions on nomadic movements into the area. Furthermore, restrictions were eased, and herders returned. Consequently, trees and shrubs such as Larix, Betula, Juniperus, and Populus proceeded to recover. For the transition to Democracy ( -40 cal yr BP to present), no correlation between grazing indicators and changing political powers is visible. Admittedly, based on only two samples, the period might be too short to indicate valid results.

\section{Conclusions}

Based on new multi-proxy analyses in the Altai Tavan Bogd National Park, western Mongolia, we reconstructed vegetation, fire, lake dynamics, climate and human impact for the last 1,350 cal yr BP 
in the highest resolution available in the area. Our multi-proxy data indicate long-term environmental trends as well as short-term climatic events both affecting settlement and herding activities in the Altai Tavan Bogd National Park since 1,350 cal yr BP (AD 600). Vegetation reconstruction suggests a forest opening after $820 \mathrm{cal} \mathrm{yr} \mathrm{BP} \mathrm{(AD} \mathrm{1130)} \mathrm{and} \mathrm{a} \mathrm{slow} \mathrm{recovery} \mathrm{of} \mathrm{forested} \mathrm{areas} \mathrm{starting} \mathrm{at}$ around 400 cal yr BP (AD 1550). There are both, long-term stability of the forest-ecosystem and climate-induced short-term shifts found in the records. Humans were present in the area for millennia and had a marked impact on the Mongolian Altai environment due to animal herding since Khaganate period (1,150-744 cal yr BP, AD 900-1206). We show that changes in human occupation due to political shift and changing Mongolian settlement had an impact on the vegetation during Mongol Empire (744-582 cal yr BP, AD 1206-1368), Qing Dynasty and Independence (259 to 26 cal yr BP, AD 1691-1924), and Socialist Government and Collective Period (26 to -40 cal yr BP, AD 1924 1990). In addition, altered climatic conditions had an influence on settlement processes regardless of specific settlement periods. Short-term lake water rises due to heavier rainfall events or increased snow melt had positive effects on pasture conditions and caused temporarily increasing grazing activities.

\section{Acknowledgements}

We are grateful for D. Saindovdon and the team at Mongolian State University of Education, Ulaanbaatar, for their kind help during field work and two reviewers for their helpful comments and suggestions for improving an earlier version of the manuscript.

\section{Funding}

The author(s) disclosed receipt of the following financial support for the research, authorship, and/or publication of this article: This research is funded by the DFG, German Science Foundation (BE 2116/28-1) and carried out at the University of Goettingen, Germany. 


\section{Chapter 5:}

\section{Manuscript 4}

\section{Late Holocene climate and land-use history in the Mongolian Altai Mountains: combined evidence from palynological, macro-charcoal and tree-ring analyses}

Julia UnKelbach $^{1}$, ChoimaA Dulamsuren $^{2}$, HeRmann Behling $^{1}$

${ }^{1}$ Department of Palynology and Climate Dynamics, Albrecht-von-Haller Institute for Plant Sciences, University of Goettingen, Untere Karspüle 2, 37073 Goettingen, Germany

${ }^{2}$ Applied Vegetation Ecology, University of Freiburg, Tennenbacher Str. 4, 79106 Freiburg, Germany

Submitted to the journal:

Eiszeitalter \& Gegenwart 


\begin{abstract}
The Mongolian Altai is an ecologically sensitive region in Central Asia where changes in climate and anthropogenic activities have a strong impact on the forest-steppe vegetation. We combine highresolution data (pollen, non-pollen palynomorphs (NPP), charcoal) of two new sedimentological archives from the Altai Tavan Bogd National Park with dendrochronological analyses on Siberian larch trees to study climatic changes and human landscape interactions over the last 1,350 cal yr BP. Multi-proxy palaeoenvironmental reconstructions show that the present landscape is a result of both short- and long-term climatic variations and of locally different land use. Combined evidence suggests that in the period from 1,350 to $670 \mathrm{cal} \mathrm{yr} \mathrm{BP}$ western Mongolia was impacted by a rather cold and dry climate, followed by an episode of improved warmer and wetter climatic conditions from 670 to $400 \mathrm{cal} \mathrm{yr} \mathrm{BP.} \mathrm{From} \mathrm{around} 400$ to $200 \mathrm{cal} \mathrm{yr} \mathrm{BP,} \mathrm{the} \mathrm{Little} \mathrm{Ice} \mathrm{Age} \mathrm{shaped} \mathrm{the} \mathrm{forest-}$ steppe vegetation in the area, favoring an expansion of steppe vegetation. After $200 \mathrm{cal} \mathrm{yr} \mathrm{BP,}$ climatic conditions improved again gradually with markedly high summer temperatures over the last 70 years. NPP data reveal periods of increased grazing activities in the forests especially during unfavorable climatic periods. During the late $20^{\text {th }}$ century, a decreasing deposition of coprophilous fungal spores with a simultaneous slight decrease of Larix sibirica forest suggest that economic timber harvesting seemed to be of more significance for forest degradation than pastural activities.
\end{abstract}

\title{
Kurzfassung
}

Der mongolische Altai ist eine ökologisch sensitive Region in Zentralasien, in der Klimaveränderungen und anthropogene Einwirkungen einen starken Einfluss auf die vorherrschende Waldsteppen-Vegetation haben. In dieser Arbeit verknüpfen wir hochauflösende Daten zweier neuer Sedimentarchive aus dem Altai Tavan Bogd Nationalpark (Pollen, Non-Pollen Palynomorphe (NPP), Holzkohle) mit dendrochronologischen Parametern der Sibirischen Lärche, um Klimaveränderungen sowie Mensch-Umwelt-Interaktionen über die letzten 1350 J.v.h. zu untersuchen. Unsere MultiProxy-Rekonstruktionen zeigen, dass die heutige Landschaft sowohl ein Ergebnis kurzzeitiger und langfristiger Klimaveränderungen als auch lokal variierender Landnutzung ist. Die zusammengeführten Daten deuten an, dass die Westmongolei von 1350 bis 670 J.v.h. von einem eher kühleren und trockenen Klima geprägt war, gefolgt von einer wärmeren und feuchteren Phase von 670 bis 400 J.v.h. Zwischen etwa 400 und 200 Jahren vor heute formte die Kleine Eiszeit die Waldsteppen-Vegetation in der Region und begünstigte eine Ausbreitung der Steppe. Nach etwa 200 J.v.h. verbesserten sich die klimatischen Verhältnisse schrittweise, insbesondere mit einem Anstieg der Sommertemperaturen während der letzten 70 Jahre. NPP Daten zeigen, dass Phasen mit stärkerer Weidenutzung in den Waldarealen mit ungünstigen Klimaperioden korrelieren. Während des späten 
20. Jahrhunderts nehmen sowohl die Ablagerung von coprophilen Pilzsporen als auch der Anteil an Larix sibirica in der Vegetation ab. Eine mögliche Erklärung ist die zunehmende Bedeutung der kommerziellen Waldabholzung beim Verlust der Wälder in der Mongolei.

\section{Introduction}

The forest-steppe ecotone in the Altai Tavan Bogd National Park (NP), western Mongolia, is overly sensitive. It responds strongly to natural and anthropogenic changes in climate as well as land-use pressure due to its extremely arid and cold climatic conditions (e.g. Gunin et al., 1999; Beket and Knapp, 2012). However, until recently, palaeoarchives of this Central Asian region have only rarely been studied (Brügger et al., 2018; Rudaya et al., 2008, 2009; Tarasov et al., 2000). More detailed multi-proxy investigations were carried out by Unkelbach et al. $(2018,2019,2020)$ examining the responses of forest and steppe communities to natural and anthropogenic variabilities during the midto late Holocene. Vegetation, grazing and fire dynamics provide general information on vegetation and environmental changes, their driving factors and the role of pastoral nomads. During the midand beginning of the late Holocene from 4,300 to $2350 \mathrm{cal} \mathrm{yr} \mathrm{BP}$, the vegetation in the area was characterized by open coniferous forest and high mountain steppe, indicating relatively warm and humid conditions in the Mongolian Altai. In the further course, steppe communities expanded noticeably due to a colder and more arid climate (Brügger et al., 2018; Unkelbach et al., 2019). The Little Ice Age (LIA), which globally lasted from the 16th to the late 19th century also caused significant cooling and glacier advances (doubling their size compared to modern times) in the Mongolian Altai (Lehmkuhl, 2012; Lehmkuhl et al., 2016). For the Russian Altai, not far from the Mongolian border, Andreev et al. (2007) dated LIA cooling to the period from 1530 to 1790 AD. During the last decades, an increase in tree and shrub vegetation indicated a warmer climate and a higher accessibility of water due to permafrost and glacier degradation in the high mountains. Coprophilous fungi reconstructions show that grazing intensified around 1,000 cal yr BP, possibly also favoring the expansion of steppe (Unkelbach et al., 2018, 2019). Changes in human occupation due to political shifts and changing Mongolian settlements had an impact on the vegetation in the area, especially during Mongol Empire (744 to $582 \mathrm{cal} \mathrm{yr} \mathrm{BP),} \mathrm{when} \mathrm{grazing} \mathrm{activities} \mathrm{increased}$ (Unkelbach et al., 2019). Regardless of specific settlement periods, short-term changes in climatic conditions favored shifts in grazing activities. At around 1,000 cal yr BP, the fire frequency increased in accord with growing anthropogenic impact and climate aridity (Unkelbach et al., 2020). Further palaeoecological studies in the Mongolian Altai were carried out by D'Arrigo et al. (2000) and Dulamsuren et al. (2014) providing climatic information reconstructed from Larix sibirica tree rings. 
These studies demonstrate short-term temperature oscillations over the last approx. 400 years as well as a continuous long-term temperature increase during the $20^{\text {th }}$ century.

In this paper, new high-resolution palaeoecological data from two additional archives from Altai Tavan Bogd NP are compared with dendrochronological data from the same locality. In addition to the capabilities of palynological data, tree-ring widths of larch trees are a suitable high-resolution parameter reflecting climate signals as well as stand density changes due to selective logging (Dulamsuren et al., 2014). A combined approach enables to achieve a better time resolution and an improvement of data quality (Birks and Birks, 2006). Similar studies from mountainous regions in Central Asia (Eastern Tibetan Plateau, Wischnewski et al., 2014), South America (Chonos Archipelago, Szeicz et al., 2003) and Europe (Northern Alps, Röpke et al., 2011; Czech Republic, Šamonil et al., 2018; Central Pyrenees, Garcés-Pastor et al., 2019) provided promising results.

Our main objectives are (1) to reconstruct the late Holocene climate and human history in the Mongolian Altai on a decennial scale by using a multi-proxy-approach and (2) to examine the potential of correlating palynological and dendrochronological data sets with regard to their different impact factors (climate, fire, grazing, humans) on the environment in the forest-steppe-ecotone.

\section{Study area}

\section{Environmental setting}

The Mongolian Altai is the highest and most extensive mountain system in Mongolia (Gunin et al., 1999), bordering Russia in the north, Kazakhstan in the west and China in the southwest. The study area $\left(48^{\circ} 15^{\prime} \mathrm{N}, 88^{\circ} 48^{\prime} \mathrm{E}\right)$ is part of the Altai Tavan Bogd NP (Fig. 5.1), established in 1996, and situated in the province Bayan-Ulgii. The NP is located above 2,000 $\mathrm{m}$ a.s.l., whereas the highest elevations exceed 4,000 $\mathrm{m}$ a.s.l. in the northern and western parts (Lkhagvadorj et al., 2013). The mountain systems are characterized by long, flat summit plateau ranges, large moraine ridges and numerous glaciofluvial terraces shaped by glaciation dynamics in the late Quaternary (Jolivet et al., 2007; Lehmkuhl et al., 2016). Leptosols are prevailing soils in the area (Dulamsuren et al., 2014).

Extreme continentality controls the area's climate due to the topographic setting and the great distance to moisture sources (Andreev et al., 2007). In Ulgii $\left(48^{\circ} 55^{\prime} \mathrm{N}, 8^{\circ} 56^{\prime} \mathrm{E}, 1,715 \mathrm{~m}\right.$ a.s.1., located approx. $120 \mathrm{~km}$ northeast), average temperatures range from $16.3{ }^{\circ} \mathrm{C}$ in July to $-17.1{ }^{\circ} \mathrm{C}$ in January. Precipitation averages $114 \mathrm{~mm}$ per year. During the short summer period from June to August most of the rainfall occurs (70-80\%). In winter (6 month), the area is covered by snow and ice (Enkhtaivan, 2006). 


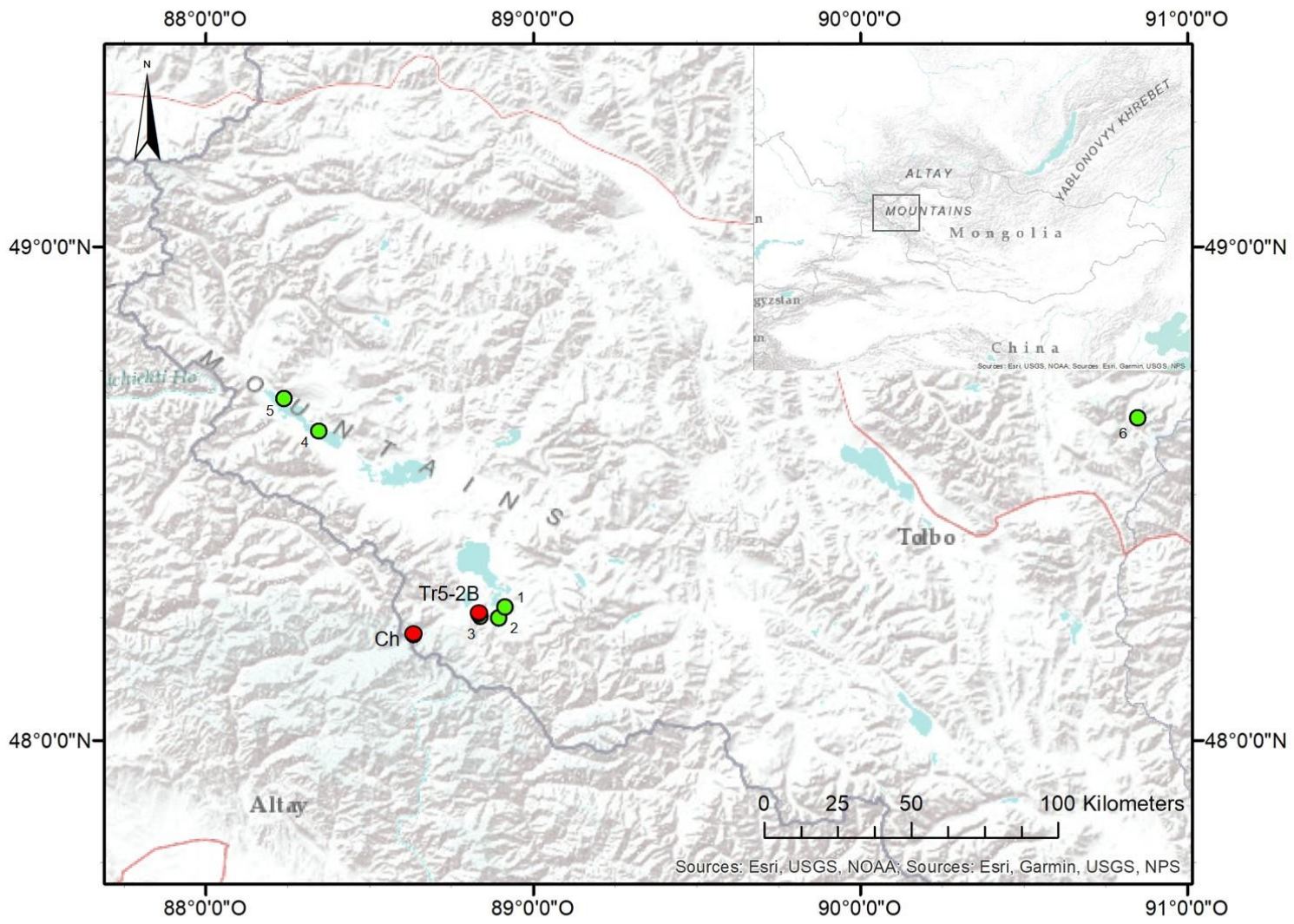

Fig. 5.1. Detailed topographic map showing the locations of cores $\operatorname{Tr} 5-2 \mathrm{~B}$ and $\mathrm{Ch}$ (red) within the area of investigation (Yamaat valley). The locations of other existing palynological archives from the Mongolian Altai are added (green): 1 - D3L6 (Unkelbach et al., 2019), 2 - G2-A (Unkelbach et al., 2018), 3 - D1L1 (Unkelbach et al., 2020), 4 - Khoton-2 (Rudaya et al., 2008; 2009), 5 - Khoton1 (Tarasov et al., 2000), 6 - Tsambagarav Glacier (Bruegger et al., 2019).

Gradients such as elevation and exposure, temperature and precipitation are the main drivers in the area influencing the composition, distribution, and productivity of vegetation (Rudaya et al., 2009). The temperature decline with elevation shapes the vertical range of vegetation distribution, while precipitation is the main factor determining a W-E-directed plant community pattern (Gunin et al., 1999). In general, vegetation ranges from semi-desert and desert communities on some slope bases (1,100 to 2,100 m a.s.1.), to high mountain cushion herb vegetation, cryo-xerophytic grassland, xerophytic shrubs and grass steppes (1,600 to 3,200 m a.s.1.) and a mountain forest belt (1,700 to 2,200 m a.s.l.) to cryophyte grassland and subalpine shrubs, lichen communities, fragments of cryophyte meadows and regular snow cover in the highest altitudes $((2,100) 2,700$ to $4,374 \mathrm{~m}$ a.s.l.) (Beket and Knapp, 2012). Forests and forest-steppes are only present on north-facing slopes, growing on the upper parts or on the central parts if a high mountain zone exists. Most of the forested areas 
are only composed of Siberian larch (Larix sibirica), whereas in some areas close to the border to China Siberian pine (Pinus sibirica) and Siberian spruce (Picea obovata) contribute to the forest assemblage (Dulamsuren et al., 2014). The transition from mountain steppe communities to alpine grassland is continuous, if forests are missing (Gunin et al., 1999). From the mountain plateaus to the basins, permafrost conditions prevail, though limited by the low soil humidity in lower elevations (Klinge et al., 2017). Permafrost only occurs under forested areas and in alpine grasslands.

The Mongolian Altai has been inhabited by modern humans since the Upper Paleolithic $(46,000$ 12,000 cal yr BP) (Tumen, 2006). During late Bronze Age (3,450-2,650 cal yr BP), animal husbandry and mobile pastoralism developed within the Eurasian steppe and were introduced to Mongolian territory (eg Fernández-Giménez et al., 2017; Houle, 2016; Miehe et al., 2009; Tumen, 2006). Organizational forms of nomadic cultures and pastoral activities adjusted and stabilized throughout Terminal Bronze Age (2,650-2,350 cal yr BP) and basically persist to this day in the Mongolian Altai.

Table 5.1. Uncalibrated and calibrated radiocarbon dates of cores Tr5-2B and Ch. Calibration was performed using the Northern Hemisphere terrestrial calibration curve IntCal13 (Reimer et al., 2013).

\begin{tabular}{|l|l|l|l|l|l|}
\hline $\begin{array}{l}\text { Laboratory } \\
\text { Code }\end{array}$ & $\begin{array}{l}\text { Core } \\
\text { name }\end{array}$ & $\begin{array}{l}\text { Depth } \\
(\mathbf{c m})\end{array}$ & $\begin{array}{l}\text { Type of } \\
\text { Material }\end{array}$ & $\begin{array}{l}\mathbf{C}^{\mathbf{1 4}} \text { Age (yr } \\
\text { BP) }\end{array}$ & $\begin{array}{l}\text { calibrated C } \\
\text { Age (cal BP +/- } \\
\mathbf{1 \sigma})\end{array}$ \\
\hline \hline Poz-89784 & Tr5-2B & 9 & Bulk sediment & $61 \pm 30$ & $178 \pm 126$ \\
\hline Poz-89785 & Tr5-2B & 21 & Bulk sediment & $497 \pm 30$ & $521 \pm 55$ \\
\hline Poz-93768 & Tr5-2B & 29 & Bulk sediment & $598 \pm 30$ & $667 \pm 74$ \\
\hline Poz-89786 & Tr5-2B & 46 & Bulk sediment & $2482 \pm 30$ & $2096 \pm 666$ \\
\hline Poz-107682 & Ch & 21 & Bulk sediment & $185 \pm 30$ & $185 \pm 105$ \\
\hline Poz-107683 & Ch & 33 & Bulk sediment & $225 \pm 30$ & $321 \pm 136$ \\
\hline
\end{tabular}

\section{Site description}

The study site (Fig. 5.1) is located in Songinot region south-west of Dayan Nuur. Two sediment and several wood cores from Larix sibirica trees were taken in Yamaat valley following a small stream flowing from behind the Chinese border to the North-East. In direction to the border the valley continues to be narrower and markedly moist. Core Tr5-2B (46 cm, 48 $15^{\prime} 12.00^{\prime \prime} \mathrm{N}$, $88^{\circ} 50^{\prime} 19.06^{\prime \prime} \mathrm{E} ; 2,380 \mathrm{~m}$ a.s.1.) was taken from peaty soil on a north-west-facing slope within the

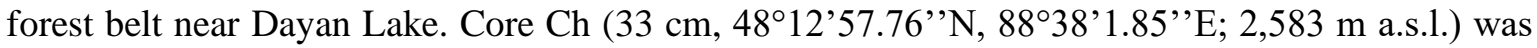
obtained from a small depression in the valley bottom below the lower forest line close to the Chinese border, which is nowadays temporarily, but not constantly, filled with water. It is located in around 
$20 \mathrm{~km}$ distance to core Tr5-2B and in direct vicinity of the small stream. In contrast to site $\operatorname{Tr} 5-2 \mathrm{~B}$, nomadic settling and livestock grazing are difficult at site $\mathrm{Ch}$, because the valley is too narrow and located in close vicinity to the national border. All wood cores were drilled on Larix sibirica trees within the area.
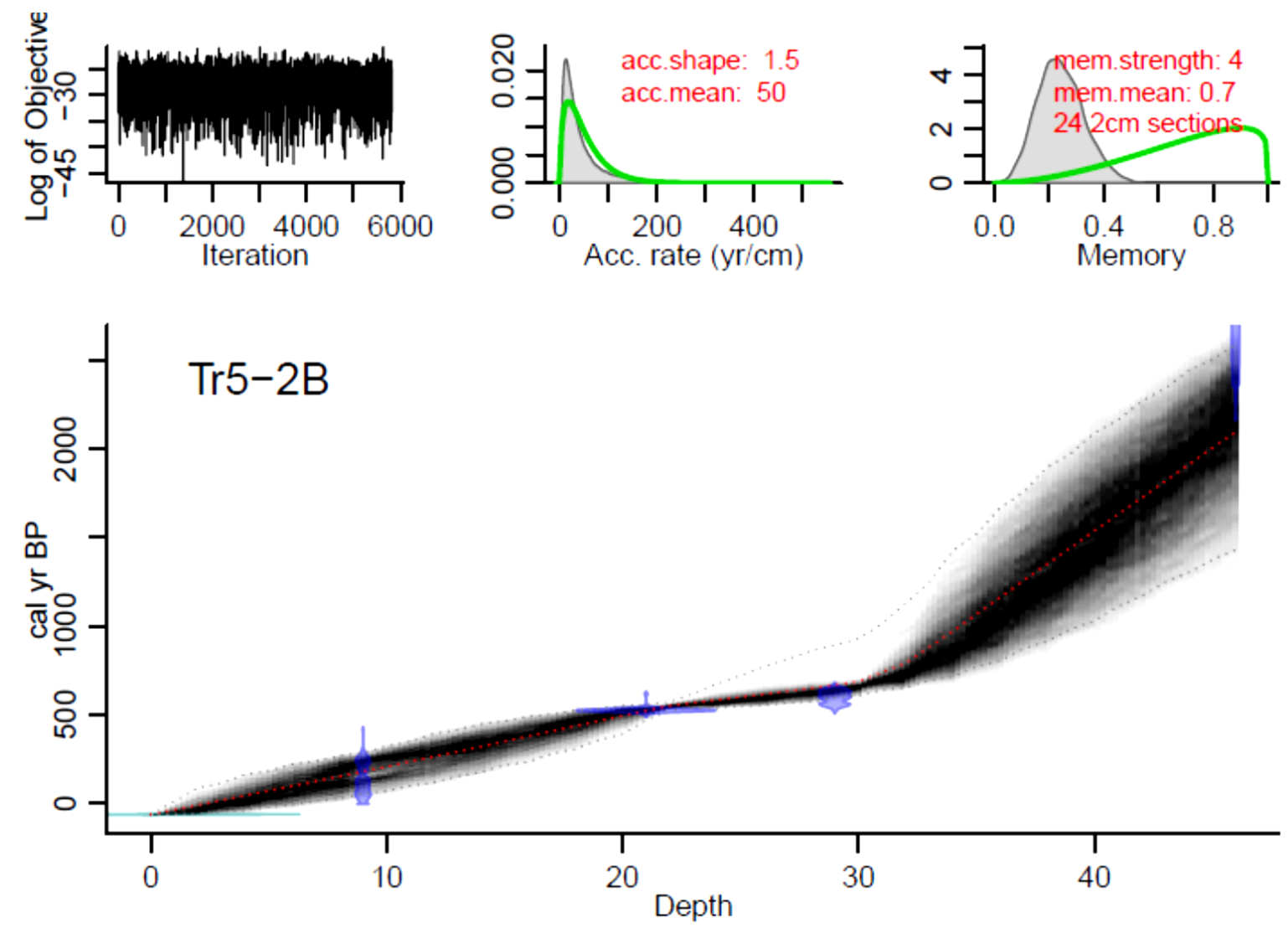

Fig. 5.2. BACON output diagram for core Tr5-2B. Upper parts show the Markov chain Monte Carlo (MCMC) iterations (left), and the prior (green) and posterior (grey) distributions for the accumulation rate (middle) and memory (right). Bottom part shows the calibrated ${ }^{14} \mathrm{C}$ dates (blue) and the agedepth-model.

\section{Material and methods}

\section{Radiocarbon dating and age-depth-modeling}

Four bulk samples samples were taken at the base and at 29, 21 and $9 \mathrm{~cm}$ core depth of core Tr5-2B. Core $\mathrm{Ch}$ was sampled accordingly at the core base and at $21 \mathrm{~cm}$ (Table 5.1). Samples were sent to Poznan Radiocarbon Laboratory, Poland, for AMS radiocarbon dating. The age-depth-models (Figs. 5.2 and 5.3) were created using rbacon package version 2.3.4 (Blaauw et al., 2018) in RStudio 
software version 3.4.4. Default settings including the Northern Hemisphere terrestrial calibration curve IntCal13 (Reimer et al., 2013) have been applied.
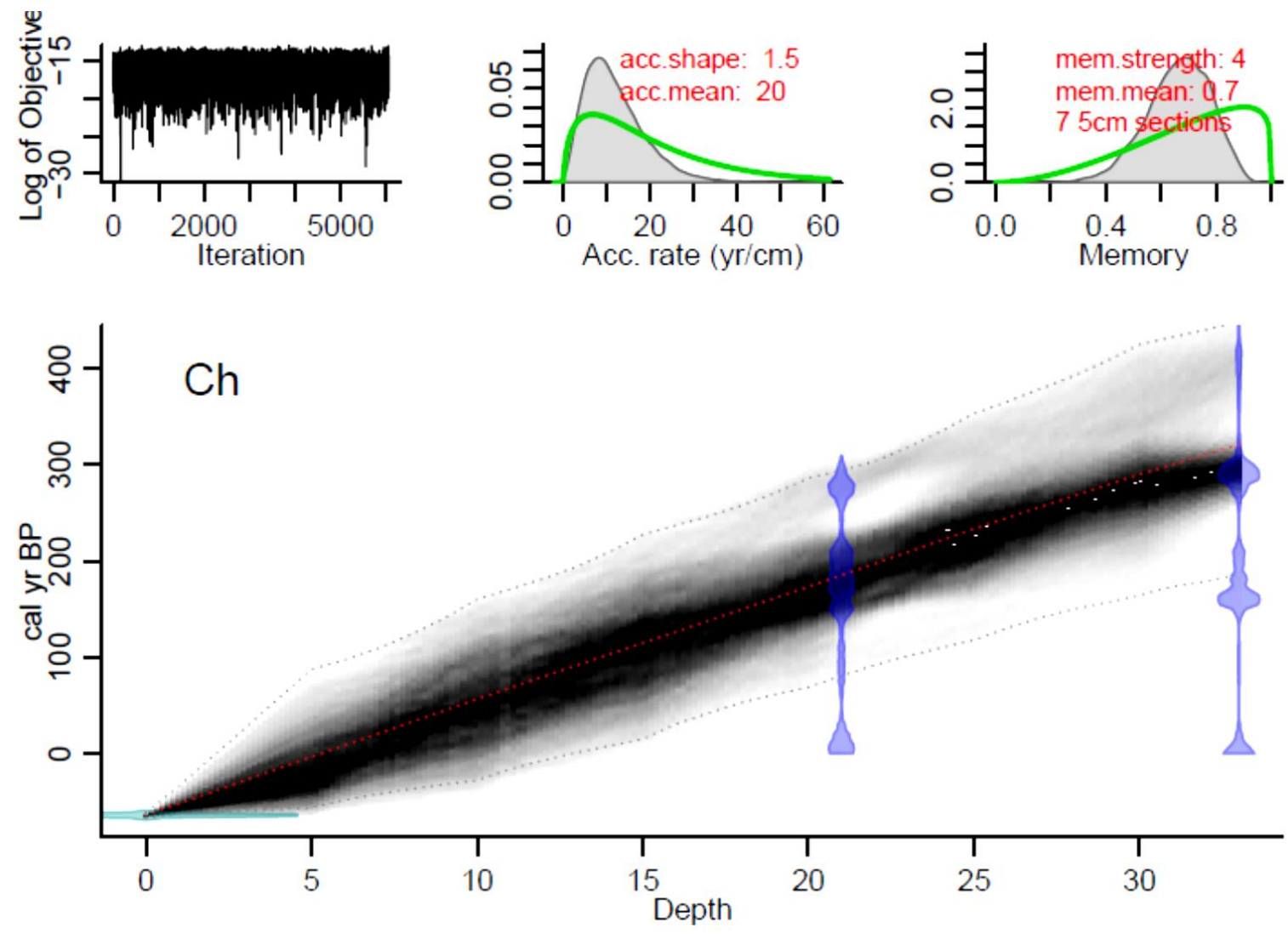

Fig. 5.3. BACON output diagram for core Ch. Upper parts show the Markov chain Monte Carlo (MCMC) iterations (left), and the prior (green) and posterior (grey) distributions for the accumulation rate (middle) and memory (right). Bottom part shows the calibrated ${ }^{14} \mathrm{C}$ dates (blue) and the agedepth-model.

\section{Palynological analysis}

Core Ch was sampled $\left(0.5 \mathrm{~cm}^{3}\right)$ continuously at $1 \mathrm{~cm}$-intervals for palynological analysis, core Tr5$2 \mathrm{~B}$ at $2 \mathrm{~cm}$-intervals. Samples of both sediment cores were prepared by employing the same treatment after Faegri and Iversen (1989) including HCl (10\%), HF (40\%), KOH (10\%) and acetolysis. Sieving was conducted twice during the preparation process to achieve a reduction of overly coarse $>120 \mu \mathrm{m}$ and fine $<10 \mu \mathrm{m}$ particles. For concentration and influx calculations, Lycopodium clavatum spores were added as an exotic marker. Pollen and spore identification were carried out using the reference collection of Mongolian pollen and spores at the Department of Palynology and Climate Dynamics (University of Goettingen) and based on relevant literature (Beug, 2004; Demske et al., 2013). In each sample, 300 terrestrial pollen grains were counted excluding spores and aquatic pollen taxa. Non-pollen palynomorphs (NPPs) were counted on the same slides and identified based on the NPP database (Shumilovskikh, 2019) and additional literature (Demske et al., 2013; van Geel, 1978). 
Unknown NPP types are presented by their respective core name and a consecutive number. New types were assigned to their taxonomic group according to their morphology. For further interpretation, the following moisture indicators were calculated: ratio of arboreal to non-arboreal pollen (AP/NAP), ratio of Artemisia to Chenopodiaceae (A/C) and ratio of Artemisia to Cyperaceae (A/Cy).

CONISS was applied on the pollen data performing a square root transformation in TILIA software (Grimm, 1991) to establish pollen zones (PZs) by statistical subdivision (Grimm, 1987). TILIA was also used for visualization of palynological data.

\section{Macro-charcoal analysis}

For macro charcoal analysis both sediment cores were sampled seamlessly $\left(0.5 \mathrm{~cm}^{3}\right)$ in $0.5 \mathrm{~cm}$ intervals. All samples were prepared using $\mathrm{KOH}(10 \%), \mathrm{H} 2 \mathrm{O} 2(6 \%)$ and wet sieving (125 $\mu \mathrm{m})$ to decrease particle fragmentation (Stevenson and Haberle, 2005). All charred macro particles were identified and counted according to the method described in Unkelbach et al. (2019). Data was illustrated in TILIA (Grimm, 1991) in total counts per sample as well as concentration and influx calculations.

Additionally, palynological samples provided micro charcoal information for comparison with macro charcoal data. Charred micro particles were counted in the same slides (and depths) as pollen and NPP. Concentration and influx values were also calculated.

\section{Dendrochronological analysis}

A total of wood cores was sampled from 94 Larix sibirica trees for tree ring analysis in 2010. Wood cores were collected at $130 \mathrm{~cm}$ height above the ground using an increment borer of $5 \mathrm{~mm}$ inner diameter. The borer was driven into the wood parallel to the contour lines of the mountain slopes to avoid compression of wood. We selected dominant and subdominant trees. Annual tree-ring width was measured with a precision of $10 \mu \mathrm{m}$ on a movable object table (Lintab 6, Rinntech, Heidelberg, Germany), the movements of which are electronically transmitted to a computer system equipped with TSAP (Time Serias Analysis and Presentation)-Win software (Rinntech).

Evaluation of tree-ring data was conducted with TSAP-Win software. Tree-ring series were controlled for missing rings and false rings during crossdating because especially missing tree rings can be relatively common in the semiarid environment of Mongolia at the drought limit of forests. Tree-ring series used for the calculation of means had a coefficient of agreement ('Gleichläufigkeit', $G L)>60 \%(\mathrm{P} \leq 0.05)$ and $t$ values $>3$. Trend lines were calculated using moving 5-year averages. Since our study was focused on the reconstruction of climate and vegetation variability over time, 
we concentrated on the oldest tree individuals. All specifications of tree age refer to the age of the oldest tree ring at $130 \mathrm{~cm}$ above the ground (cambial age); approximate 10 to 20 years should be added to deduce tree age from cambial age.

\section{Results}

\section{Lithology, chronology and sedimentation rate}

Based on visual examination, core Tr5-2B can be separated lithologically into five units (Appendix B9). The lowermost unit $(46-29 \mathrm{~cm})$ consists of light brown, silty sand with small admixed stones. The following layer $(29-19 \mathrm{~cm}$ ) is formed of dark brown silt. Middle brown silty sediments comprise the third unit $(19-13.5 \mathrm{~cm})$, followed by the same dark brown silt layer $(13.5-6.5 \mathrm{~cm})$ as found in the second unit. The uppermost unit $(6.5-0 \mathrm{~cm})$ consists of dark brown humus soil. Four AMS radiocarbon dates (Table 5.1) are the basis for the chronology of record Tr5-2B. The uppermost sample $(0 \mathrm{~cm})$ is considered as the year of coring (2014). The core base $(46 \mathrm{~cm})$ was calibrated to 2,100 cal yr BP. A continuous record was established by the age-depth-model; hence proxies could only be studied from 38 to $0 \mathrm{~cm}$ due to poor pollen and NPP preservation. A sedimentation rate of $0.12 \mathrm{~mm} / \mathrm{yr}$ was calculated for the lowermost section $(46-29 \mathrm{~cm})$. The model indicates a sedimentation rate of $0.55 \mathrm{~mm} / \mathrm{yr}$ for the section from 29 to $21 \mathrm{~cm}$ and of $0.43 \mathrm{~mm} / \mathrm{yr}$ for the following section $(21-9 \mathrm{~cm})$. For the uppermost section, a sedimentation rate of $0.37 \mathrm{~mm} / \mathrm{yr}$ is calculated.

Core Ch can be subdivided into two lithological units (Appendix B7). The basal unit $(33-9 \mathrm{~cm})$ is characterized by homogenous middle brown, silty sediments. Dark brown humus soil forms the upper unit $(9-0 \mathrm{~cm})$. In the upper depths, rootlets and other coarse organic material is visible. The agedepth-model of the short record $\mathrm{Ch}$ is based on two AMS radiocarbon dates (Table 5.1). The year of coring (2014) is set as the age of the sediment surface (uppermost sample). The core base $(33 \mathrm{~cm}$ ) was radiocarbon dated and calibrated to $320 \mathrm{cal} \mathrm{yr}$ BP. An additional bulk sample at $21 \mathrm{~cm}$ was measured and calibrated to $185 \mathrm{cal}$ yr BP. For the lower core section $(33-21 \mathrm{~cm})$, a sedimentation rate of $0.88 \mathrm{~mm}$ per year was calculated based on the age-depth-model. A sedimentation rate of 0.84 $\mathrm{mm} / \mathrm{yr}$ is calculated for the upper section $(21-0 \mathrm{~cm})$.

\section{Pollen results}

\section{Core Tr5-2B}

The pollen results of core Tr5-2B are presented in Appendix B9 and Fig. 5.4. In total, 48 pollen and spore types could be identified. According to CONISS the pollen diagram can be divided into three 
local pollen zones (PZ I-III). PZ II is subdivided into PZ IIa and PZ IIb. The palynological record has an average resolution of 136 years per sample for PZ I and of 48 years per sample for PZ II. The average time resolution for PZ III is 22 years per sample. In general, the entire record is characterized by an abundance of Larix sibirica (13-45\%), Cyperaceae (8-41\%) and Poaceae species (6-17\%). Aquatic taxa and mosses are absent.

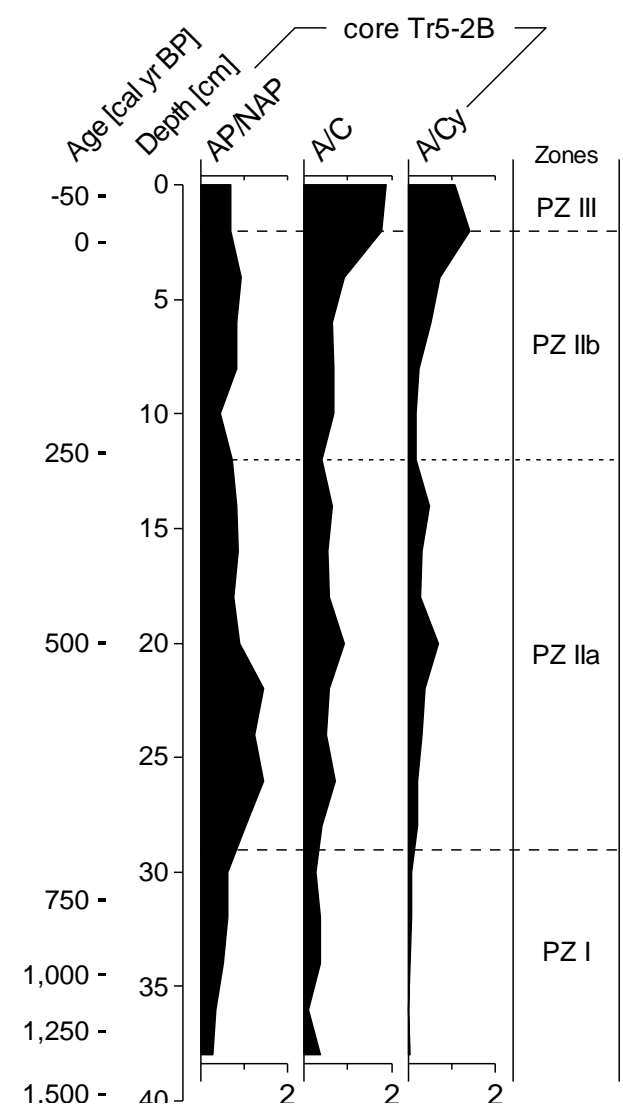

Fig. 5.4. Moisture indicators of core Tr5-2B. AP: Arboreal pollen sum, NAP: non-arboreal pollen sum, A: Artemisia, C: Chenopodiaceae, Cy: Cyperaceae
In PZ I (38-29 cm; 1,350-670 cal yr BP), proportions of Larix sibirica are relatively low (13-27\%), whereas the shares of Cyperaceae (24-41\%) and Poaceae (10-17\%) show comparably high values. The percentages of Artemisia (1-2\%) and Chenopodiaceae (3-6\%) are at their minimum. Polygonaceae, Ranunculus and Rosaceae occur steadily. All pollen ratios (AP/NAP 0.31-0.65, A/C 0.08-0.36 and A/Cy 0.01-0.06) are low. Pollen influx is very low.

Percentages of Larix sibirica (19-45\%) increase to their maximum in PZ II (29-2 cm; 670 to -20 cal yr BP), while Cyperaceae (9-20\%) decreases markedly. Artemisia (37\%) and Chenopodiaceae (4-8\%) increase. In PZ IIa (29$12 \mathrm{~cm} ; 670-270 \mathrm{cal}$ yr BP), several herbaceous taxa, e.g. Apiaceae, Cortusa and Rhododendron disappear from the pollen assemblage, but occur again more frequently in $\mathrm{PZ}$ Ilb $(12-2 \mathrm{~cm} ; 270$ to $-20 \mathrm{cal} \mathrm{yr} \mathrm{BP})$. AP/NAP ratio increases markedly in PZ IIa (0.77-1.45) and decreases in $\mathrm{PZ} \mathrm{IIb.} \mathrm{A/C} \mathrm{and} \mathrm{A/Cy} \mathrm{ratios} \mathrm{increase} \mathrm{gradually} \mathrm{and} \mathrm{reach}$ provisional maxima in the upper part of PZ IIb (A/C up to 0.91 and $\mathrm{A} / \mathrm{Cy}$ up to 0.71 ). Plant diversity and pollen

influx increase in PZ II.

The uppermost zone, PZ III ( $2-0 \mathrm{~cm}$; -20 cal yr BP to present) is characterized by a decrease of Larix sibirica (28-29\%), while the proportions of Betula (4-5\%) and Juniperus (2\%) increase. Pinus sibirica (1-2\%) and Picea obovata (1\%) decrease. Among the herbaceous taxa the diagram suggests an increase of Artemisia percentages and of several other taxa such as Cortusa, Polygonaceae, Rhododendron and Thalictrum. In PZ III, AP/NAP ratio decreases while A/C (1.77-1.88) and A/Cy (1.07-1.39) ratios increase markedly. The pollen influx is stable compared to PZ IIb. 


\section{Core $\mathrm{Ch}$}

In pollen record Ch (Appendix B7 and Fig. 5.5), 63 different pollen and spore taxa were found. The diagram is divided into two local pollen zones (PZ II-III) with two subzones (PZ IIa, PZ IIb). The zonation starts with PZ II to allow a better correlation of the two sediment cores. The high average resolution of pollen samples is 12 years per sample for PZ IIa and PZ IIb, whereas the time resolution averages 10 years per sample in PZ III. Local PZ II is characterized by an abundance of herbaceous taxa (66-89\%) dominated by Cyperaceae (21-43\%), whereas in PZ III tree and shrub (43-53\%) and herbaceous species (46-55\%) are equally distributed. In addition to Cyperaceae, Poaceae (7-20\%), Artemisia (1-10\%) and Chenopodiaceae species (3-16\%) show high proportions in the pollen assemblage over the whole record.

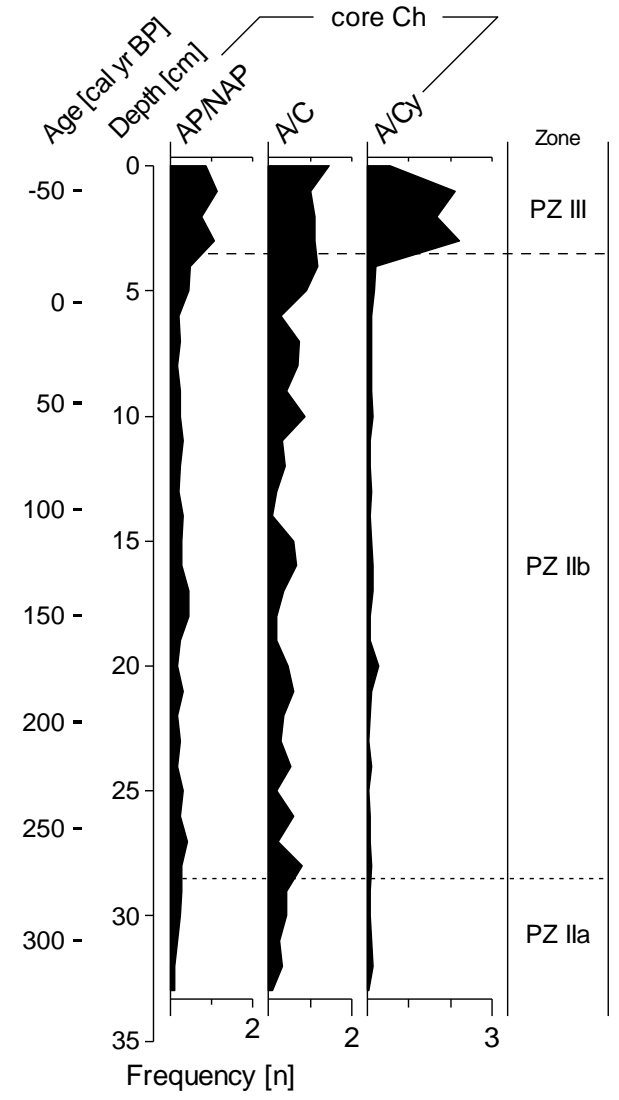

Fig. 5.5. Moisture indicators of core Ch. AP: Arboreal pollen sum, NAP: non-arboreal pollen sum, A: Artemisia, C: Chenopodiaceae, Cy: Cyperaceae
The lowermost zone, PZ IIa (33-28.5 cm; 320-270 cal yr $\mathrm{BP})$, is characterized by a rather low abundance of coniferous taxa: Larix sibirica (5-12\%), Pinus sibirica (12\%) and Picea obovata (3-6\%). Ephedra fragilis is frequent. Cyperaceae (23-32\%) and Cichorioideae (9$30 \%$ ) are abundant among the herbaceous pollen. Senecio-type pollen, Fabaceae and Valeriana occur frequently. Aquatic plants, ferns and mosses are not present in PZ IIa. AP/NAP (0.11-0.30) and A/C (0.080.43 ) ratios are generally low but increase in the upper part of PZ IIa. A/Cy ratio (0.04-0.14) is constantly low. Pollen influx is low.

In PZ IIb (28.5-3.5 cm; 270 to -20 cal yr BP), percentages of tree and shrub pollen increase slightly. Among the herbaceous taxa, the transition from PZ IIa to PZ IIb is highlighted by a marked decrease of Cichorioideae pollen to an average of 3\%. Percentages of Ephedra distachya and Populus increase. Some herbaceous taxa, e.g. Geum, Rhodiola and Rumex, as well as Sparganium and ferns occur for the first time. Chenopodiaceae percentages vary, whereas Caryophyllaceae (1-4\%) and Ranunculus

(1-5\%) values increase. Sparganium is not present while Meesia triquetra occurs infrequently. In general, AP/NAP (0.20-0.49) and A/Cy (0.03-0.27) ratios are stable in PZ IIb, whereas the A/C ratio (0.19-1.20) increases and varies markedly. Pollen influx increases but varies over the entire period. The uppermost zone, PZ III $(3.5-0 \mathrm{~cm} ;-20 \mathrm{cal}$ yr BP to present), is mainly characterized by a marked increase of Salix (28-39\%) and a respective decrease of many other tree, shrub and herbaceous taxa, 
e.g. Larix sibirica (1-5\%), Picea obovata (1-3\%) and Cyperaceae (3-10\%). Populus increases as well as Plantago, Rosaceae and Sorbarieae-type. As in PZ I, no aquatic plant taxa, ferns or mosses are present in the assemblage. In PZ III, all ratios increase markedly and reach their respective maxima: AP/NAP up to 1.16 , A/C up to 1.46 and A/Cy up to 2.21. Pollen influx increases further resulting in a maximum in the topmost sample.

\section{Non-pollen palynomorph results}

\section{Core Tr5-2B}

The NPP percentage diagram of core Tr5-2B (Appendix B10) consists of 10 taxonomic NPP groups. The detailed diagram (S1) can be found in the Supporting information. 26 NPP types (72\%) could be identified reliably, but all 36 types were assigned to one of the presented taxonomic groups. In general, the NPP assemblage is dominated by Glomus (3-26\%), coprophilous fungi (1-31\%), plant parasites (6-28\%) and other fungal types (3-95\%). The zonation is based on the pollen results.

In PZ I, Glomus (16-34\%), Sporormiella (5-21\%), Arnium (12-16\%) and plant parasites (Uredospore and HdV-4) are present in high percentages. Sordaria spores occur frequently as well as conifer stomata and animal remains.

The diversity of taxa decreases in PZ IIa. Arnium and plant parasites increase slightly while the proportions of Glomeromycota (3-9\%), coprophilous fungi (5-14\%), other fungi (3-8\%) and conifer stomata (1-4\%) decrease. A more prominent increase of NPP diversity can be observed in PZ IIb. In this zone, the assemblage is dominated by other fungi (14-64\%), especially fruit body types and Tr52b-7, as well as coprophilous fungi (5-31\%). Glomus, Sporormiella and Leptosphaeria proportions increase markedly. Neorhabdocoela and Assulina are present.

PZ III is characterized by a continual increase of other fungi (76-95\%) and plant parasites (10-21\%) shares. Glomeromycota (1-3\%), Sporormiella (1-7\%) and Sordaria (1\%) percentages decrease markedly.

\section{Core Ch}

The NPP percentage diagram (Appendix B8) shows the 10 taxonomic NPP groups of core Ch. The detailed diagram (S2) of all 108 recorded NPP types can be found in the Supporting information. Only $51 \%$ of all recorded types were identified by name or HdV-code, but all could be assigned to their respective taxonomic group. The NPP assemblage is characterized by Glomeromycota (2-83\%), coprophilous (1-21\%) and other fungi $(7-76 \%)$ as well as animal remains $(2-10 \%)$. The zonation is adopted from the pollen record. 
PZ IIa is dominated by Glomus (72-83\%). Scolescoporites, algae HdV-200 occur in high proportions, Sporormiella is absent and Sordaria spores are rare. In general, the diversity of NPP types and the NPP concentration are very low in PZ I.

In PZ IIb, the diversity of fungal spores and animal remains increases. Arnium, Tr5-2B-1 and Tr52B-11 increase. Sporormiella spores are still absent in the beginning of PZ IIb but occur in high proportions (2-8\%) in the uppermost part. Sordaria spores are more frequent in the lowermost part and likewise reach their maximum (14\%) at the end of PZ IIb.

The NPP assemblage in PZ III is characterized by a marked decrease of Glomeromycota (2-5\%) and a major increase of other fungal types. A marked maximum of Pleospora-type HdV-3B (35\%) occurs at the beginning of PZ III. The proportions of Sporormiella and Sordaria decrease slightly.

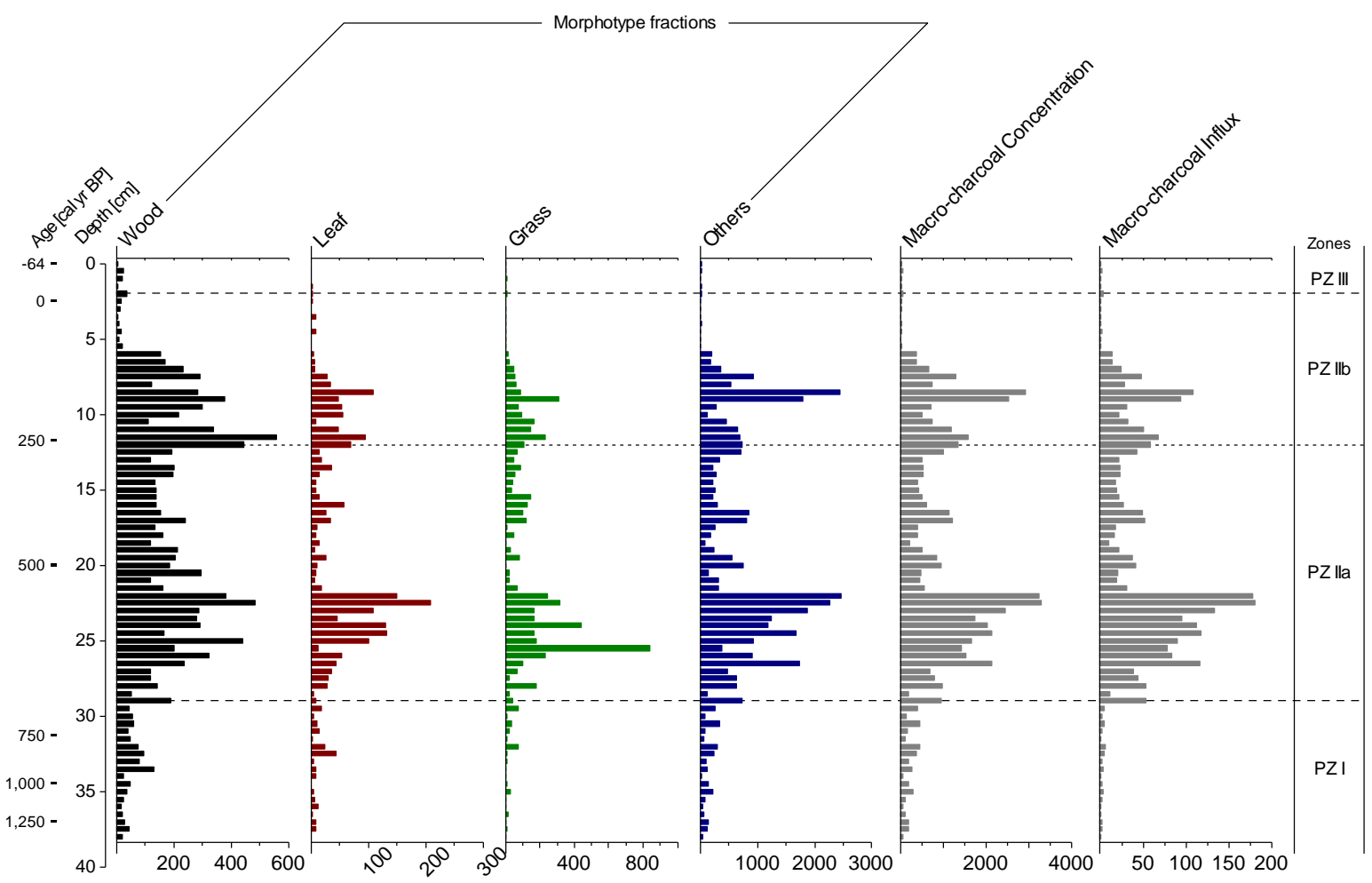

Fig. 5.6. Macro-charcoal diagram of core Tr5-2B. Total charred particles are divided into wood, dicot leaf, grass and other charcoal fragments. Macro-charcoal concentration [particles $/ \mathrm{cm}^{3}$ ] and macrocharcoal influx [particles/ $\mathrm{cm}^{2} / \mathrm{yr}$ ] have been calculated using the sum of total charcoal counts.

\section{Charcoal results}

\section{Core Tr5-2B}

The micro charcoal record (Appendix B9) is established based on the same time resolution as the palynological record. The influx of micro charcoal particles changes from lower values in PZ I to several maxima in PZ II. In PZ III, the influx decreases to its minimum. The micro charcoal results are generally consistent with the macro charcoal record. 
For PZ I, the macro charcoal record (Fig. 5.6) has an average time resolution of 38 years per sample, for PZ II of 13 years and for PZ III an average resolution of 9 years per sample. In PZ I and PZ III almost no charred macro particles were deposited, whereas several maxima occur in PZ II. Five maxima are suggested for PZ II: three in PZ IIa (26, 22 and $17 \mathrm{~cm})$ and two in PZ IIb (11.5 and 8.5 $\mathrm{cm})$. Very low charred material deposition is found before $660 \mathrm{cal} \mathrm{yr} \mathrm{BP}$ and after $100 \mathrm{cal} \mathrm{yr} \mathrm{BP.}$

In terms of the different morphological types, the dominating macro charcoal fraction is others (mosses, rootlets, seeds and unidentifiably small particles; 65\%). Charred wood-type material (21\%) occurs more frequently than grass-type (11\%) and leaf-type (4\%) macro charcoal. Trends seem generally consistent within the morphotypes; however, the record of the wood-type fraction diversifies slightly in PZ IIb.

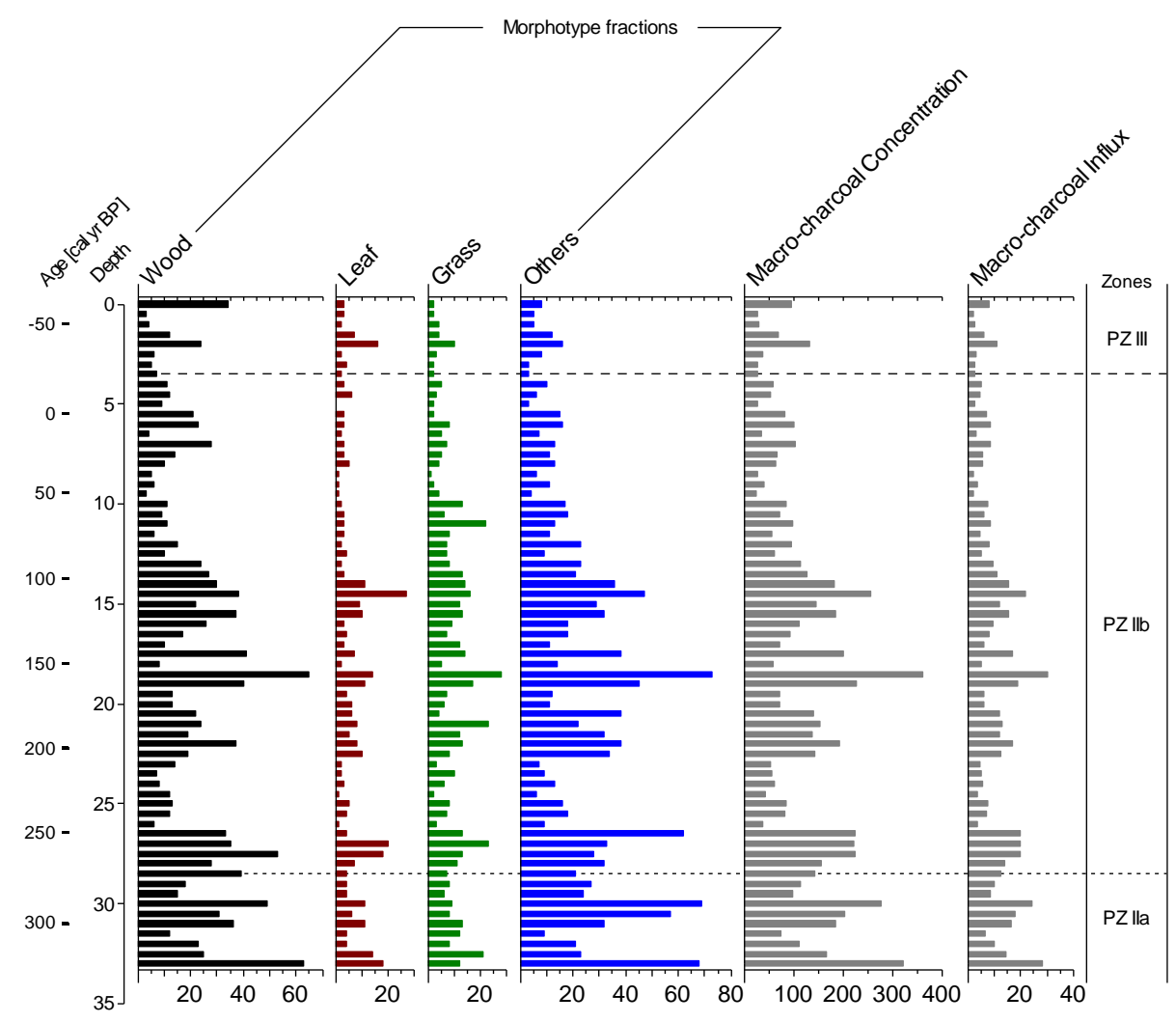

Fig. 5.7. Macro-charcoal diagram of core Ch. Total charred particles are divided into wood, dicot leaf, grass and other charcoal fragments. Macro-charcoal concentration [particles $/ \mathrm{cm}^{3}$ ] and macrocharcoal influx [particles $/ \mathrm{cm}^{2} / \mathrm{yr}$ ] have been calculated using the sum of total charcoal counts.

\section{Core Ch}

Whereas in PZ IIa and PZ III the influx of charred micro particles (Appendix B7) is rather low, PZ IIb is characterized by a higher micro charcoal deposition. Over the last 320 cal yr BP, six maxima of increased micro charcoal influx can be observed: one at the end of PZ IIa $(29 \mathrm{~cm})$ and five in PZ 
IIb $(24,22,16,11$ and $7 \mathrm{~cm})$. Since $10 \mathrm{cal} \mathrm{yr} \mathrm{BP,} \mathrm{the} \mathrm{influx} \mathrm{of} \mathrm{micro} \mathrm{charcoal} \mathrm{particles} \mathrm{decreases}$ steadily.

Macro charcoal particles are present at all depths along core Ch. The record (Fig. 5.7) has an average resolution of 5 years per sample for PZ IIa, of 6 years per sample for PZ IIb and of 5 years per sample for PZ III. The macro charcoal influx is high in PZ IIa and generally decreases subsequently. As observed in the micro charcoal record, six maxima of increased influx of charred macro particles are found, but they differ from the micro charcoal results in their temporal distribution. Two maxima occur in PZ IIa (33 and $30 \mathrm{~cm}$ ) and four in PZ IIb $(27,22,18.5$ and $14.5 \mathrm{~cm})$. Very low deposition of macro charcoal particles can be observed from $60 \mathrm{cal} \mathrm{yr} \mathrm{BP}$ to present.

Among the four different macro charcoal morphotypes the dominating fractions are wood-type charcoal (36\% of total macro charcoal particles counted) and charred mosses, seeds, roots and indeterminate particles (38\%). Charred grass-type material (15\%) occurs more frequently than leaftype particles $(10 \%)$. Within the four morphological groups, the composition of charred material is nearly consistent over the whole period.

\section{Dendrochronological results}

There were few tree individuals that stood out from the majority of Larix sibirica trees by their high age. The oldest sample tree had established in the mid- $15^{\text {th }}$ century and had a cambial age (at sampling height) of 565 years. The second oldest tree originated from the early $16^{\text {th }}$ century and had a cambial age of 490 years. These two tree-ring series were merged to a mean chronology covering the period from 1445 to $2010 \mathrm{AD}$ (Fig. 5.8a). This chronology shows depressed growth from ca. 1560 to 1750 , but an upward trend for increased annual increment since the late $18^{\text {th }}$ century. The long-term trends for depressed or increasing stemwood formation were interrupted by short-term minima of tree-ring width (e.g. around 1650, 1720, 1785, 1820, 1850, $1890 \mathrm{AD}$ ), which are generally the results of climate extremes lasting one or several consecutive years.

The chronologies in Fig. 5.8b, c, d cover shorter time intervals, but are based on larger sample sizes, including trees of a cambial age of 315 to 490 years ( 9 trees; Fig. 5.8b), 200 to 310 years ( 9 trees; Fig. 5.8c), 100 to 150 years ( 25 trees; Fig. 5.8d). These shorter chronologies confirm both the longterm trends and the dating of short climate extremes visible from Fig. 5.8a, but partly have a better resolution, for instance, for the increase of annual stem increment in the mid-18 ${ }^{\text {th }}$ century (Fig. 5.8c) or since the 1960s (Fig. 5.8d). 

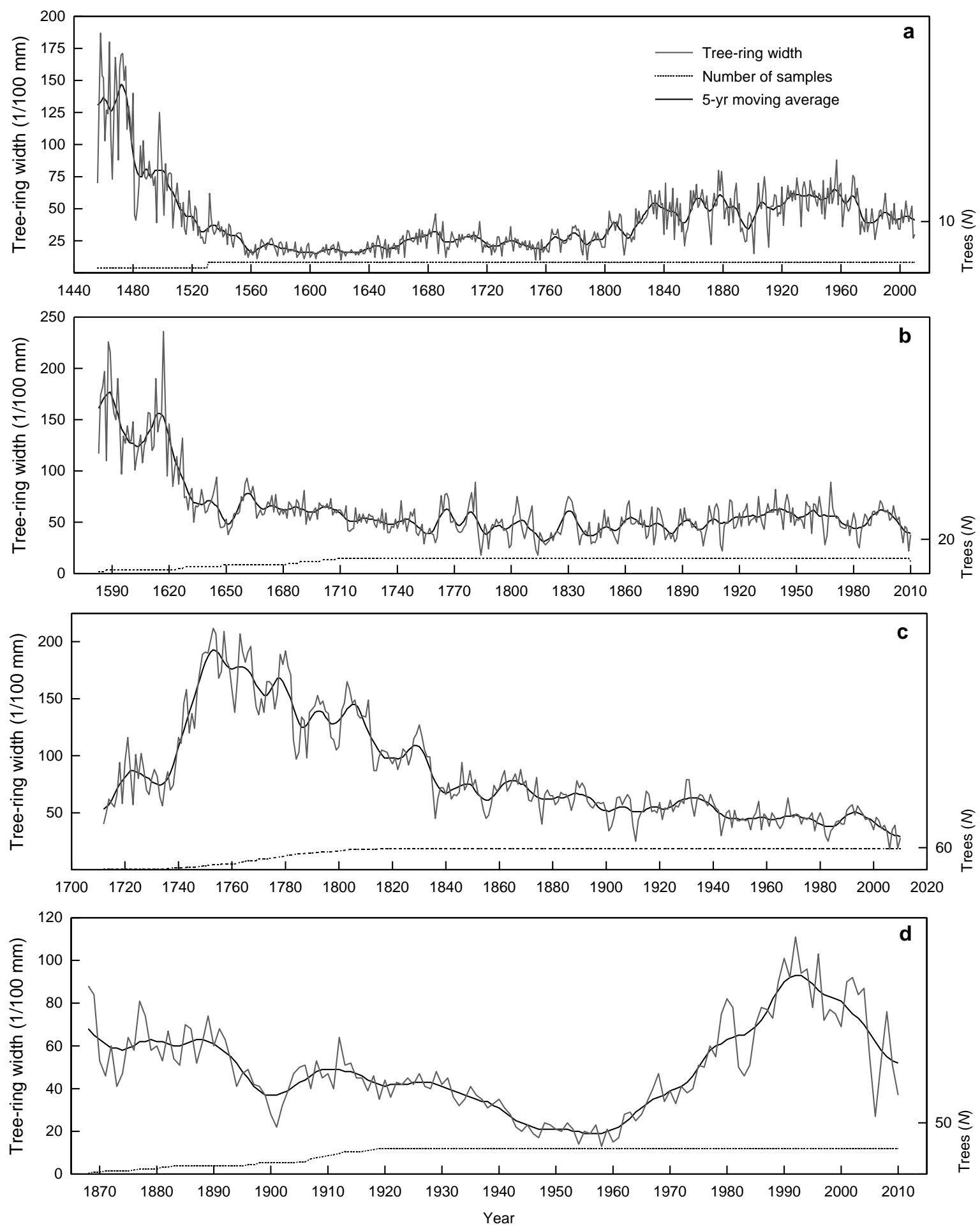

Fig. 5.8. Tree-ring chronologies of Larix sibirica from Lake Dayan, Mongolian Altai including trees of differing in cambial age: (a) 490 to 565 years, (b) 315 to 490 years, (c) 200 to 310 years, (d) 100 to 150 years. 


\section{Discussion}

\section{Vegetation and climate dynamics}

\section{Interpretation of palynological results}

The interpretation of the pollen results is based on the combined results of both environmental archives Tr5-2B (forest, slope) and Ch (steppe, valley bottom). With respect to their different positions within the forest-steppe-ecotone, especially the Larix sibirica records must be interpreted with caution. Several authors reported that Larix is usually greatly underrepresented in fossil pollen records because of its low pollen productivity and its low dispersal distance (Gunin et al., 1999; Minckley and Whitlock, 2000; Nashiro et al., 1997). Pélanková and Chytrý (2009) emphasized that in addition to landscape openness another influencing factor is the presence of other tree species. They suggest that in continental steppe or forest-steppe regions, where Larix is the only dominant tree, the proportion of Larix in the pollen diagram may be a good indicator of the actual abundance of Larix in the landscape. As expected, the forest record (Tr5-2B) shows clearly higher Larix proportions as the steppe record $(\mathrm{Ch})$, located in a greater distance to a mixed coniferous forest of larch, pine, and spruce.

From 1,350 to 670 cal yr BP (PZ I), the studied valley in the Altai Tavan Bogd NP was dominated by moist high mountain vegetation and grass steppe, mainly composed of Cyperaceae, Poaceae and Chenopodiaceae. The relatively low representation of Larix sibirica suggests that the forest belt surrounding the study site (Tr5-2B) already existed but had a rather open character. Most likely, due to the constantly low shares of Pinus sibirica and Picea obovata (Appendix B9), pine and spruce never added to the forest composition at this location. Relatively dry and rather cold climate conditions can be inferred from the reconstructed vegetation data and moisture indicators (Fig. 5.4). In the period from 670 to $290 \mathrm{cal}$ yr BP (PZ IIa), an increasing abundance of Larix sibirica suggests a densification of larch stands or a probable forest expansion (Fig. 3a). The landscape surrounding the steppe study site closer to the Chinese border $(\mathrm{Ch})$ is characterized by a steppe vegetation comprising Poaceae, Asteraceae and Chenopodiaceae communities. Forested areas were clearly more distant compared to site Tr5-2B and probably generally more open. A slightly higher representation of Pinus sibirica and Picea obovata may indicate their local occurrence in the forest assemblage.

After 290 cal yr BP (PZ IIb), decreasing proportions of trees and shrubs (Appendix B9) indicate a short-term expansion of moist high mountain steppe which may be associated with the Litte Ice Age (LIA) period (420-160 cal yr BP, e.g. Andreev et al., 2007; Unkelbach et al., 2019; 2020). Forest recovered since around $180 \mathrm{cal}$ yr BP (Appendix B9) and the diversity of steppe species increased (Appendix B7), both indicating better climatic conditions.

Over the last 40 years (PZ III), local vegetation differences emerged, especially regarding shrub community distribution and composition. Around the forest site (Tr5-2B) an increase of Betula and 
Juniperus proportions indicate lighter woodland interspersed with greater alpine steppe areas including Cortusa, Gentiana, Rhododendron and Thalictrum. Whereas around the steppe site (Ch) Populus and especially Salix stands increased markedly. We infer that the climate warming of the $20^{\text {th }}$ century facilitated permafrost degradation in the area which lead to increasingly moister soil conditions. Our results suggest that the forest-steppe ecosystem of the Mongolian Altai is a very heterogenic landscape where climate variabilities can cause different vegetation responses over short distances and altitudinal differences.

\section{Interpretation of tree-ring data}

The harsh mountain climate of the Mongolian Altai leaves a strong imprint in the annual radial stem increment as it has been shown in previous dendrochronological studies from this region (D'Arrigo et al., 2000; Dulamsuren et al., 2014). Since the late $20^{\text {th }}$ century, also timber harvest plays a major role in controlling annual stem increment due to logging-induced changes in the stand structure and thus competition. In a climate-response analysis based on ca. 1800 Larix sibirica trees, Dulamsuren et al. (2014) showed that tree growth in the period from 1940 to 2010, which was covered by weather data, was primarily promoted by high summer temperatures. Temperature limitation of annual stem increment is typical for high mountain forests, but contrast with most $L$. sibirica forests in Inner Asia at lower elevations, which are mostly limited by summer drought. Under drought limitation, treering width increases with increasing summer precipitation, but decreasing summer temperature (Dulamsuren et al., 2010, 2013; Liu et al., 2013). The evaluation of temperature and precipitation extremes for the Mongolian Altai by Dulamsuren et al. (2014) in the period from 1940 to 2010 revealed that years, which were cold and dry at the same time resulted in particularly low stem increment. Such an extreme occurred, for example, in the early 1980s and the resulting growth minimum is also visible in our data in Fig. 5.8d. It is plausible to assume that most short-term minima of tree-ring width (Fig. 5.8) in the centuries before the availability of instrumental weather data also represent cold and dry extreme years. The long-term trends in annual stem increment correspond with long-term shifts in climate. The depressed growth from the mid- $16^{\text {th }}$ to the mid- $18^{\text {th }}$ century (Fig. 5.8a) can be related to the LIA period. Improved climatic conditions since the mid-1 $8^{\text {th }}$ century have not only resulted in increased tree-ring width, but probably also in increased regeneration, which might be the cause of the increasing number of available sample trees since that point in time (Fig. 5.8c). 


\section{Grazing dynamics}

Grazing dynamics and anthropogenic influence on the environment are reconstructed based on coprophilous fungi data (Sporormiella and Sordaria-type spores). These fungi can be used as an indicator for the presence of megaherbivores in the immediate surrounding of the site and, for the forest-steppe-ecotone of Mongolia, display the history of grazing pressure by nomadic pastoralists (e.g. Baker et al., 2013; Davis, 1987; Perrotti and van Asperen, 2018). The consistent distribution of coprophilous fungal spores (Appendix B10) suggests ongoing nomadic activities in the Mongolian Altai since the beginning of the record in 1,350 cal yr BP (see also Unkelbach et al., 2019; 2020). From 1,350 to $670 \mathrm{cal}$ yr BP (PZ I), coprophilous fungi were rather plentiful compared to modern times indicating a high level of grazing pressure on the environment. This fact may be related to the minor expansion of forest at the beginning of the record (Appendix B9), as browsing and trampling of livestock reduce the number of tree saplings, diminish tree stands and affect their recovery (Hauck et al., 2012; Khishigjargal et al., 2013). In the period from 670 cal yr BP to AD 1970 (PZ II), peaks in the coprophilous fungi records (Appendix B10) seem to correspond to reduced forest distribution as well. Over the last approx. 50 years (PZ III), coprophilous fungi data suggests that the grazing pressure around the site decreased given the vicinity to the Chinese border, but not favoring an expansion of forest.

A comparison of both coprophilous fungi records shows that the data do not coincide in some points, e.g. maxima at different time intervals, initial occurrence of Sporormiella spores in core Ch only starting at around $150 \mathrm{cal} \mathrm{yr} \mathrm{BP}$ (Appendix B8). These differences enable us to draw more conclusions about the local character of anthropogenic impact by nomadic pastoralists on the environment in the Mongolian Altai. Whereas the pastures around the forest site (Tr5-2B) have always been used extensively for settling and grazing, the border site (Ch) has only been exploited by grazing animals over the last two centuries.

\section{Fire dynamics}

Previous studies revealed that the fire frequency in the Mongolian Altai is rather low due to the general lack of biomass resources in arid Central Asia (e.g. Bruegger et al., 2018; Eichler et al., 2011). This connection is confirmed in both our new charcoal records (Fig. 5.6 and 5.7) from the area. However, as expected, the extent of charcoal deposition varied locally on a greater scale. Given the fact that the abundance of macro charcoal particles in diameter decreases increasing the distance between fire source and deposition site (e.g. Clark, 1988), the influx of charred macro particles is generally much higher in the record from the forest site (Tr5-2B).

Initially, the fire frequency was very low from 1,350 to $670 \mathrm{cal} \mathrm{yr} \mathrm{BP.} \mathrm{After} 670 \mathrm{cal} \mathrm{yr} \mathrm{BP}$, it increased in accord with growing anthropogenic impact (Appendix 10). The first fire activity 
maximum is documented from around 660 to $550 \mathrm{cal}$ yr BP during the Mongol Empire period. It is in accord with other macro charcoal records from the area (Unkelbach et al., 2019, 2020), thus being of a rather regional extent. At least substantial enough for charred material to be deposited in a radius of 20 kilometers or more. The same applies to two subsequent periods of increased fire activity from around 250 to $220 \mathrm{cal} \mathrm{yr}$ BP and from around 170 to $150 \mathrm{cal} \mathrm{yr}$ BP. Over the last $100 \mathrm{cal} \mathrm{yr}$ BP, the influx of charcoal material decreased drastically. A possible explanation might be that in modern times the local nomadic pastoralists are more aware of the additional risk of environmental destruction due to unlimited use of fire and reduce it to a minimum.

\section{Synthetic interpretation of the environmental data}

For data synthesis we will mainly focus on the last 500 cal yr BP (1450-2014 AD) for which all multi-proxy data are available. The high-resolution dendrochronology will provide the basis for comparison with the other palynological and charcoal proxies.

According to the tree-ring data (Fig. 5.8), the period from 500 to $400 \mathrm{cal}$ yr BP (1450-1550 AD) was assumed to be warm and possibly rather humid. In the period from 400 to 200 cal yr BP (1550-1750 $\mathrm{AD}$ ), a depressed tree growth suggests lower temperatures and less precipitation in the area reflecting an impact by the LIA. After 200 cal yr BP (1750 AD) climate improved to warmer and more humid conditions. From 10 cal yr BP (1940 AD) to present, stem increments generally increased even more indicating the global climate warming. During this period, temperature in the study area increased in all seasons, but the increase in summer temperatures had the highest impact on the trees' productivity (Dulamsuren et al., 2014), as it is generally found in cold-limited ecosystems. Other available treering records from the Mongolian Altai at Khoton Nuur (Davi et al., 2009) and Khalzan Kalmar (D'Arrigo et al., 2000) confirm our reconstructions.

The environmental changes reconstructed from our pollen records Tr5-2B and Ch (Appendix B7 and B9) mainly coincide with our dendrochronological data. The general trend from a rather warm and moist climate with an expanded arboreal vegetation (670-400 cal yr BP) to a slight decrease in Larix stands due to cooler and drier conditions during LIA (until approx. 200 cal yr BP) and forest recovery in accordance with improved climatic conditions since around $200 \mathrm{cal} \mathrm{yr} \mathrm{BP}$ are consistent with our dendrochronological findings. However, the more prominent increase of summer temperature over the last approx. 70 years and the higher availability of water due to the degradation of permafrost (Dulamsuren et al., 2014; Walther et al., 2017) are not consistently reflected in the arboreal pollen assemblage in both pollen records, but left a clear imprint in the tree-ring data. The trees in the Mongolian Altai benefit from increasing summer temperatures despite constantly low precipitation due to permafrost meltwater captured forested slope tops from upslope grassland areas. Otherwise increased temperature could have easily resulted in increased drought stress and growth depressions. 
Whereas the $\mathrm{A} / \mathrm{C}$ and $\mathrm{A} / \mathrm{Cy}$ ratios of both sediment cores increase since around $\mathrm{AD} 1940$ indicating a shift towards more hydrophilic vegetation (e.g. Herzschuh, 2007; Zhao et al., 2012), only at the steppe site $\mathrm{Ch}$, the arboreal vegetation is impacted as demonstrated by the marked increase in willow species (Appendix B7). In contrast, the arboreal vegetation at the forest site even decreases slightly. Considering the increased timber harvesting in Mongolia since the late $20^{\text {th }}$ century (Dulamsuren et al., 2014), harmful human induced impacts are visible in the forest-steppe ecotone of the Mongolian Altai.

The grazing pressure does not seem to contribute to any major extent to the environmental changes at site Ch. The local peaks in the coprophilous fungi record (Appendix B8) from AD 1850 to 1930 cannot be linked with any significant changes in vegetation. Since nomadic settlement and pasture use are not possible due to the geographical setting of the valley, coprophilous fungi deposition may either be a result of wild animal grazing (e.g. Ekblom and Gillson, 2010) or long-distance transport (Davis and Shafer, 2006). However, at the forest site Tr5-2B the grazing maximum occurred during and shortly after LIA (Appendix B10) when the vegetation cover was reduced. Presumably, in this period livestock preferred forested areas due to its higher biomass (Arnold, 1987). In general, both cores from peat sequences seem to reflect rather local grazing trends because other studies on anthropogenic impact in the Mongolian Altai (Unkelbach et al., 2019; 2020) proved the significance of grazing activities as a cause of vegetation changes.

The local peaks in the macro charcoal influx (Fig. 5.6 and 5.7) cannot be linked with any vegetation changes (Appendix B7 and B9) or climate oscillations (Fig. 5.8) over the last $500 \mathrm{cal}$ yr BP. The general trends of charcoal are not in accord with the findings by Brügger et al. (2018) from the Tsambagarav glacier in the north-eastern part of the Mongolian Altai which is in about $150 \mathrm{~km}$ distance to our study area. They reconstructed that dead biomass resulting from forest and steppe community diebacks due to an increase in aridity serve as additional fuel for future fires from the correlation of dry periods with increased fire activity. The extent of charcoal deposition differs depending on the distance to the fire source and according to Umbanhowar et al. (2009) also on grazing activity. Overgrazing reduces biomass and consequently the fuel for fire. Pastureland is used locally, hence at some locations more biomass is reduced by livestock than in other areas. Hence, it can be assumed that presumably all fires in the area are of anthropogenic origin.

\section{Conclusions}

Our new palaeoecological findings contribute to the understanding of the late Holocene climate and human land use history over the last 1,350 cal yr BP in western Mongolia. The period from 1,350 to $670 \mathrm{cal}$ yr BP was characterized by high proportions of moist high mountain vegetation and grass 
steppe indicating relatively cold and rather dry climatic conditions. An increasing abundance of Larix suggests a climatic improvement from 670 to $400 \mathrm{cal}$ yr BP. Smaller stem increments and an increasing abundance of steppe vegetation point to an episode of cooler and drier conditions associated with the LIA. At around $200 \mathrm{cal} \mathrm{yr} \mathrm{BP,} \mathrm{the} \mathrm{forest} \mathrm{started} \mathrm{to} \mathrm{recover} \mathrm{gradually} \mathrm{indicating}$ warmer and wetter conditions. Since the mid- $20^{\text {th }}$ century pollen and tree-ring data reflect the ongoing global climate warming.

Our study revealed the strong potential of including dendrochronological datasets into multi-proxy palaeoecological studies. The results from the Mongolian Altai show that each discipline of our research offered temporally and spatially independent insights into climate dynamics and humanenvironment interactions. Although data availability is limited and differing time resolutions complicate a joint evaluation of data, tree-ring records strengthen the entire palaeoecological chronology.

\section{Acknowledgements}

This research project was carried out at Georg-August-Universität Göttingen, Germany, and supported by the German Science Foundation (DFG) (AZ: BE 2116/28-1) as well as by a grant from the Volkswagen Foundation to Ch. Dulamsuren for the project "Forest regeneration and biodiversity at the forest-steppe border of the Altai and Khangai Mountains under contrasting developments of livestock numbers in Kazakhstan and Mongolia". The team of Prof. G. Punsalpaamuu from the Mongolian State University of Education, Ulaanbaatar, and Prof. U. Beket from Bayan-Ulgii are thanked for their help during field work. We ae grateful to U. Nüsse-Hahne and A. Lemkul for preparing palynological and macro charcoal samples. 


\section{Chapter 6: Synthesis}

The late Holocene multi-proxy records from the Altai Tavan Bogd National Park in the Mongolian Altai are an important contribution to the understanding of vegetation-, fire-, climate- and human history in the high altitudes of Central Asia. In particular, the new data contributes to raise awareness about human involvement in environmental changes during the late Holocene.

The purpose of combining a multi-proxy approach with a multi-site study was to derive as much information on the dynamics of the forest-steppe biome in the Mongolian Altai as possible. The advantage of including various archives (lacustrine and peat sediments) with different catchment areas (large and small lake) and locations at different altitudes (steppe below forest line, within the forest belt, steppe above the forest line) is the detection of local and regional signals as well as natural and anthropogenic influences. Since this is the first time that this kind of study was carried out on Central Asian sediments, data interpretation is challenging. Strengths and weaknesses of all proxies need to be considered, whereas difficulties in the interpretation of multi-site data mainly result from different temporal resolution of the five sediment cores and differing recorded time periods.

\section{Palaeoenvironmental change in the Mongolian Altai since 4,310 cal yr BP Vegetation-, climate-, grazing- and fire dynamics}

Vegetation and climate over the last 4,310 cal yr BP are reconstructed based on pollen data of five sediment cores (D3L6, D1L1, Ch, Tr5-2B and G2-A; Fig. 1.6) and diatom analyses on two lacustrine cores (D3L6 and D1L1). A composite diagram of the tree and shrub percentages of all sediment cores examined within the framework of this study is shown in Figure 6.1. It reflects the forest dynamics in the area around Dayan Nuur in the Mongolian Altai during the end of the mid- and the late Holocene.

Pollen-based reconstructions show that pollen assemblages differ on a very small spatial scale. However, there is a recognizable trend in four of five sediment cores. During the mid-Holocene and the beginning of the late Holocene (4,310 to 1,040 cal yr BP), the area was dominated by a mixture of open coniferous forest and high-mountain steppe suggesting warm and moist climatic conditions. At some point, steppe communities expanded noticeably, and forest was reduced. The timeframe and the extent of forest reduction vary from 2,610 cal yr BP inferred from the peat core above the forest belt to $1,040 \mathrm{cal} \mathrm{yr}$ BP inferred from lacustrine sediments in the large lake (D3L6) below the lower forest line to 820 cal yr BP inferred from the smaller lake (D1L1) below the lower forest line. In any case, the minimum of forest area occurred between 1,000 and $500 \mathrm{cal} \mathrm{yr} \mathrm{BP,} \mathrm{indicating} \mathrm{colder} \mathrm{and}$ 
drier conditions. A correlation of D3L6 (large lake) and Tr5-2B (within forest belt) pollen data suggests that forest was markedly reduced on the north-facing slopes in the area, but Larix sibirica stands did not disappear completely.

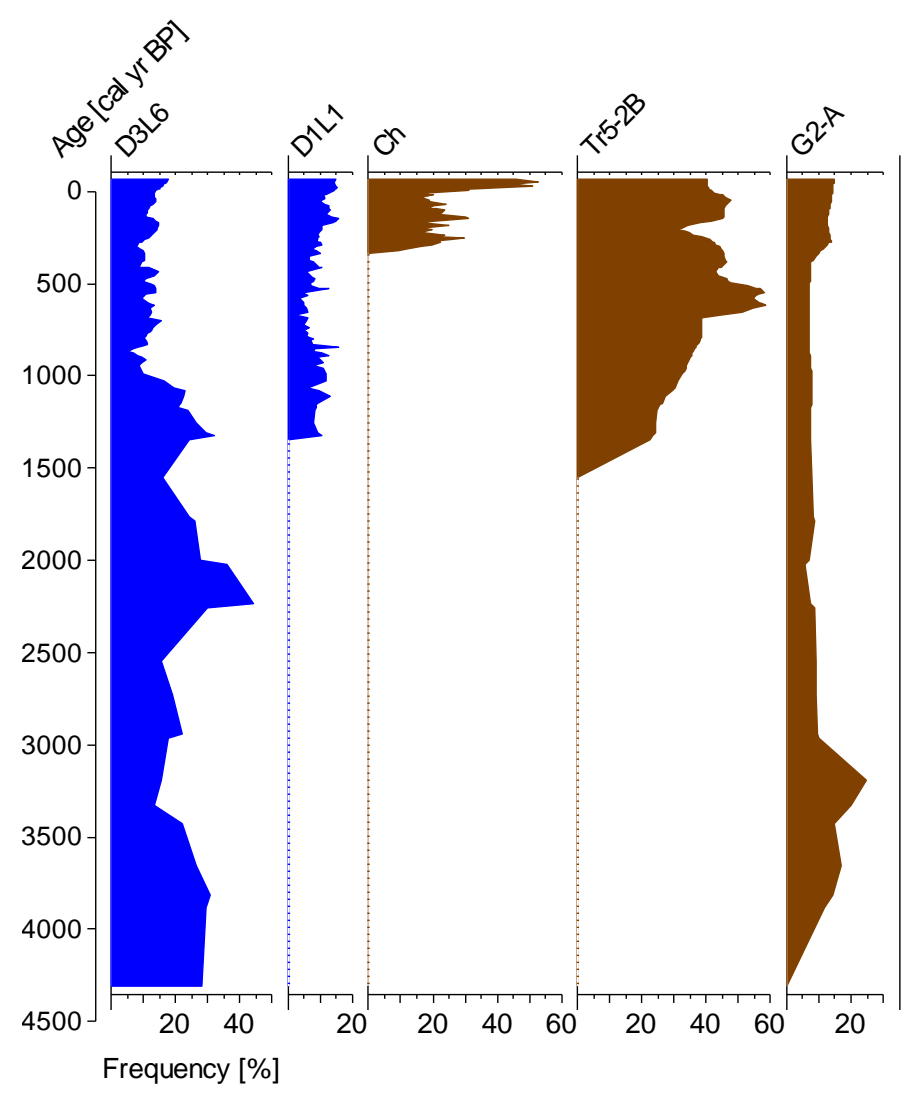

Fig 6.1 Multi-site trees and shrubs pollen percentages. Large lake: D3L6, small lake: D1L1 (blue), peat core below forest belt: $\mathrm{Ch}$, within forest belt: $\operatorname{Tr} 5-2 \mathrm{~B}$ and above forest belt: G2-A (brown).
Over the last centuries, since around 250 cal yr BP, a slow recovery of the open larch forest landscape took place. Furthermore, all investigated sites show a prominent increase in tree and shrub vegetation from around 20 cal $\mathrm{yr} \mathrm{BP}$ (AD 1930) to present. There is no doubt that the climate warming of the $20^{\text {th }}$ century has an impact on permafrost degradation and glacier melting in the area (Walther et al., 2017), and the increased vegetation cover reflects shifts in moisture availability.

The new palynological data are in line with several records from the Mongolian Altai and adjacent areas (e.g. Brügger et al., 2018; Huang et al., 2018; Liu et al., 2009; Sun et al., 2013) suggesting a warm and humid period during the mid-Holocene and a climatic cooling under increasing aridity for the

late Holocene in north-western Mongolia. In contrast, reconstructions from Central Mongolia (e.g. Fowell et al., 2003; Peck et al., 2002; Soninkhishig et al., 2003; Wang et al., 2009) provide information of a more humid episode during the late Holocene. In this respect, some explanations have been offered regarding different circulation systems impacting north-western and central/eastern Mongolia. As nowadays, in the late Holocene, the Altai Mountains were only dominated by the westerlies, whereas the limit of the south-eastern Asian and Indian summer monsoon was shifted several hundreds of kilometers to the West (Fig. 1.3).

Grazing dynamics and anthropogenic influence on environmental changes during the last 4,310 cal yr BP are reconstructed based on coprophilous fungi data (Sporormiella and Sordaria-type fungal spores) from four of the five sediment cores (D3L6, D1L1, Ch and Tr5-2B). In Fig. 6.2, a composite 
diagram of the Sporormiella influx is displayed. It reflects the grazing pressure in the Dayan Nuur area during the mid- and late Holocene allowing conclusions regarding nomadic settlement in the study area.

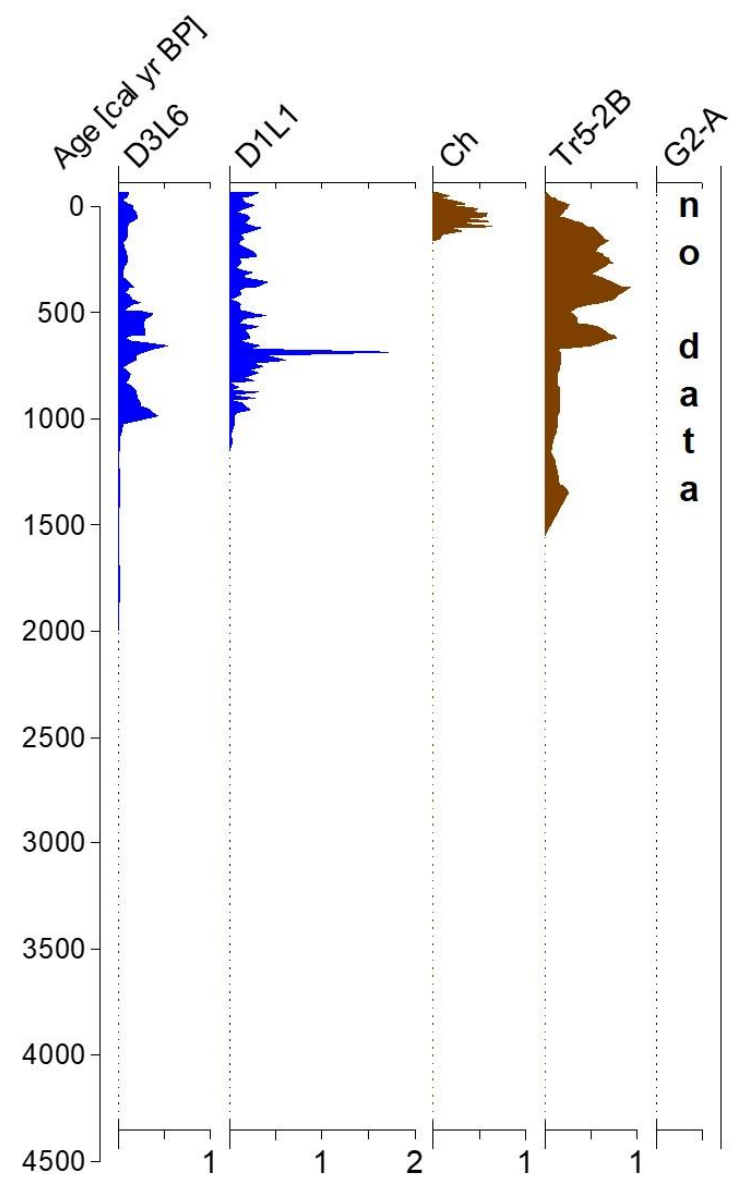

Fig 6.2 Multi-site Sporormiella influx. Big lake: D3L6, small lake: D1L1 (blue), peat core below forest belt: $\mathrm{Ch}$, within forest belt: Tr5-2B and above forest belt: G2-A (brown).
Sporormiella spore data show that influx values of coprophilous fungi seem to vary according to the origin of the sediment core within the study area. Similar trends can be observed in the two lacustrine sediment cores, whereas the Sporormiella-based reconstructions from the two peat sequences close to the Chinese border and within the forest tree line show contrasting results. However, the first occurrences of a few Sporormiella spores between around 2,000 and 1,000 cal yr BP (D3L6) are the first evidence of a change from hunters and gatherers to nomadic herding in the area. Around 1,000 cal yr BP local grazing activities intensified in lower elevations (D1L1, D3L6) and expanded to the forest belt in higher elevations at around $700 \mathrm{cal}$ yr BP (Tr52B). Grazing intensification correlated with a marked forest decline (D1L1, D3L6), possibly indicating a shift of the lower forest boundary to higher elevations. During the Mongol Empire (744 to 582 cal yr BP), a consistent short-term grazing maximum occurred. It was most likely caused by temporarily altered climatic conditions (rise in temperature and precipitation) which had positive effects on pasture conditions. Since then, nomads have constantly been present in the area south of Dayan Nuur regardless of the political power on Mongolian territory. Whereas over the last around $600 \mathrm{cal}$ yr BP grazing pressure oscillated on a lesser scale in lower elevations, grazing within the forest increased. Presumably, livestock preferred forested areas due to its higher biomass (Arnold, 1987).

The reconstruction of fire dynamics since 4,310 cal yr BP in the Altai Tavan Bogd National Park is based on macro-charcoal data of the five above mentioned sediment cores. A composite diagram of 
macro-charcoal influx results in presented in Fig. 6.3. It depicts periods of lower and increased regional fire activity during the mid- and late Holocene.

In general, trends in fire frequency are more consistent among the five cores than forest expansion and grazing activity data. In all cores, fire frequency was very low from 4,310 to 1,000 cal yr BP. After 1,000 cal yr BP, fire frequency increased in accord with growing anthropogenic impact and climate aridity. Fire maxima over the last approx. 1,000 cal yr BP are reflected in all but one sediment cores (G2-A, peat core above the forest belt). The most prominent episodes of increased fire activity occurred from around 930 to $780 \mathrm{cal}$ yr BP, from 570 to $520 \mathrm{cal}$ yr BP and from 260 to $160 \mathrm{cal} \mathrm{yr}$ $\mathrm{BP}$, whereas the extent of charcoal deposition varied locally. The strong representation of macrocharcoal in core Tr5-2B within the forest belt from 570 to 520 cal yr BP may suggest a rather local origin of the fire indicated by more burned biomass.

Over the last $200 \mathrm{cal}$ yr BP, only a very low amount of charred material was deposited in the area indicating a markedly decreased fire frequency. One possible explanation for these observations could be that in modern times local nomadic inhabitants are more aware of the additional risk for environmental destruction due to unlimited use of fire and reduce it to a minimum.

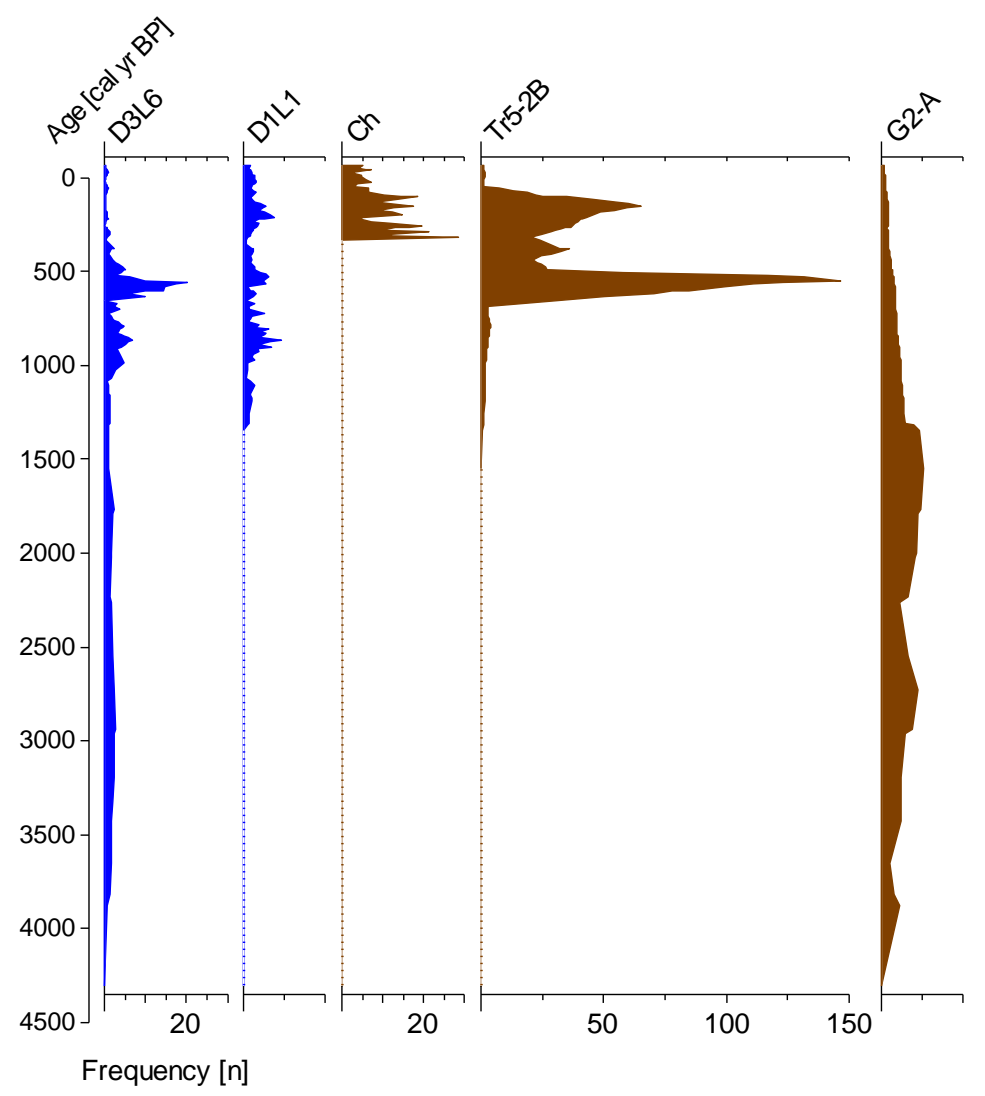

Fig. 6.3 Multi-site macro-charcoal influx. Big lake: D3L6, small lake: D1L1 (blue), peat core below forest belt: $\mathrm{Ch}$, within forest belt: Tr5-2B and above forest belt: G2-A (brown).
The general trends of charcoal influx in his research are in accordance with the findings by Brügger et al. (2018) from Tsambagarav glacier in the north-eastern part of the Mongolian Altai. They reconstructed that dead biomass resulting from forest and steppe community diebacks due to an increase in aridity serve as additional fuel for future fires from the correlation of dry periods with increased fire activity. This coherence seems to explain the charcoal influx maximum starting from 1,000 cal yr BP after the Larix forest reduction. The extent of charcoal deposition differs depending on 
the distance to the fire source and according to Umbanhowar et al. (2009) also on grazing activity. Overgrazing reduces biomass and consequently the fuel for fire. Pastureland is used locally, hence at some locations more biomass is reduced by livestock than in other areas.

\section{Multi-proxy multi-site evidence}

Multi-proxy research is a valuable tool to gather information on independent palaeoproxies, learn about ecosystem processes and put future actions into perspective. However, there are several factors that need to be considered to assess the findings from this study regarding the reliability of multiproxy evidence as well as the strengths and weaknesses of the multi-site approach. A multi-site study enables to examine the varying response to natural and anthropogenic impact of different vegetation types and to determine whether environmental changes are regional or rather local For example, it is possible to distinguish between locally limited or widespread regional fires, if steppe vegetation responds differently to fire activity than forest vegetation or if grazing activity is attached to a specific vegetation type of a certain elevation.

As expected, the composite diagrams in Figs. 6.1 to 6.3 show both similarities (regional signals) and differences (local signals), whereas the differing time resolutions impede a joint evaluation. However, some important aspects become apparent regarding the different types of archives. Both lacustrine records provide similar patterns of vegetation and grazing dynamics for the overlapping period, indicating valid and rather regional trends. Vegetation and grazing dynamics reconstructed from the peat sequences vary widely, especially in core Tr5-2B from within the forest belt. These differences could either be attributed to productivity and pollen transport of the immediate plant communities or a varying response of Larix forest vegetation to natural and anthropogenic influences compared to steppe vegetation.

Regarding the fire frequency during the mid- and late Holocene similar patterns are observed in all sediment cores below and within the forest belt. Markedly contrasting trends are found in the record above the forest line. Lacustrine sediment record D3L6 confirms the regional significance of fire events from around 1,000 to $500 \mathrm{cal}$ yr BP and their rather local extent from $500 \mathrm{cal}$ yr BP to present.

\section{Outlook}

\section{Implications for sustainable land use and conservation management}

The new research data from Altai Tavan Bogd National Park can contribute to the understanding of climate change and especially vegetation degradation due to overgrazing pose in the Altai Mountains. Despite of that Mongolia is sparsely populated but overgrazing by livestock is a serious threat to the environment as well as (illegal) tree-cutting for export, mining and poaching, because local 
inhabitants are socio-economically fully dependent on these natural resources. In the past, the traditional way of herding and grazing has been characterized by resource-preserving actions, but due to more intensive, market-driven practices (e.g. increased global demand for Kashmir wool, herders competing for the best pastures), nomads have to pursue new ways of sustaining their income (Beket and Knapp, 2012).

The multi-site data examined in this research reveals general vegetation recovery (expansion of forest and shrub species, increase in biodiversity) over the last decades, but they rather seem to originate from effects of climate warming than as a consequence of the current management strategies in the National Park. To promote a sustainable vegetation development, more political and management actions are required, which should combine socio-economical demands of the local inhabitants with the conservation of the forest-steppe biome. These actions could include a reorganization of the three existing zones within the National Park, e.g. an expansion of the special conservation zone at the cost of the tourism and limited use zone or a restriction of grazing activities in the tourism zone. In any case, more care should be taken to ensure compliance with restrictions concerning land use and hunting activities. One political element could be subsidizing and economically support herding families who are willing to reduce their number of livestock to improve the conservation management situation in the Altai Tavan Bogd National Park.

\section{Perspectives on future research}

The high-resolution multi-proxy results complied in this thesis underline the importance of multisite investigations for a better understanding of palaeoenvironmental processes and their driving factors. The number of comparable studies is still rather limited; therefore, it is essential to encourage the establishment of more relevant research in the Altai Mountains and in other areas all over the world. Additionally, it would be of interest to find longer records spanning back to the early Holocene. Several palaeoecological investigations in other forest-steppe areas in northern and central Mongolia are needed. These studies might unravel more information on climate patterns and the significance of different circulation systems impacting Central Asia. These studies will also allow to gain a more comprehensive view on local human impact and their role in environmental and biodiversity changes during the Holocene.

Pollen-based vegetation reconstructions suggest stable climate patterns with short-term oscillations over the past 4,310 cal yr BP. An advantage of the stable climate patterns is that the area is particularly suitable to investigate anthropogenic influence on the vegetation. More archaeological studies dealing with herding and grazing habits (e.g. nomadic movements, number and types of livestock, etc.) in high-mountain areas of Central Asia might be useful to unravel external influences that may lead to significant changes in nomadic activities. Understanding these diverse socio- 
political processes over the past two millennia may contribute to the basic understanding of the extent of human impact on the vegetation in the Mongolian Altai. It is of particular importance because the new data suggests that anthropogenic impact might be a more prominent impact factor for environmental change and vegetation degradation than climate change. The results show that over the last 1,000 cal yr BP, human impact due to grazing and other economic activities seems to superimpose climate signals. Another approach could be to find more suitable proxies to better depict the human impact in the sediment archives, because the reconstruction of grazing and herding activities just from NPPs was challenging. The identification of all coprophilous fungi is difficult due to the lack of reference material for Central Asia. Additionally, some coprophilous fungi cannot be sufficiently distinguished from saprophilous fungi, because they do also grow on other organic matter such as decayed wood (e.g. Arnium, Delitschia). Hence, the interpretation of anthropogenic impact in this research was only based on Sporormiella and Sordaria-type fungal spores, which could be identified reliably. However, the main challenge was to evaluate the extent of "background signal" by wild animals in the samples. Distortion of results by wild animals is considered negligible in this study. If there was a significant number of wild animals in the area, there would have been coprophilous fungi in the samples prior to their first occurrence at around 2,350 cal yr BP.

The slight trend of vegetation recovery over the last 70 to 50 years and the establishment of the National Park in 1996 do not diminish the need to manage the conservation of the forest-steppe ecotone and its biodiversity. Further studies on recent environmental processes and stricter political actions might be needed to make sure conservation strategies are implemented the most efficient way. Additional statistical calibration of recent pollen data might as well improve the interpretation of palynological processes. 


\section{Bibliography}

AM Online Projects, 2019. Klima \& Wetter in Ölgii. https://de.climate-data.org/location/29828/ (accessed 15 January 2019).

An, C.B., Lu, Y.B., Zhao, J.J., Tao, S.C., Dong, W.M., Li, H., Jin, M., Wang, Z.L., 2011. A highresolution record of Holocene environmental and climatic changes from lake Balikun (Xinjiang, China), implications for central Asia. The Holocene 22, 43-52.

Andreev, A.A., Pierau, R., Kalugin, I.A., Daryin, A.V., Smolyaninova, L.G., Diekmann, B., 2007. Environmental changes in the northern Altai during the last millennium documented in Lake Teletskoye pollen record. Quaternary Research 67, 394-399.

Arnold, G.W., 1987. Influence of the biomass, botanical composition and sward height of annual pastures on foraging behavior by sheep. Journal of Applied Ecology 24(3), 759-772.

Baker, A.G., Bhagwat, S.A., Willis, K.J., 2013. Do dung fungal spores make a good proxy for past distribution of large herbivores. Quaternary Science Reviews 62, 21-31.

Beket, U., 2009. The Vegetation of the Mongolian Altai. Problems of sustainable land use and nature conservation. BfN-Skripten 257, 1-318.

Beket, U. and Knapp, H.D., 2012. Protection of the Natural and Cultural Heritage of the Mongolian Altai. Exploration into the Biological Resources of Mongolia 12, 335-352.

Beug, H.J., 2004. Leitfaden der Pollenbestimmung für Mitteleuropa und angrenzende Gebiete. Pfeil, München.

Bhateria, R., Jain, D., 2016. Water quality assessment of lake water: a review. Sustainable Water Resources Management 2, 161-173.

Biagioni, S., 2015. Long-term dynamics of tropical rainforests, climate, fire, human impact and land-use change in Indonesia - A focus on the montane rainforests in Central Sulawesi and peatswamp rainforests in Sumatra. Dissertation. Georg-August-Universität Göttingen, pp. 201.

Birks, H.H., Birks, H.J.B., 2006. Multi-proxy studies in palaeolimnology. Vegetation History and Archaeobotany 15, 235-251.

Birks, H.J.B., 2003. Quantitative palaeoenvironmental reconstructions from Holocene biological data, in: Mackay A., Battarbee, R.W., Birks, H.J.B., Oldfield, F. (Eds.), Global change in the Holocene. Hodder Arnold, London, pp 107-123.

Birks, H.J.B., Berglund, B.E., 2018. One hundred years of Quaternary pollen analysis 1916-2016. Vegetation History and Archaeobotany 27(2), 271-309. 
Birks, H.J.B., Birks, H.H., 1980. Quaternary palaeoecology. Edward Arnold, London.

Blaauw, M., Christen, J.A., 2011. Flexible paleoclimate age-depth models using an autoregressive gamma process. Bayesian Anal. 6, 457-474.

Blaauw, M., Christen, J.A., Vazquez, J.E., Belding, T., Theiler, J., Gough, B., Karney, C., 2018. Rbacon - Age-Depth Modelling using Bayesian Statistics. Version 2.3.4 (15 April 2018)

Blyakharchuk, T.A., 2008. Reconstructing the vegetation of forest and alpine-steppe landscapes in the southwestern part of Tuva since the Late Glacial period till the present. Geography and Natural Resources 29.1, 57-62.

Blyakharchuk, T.A., Eirikh, A., Mitrofanova, E., Li, H. C., Kang, S.C., 2017. High resolution palaeoecological records for climatic and environmental changes during the last 1350 years from Manzherok Lake, western foothills of the Altai Mountains, Russia. Quaternary International 447, 59-74.

Blyakharchuk, T.A., Wright, H.E., Borodavko, P.S., van der Knaap, W.O., Ammann, B., 2004. Late Glacial and Holocene vegetational changes on the Ulagan high-mountain plateau, Altai Mountains, southern Siberia. Palaeogeography, Palaeoclimatology, Palaeoecology 209, 259-279.

Blyakharchuk, T.A., Wright, H.E., Borodavko, P.S., van der Knaap, W.O., Ammann, B., 2007. Late Glacialvegetational history of the Altai Mountains (southwestern Tuva Republic, Siberia). Palaeogeography, Palaeoclimatology, Palaeoecology 245, 518-534.

Brugger, S.O., Gobet, E., Sigl, M., Osmont, D., Papina, T., Rudaya, N., Schwikowski, M., Tinner, W., 2018. Ice records provide new insights into climatic vulnerability of Central Asian forest and steppe communities. Global and Planetary Change 169, 188-201.

Burney, D.A., Robinson, G.S., Burney, L.P., 2003. Sporormiella and the late Holocene extinctions in Madagascar. Proceedings of the National Academy of Sciences 100, 10800-10805.

Chen, C.A., Lan, H., Lou, J., Chen, Y., 2003. The Dry Holocene Megathermal in Inner Mongolia. Palaeogeography, Palaeoclimatology, Palaeoecology 193, 181-200.

Chen, F., Yuan, Y., Wei, W., Fan, Z., Zhang, T., Shang, H., Zhang, R., Yu, S., Ji, C., Qin, L., 2012. Climatic response of ring width and maximum latewood density of Larix sibirica in the Altay Mountains, reveals recent warming trends. Annals of Forest Science 69, 723-733.

Chenlemuge T., Hertel, D., Dulamsuren, Ch., Khishigjargal, M., Leuschner, C., Hauck, M., 2013. Extremely low fine root biomass in Larix sibirica forests at the southern drought limit of the boreal forest. Flora 208, 488-496. 
Chlachula, J., 2019. Environmental context and adaptations of prehistoric and early historical occupation in the Southern Altai (SW Siberia-East Kazakhstan). Archaeological and Anthropological Sciences 11(5), 2215-2236.

Clark, J.S., 1988. Particle motion and the theory of charcoal analysis: source area, transport, deposition and sampling. Quaternary Research 30, 67-80.

Clark, J.S., 1990. Fire and climate change during the last $750 \mathrm{yr}$ in Northwestern Minnesota. Ecological Monographs 60, 135-159.

Clark, J.S., Royall, P.D., 1995. Particle-size evidence for source areas of charcoal accumulation in late Holocene sediments of eastern north American lakes. Quaternary Research 43, 80-89.

Croudace, I.W., Rindby, A., Rothwell, R.G., 2006. ITRAX: description and evaluation of a new multi-function X-ray core scanner, in: R.G. Rothwell (Ed.), New Techniques in sediment core analysis. Geological Society Special Publications, pp. 51-63.

Cunningham, D., Windley, B., Dorjnamjaa, D., Badamgarov, G., Saandar, M., 1996. A structural transect across the Mongolian Western Altai: Active transpressional mountain building in central Asia. Tectonics 15, 142-156.

Cunningham, D., 2005. Active intracontinental transpressional mountain building in the Mongolian Altai: Defining a new class of orogen. Earth Planet Science Letters 240/2, 436-444.

D’Arrigo, R., Jacoby, G., Pederson, N., Frank, D., Buckley, B., Nachin, B., Mijidorj, R., Dugarjav, C., 2000. Mongolian tree-rings, temperature sensitivity and reconstructions of Northern Hemisphere temperature. The Holocene 10.6, 669-672.

Davi, N.K., Jacoby, G.C., D’Arrigo, R.D.D., Baatarbileg, N., Jinbao, L., Curtis, A.E., 2009. A treering-based drought index reconstruction for far-western Mongolia: 1565-2004. International Journal of Climatology 29, 1508-1514.

Davis, O.K., 1987. Spores of the Dung Fungus Sporormiella: Increased Abundance in Historic Sediments and before Pleistocene Megafaunal Extinction. Quaternary Research 28, 290-294.

Davis, O.K., Agenbroad, L., Martin, P.S., Mead, J.I., 1984. The Pleistocene dung blanket of Bechan Cave, Utah. Special Publication of the Carnegie Museum of Natural History 8, 267-282.

Davis, O.K. Shafer, D.S., 2006. Sporormiella fungal spores, a palynological means of detecting herbivore density. Palaeogeography, Palaeoclimatology, Palaeoecology 237, 40-50.

Davison, W., 1988. Interactions of iron, carbon and sulphur in marine and lacustrine sediments, in: Fleet, A.J., Kelts, K., Talbott, M.R. (Eds.). Lacustrine Petroluem Source Rocks. Geological Society Special Publications, pp. 131-137. 
Demske, D., Tarasov, P.E., Nakagawa, T., Suigetsu 2006 Project Members, 2013. Atlas of pollen, spores and further non-pollen palynomorphs recorded in the glacial-interglacial late Quaternary sediments of Lake Suigetsu, central Japan. Quaternary International 290-291, 164-238.

Dirksen, V.G., van Geel, B., Koulkova, M.A., Zaitseva, G.I., Sementsov, A.A., Scott, E.M., Cook, G.T., van der Plicht, J., Lebedeva, L.M., Bourova, N.D., Bokovenko, N.A. 2007. Chronology of Holocene climate and vegetation changes and their connection to cultural dynamics in Southern Siberia. Radiocarbon 49(2), 1103-1121.

Doveri, F., 2004. Fungi fimicoli italici. A guide to the recognition of Basidiomycetes and Ascomycetes living on feacal material.

Dulamsuren, Ch., Hauck, M., Leuschner, C., 2010. Recent drought stress leads to growth reductions in Larix sibirica in the western Khentey, Mongolia. Global Change Biology 16, 30243035.

Dulamsuren, C., Khishigjargal, M., Leuschner, C., Hauck, M., 2014. Response of tree-ring width to climate warming and selective logging in larch forests of the Mongolian Altai. Journal of Plant Ecology 7, 24-38.

Dulamsuren, Ch., Klinge, M., Degener, J., Khishigjargal, M., Chenlemuge, T., Enerel, B., Yeruult, Y., Saindovdon, D., Ganbaatar, K., Tsogtbaatar, J., Leuschner, C., Hauck, M., 2016. Carbon pool densities and a first estimate of the total carbon pool in the Mongolian forest-steppe. Global Change Biology 22, 830-844.

Dulamsuren, Ch., Wommelsdorf, T., Zhao, F., Xue, Y., Zhumadilov, B.Z., Leuschner, C., Hauck, M., 2013. Increased summer temperatures reduce the growth and regeneration of Larix sibirica in southern boreal forests of eastern Kazakhstan. Ecosystems 16, 1536-1549.

Earle, C.J., 2015. The Gymnosperm Database. http://www.conifers.org (accessed 22 February 2018)

Eichler, A., Tinner, W., Brütsch, S., Olivier, S., Papina, T., Schwikowski, M., 2011. An ice-core based history of Siberian forest fires since AD 1250. Quaternary Science Reviews 30, 1027-1034.

Ekberg I., Eriksson, G., 1966. Development and fertility of pollen in three species of Larix. Hereditas 57, 303-311.

Ekblom, A., Gillson, L., 2010. Dung fungi as indicators of past herbivore abundance, Kruger and Limpopo National Park. Palaeogeography, Palaeoclimatology, Palaeoecology 296(1-2), 14-27.

El-Moslimany, A.P., 1990. Ecological significance of common nonarboreal pollen: Examples from drylands of the Middle East. Review of Palaeobotany and Palynology 64, 343-350. 
Enkhtaivan, D., 2006. Physical-Geographical characteristics of the Altai region. In: Vogtmann, H., Dobretsov, N. (Eds.). Environmental Security and Sustainable Land Use - with special reference to Central Asia. NATO Security through Science Series, Springer, Dordrecht.

Ėnkhtör, A., Bemmann, J., Brosseder, U., 2018. The first excavations of bronze and iron age monuments in the middle Orkhon Valley, Central Mongolia: Results from rescue investigations in 2006 and 2007. Asian Archaeology 1, 3-44.

Faegri, K., Iversen, J., 1950. Textbook of Pollen Analysis. Einar Munksgaard, Copenhagen. Faegri, K., Iversen, J., 1989. Textbook of Pollen Analysis, fourth ed. Jon Wiley and Sons, New York.

Feng, Z., Sun, A., Abdusalih, N., Ran, M., Kurban, A., Lan, B., Zhang, D., Yang, Y., 2017. Vegetation changes and associated climatic changes in the southern Altai Mountains within China during the Holocene. The Holocene 27(5), 683-693.

Fernández-Giménez, M.E., 1999. Sustaining the steppes: A geographical history of pastoral land use in Mongolia. The Geographical Review 89 (3), 315-342.

Fernández-Giménez, M.E., Venable, N.H., Angerer, J., Fassnacht, S.R., Reid, R.S., Khishigbayar, J., 2017. Exploring linked ecological and cultural tipping points in Mongolia. Anthropocene 17, 4669.

Fowell, S. J., Hansen, B. C., Peck, J. A., Khosbayar, P., Ganbold, E., 2003. Mid to late Holocene climate evolution of the Lake Telmen Basin, North Central Mongolia, based on palynological data. Quaternary Research, 59(3), 353-363.

Frachetti, M.D. 2012. Multiregional emergence of mobile pastoralism and nonuniform institutional complexity across Eurasia. Current Anthropology 53(1), 2-38.

Fries, M., 1967. Lennart von Post's pollen diagram series of 1916. Review of Palaeobotany and Palynology 4(1-4), 9-13.

Garcés-Pastor, S., Gutiérrez-Merino, E., Martínez-Sancho, E., Dorado-Liñán, I., Julio Camarero, J., Cañellas-Boltà, N., Vegas-Vilarrúbia, T., 2019. Subalpine forest dynamics reconstructed throughout the last 700 years in the Central Pyrenees by means of tree rings and pollen. The Holocene 29(2), 300-312.

González-Ruiz, M., Santos, C., Jordana, X., Simón, M., Laluzera-Fox, C., Gigli, E., Aluja, M.P., Malgosa, A., 2012. Tracing the Origin of the East-West Population Admixture in the Altai Region (Central Asia). PLos One 7, 1-11.

Google Inc., 2019. Google Earth Pro, version 7.3 https://www.google.de/earth/download/ 
gep/agree.html (accessed 03 August 2019)

Grimm, E., 1987. CONISS: A FORTRAN 77 program for stratigraphically constrained cluster analysis by the methods of incremental sum of squares. Computers \& Geoscience 13, 13-15. Grimm, E., 1991. TILIA and TILIAGRAPH. Springfield, Illinois, United States of America. Grunert, J., Lehmkuhl, F., Walther, M., 2000. Paleoclimatic evolution of the Uvs Nuur basin and adjacent areas (Western Mongolia). Quaternary International 65/66, 171-192.

Guiot, J., Wu, H., Garreta, V., Hatté, C., Magny, M., 2009. A few prospective ideas on climate reconstruction: from a statistical single proxy approach towards a multi-proxy and dynamical approach. 〈hal-00429384〉

Gunin, P.D., Vostokova, E.A., Dorofeyuk, N.I., Tarasov, P.E., Black, C.C., 1999. Vegetation dynamics of Mongolia. Kluwer Academic Publishers, Dordrecht.

Haberzettl, T., Wille, M., Fey, M., Janssen, S., Lücke, A., Mayr, C., Ohlendorf, C., Schäbitz, F., Schleser, G.H., Zolitschka, B., 2006. Environmental change and fire history of southern Patagonia (Argentina) during the last five centuries. Quaternary International 158, 72-82.

Hauck, M., Javkhlan, S., Lkhagvadorj, D., Bayartogtokh, B., Dulamsuren, C., Leuschner, C., 2012. Edge and land-use effects on epiphytic lichen diversity in the forest-steppe ecotone of the Mongolian Altai. Flora-Morphology, Distribution, Functional Ecology of Plants 207(6), 450-458. Havinga, A.J., 1967. Palynology and pollen preservation. Review of Palaeobotany and Palynology 2, 81-98.

Herzschuh, U., 2006. Palaeo-moisture evolution in monsoonal Central Asia during the last 50,000 years. Quaternary Science Reviews 25, 163-178.

Herzschuh, U., 2007. Reliability of pollen ratios for environmental reconstructions on the Tibetan Plateau. Journal of Biogeography 34, 1265-1273.

Herzschuh, U., Kramer, A., Mischke, S., Zhang, C., 2009. Quantitative climate and vegetation trends since the late glacial on the northeastern Tibetan Plateau deduced from Koucha Lake pollen spectra. Quaternary Research 71, 162-171.

Higuera, P.E., Brubaker, L.B., Anderson, P.M., Hu, F.S., Brown, T.A., 2009. Vegetation mediated the impacts of postglacial climatic change on fire regimes in the south-central Brooks Range, Alaska. Ecology Monographs 79, 201-219.

Higuera, P.E., Peters, M.E., Brubaker, L.B., Gavin, D.G., 2007. Understanding the origin and analysis of sediment-charcoal records with a simulation model. Quaternary Science Reviews 26, 1790-1809. 
Hilbig, W., 1995. The Vegetation of Mongolia. SPB Academic Publishing, Amsterdam.

Hirano, A., Batbileg, B., 2013. Identifying Trends in the Distribution of Vegetation in Mongolia in the Decade after its Transition to a Market Economy. Japan Agricultural Research Quarterly 47(2), 203-208.

Hodell, D.A., Anselmetti, F.S., Ariztegui, D., Brenner, M., Curtis, J.H., Gilli, A., Grzesik, D.A., Guilderson, T.J., Müller, A.D., Bush, M.B., Correa-Metrio, A., Escobar, J., Kutterolf, S., 2008. An 85-ka record of climate change in lowland Central America. Quaternary Science Reviews 27, 1152-1165.

Holcombe, C., 2014. The Xianbei in Chinese History. Early Medieval China 19, 1-38.

Houle, J.L., 2015. Bronze Age Mongolia. DOI:10.1093/oxfordhb/9780199935413.013.20

Huang, X., Peng, W., Rudaya, N., Grimm, E.C., Chen, X., Cao, X., Zhang, J., Liu, S., Chen, C., Chen, F., 2018. Holocene Vegetation and Climate Dynamics in the Altai Mountains and Surrounding Areas. Geophysical Research Letters 45, 6628-6636.

Ilyashuk, B.P., Ilyashuk, E.A., 2007. Chironomid record of Late Quaternary climatic and environmental changes from two sites in Central Asia (Tuva Republic, Russia) - local, regional or global causes? Quaternary Science Reviews 26, 705-731.

Jacoby, G.C., Baatarbileg, N., 2003. Results of the Dendrochronological Studies in Mongolia. Mongolian Journal of Biological Sciences 1(1), 69-76.

Jäger, E.J., 2011. Rothmaler - Exkursionsflora von Deutschland. Gefäßpflanzen: Grundband. 20. Auflage. Spektrum Akademischer Verlag, Heidelberg.

Johnson, D.A., Sheehy, D.P., Miller, D., Damiran, D., 2006. Mongolian rangelands in transition. Sécheresse 17(1-2), 133-141.

Jolivet, M., Ritz, J., Vassallo, R., Larroque, C., Braucher, R., Todbileg, M., Chauvet, A., Sue, C., Arnaud, N., De Vicente, R., Arzhanikova, A., Arzhanikov, S., 2007. Mongolian Summits: An uplifted, flat, old but still preserved erosion surface. The Geological Society of America 35(10), 871-874.

Juggins, S., 2017. rioja - Analysis of Quaternary Science Data, version 0.9-15.1 (accessed 16 June 2017)

Kalugin, I., Darin, A., Rogozin, D., Tretyakov, G., 2013. Seasonal and centennial cycles of carbonate mineralisation during the past 2500 years from varved sediment in Lake Shira, South Siberia. Quaternary International 290-291, 245-252. 
Kalugin, I., Selegei, V., Gldberg, E., Seret, G., 2005. Rhythmic fine-grained sediment deposition in Lake Teletskoye, Altai, Siberia, in relation to regional climate change. Quaternary International $136,5-13$.

Khishigjargal, M., Dulamsuren, Ch., Lkhagvadorj, D., Leuschner, C., Hauck, M., 2013. Contrasting responses of seedling and sapling densities to livestock density in the Mongolian forest-steppe. Plant Ecology 214, 1391-1403.

Klinge, M., Böhner, J., Lehmkuhl, F., 2003. Climate pattern, snow- and timberlines in the Altai Mountains, Central Asia. Erdkunde 57, 296-308.

Klinge, M., Dulamsuren, C., Erasmi, S., Karger, D. N., Hauck, M., 2018. Climate effects on vegetation vitality at the treeline of boreal forests of Mongolia. Biogeosciences 15(5), 1319-1333.

Klinge, M., Lehmkuhl, F., Schulte, P., Hülle, D., Nottebaum, V., 2017. Implications of (reworked) aeolian sediments and paleosols for Holocene environmental change in Western Mongolia. Geomorphology 292, 59-71.

Klinge, M., Sauer, D., 2019. Spatial pattern of Late Glacial and Holocene climatic and environmental development in Western Mongolia - A critical review and synthesis. Quaternary Science Reviews 210, 26-50.

Kovalev, A.A., Erdenebaatar, D. 2009. Discovery of new cultures of the Bronze Age in Mongolia according to the data obtained by the international Central Asian Archaeological Expedition. In Bemmann, J., Parzinger, H., Pohl, E., Tseveendorj, D., editors, Current archeological research in Mongolia, pp. 149-170.

Kradin, N.N., 2005. From tribal confederation to empire: the evolution of the Rouran society. Acta Orientalia 58(2), 149-169.

Krammer, K., Lange-Bertalot, H., 1986. Bacillariophyceae: Naviculaceae, in: Ettle, H., Gerloff, J., Heynig, H., Mollenhauer, D. (Eds.), Süsswasserflora von Mitteleuropa, Vol. 2/1, G. Fisher, Stuttgart, New York.

Krammer, K., Lange-Bertalot, H., 1988. Bacillariophyceae: Bacillariaceae, Epithemiaceae, Surirellaceae. Surirellaceae, in: Ettle, H., Gerloff, J., Heynig, H., Mollenhauer, D. (Eds.), Süsswasserflora von Mitteleuropa, Vol. 2/2, G. Fisher, Stuttgart, New York.

Krammer, K., Lange-Bertalot, H., 1991a. Bacillariophyceae: Centrales, Fragilariaceae, Eunotiaceae, in: Ettle, H., Gerloff, J., Heynig, H., Mollenhauer, D. (Eds.), Süsswasserflora von Mitteleuropa, Vol. 2/3, G. Fisher, Stuttgart, Jena. 
Krammer, K., Lange-Bertalot, H., 1991b. Bacillariophyceae: Achnanthaceae, in: Ettle, H., Gartner, G., Gerloff, J., Heynig, H., Mollenhauer, D. (Eds.), Süsswasserflora von Mitteleuropa, Vol. 2/4, G. Fisher, Stuttgart, Jena.

Kürschner, H., Herzschuh, U., Wagner, D., 2005. Phytosociological studies in the north-eastern Tibetian Plateau (NW China) - a first contribution to the scrub and alpine meadow vegetation. Botanische Jahrbücher 126(3), 273-315.

Kylander, M., Ampel, L., Wohlfarth, B., Veres, D., 2011. High-resolution X-ray fluorescence core scanning analysis of Les Echets (France) sedimentary sequence: new insights from chemical proxies. Journal of Quaternary Science 26, 109-117.

Lehmkuhl, F., 1997. The spatial distribution of loess and loess-like sediments in the mountain areas of Central and High Asia. Zeitschrift für Geomorphologie, Supplementband, 97-116.

Lehmkuhl, F., 2012. Holocene glaciers in the Mongolian Altai: An example from the TurgenKharkhiraa. Journal of Asian Earth Sciences 52, 12-20.

Lehmkuhl, F., Grunert, J., Hülle, D., Batkhishig, O., Stauch, G., 2018. Paleolakes in the Gobi region of southern Mongolia. Quaternary Science Reviews 179, 1-23.

Lehmkuhl, F., Hilgers, A., Fries, S., Hülle, D., Schlütz, F., Shumilovskikh, L., Felauer, T., Protze, J., 2011. Holocene geomorphological processes and soil development as indicator for environmental change around Karakorum, Upper Orkhon Valley (Central Mongolia). Catena 87, $31-44$.

Lehmkuhl, F., Klinge, M., Rother, H., Hülle, D., 2016. Distribution and timing of Holocene and late Pleistocene glacier fluctuations in western Mongolia. Annals of Glaciology 57(71), 169-178.

Lehmkuhl, F., Klinge, M., Stauch, G., 2011. The extent and timing of Late Pleistocene Glaciations in the Altai and neighbouring mountain systems. Developments in Quaternary Sciences 15, 967979.

Li, Y., Zhang, Y., Wang, J., Wang, L., Li, Y., Chen, L., Zhao, L., Kong, Z., 2019. Preliminary study on pollen, charcoal records and environmental evolution of Alahake Saline Lake Xinjiang since 4,700 cal yr BP. Quaternary International 513, 8-17.

Lin, X., Rioual, P., Peng, W., Yang, H., Huang, X., 2018. Impact of recent climate change on Lake Kanas, Altai Mountains (N.W. China), inferred from diatom and geochemical evidence. Journal of Paleolimnology 59, 461-477.

Liu, H., Cui, H., Pott, R., Speier, M., 1999. The surface pollen of the woodland-steppe ecotone in southeastern Inner Mongolia, China. Review of Palaeobotany and Palynology 105, 237-250. 
Liu, H., Williams, A.P., Allen, C.D., Guo, D., Wu, X., Anenkhonov, O.A., Liang, E., Sandanov, D.V., Yin, Y., Qi, Z., Badmaeva, N.K., 2013. Rapid warming accelerates tree growth decline in semi-arid forests of Inner Asia. Global Change Biology 19, 2500-2510.

Liu, X., Herzschuh, U., Shen, J., Jiang, Q., Xiao, X., 2008. Holocene environmental and climatic changes inferred from Wulungu Lake in northern Xinjiang, China. Quaternary Research 70, 412425 .

Lkhagvadorj, D., Hauck, M., Dulamsuren, C., Tsogtbaatar, J., 2013. Pastoral nomadism in the forest-steppe of the Mongolian Altai under a changing economy and a warming climate. Journal of Arid Environments 88, 82-89.

Mann, M.E., 2002. The value of multiple proxies. Science 297, 1481-1482.

Miehe, G., Miehe, S., Kaiser, K., Reudenbach, C., Behrendes, L., Duo, L., Schlütz, F., 2009. How old is pastoralism in Tibet? An ecological approach to the making of a Tibetan landscape. Palaeogeography, Palaeoclimatology, Palaeoecology 276, 130-147.

Miehe, G., Schlütz, F., Miehe, S., Opgenoorth, L., Cermak, J., Samiya, R., Jäger, E.J., Wesche, K., 2007. Mountain forest islands and Holocene environmental changes in Central Asia: A case study from the southern Gobi Altay, Mongolia. Palaeogeography, Palaeoclimatology, Palaeoecology 250, $150-166$.

Minckley, T., Whitlock, C., 2000. Spacial variation of modern pollen in Oregon and southern Washington, USA. Review of Palaeobotany and Palynology 112, 97-127.

Murad, W., 2011. Late Quaternary Vegetation History and Climate Change in the Gobi Desert, South Mongolia. Dissertation. Georg-August-Universität Göttingen, pp. 139.

Mustaphi, C.C., Pisaric, M.F.J., 2014. A classification for macroscopic charcoal morphologies found in Holocene lacustrine sediments. Progress in Physical Geography, 1-14.

Nelle, O., Dreibrodt, S., Dannath, Y., 2010. Combining pollen and charcoal: evaluating Holocene vegetation composition and dynamics. Journal of Archaeological Science 37, 2126-2135.

Neuffer, B., Oyuntsetseg, B., Schamsran Z., Friesen, N., Hurka, H., 2003. Contribution to the knowledge of the Flora of the Mongolian Altai. Feddes Repertorium 114, 358-371.

Noshiro, S., Terada, K., Tsuji, S., Suzuki, M., 1997. Larix-Picea forests of the Last Glacial Age on the eastern slope of Towada volcano in northern Japan. Review of Palaeobotany and Palynology 98, 207-222. 
Ohlendorf, C., Wennrich, V., Enters, D., 2015. Experiences with XRF-canning of long sediment records, in: G. Rothwell, I.W. Croudace (Eds.), Micro-XRF Studies of Sediment Cores. Springer, Netherlands, pp. 351-372.

Oksanen, J., 2013. Multivariate Analysis of Ecological Communities in R: Vegan Tutorial (accessed 17 June 2017).

Oksanen, J., Blanchet, F.G., Friendly, M., Kindt, R., Legendre, P., McGlinn, D., Minchin, P.R., O'Hara, R.B., Simpson, G.L., Solymos, P., Henry, M., Stevens, H., Szoecs, E., Wagner, H., 2018. vegan - Community Ecology Package, version 2.5-1 (accessed 13 April 2018).

Park, J. S., Diimaajav, E., Gelegdorj, E., 2017. Evolution of Mongolian bronze technology with the rise of the Xiongnu State. Archaeological and Anthropological Sciences 9(5), 789-798.

Peck, J. A., Khosbayar, P., Fowell, S. J., Pearce, R. B., Ariunbileg, S., Hansen, B. C., Soninkhishig, N., 2002. Mid to Late Holocene climate change in north central Mongolia as recorded in the sediments of Lake Telmen. Palaeogeography, Palaeoclimatology, Palaeoecology 183(1-2), 135153.

Pederson, N., Hessl, A. E., Baatarbileg, N., Anchukaitis, K. J., Di Cosmo, N., 2014. Pluvials, droughts, the Mongol Empire, and modern Mongolia. Proceedings of the National Academy of Sciences 111(12), 4375-4379.

Pelánková, B., Chytrý, M., 2009. Surface pollen-vegetation relationships in the forest-steppe, taiga ad tundra landscape of the Russian Altai Mountains. Review of Palaeobotany and Palynology 157, 253-265.

Perrotti, A.G., van Asperen, E., 2019. Dung fungi as a proxy for megaherbivores: opportunities and limitations for archaeological applications. Vegetation History and Archaeobotany 28, 93-104.

Pitkänen, A., Huttunen, P., 1999. A 1300-year forest-fire history at a site in eastern Finland based on charcoal and pollen records in laminated lake sediment. The Holocene 9.3, 311-320.

Raper, D., Bush, M., 2009. A test of Sporormiella representation as a predictor of megaherbivore presence and abundance. Quaternary Research 71, 490-496.

Reimer, P.J., Bard, E., Bayliss, A., Beck, J.W., Blackwell, P.G., Bronk Ramsey, C., Buck, C.E., Edwards, R.L., Friedrich, M., Grootes, P.M., Guilderson, T.P., Haflidason, H., Hajdas, I., Hatté, C., Heaton, T.J., Hoffmann, D.L., Hogg, A.G., Hughen, K.A., Kaiser, K.F., Kromer, B., Manning, S.W., Niu, M., Reimer, R.W., Richards, D.A., Scott, M.E., Southon, J.R., Turney, C.S.M., van der Plicht, J., 2013. IntCal13 and Marine13 radiocarbon age calibration curves 0-50,000 yr cal yr BP. Radiocarbon 55(4), 1869-1887. 
Roepke, A., Stobbe, A., Oeggl, K., Kalis, A.J., Tinner, W., 2011. Late Holocene land-use history and environmental changes at the high altitudes of St Antönien (Switzerland, Northern Alps): Combined evidence from pollen, soil and tree-ring analyses. Holocene 21(3), 485-498.

Rogers, J. D., Bemmann, J., Schmauder, M., 2015. Empire dynamics and Inner Asia. Complexity of interaction along the Eurasian steppe zone in the first millennium. Bonn Contributions to Asian Archaeology 7, 73-88.

RStudio Team, 2019. RStudio: Integrated Development for R. RStudio, Inc., Boston, MA http://www.rstudio.com/ (accessed 30 January 2019).

Rudaya, N., Li, H.C., 2013. A new approach for reconstruction of the Holocene climate in the Mongolian Altai: The high-resolution $\delta^{13} \mathrm{C}$ records of TOC and pollen complexes in Hoton-Nur Lake sediments. Journal of Asian Earth Sciences 69, 185-195.

Rudaya, N., Nazarova, L., Novenko, E., Andreev, A., Kalugin, I., Daryin, A., Babich, V., Li, H., Shilov, P., 2016. Quantitative reconstructions of mid-to late Holocene climate and vegetation in the north-eastern Altai Mountains recorded in Lake Teletskoye. Global Planetary Change 141, 12-24.

Rudaya, N., Tarasov, P.E., Dorofeyuk, N.I., Kalugin, I.A., Andreev, A.A., Diekmann, B., Daryin, A.V., 2008. Environmental changes in the Mongolian Altai during the Holocene. Archaeology Ethnology and Anthropology of Eurasia 36/4, 2-14.

Rudaya, N., Tarasov, P.E., Dorofeyuk, N.I., Solovieva, N., Kalugin, I., Andreev, A., Daryin, A., Diekmann, B., Riedel, F., Tserendash, N., Wagner, M., 2009. Holocene environments and climate in the Mongolian Altai reconstructed from the Hoton-Nur pollen and diatom records: a step towards better understanding climate dynamics in Central Asia. Quaternary Science Reviews 28, 540-554.

Šamonil, P., Moravcová, A., Pokorný, P., Žáčková, P., Kašpar, J., Vašǐčková, I., ... Leuschner, H. H., 2018. The disturbance regime of an Early Holocene swamp forest in the Czech Republic, as revealed by dendroecological, pollen and macrofossil data. Palaeogeography, Palaeoclimatology, Palaeoecology 507, 81-96.

Savina, L.N., Burenina, T.A., 1981. Sokhrannost'pyl’tsy listvennitsy v lesnykh pochvakh i otrazhenie sostava listvennichnykh lesov Mongolii v retsentnykh spektrakh (Preservation of Larix pollen in forest floors, and the resent pollen spectra as a reflection of composition of the larch forests of Mongolia), in: Savina, L.N. (Ed.): Paleobotanicheskie issledovaniya v lesakh Severnoi Azii (Palaeobotanical invesigations in the forests of North Asia), pp. 62-83.

Schaller, T., Wehrli, B., 1996. Geochemical-focusing of manganese in lake sediments - an indicator of deep-water oxygen conditions. Aquatic Geochemistry 2, 359-378. 
Schlütz, F., Dulamsuren, C., Wieckowska, M., Mühlenberg, M., Hauck, M., 2008. Late Holocene vegetation history suggests natural origin of steppes in the northern Mongolian mountain taiga. Palaeogeography, Palaeoclimatology, Palaeoecology 261, 203-217.

Schlütz, F., Lehmkuhl, F., 2007. Climatic change in the Russian Altai, southern Siberia, based on palynological and geomorphological results, with implications for climatic teleconnections and human history since the middle Holocene. Vegetation History and Archaeobotany 16, 101-118. Schlütz, F., Miehe, G., Lehmkuhl, F., 2007. Zur Geschichte des größten alpinen Ökosystems der Erde: Palynologische Untersuchungen zu den Kobresia-Matten SE-Tibets. Berichte der ReinholdTüxen-Gesellschaft 19, 23-36.

Schmidt, R.W., Seguchi, N., 2016. Craniofacial variation of the Xiongnu Iron Age nomads of Mongolia reveals their possible origins and population history. Quaternary International 405, 110 121.

Schwanghart, W., Frechen, M., Kuhn, N.J., Schüttin, B., 2009. Holocene environmental changes in the Ugii Nuur basin, Mongolia. Palaeogeography, Palaeoclimatology, Palaeoecology 279, 160-171.

Shumilovskikh, L. S. 2018. NON-POLLEN PALYNOMORPHS "extra fossils" in pollen slides. http://nonpollenpalynomorphs.tsu.ru/ (accessed 11 October 2018).

Shumilovskikh, L.S., 2019. NPP database. http://nonpollenpalynomorphs.tsu.ru /NPP_Database.html (accessed 03 June 2019).

Shumilovskikh, L.S., Schlütz, F., Achterberg, I., Bauerochse, A., Leuschner, H.H., 2015. Nonpollen Palynomorphs from Mid-Holocene peat of the raised bog Borsteler Moor (Lower Saxony, Germany). Studia Quaternaria 32, 5-18.

Sidorova, O.V., Saurer, M., Myglan, V.S., Eichler, A., Schwikowski, M., Kirdyanov, A.V., Bryukhanova, M.V., Gerasimova, O.V., Kalugin, I.A., Daryin, A.V., Siegwolf, R.T.W., 2012. A multi-proxy approach for revealing recent climatic changes in the Russian Altai. Climate Dynamics 38, 175-188.

Simpson, G.L., Oksanen, J., 2016. analogue - Analogue and Weighted Averaging Methods for Palaeoecology, version 0.17-0 (accessed 27 February 2016).

Smol, J.P., 2002. Pollution of lakes and rivers-a paleoenvironmental perspective. Arnold, London.

Soma, T., 2014. Current Situation and Issues of Transhumant Animal Herding in Sagsai County, Bayan-Ulgii Province, Western Mongolia. E-journal GEO 9, 102-119.

Sommer, M., Treter, U., 1999. Die Lärchenwälder der Gebirgswaldsteppe in den Randgebirgen des Uvs Nuur-Beckens. Die Erde 130, 173-188. 
Soninkhishig, N., Edlund, M.B., Peck, J.A., 2003. Diatom-based paleoenvironmental reconstruction of Lake Telmen for the last 6230 years. Mongolian Journal of Biological Sciences $1(1), 55-68$.

Stevens, L., Ito, E., Olson, D., 2000. Relationship of Mn-carbonates in varved lake-sediments to catchment vegetation in Big Watab Lake, MN, USA. Journal of Paleolimnology 24(2), 199-211.

Stevenson, J., Haberle, S., 2005. Macro Charcoal Analysis: A modified technique used by the Department of Archaeology and Natural History. Palaeoworks Technical Papers 5. Australian National University, Canberra.

Stivrins, N., Cerina, A., Gałka, M., Heinsalu, A., Lõugas, L., Veski, S., 2019. Large herbivore population and vegetation dynamics 14,600-8300 years ago in central Latvia, northeastern Europe. Review of Palaeobotany and Palynology 266, 42-51.

Sugita, S., 2007. Theory of quantitative reconstruction of vegetation II: all you need is LOVE. The Holocene 17.2, 243-257.

Sun, A., Feng, Z., Ran, M., Zhang, C., 2013. Pollen-recorded bioclimatic variations of the last 22,600 years retrieved from Achit Nuur core in the western Mongolian Plateau. Quaternary International 311, 36-43.

Syromyatina, M.V., Kurochkin, Y.N., Bliakharskii, D.P., Chistyakov, K.V., 2015. Current dynamics of glaciers in the Tavan Bogd Mountains (Northwest Mongolia). Environmental Earth Science 74, 1905-1914.

Szeicz, J.M., Haberle, S.G., Bennett, K.D., 2003. Dynamics of North Patagonian rainforests from fine-resolution pollen, charcoal and tree-ring analysis, Chonos Archipelago, Southern Chile. Austral Ecology 28, 413-422.

Tao, S.C., An, C.B., Chen, F.H., Tang, L.Y., Wang, Z.L., Lü, Y.B., Li, Z.F., Zheng, T.M., Zhao, J.J., 2010. Pollen-inferred vegetation and environmental changes since 16,7 ka BP at Balikun Lake, Xinjiang. Chinese Science Bulletin 55, 2,449-2,457.

Tarasov, P.E., Demske, D., Leipe, C., Long, T., Müller, S., Hoelzmann, P., Wagner, M., 2019. An 8500-year palynological record of vegetation, climate change and human activity in the Bosten Lake region of Northwest China. Palaeogeography, Palaeoclimatology, Palaeoecology 516, 166178.

Tarasov, P.E., Dorofeyuk, N., Metel'tseva, E., 2000. Holocene vegetation and climate changes in Hoton-Nur basin, northwest Mongolia. Boreas 29, 117-126. 
Tarasov, P.E., Müller, S., Zech, M., Andreeva, D., Diekmann, B., Leipe, C., 2013. Last glacial vegetation reconstructions in the extreme-continental eastern Asia: potentials of pollen and nalkane biomarker analyses. Quaternary International 290-291, 253-263.

Telford, R.J., Birks, H.J.B., 2009. Evaluation of transfer functions in spacially structured environments. Quaternary Science Reviews 28, 1309-1316.

Tian, F., Herzschuh, U., Dallmeyer, A., Xu, Q., Mischke, S., Biskaborn, B., 2013. Environmental variability in the monsoon-westerlies transition zone during the last 1200 years: lake sediment analyses from central Mongolia and supra-regional synthesis. Quaternary Science Reviews 73, 3147.

Tian, F., Herzschuh, U., Telford, R. J., Mischke, S., Van der Meeren, T., Krengel, M., 2014. A modern pollen-climate calibration set from central-western Mongolia and its application to a late glacial-Holocene record. Journal of Biogeography 41(10), 1909-1922.

Tumen, D., 2006. Paleoanthropology of ancient populations of Mongolia. Mongolian Journal of Anthropology, Archaeology and Ethnology 54(2), 90-108.

Twitchett, D., Mote, F., 1998. The Cambridge History of China. Cambridge University Press, doi:10.1017/CHOL9780521243339

Umbanhowar, C.E., McGrath, M.J., 1998. Experimental production and analysis of microscopic charcoal from wood, leaves and grasses. The Holocene 8.3, 341-346.

Umbanhowar, C.E., Shinneman, A.L.C., Tserenkhand, G., Hammon, E.R., Lor, P., Nail, K., 2009. Regional fire history based on charcoal analysis of sediments from nine lakes in western Mongolia. The Holocene 19.4, 611-624.

Unkel, I., Schimmelmann, A., Shriner, C., Forsén, J., Heymann, C., Brückner, H., 2014. The environmental history of the last 6500 years in the Asea Valley (Peloponnese, Greece) and its linkage to the local archaeological record. Zeitschrift für Geomorphologie 58(Suppl. 2), 89-107. Unkelbach, J., Dulamsuren, C., Punsalpaamuu, G., Saindovdon, D., Behling, H., 2018. Late Holocene vegetation, climate, human and fire history of the forest-steppe ecosystem inferred from core G2-A in the 'Altai Tavan Bogd' conservation area in Mongolia. Vegetation History and Archaeobotany 27(5), 665-677.

Unkelbach, J., Kashima, K., Enters, D., Dulamsuren, Ch., Behling, H., 2020. Decadal highresolution multi-proxy analysis to reconstruct natural and human induced environmental changes over the last 1350 cal. yr BP in the Altai Tavan Bogd National Park, western Mongolia. The Holocene, https://doi.org/10.1177/0959683620908662. 
Unkelbach, J., Kashima, K., Enters, D., Dulamsuren, Ch., Punsalpaamuu, G., Behling, H., 2019. Late Holocene (Meghalayan) palaeoenvironmental evolution inferred from multi-proxy-studies of lacustrine sediments from the Dayan Nuur region of Mongolia. Palaeogeography,

Palaeoclimatology, Palaeoecology 530, 1-14.

Vadetskaya, E.B. 1986. Arkeologicheskie Pamyatniki v stepyakh srednevo Yeniseya. Leningrad (in Russian).

Van Dam, H., Mertens, A., Sinkeldam, J., 1994. A coded checklist and ecological indicator values of freshwater diatoms from the Netherlands. Netherlands Journal of Aquatic Ecology 28(1), 117133.

Van Geel, B., 1978. A palaeoecological study of Holocene peat bog sections in Germany and the Netherlands. Review of Palaeobotany and Palynology 25, 1-120.

Van Geel, B., 2001. Non-pollen palynomorphs, in: Smol, J.P., Birks, H.J.B., Last, W.M. (Eds.), Tracking environmental change using lake sediments. Volume 3: Terrestrial, algal, and siliceous indicators, Kluwer Academic Publishers, Dordrecht, pp. 99-119.

Van Geel, B., Bokovenko, N.A., Burova, N.D., Chugunov, K.V., Dergachev, V.A., Dirksen, V.G., Kulkova, M., Nagler, A., Parzinger, H., Van der Plicht, J., Vasiliev, S.S., Zaitseva, G.I., 2004. Climate change and the expansion of the Scythian culture after 850 BC: a hypothesis. Journal of Archaeological Science 31, 1735-1742.

Van Geel, B., Buurman, J., Brinkkemper, O., Schelvis, J., Aptroot, A., van Reenen, G., Hakbijl, T., 2003. Environmental reconstruction of a Roman Period settlement site in Uitgeest (The Netherlands), with special reference to coprophilous fungi. Journal of Archaeological Science 30, 873-883.

Van Geel, B., Gelorini, V., Lyaruu, A., Aptroot, A., Rucina, S., Marchant, R., Sinninghe Damsté, J. S., Verschuren, D., 2011. Diversity and ecology of tropical African fungal spores from a 25,000year palaeoenvironmental record in southeastern Kenya. Review of Palaeobotany and Palynology $164,174-190$.

Volkov, V.V., 1995. Early Nomads of Mongolia, in: J. Davis-Kimball, V. A. Bashilov, L. T. Yablonsky (Eds.), Nomads of the Eurasian steppes in the early Iron Age. Zinat Press, New Haven, pp. 317-333.

Walther, M., Dashtseren, A., Kamp, U., Temujin, K., Meixner, F., Pan, C.G., Gansukh, Y., 2017. Glaciers, permafrost and lake levels at the Tsengel Khairkhan Massif, Mongolian Altai, during the Late Pleistocene and Holocene. Geosciences 73, 1-20. 
Wang, W., Ma, Y.Z., Feng, Z.D., Meng, H., Sang, Y., Zhai, X.W., 2009. Vegetation and climate changes during the last $8660 \mathrm{cal} \mathrm{y.} \mathrm{BP} \mathrm{in} \mathrm{central} \mathrm{Mongolia,} \mathrm{based} \mathrm{on} \mathrm{a} \mathrm{high-resolution} \mathrm{pollen}$ record from Lake Ugii Nuur. Chinese Science Bulletin 54, 1,579-1,589.

Wang, W., Ma, Y.Z., Feng, Z.D., Narantsetseg, T., Liu, K.B., Zhai, X.W., 2011. A prolonged dry mid-Holocene climate revealed by pollen and diatom records from Lake Ugii Nuur in central Mongolia. Quaternary International 229, 74-83.

Watanabe, T., Ohtsuka, T., Tuji, A., Houki, A., 2005. Picture book and ecology of the freshwater diatoms. Uchida Rokakuho Publishing Co., Tokyo.

Wersin, P., Höhener, P., Giovanoli, R., Stumm, W., 1991. Early diagenetic influences on iron transformations in a freshwater lake sediment. Chemical Geology 90, 233-252.

Wesche, K., Miehe, S., Miehe, G., 2005. Plant communities of the Gobi Gurvan Sayhan National Park (South Gobi Aymag, Mongolia). Candollea 60, 149-205.

Whitlock, C., Larsen, C., 2001. Charcoal as a fire proxy, in: Smol, J.P., Birks, H.J.B., Last, W.M. (Eds.), Tracking Environmental Change Using Lake Sediments. Terrestrial, Algal and Siliceeous Indicators, vol. 3. Kluwer Academic Publishers, Dordrecht, pp. 75-93.

Whitlock, C., Millspaugh, S.H., 1996. Testing the assumptions of fire-history studies: an examination of modern charcoal accumulation in Yellowstne National Park, USA. The Holocene 6, $7-15$.

Whitmore, T.J., 1989. Florida diatom assemblages as indicators of trophic state and pH. Limnology and Oceanography 34(5), 882-895.

Wick, L., Möhl, A., 2006. The mid-Holocene extinction of silver fir (Abies alba) in the Southern Alps: a consequence of forest fires? Palaeobotanical records and forest simulations. Vegetation History and Archaeobotany 15, 435-444.

Willard, D.A., Bernhardt, C.E., Weimer, L., Cooper, S.R., Gamez, D., Jensen, J., 2004. Atlas of pollen and spores of the Florida Everglades. Palynology 28, 175-227.

Wischnewski, J., Herzschuh, U., Rühland, K. M., Bräuning, A., Mischke, S., Smol, J. P., Wang, L. 2014. Recent ecological responses to climate variability and human impacts in the Nianbaoyeze Mountains (eastern Tibetan Plateau) inferred from pollen, diatom and tree-ring data. Journal of Paleolimnology 51(2), 287-302.

Ykhanbai, H., Bulgan, E., Beket, U., Vernooy, R., Graham, J., 2004. Reversing grassland degradation and improving herders' livelihoods in the Altai Mountains of Mongolia. Mountain Research and Development 24(2), 96-100. 
Zhang, D., Feng, Z., 2018. Holocene climate variations in the Altai Mountains and the surrounding areas: A synthesis of pollen records. Earth Science Reviews 185, 847-869.

Zhang, Q., Cheng, G., Yao, T., Kang, X., Huang, J., 2003. A 2,326-year tree-ring record of climate variability on the northeastern Qinghai-Tibetan Plateau. Geophysical Research Letters 30, 17391742.

Zhang, Y., Meyers, P.A., Liu, X., Wang, G., Ma, X., Li, X., Yuan, Y., Wen, B., 2016. Holocene climate changes in the central Asia mountain region inferred from a peat sequence from the Altai Mountains, Xinjiang, northwestern China. Quaternary Science Reviews 152, 19-30.

Zhao, Y., Liu, H., Li, F., Huang, J.S., Zhao, W., Herzschuh, U., Tang, Y., 2012. Application and limitations of the Artemisia/Chenopodiaceae pollen ratio in arid and semi-arid China. The Holocene 22(12), 1385-1392. 


\section{Appendix A}

Atlas of identified pollen, spore, non-pollen palynomorph taxa and macro-charcoal morphotypes

Appendix A1: Atlas of identified pollen and spore taxa

Appendix A2: Atlas of identified non-pollen palynomorphs (NPPs)

Appendix A3: Atlas of identified macro-charcoal morphotypes 


\section{Appendix A1: Atlas of identified pollen and spore taxa}

The atlas comprises all pollen and spore taxa identified during the research in the Mongolian Altai. They are presented by pollen type (if available), family and lake code of records, where they occur. Scale bars are depicted within the pollen and spore pictures. By analogy with the pollen diagrams, the atlas is divided into (A) trees and shrubs, (B) herbaceous and aquatic plants, (C) unknown pollen types and (D) ferns and mosses. Unknown pollen types are presented by lake code of (first) occurrence and a consecutive letter.

\section{(A) Trees and shrubs}

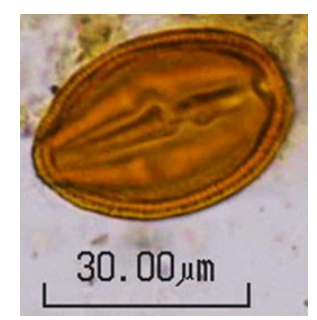

Rhus toxicodendron Anacardiaceae Ch, D1L1

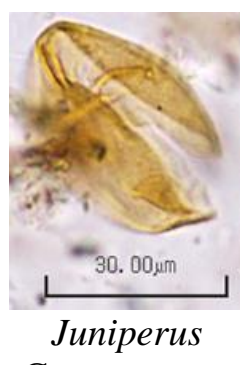

Cupressaceae Ch, D1L1, D3L6, G2-A, Tr5-2B

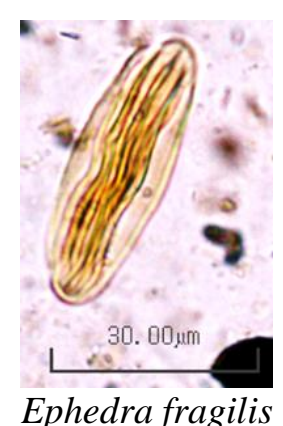

Ephedraceae

Ch, D1L1, D3L6, G2-A, Tr5-2B

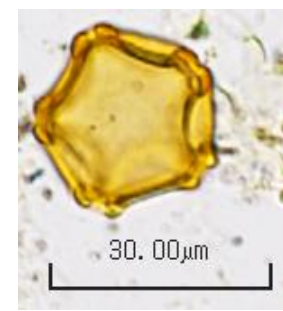

Alnus

Betulaceae

Ch, D3L6

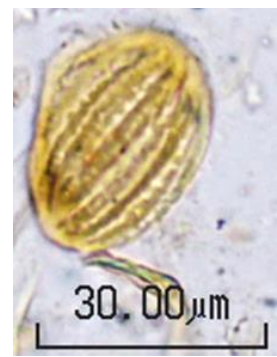

Ephedra sp.

Ephedraceae

Ch, D1L1

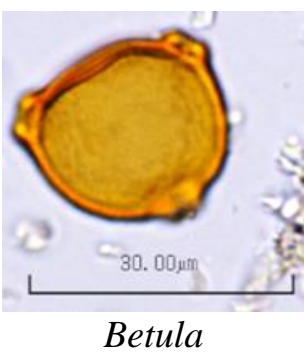

Betulaceae

Ch, D1L1, D3L6,

G2-A, Tr5-2B

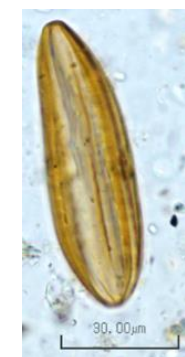

Ephedra distachya

Ephedraceae

Ch, D1L1, D3L6,

G2-A, Tr5-2B

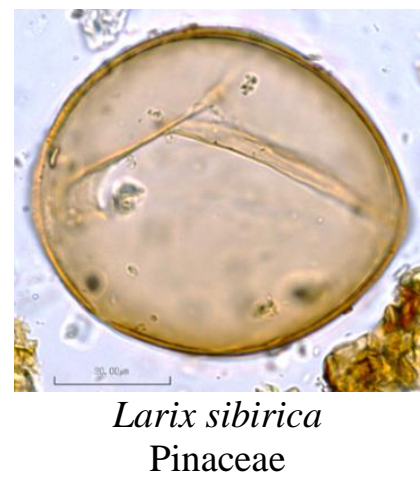

Ch, D1L1, D3L6, G2-A, Tr5-2B

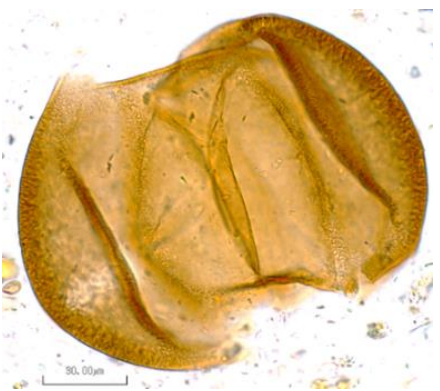

Picea obovata

Pinaceae

Ch, D1L1, D3L6, G2-A, Tr5-2B 


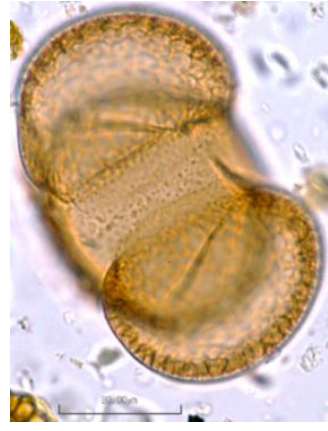

Pinus sibirica

Pinaceae

Ch, D1L1, D3L6,

G2-A, Tr5-2B

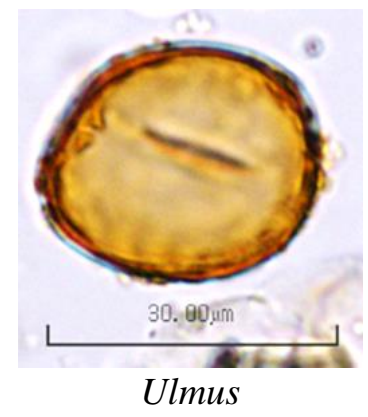

Ulmaceae

Ch, D1L1, D3L6,

G2-A, Tr5-2B

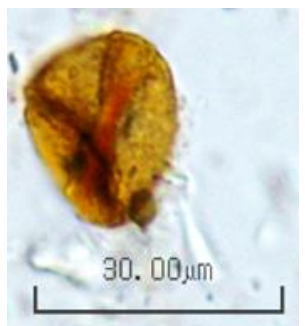

Populus suaveolens Salicaceae

Ch, D1L1, D3L6, G2-A, Tr5-2B
30. $00 \mu \mathrm{m}$

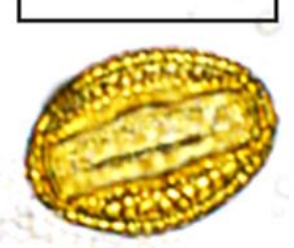

Salix

Salicaceae

Ch, D1L1, D3L6,

G2-A, Tr5-2B

(B) Herbaceous and aquatic plants

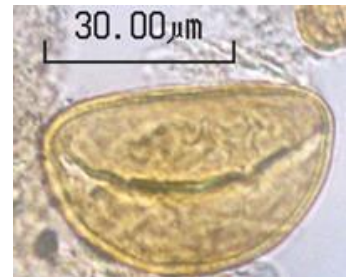

Allium

Amaryllidaceae

Ch, D1L1, G2-A

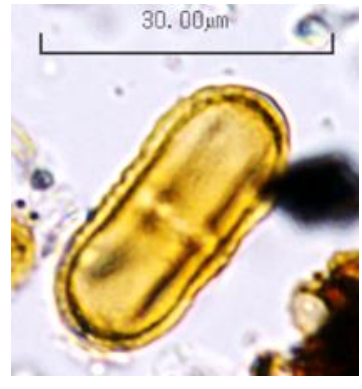

Apiaceae

Ch, D1L1, D3L6,

G2-A, Tr5-2B

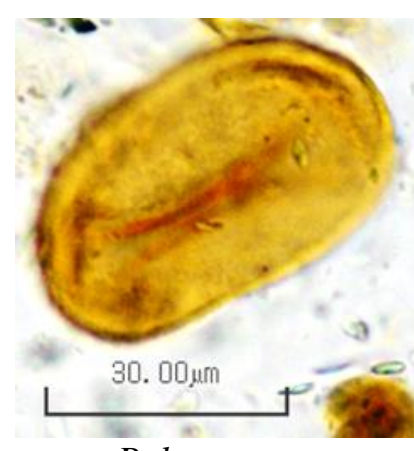

Polygonatum

Aspagaraceae

D3L6, G2-A, Tr5-2B 

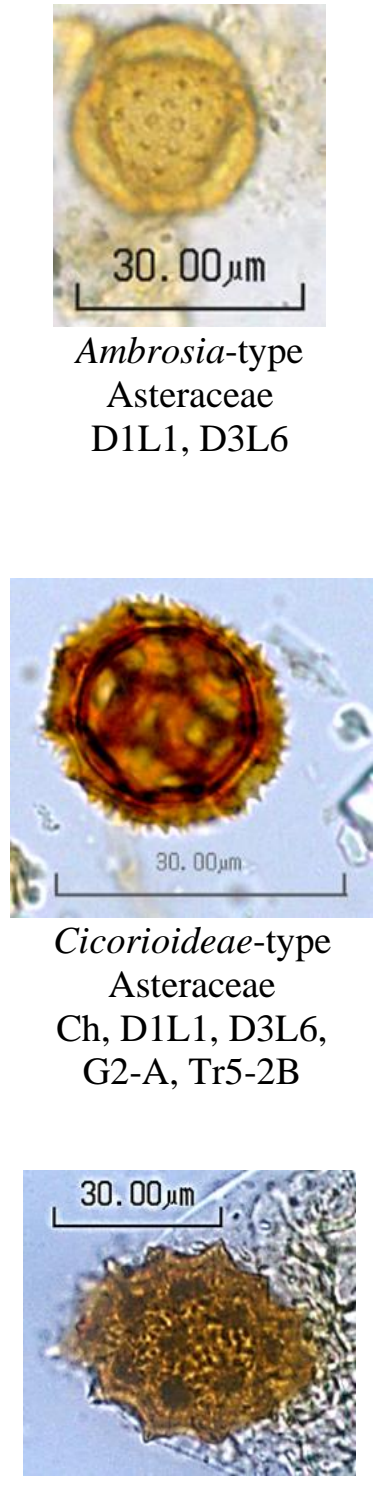

Asteraceae Ch, D1L1

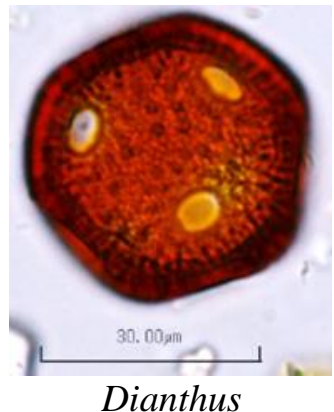

Caryophyllaceae Ch, D1L1, D3L6, G2-A, Tr5-2B

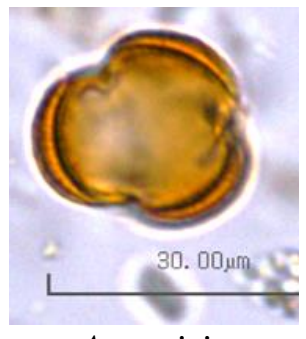

Artemisia

Asteraceae

Ch, D1L1, D3L6,

G2-A, Tr5-2B

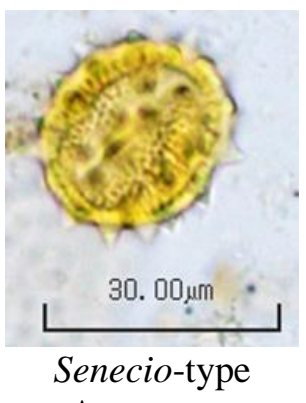

Asteraceae

Ch, D1L1, D3L6,

G2-A, Tr5-2B

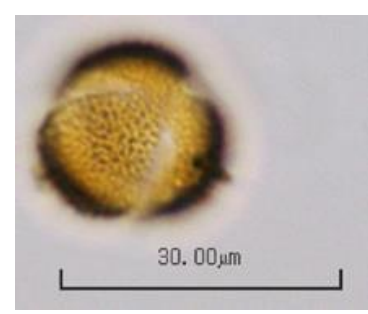

Brassicaceae Ch, D1L1, D3L6, G2-A, Tr5-2B

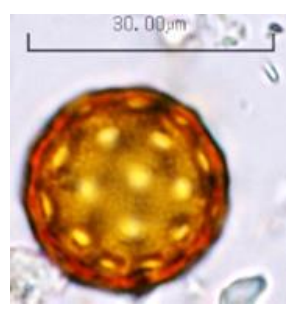

Chenopodiaceae Ch, D1L1, D3L6, G2-A, Tr5-2B

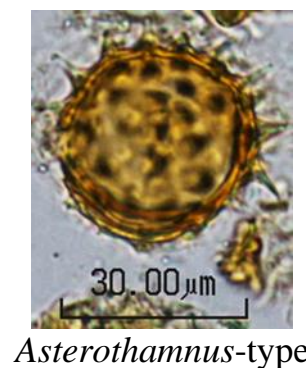

Asteraceae

Ch, D1L1

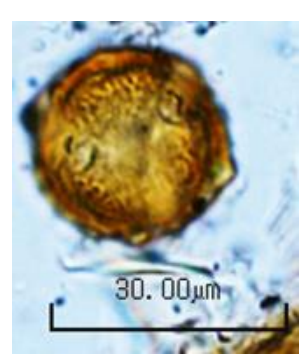

Serratula-type

Asteraceae

Ch, D1L1

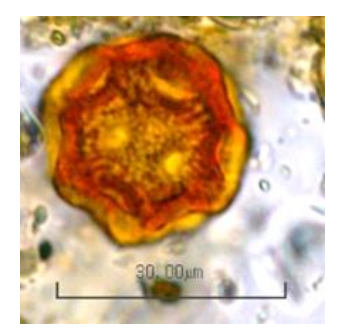

Caryophyllaceae Ch, D1L1, D3L6, G2-A, Tr5-2B

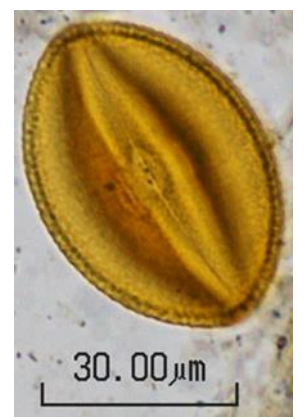

Helianthemum-type

Cistaceae

Ch, D1L1 


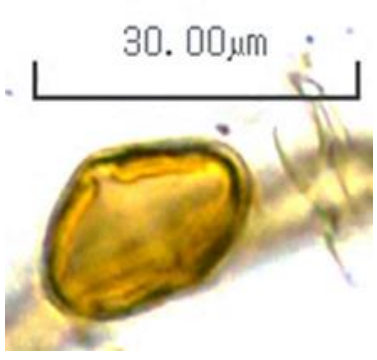

Orostachys

Crassulaceae

$\mathrm{Ch}$

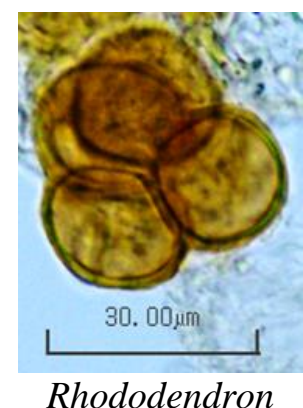

Ericaceae

D1L1, D3L6, G2-A, Tr5-2B

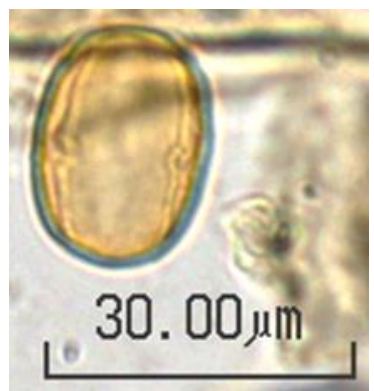

Caragana

Fabaceae

Ch, D1L1

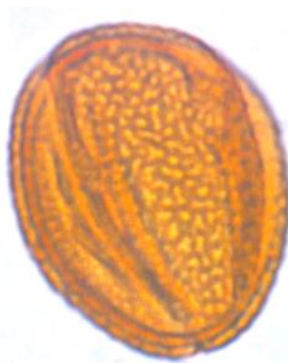

Gentiana grandiflora

Gentianaceae

Ch, D1L1, D3L6, Tr5-2B

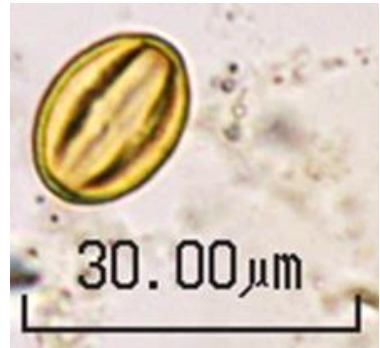

Rhodiola

Crassulaceae

Ch, D1L1

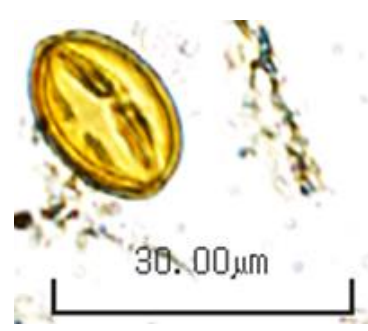

Fabaceae

Ch, D1L1, D3L6, Tr5-2B

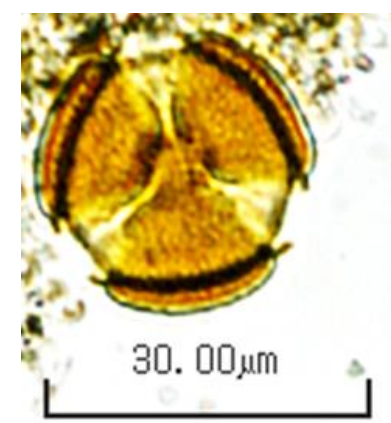

Gentiana

Gentianaceae

D3L6

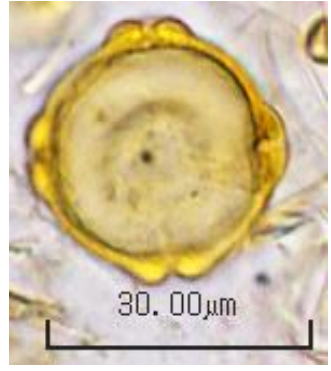

Myriophyllum

Haloragaceae

D1L1, D3L6, G2-A

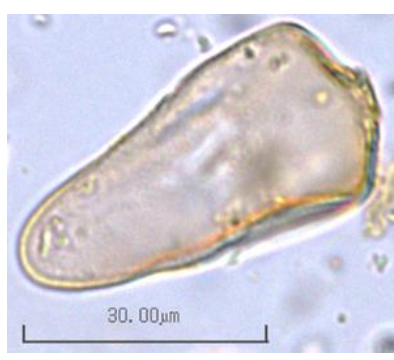

Cyperaceae

Ch, D1L1, D3L6,

G2-A, Tr5-2B

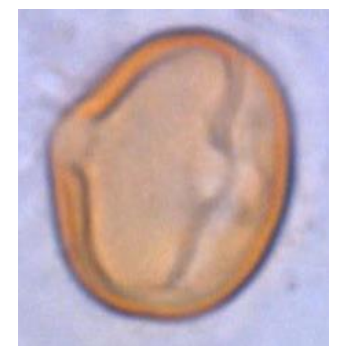

Astragalus chainngaica

Fabaceae

Ch, D1L1, D3L6, Tr5-2B

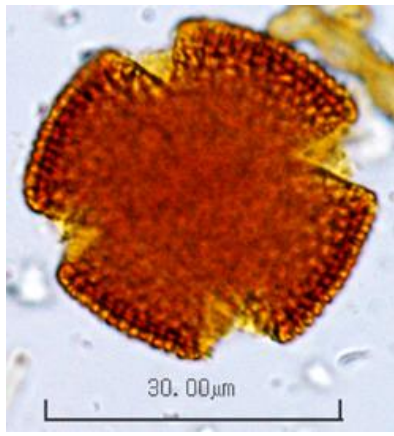

Gentiana barbata

Gentianaceae

Ch, D1L1, D3L6,

G2-A, Tr5-2B

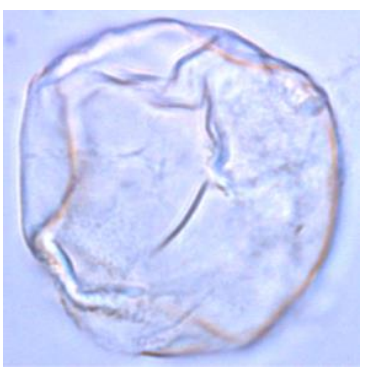

Luzula sibirica

Juncaceae

D3L6 


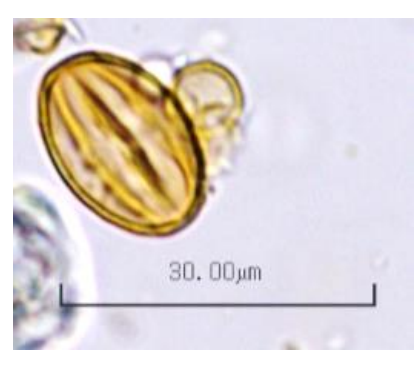

Lamiaceae

Ch, D1L1, D3L6, G2-A, Tr5-2B

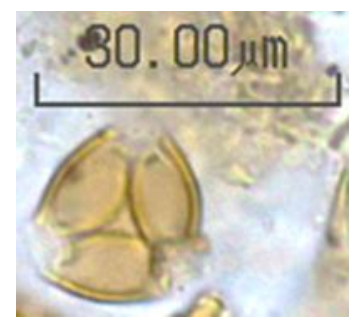

Nymphoides

Menyanthaceae

D1L1

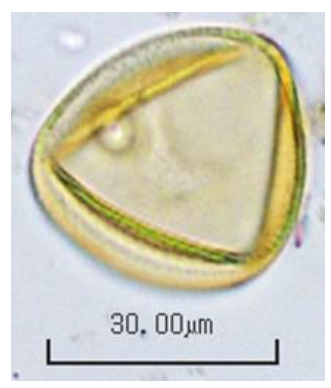

Poaceae

Ch, D1L1, D3L6,

G2-A, Tr5-2B

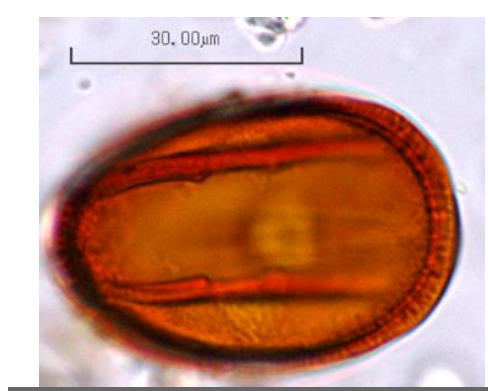

Polygonum bistorta

Polygonaceae

Ch, D1L1, D3L6,

G2-A, Tr5-2B

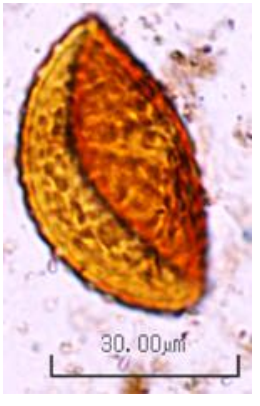

Liliaceae

D1L1, D3L6, G2-A, Tr5-2B

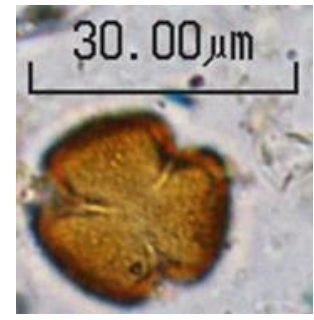

Linaria

Plantaginaceae

Ch, D1L1

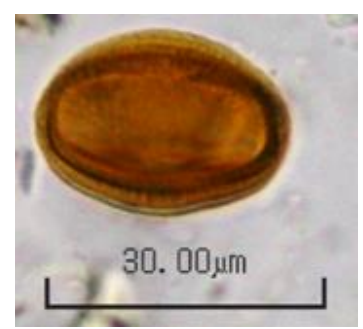

Polygonaceae Ch, D1L1, D3L6, G2-A, Tr5-2B

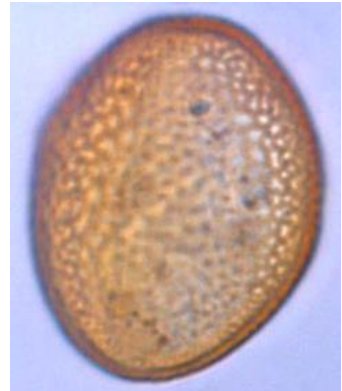

Lloydia setotina Liliaceae

D1L1, D3L6, Tr5-2B

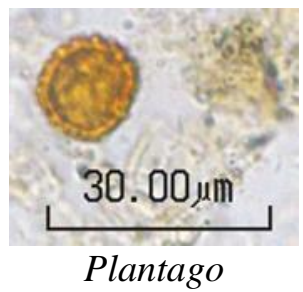

Plantaginaceae

Ch, D1L1

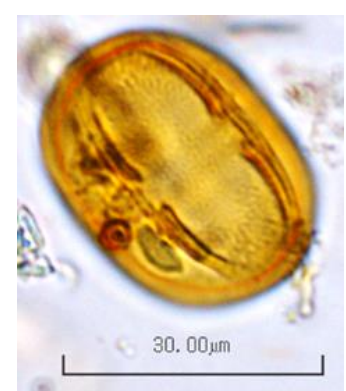

Polygonum aviculare

Polygonaceae

Ch, D1L1, D3L6,

G2-A, Tr5-2B

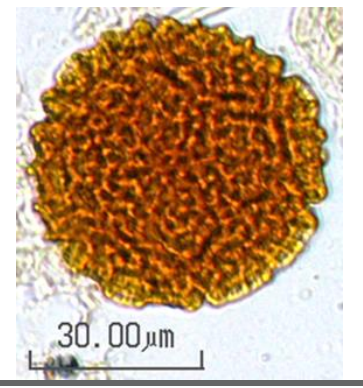

Polygonum persicaria

Polygonaceae

Ch, D1L1

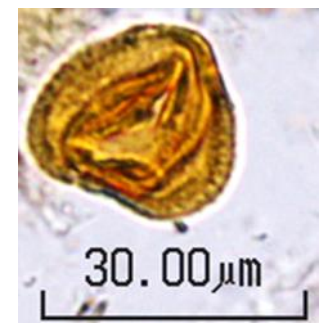

Rumex

Polygonaceae

Ch, D1L1, D3L6,

G2-A, Tr5-2B 


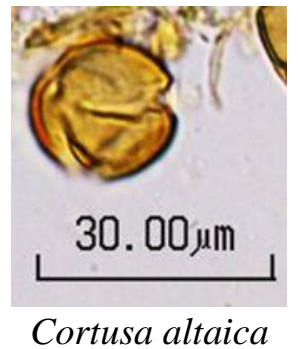

Primulaceae

Ch, D1L1, D3L6, Tr5-2B

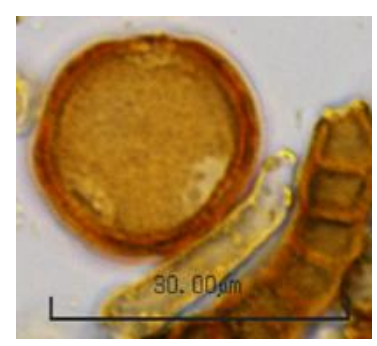

Thalictrum

Ranunculaceae

Ch, D1L1, D3L6,

G2-A, Tr5-2B
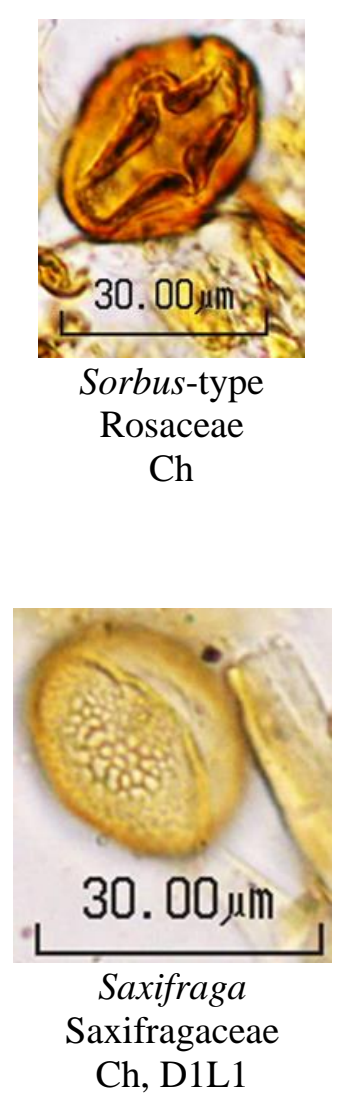

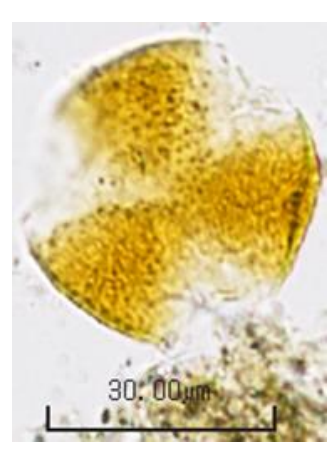

Ranunculaceae Ch, D1L1, D3L6, G2-A, Tr5-2B

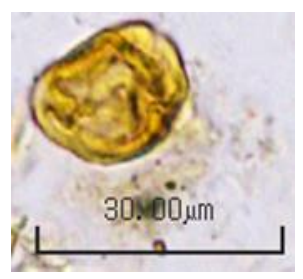

Geum

Rosaceae

Ch, D1L1, D3L6, G2-A, Tr5-2B

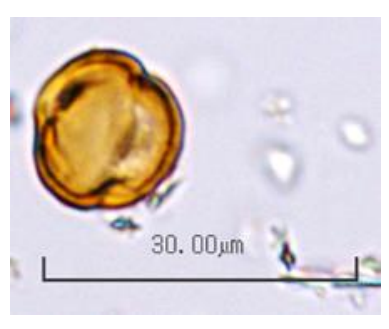

Rosaceae

Ch, D1L1, D3L6, G2-A, Tr5-2B

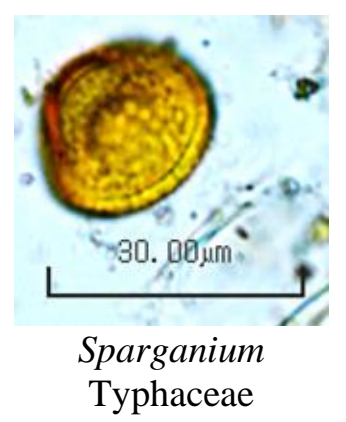

Ch, D1L1, D3L6

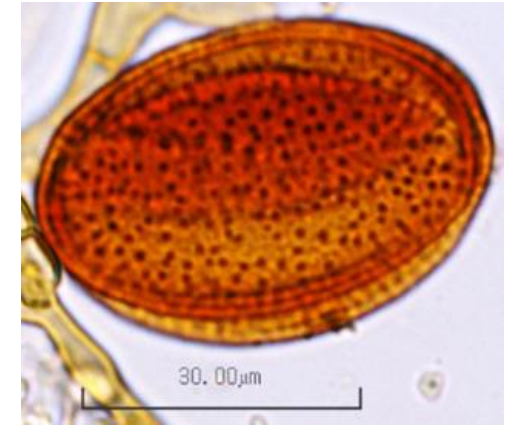

Ranunculus pulchellus Ranunculaceae D1L1, G2-A, Tr5-2B

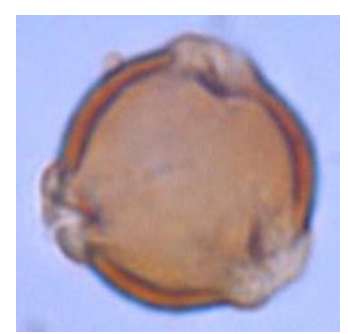

Potentilla

Rosaceae

Ch, D1L1, D3L6, Tr5-2B

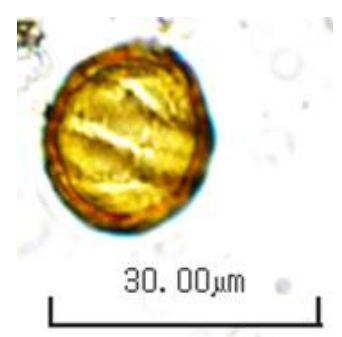

Galium

Rubiaceae

Ch, D1L1, D3L6, Tr5-2B

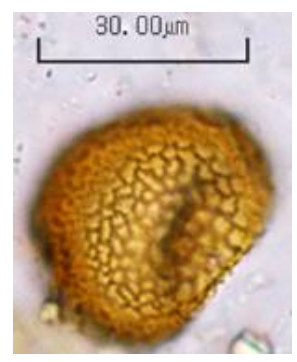

Typha

Typhaceae

Ch, D1L1, G2-A, Tr5-2B 


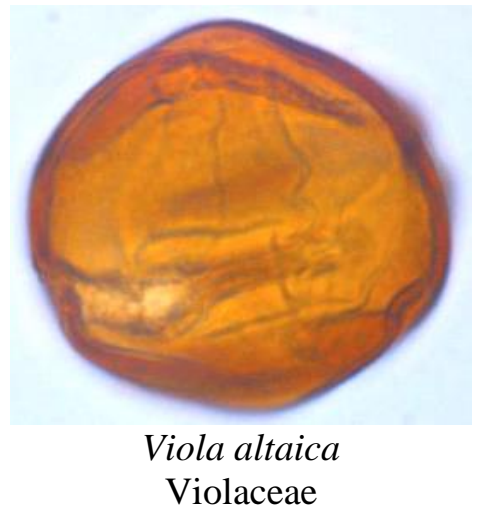

Ch, D1L1, D3L6, Tr5-2B

(C) Unknown pollen types

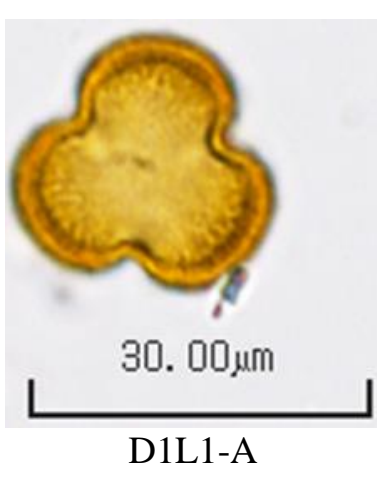

D1L1

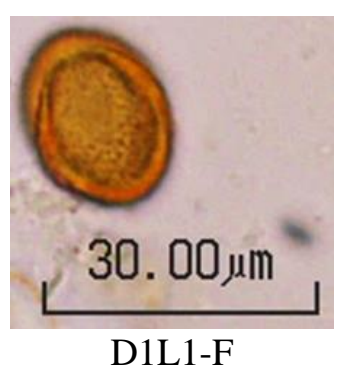

Ch, D1L1

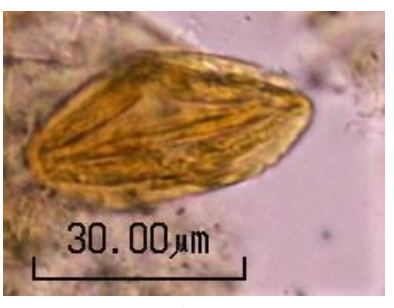

Ch-A

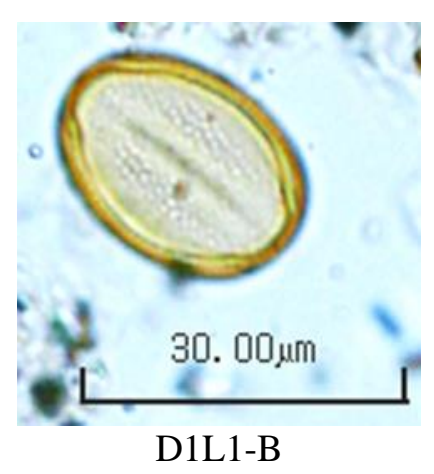

D1L1

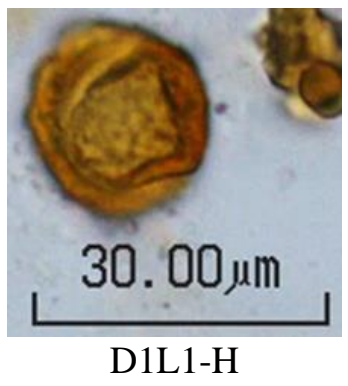

D1L1

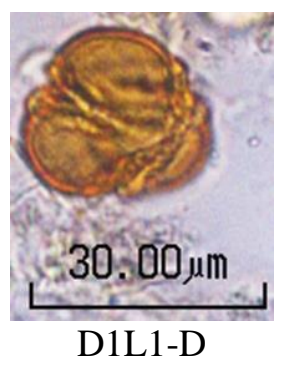

D1L1

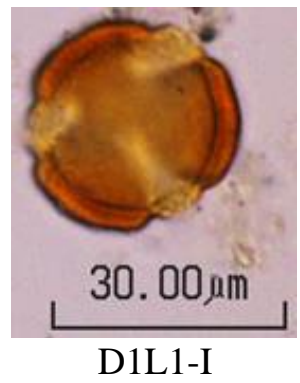

D1L1

$\mathrm{Ch}$ 
(D) Ferns and mosses

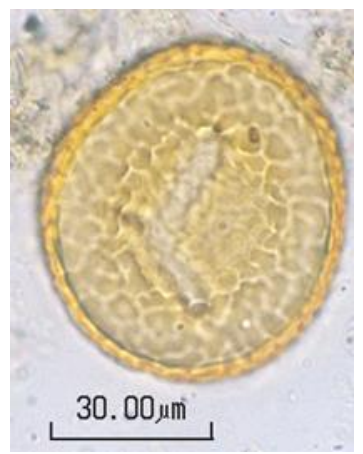

Trilete fern spore

Ch, D1L1, G2-A

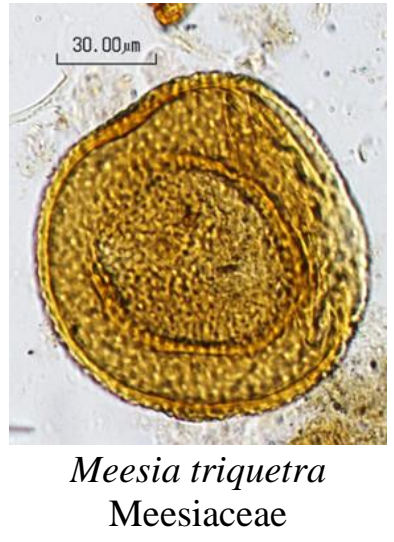

$\mathrm{Ch}$

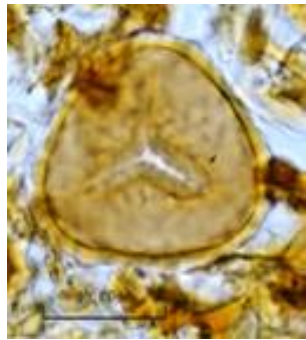

Sphagnum Sphagnaceae D1L1, D3L6 


\section{Appendix A2: Atlas of identified non-pollen palynomorphs (NPPs)}

The atlas comprises all NPP taxa identified during the research in the Mongolian Altai. They are presented by name, HdV-code and lake code of records, where they occur. Scale bars are depicted within the NPP pictures. By analogy with the NPP diagrams, the atlas is divided into (A) Glomeromycota, (B) Coprophilous fungi, (C) Coprophilous/Saprophilous fungi and (D) Saprophilous fungi, (E) Soil fungi, (F) Plant parasites, (G) Other fungi, (H) Microfossils, (I) Animal remains, (J) Testate Amoebae, (K) Plant remains and (L) Algae. Unknown NPP types are presented by lake code of (first) occurrence and a consecutive number.

\section{(A) Glomeromycota}

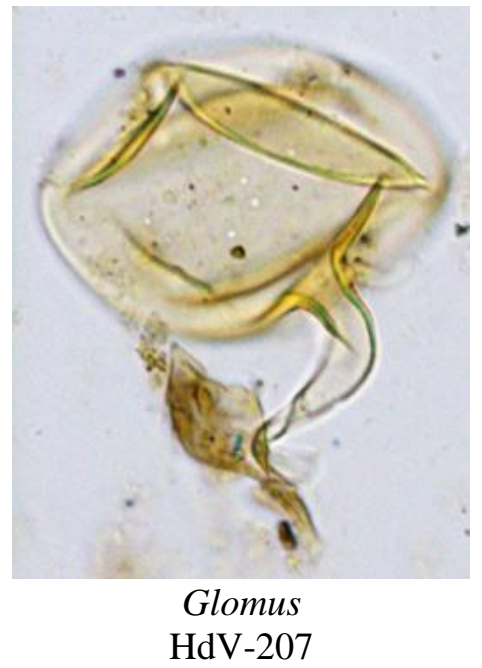

Ch, D1L1, D3L6, Tr5-2B

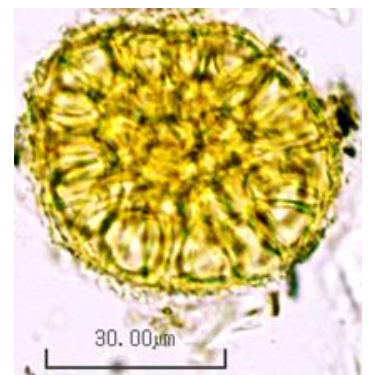

Glomosporium leptideum

Ch, D1L1, D3L6

(B) Coprophilous fungi

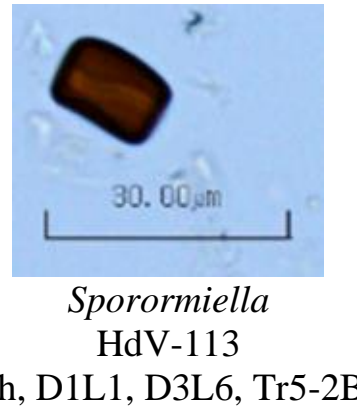

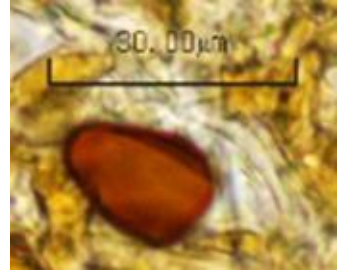

Sporormiella

HdV-113

Ch, D1L1, D3L6, Tr5-2B
30. $00 \mu \mathrm{m}$

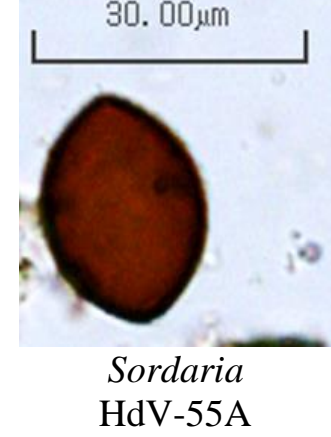

Ch, D1L1, D3L6, Tr5-2B 
(C) Coprophilous/Saprophilous fungi

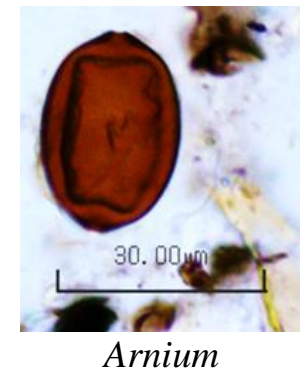

Ch, D1L1, D3L6, Tr5-2B

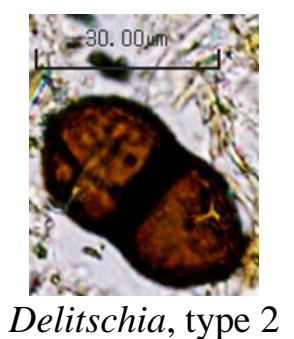

Ch, D1L1, D3L6, Tr5-2B

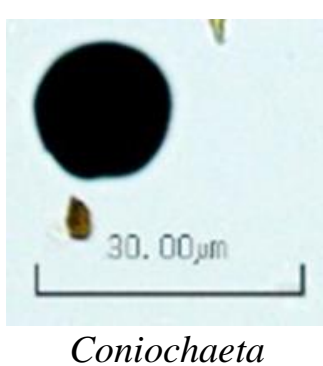

Ch, D1L1, D3L6, Tr5-2B

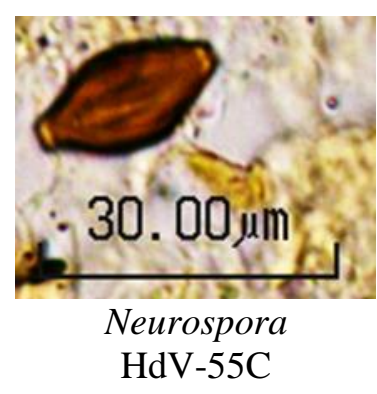

$\mathrm{Ch}$

\section{(D) Saprophilous fungi}

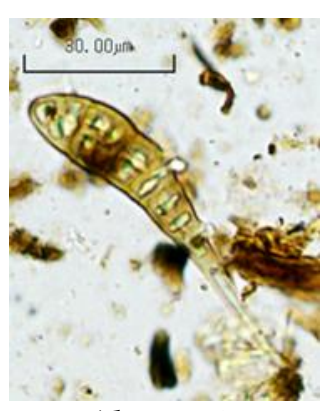

Alternaria

Ch, Tr5-2B

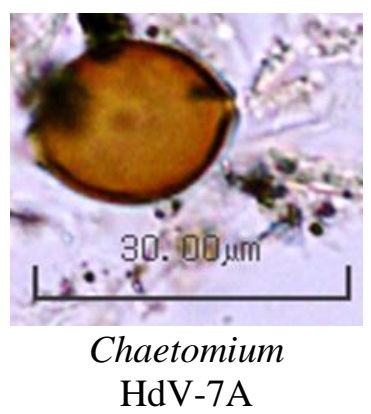

Ch, D1L1, D3L6

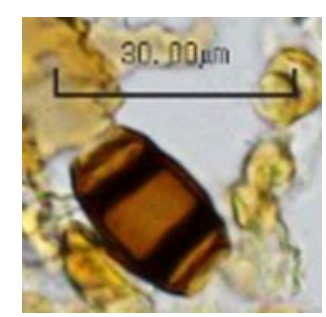

Brachysporium, type 1 HdV-359

D3L6, Tr5-2B

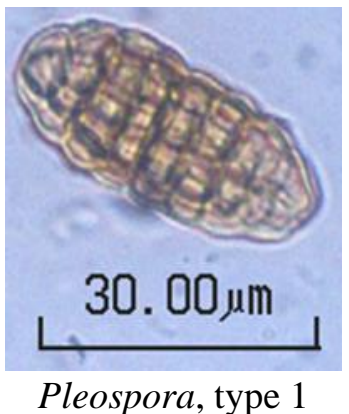

HdV-3A

Ch, D1L1

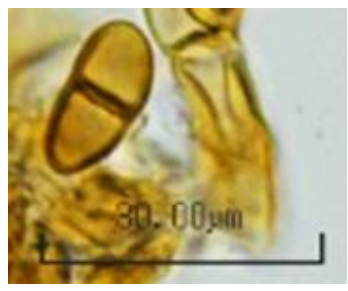

Delitschia, type 1

Ch, D1L1, D3L6, Tr5-2B

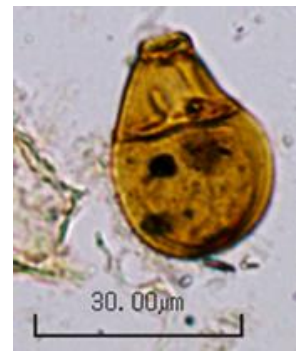

Brachysporium, type 2 $\mathrm{HdV}-462$

D1L1, D3L6, Tr5-2B

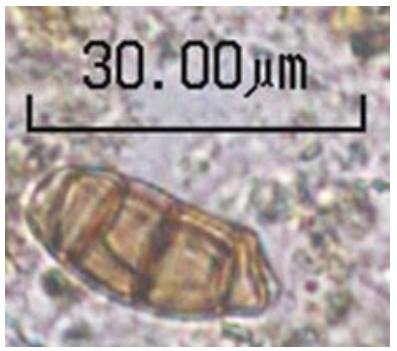

Pleospora, type 2

$\mathrm{HdV}-3 \mathrm{~B}$

Ch, D1L1 
(E) Soil fungi

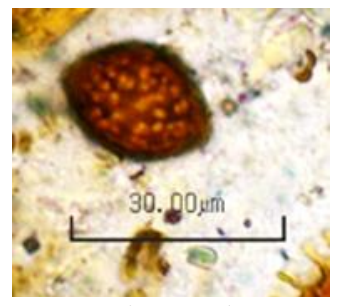

Sphaerodes

Ch, D1L1, D3L6, Tr5-2B

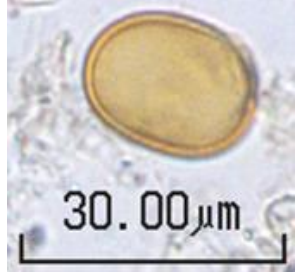

HdV-527

Ch, D1L1

\section{(F) Plant parasites}

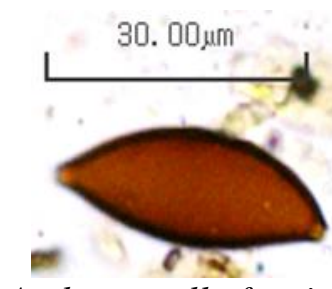

Anthostomella fuegiana $\mathrm{HdV}-4$

Ch, D1L1, Tr5-2B

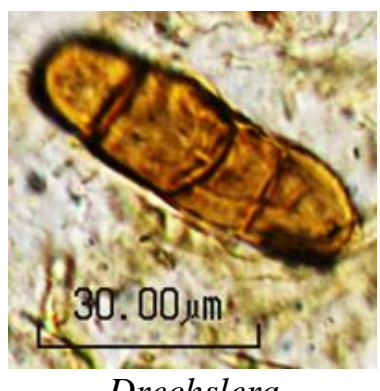

Drechslera

HdV-503

$\mathrm{Ch}$

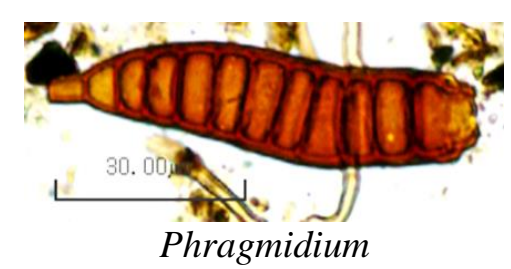

D3L6

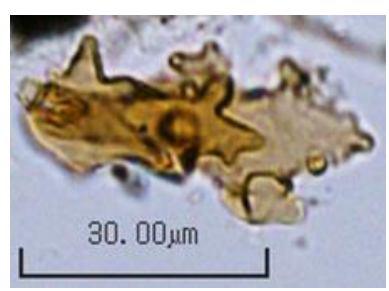

Gaeumannomyces $\mathrm{HdV}-126$

Ch, D1L1, D3L6

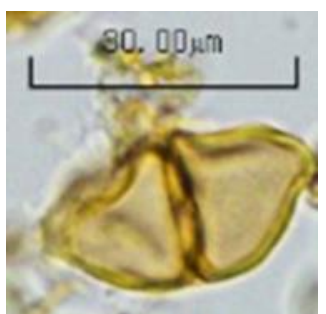

Puccinia

HdV-357

Ch, D1L1, D3L6, Tr5-2B

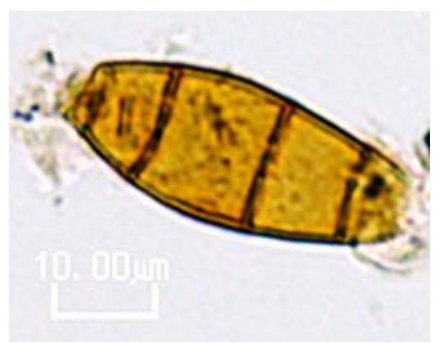

Clasterosporium caricinum HdV-25

$\mathrm{Ch}$

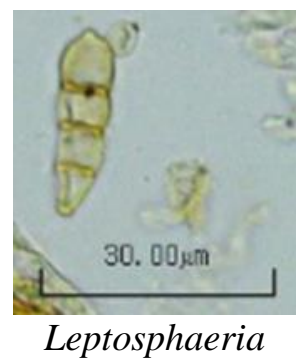

Ch, D1L1, D3L6, Tr5-2B

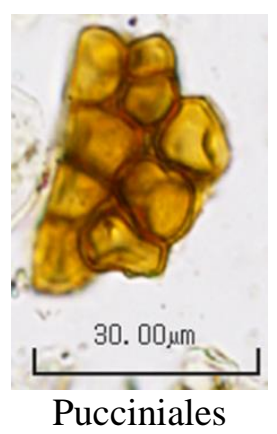

$\mathrm{Ch}$ 


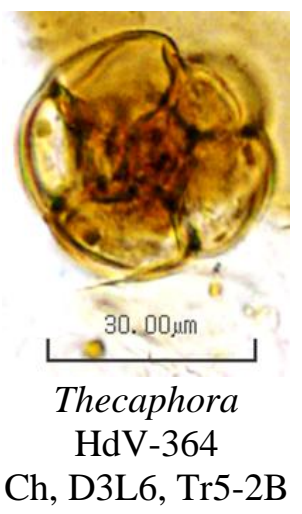

Ch, D3L6, Tr5-2B

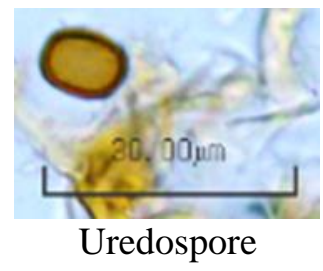

Ch, D1L1, D3L6, Tr5-2B

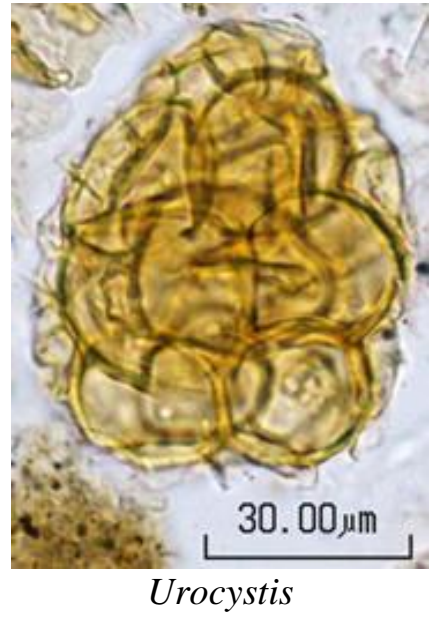

Ch, D1L1

\section{(G) Other fungi}

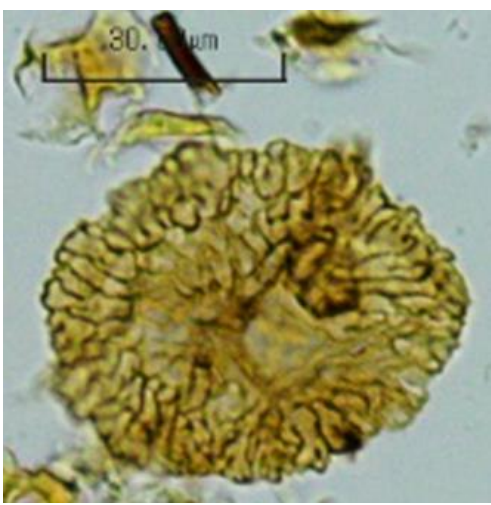

Fruit body, type 1 HdV-8B

Ch, D1L1, D3L6, Tr5-2B

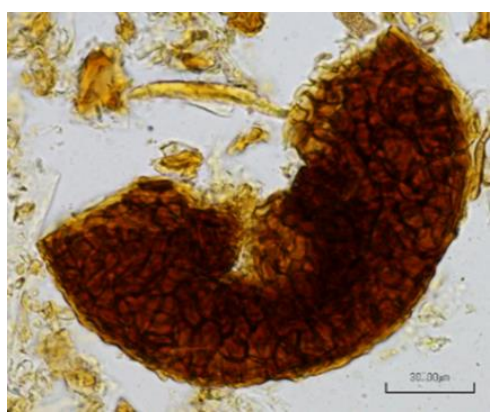

Fruit body, type 4

Ch, D1L1, D3L6

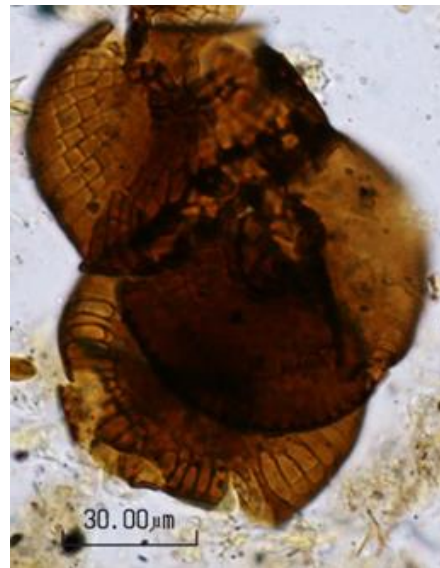

Fruit body, type 2 HdV-8E

Ch, Tr5-2B

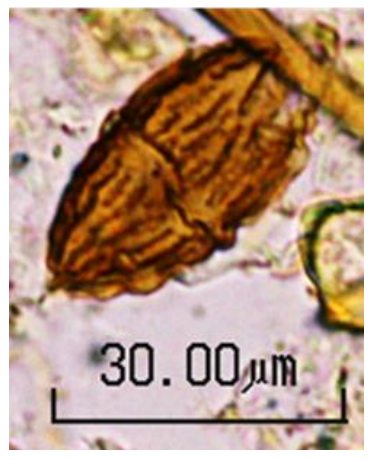

HdV-16A

$\mathrm{Ch}$

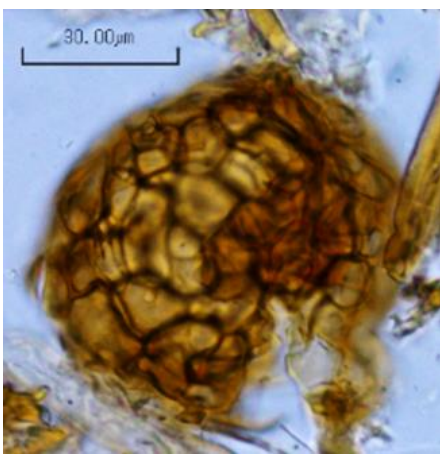

Fruit body, type 3

Ch, D1L1, D3L6, Tr5-2B

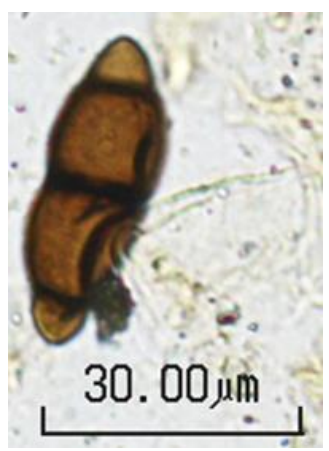

HdV-16C

$\mathrm{Ch}$ 


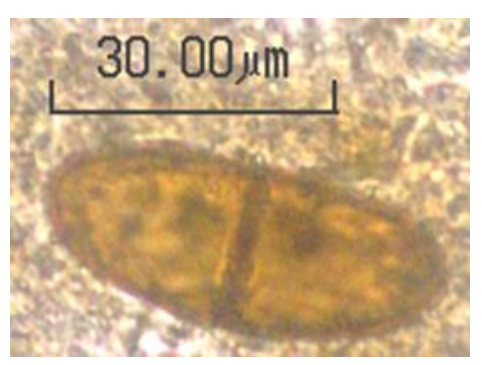

HdV-18

Ch, D1L1

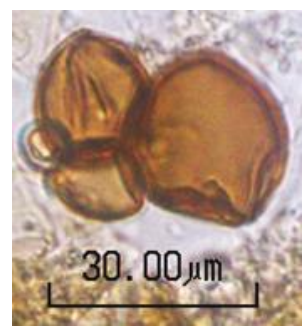

HdV-200

Ch, D1L1

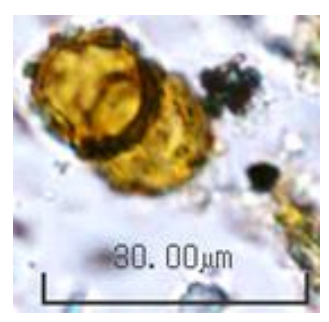

HdV-495

D1L1

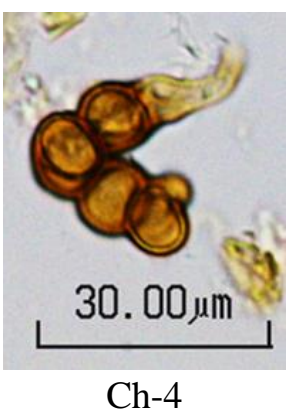

$\mathrm{Ch}$

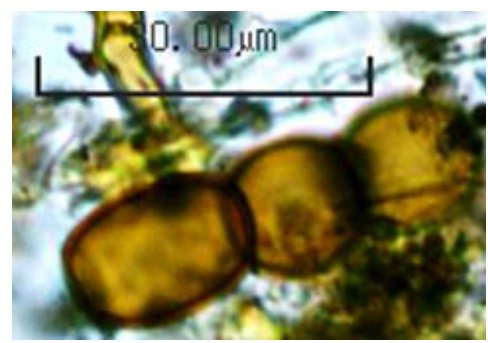

HdV-38

Ch, D1L1

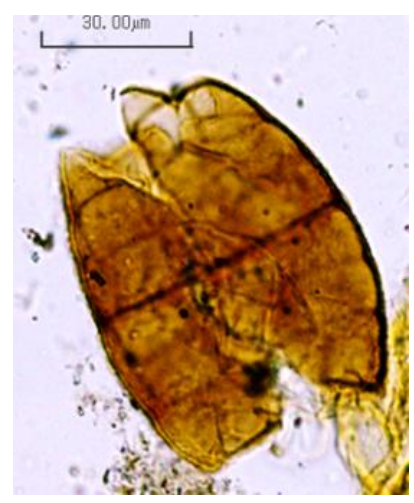

HdV-359

D1L1

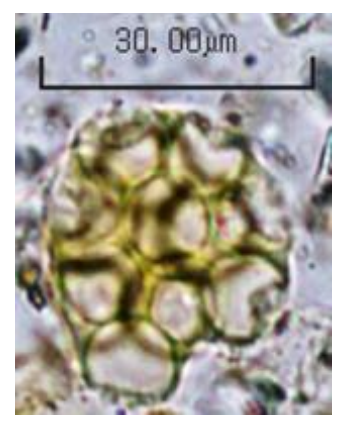

HdV-496

Ch, D1L1

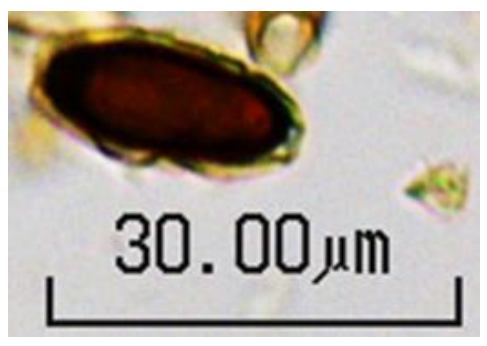

Ch-7

Ch

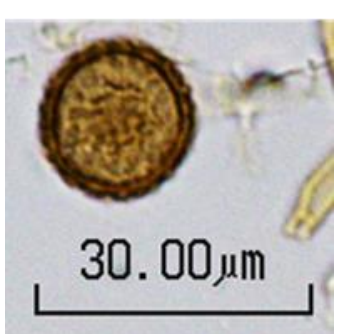

HdV-86

D1L1

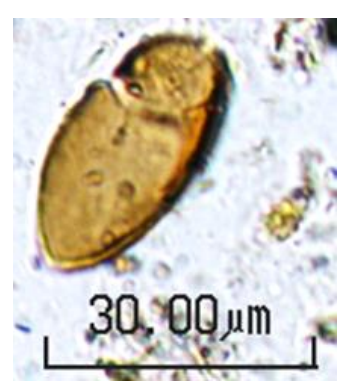

HdV-366

Ch, D1L1

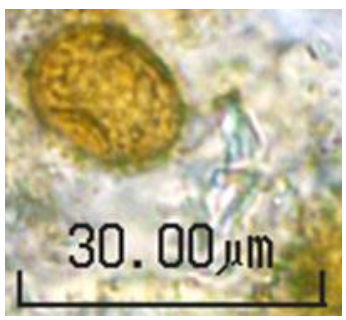

HdV-1032

Ch, D1L1

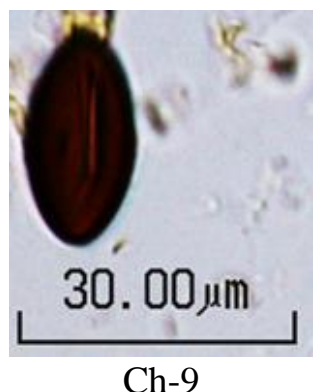

Ch 


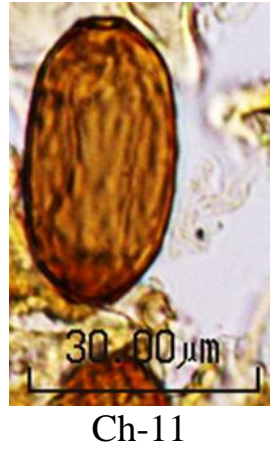

Ch

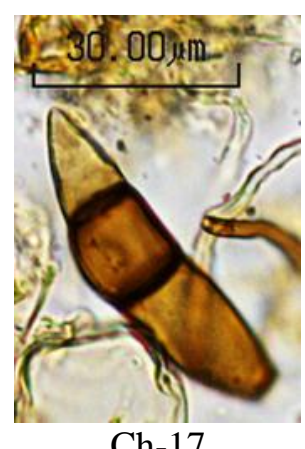

$\mathrm{Ch}$

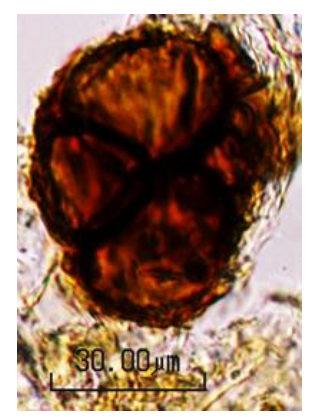

Ch-22

Ch

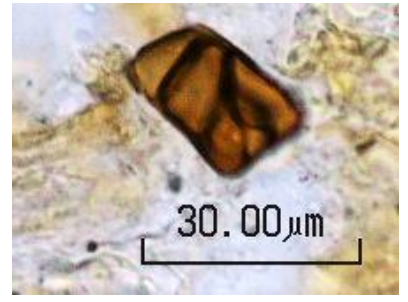

Ch-28

Ch

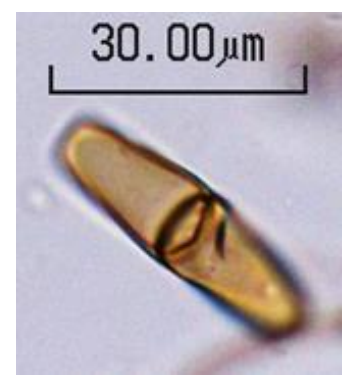

Ch-12

Ch

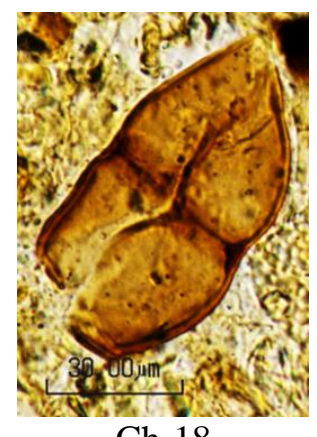

Ch-18

$\mathrm{Ch}$

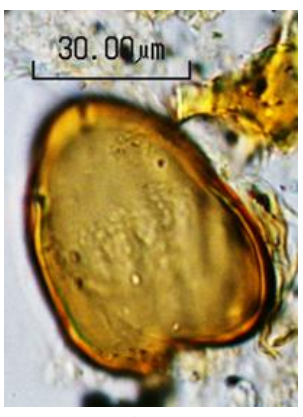

Ch-25

Ch

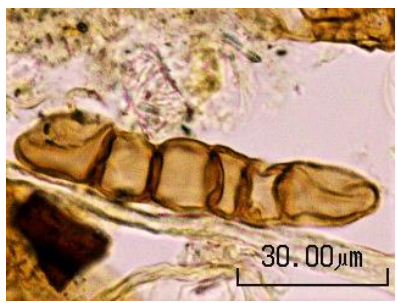

Ch-29

$\mathrm{Ch}$

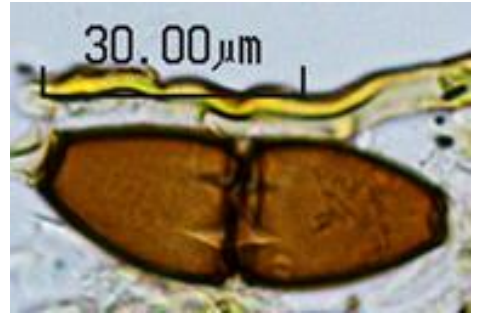

Ch-13

$\mathrm{Ch}$

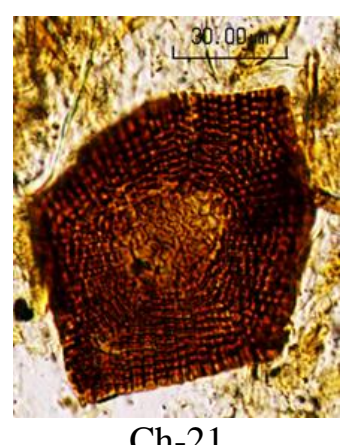

Ch

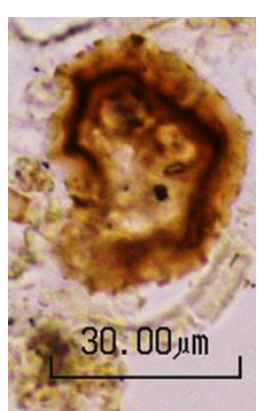

Ch-27

Ch

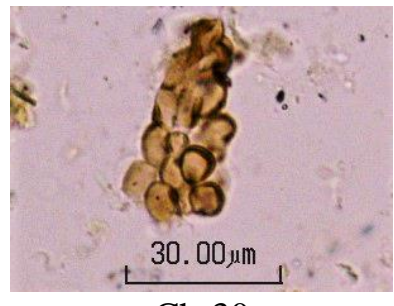

Ch-30

$\mathrm{Ch}$ 


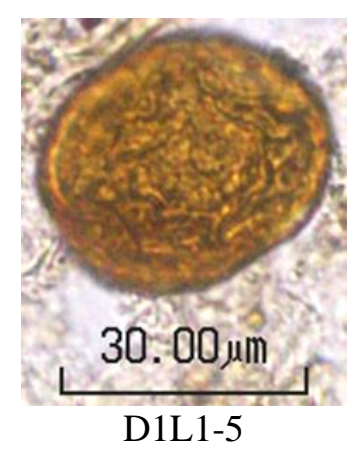

Ch, D1L1

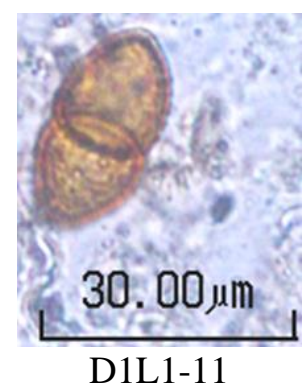

Ch, D1L1

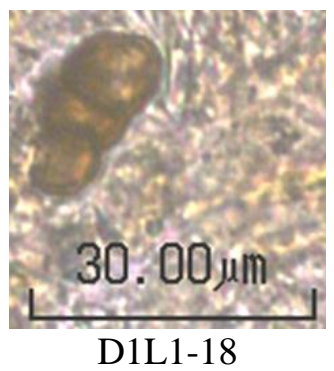

D1L1

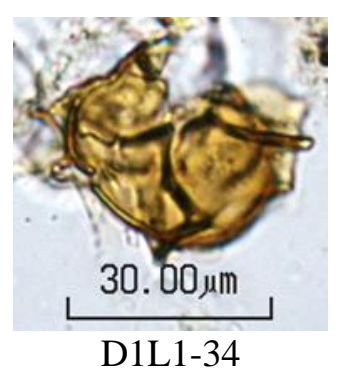

D1L1

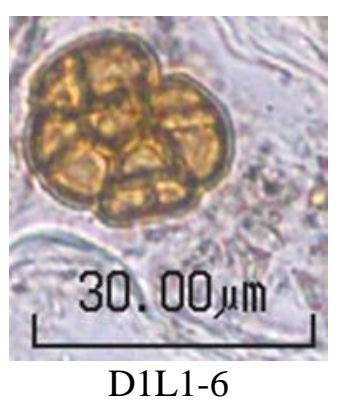

D1L1

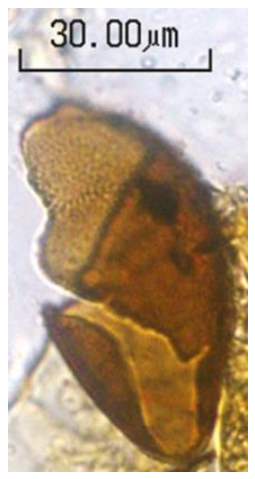

D1L1-13

Ch, D1L1

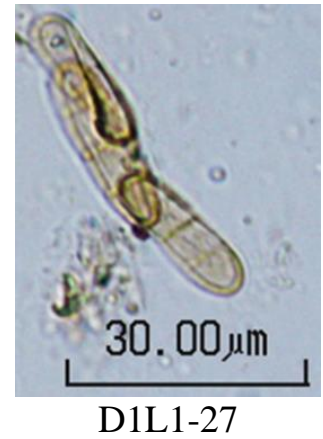

Ch, D1L1

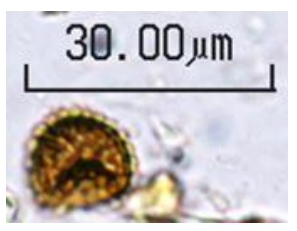

D1L1-37

D1L1

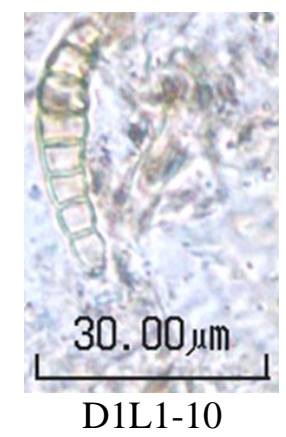

Ch, D1L1

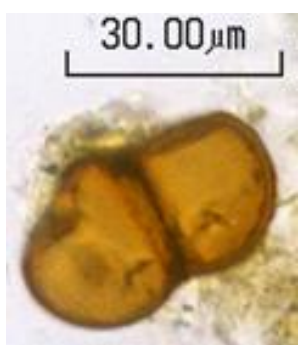

D1L1-14

Ch, D1L1

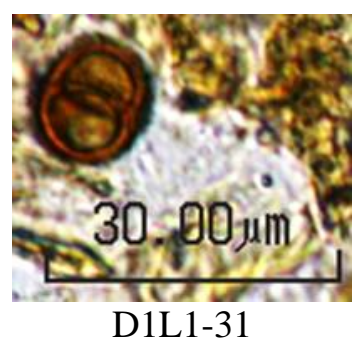

D1L1

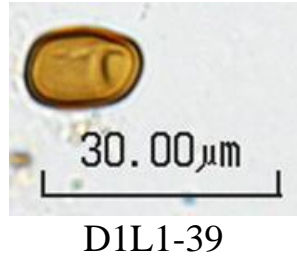

Ch, D1L1 


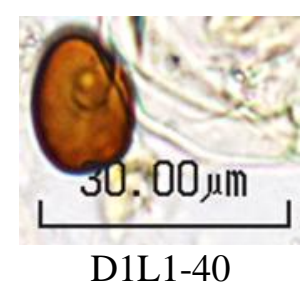

Ch, D1L1

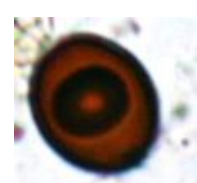

30. $00 \mu \mathrm{m}$

D1L1-47

D1L1

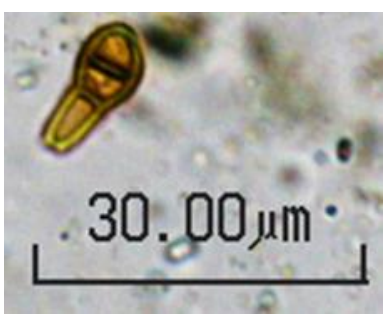

D1L1-52

D1L1

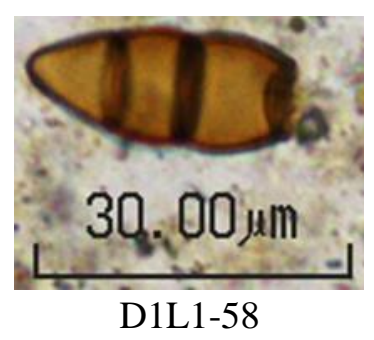

Ch, D1L1

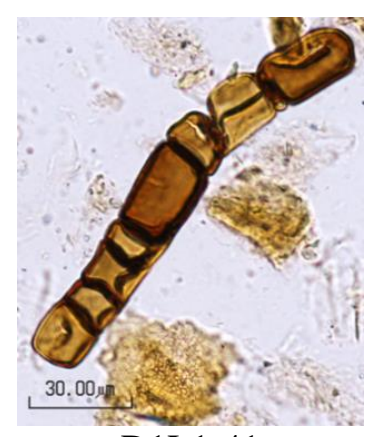

D1L1-41

Ch, D1L1

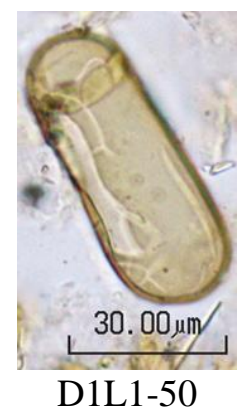

Ch, D1L1

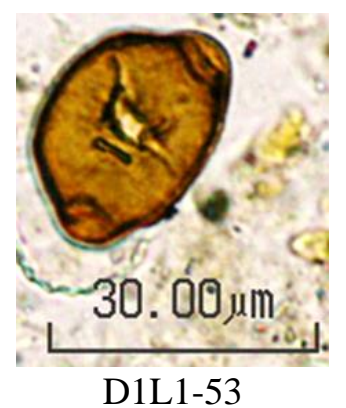

Ch, D1L1

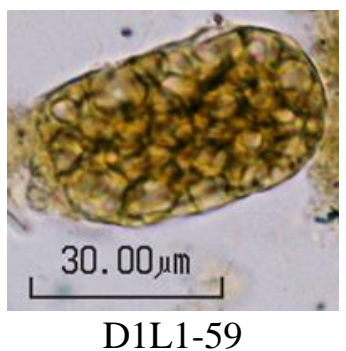

D1L1

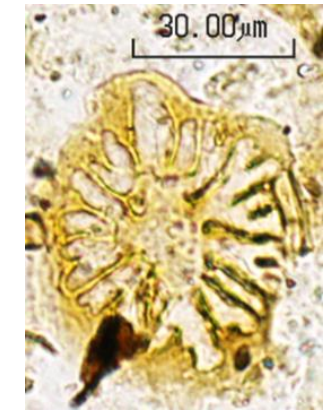

D1L1-44

Ch, D1L1

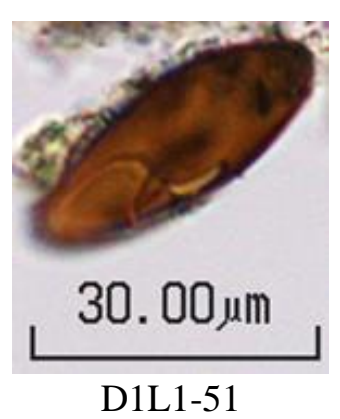

Ch, D1L1

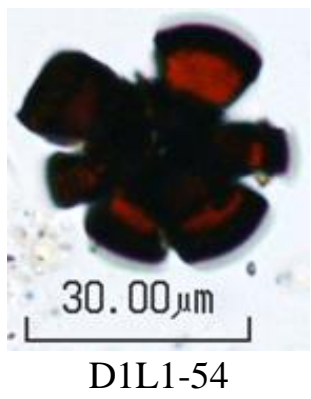

D1L1

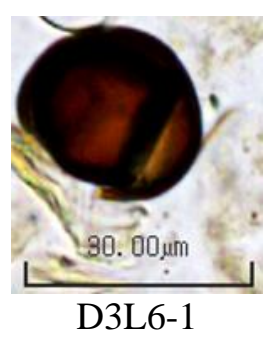

Ch, D1L1, D3L6 


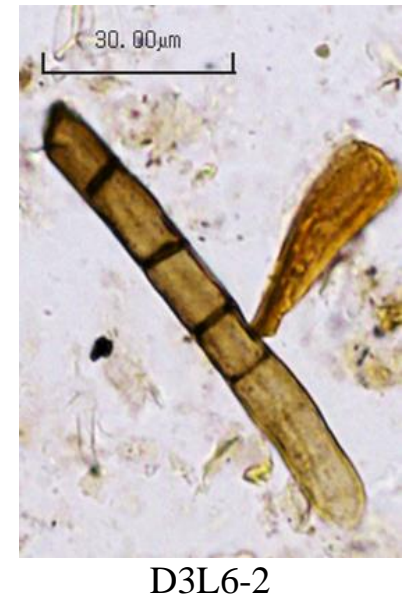

D3L6

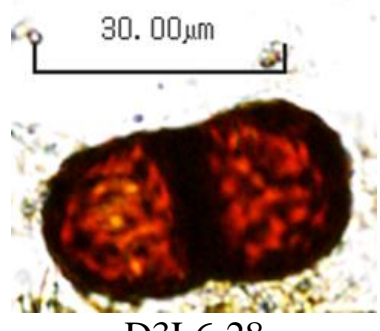

D3L6-28

D1L1, D3L6

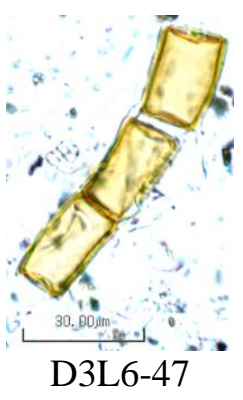

D3L6

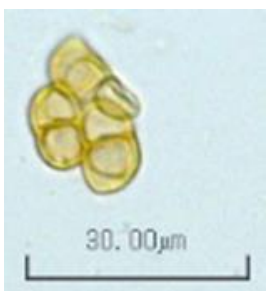

Tr5-2B-1

Ch, D1L1, D3L6, Tr5-2B

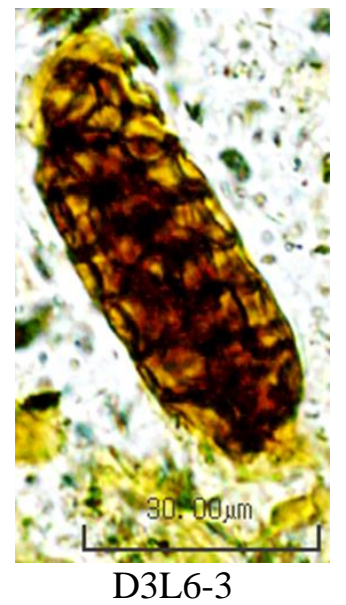

Ch, D1L1, D3L6

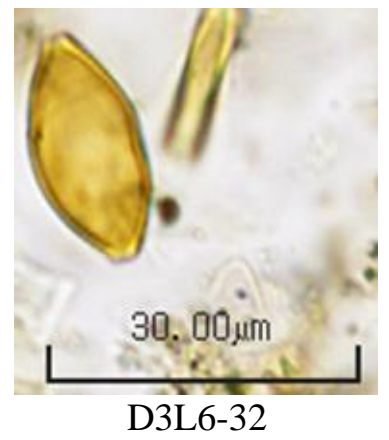

Ch, D1L1, D3L6

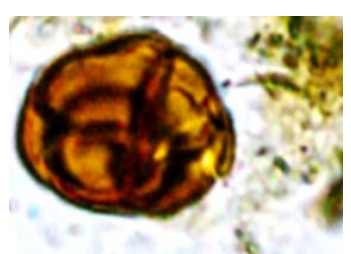

30. $00 \mu \mathrm{m}$

D3L6-57

Ch, D1L1, D3L6

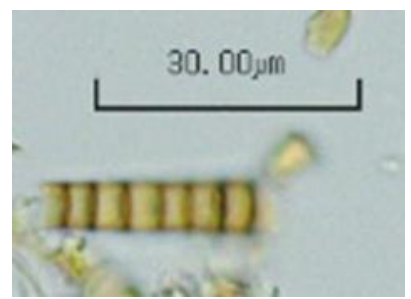

$\operatorname{Tr} 5-2 \mathrm{~B}-3$

D1L1, Tr5-2B

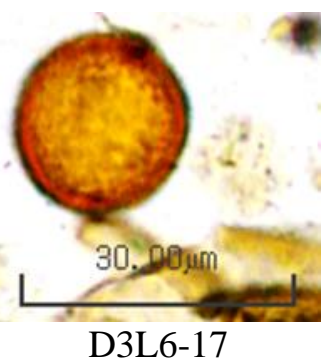

D1L1, D3L6

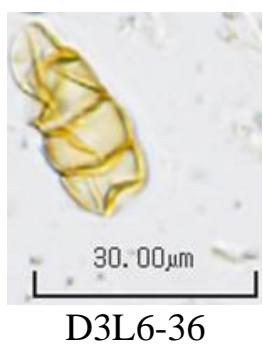

Ch, D1L1, D3L6

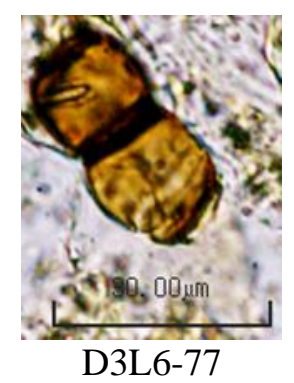

D1L1, D3L6

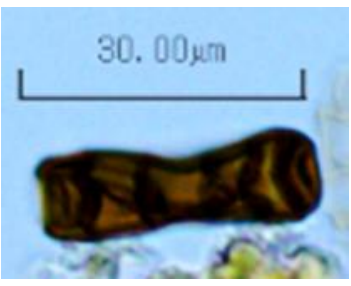

$\operatorname{Tr} 5-2 \mathrm{~B}-6$

$\operatorname{Tr} 5-2 \mathrm{~B}$ 


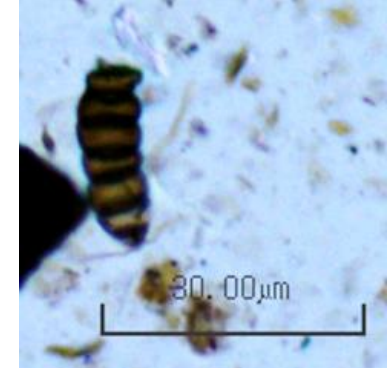

Tr5-2B-7

$\operatorname{Tr} 5-2 \mathrm{~B}$

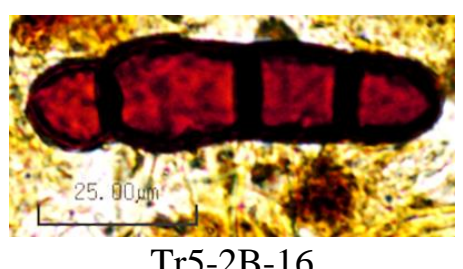

Tr5-2B-16

$\operatorname{Tr} 5-2 \mathrm{~B}$

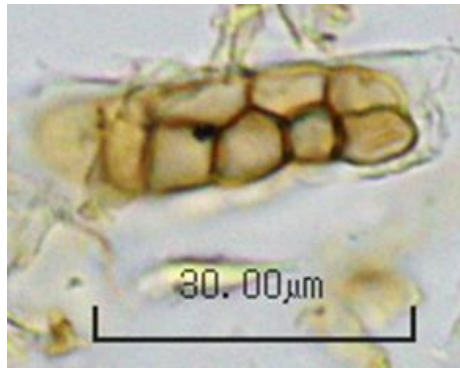

Tr5-2B-11

Ch, D1L1, D3L6, Tr5-2B

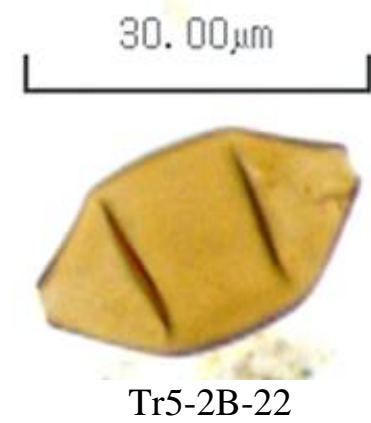

$\operatorname{Tr} 5-2 \mathrm{~B}$

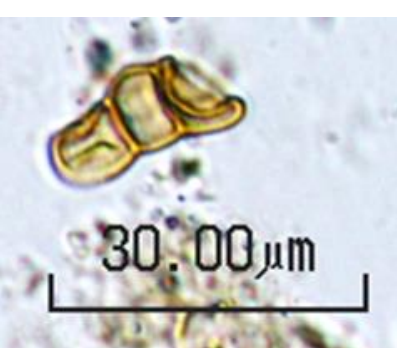

Tr5-2B-15

Ch, Tr5-2B

(H) Microfossils

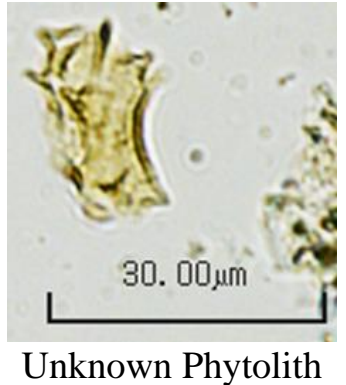

D1L1, D3L6

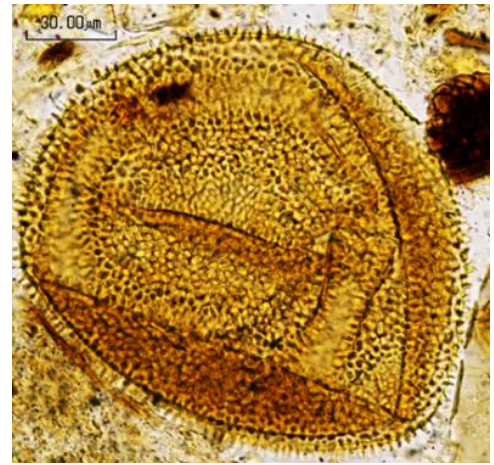

HdV-188

$\mathrm{Ch}$

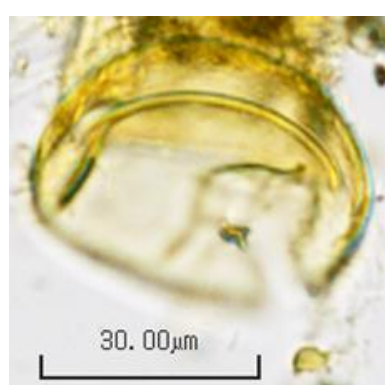

HdV-222

Ch, D1L1, D3L6 


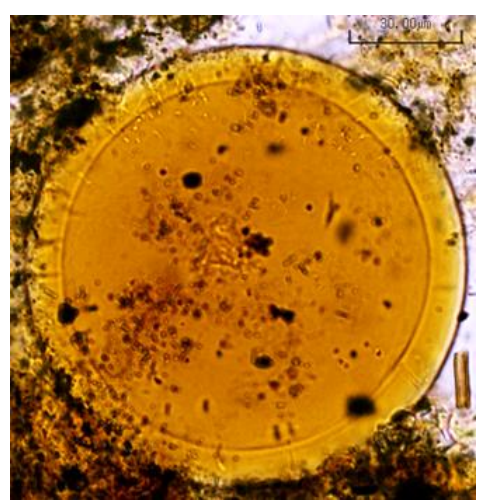

HdV-731

D1L1, D3L6

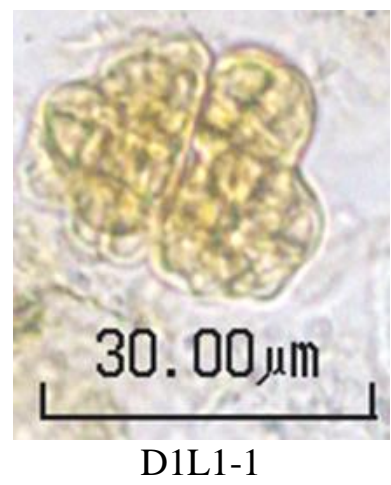

Ch, D1L1

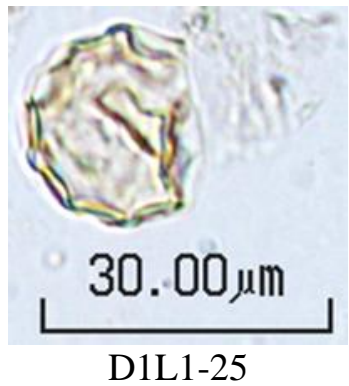

Ch, D1L1

\section{(I) Animal remains}

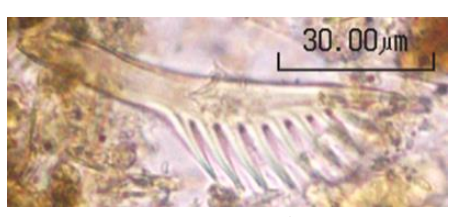

Aranaria claw

HdV-71

D1L1

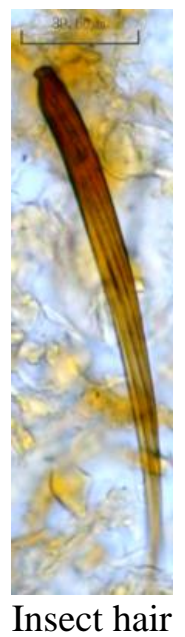

Ch, D1L1, D3L6, Tr5-2B

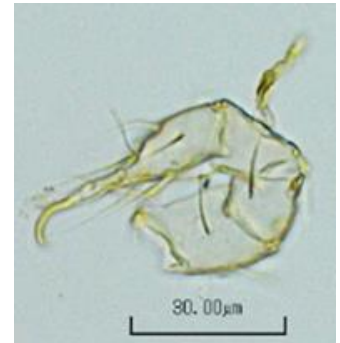

Acari part

HdV-36

Ch, D3L6, Tr5-2B

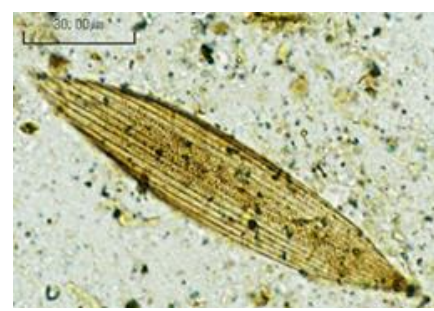

Lepidoptera scale

Ch, D1L1, D3L6, Tr5-2B

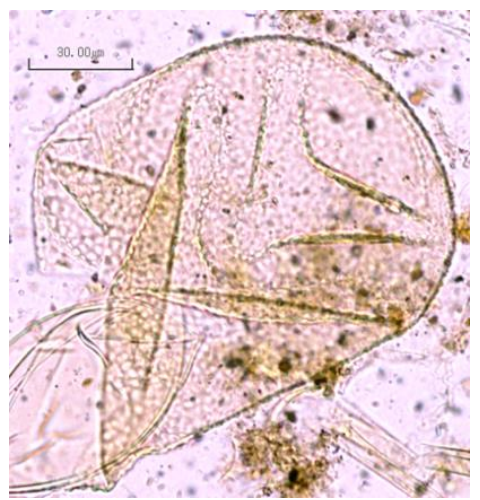

Brachionus egg

Ch, D1L1, D3L6

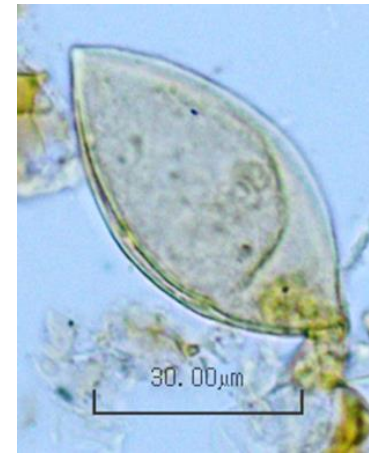

Operculum of Neorhabdocoela

Ch, D1L1, D3L6, Tr5-2B 


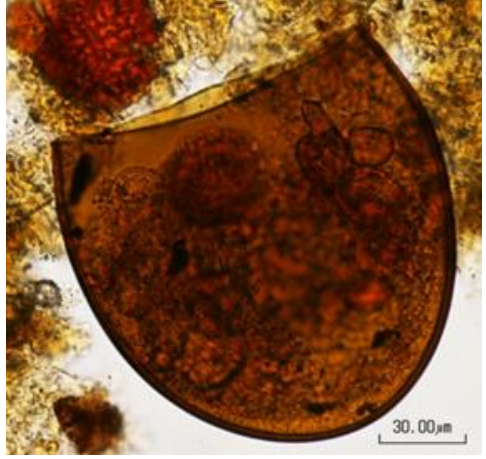

Rhabdocoela cocoon HdV-353B

$\mathrm{Ch}$

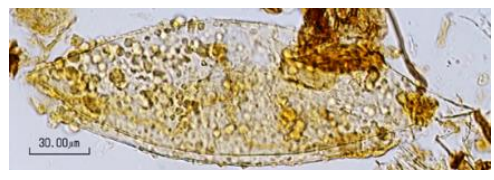

HdV-221

$\mathrm{Ch}$

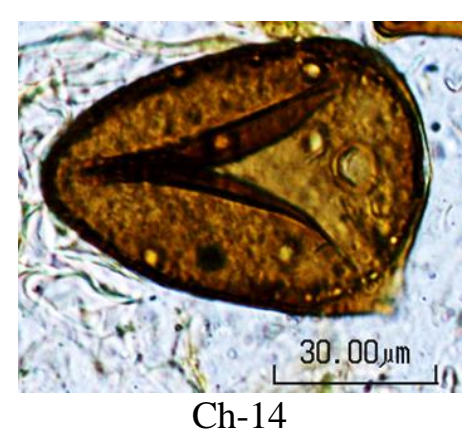

$\mathrm{Ch}$

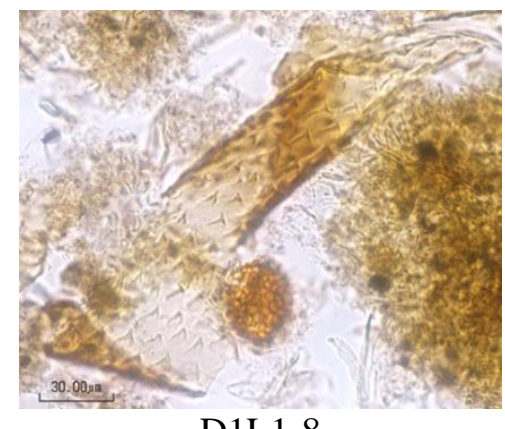

D1L1-8

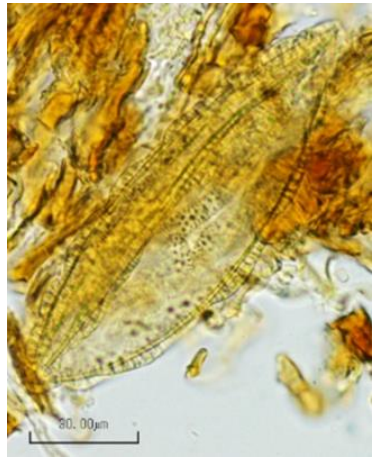

Rotatoria egg

Ch, D1L1, D3L6, Tr5-2B

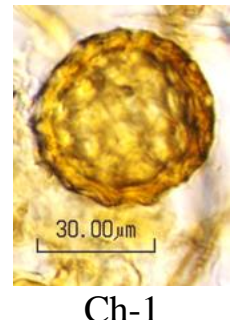

Ch

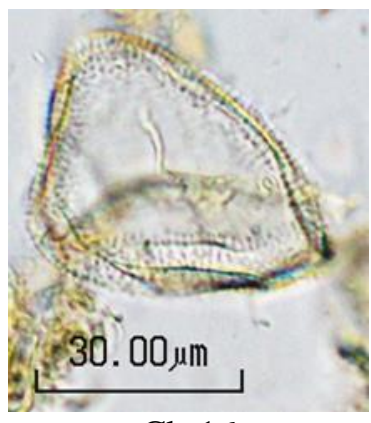

Ch-16

$\mathrm{Ch}$

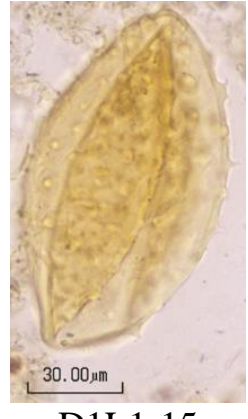

D1L1-15

Ch, D1L1

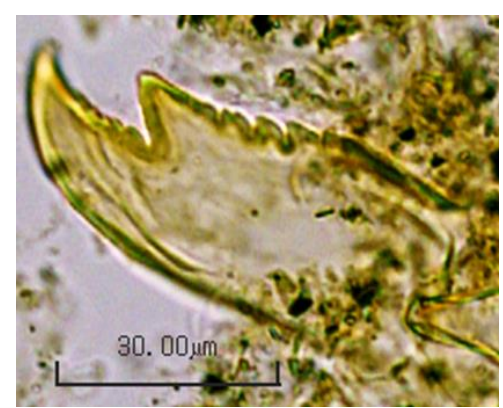

Unknown Crustaceae fragment

Ch, D1L1, D3L6

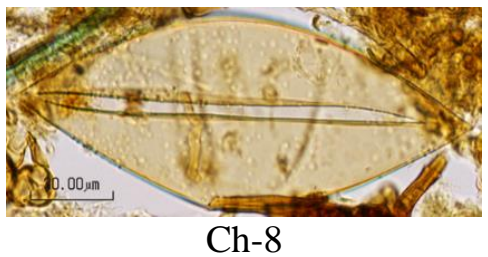

$\mathrm{Ch}$

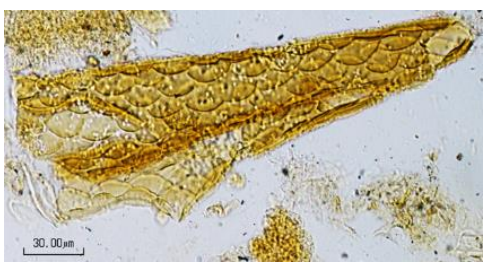

Ch-26

$\mathrm{Ch}$

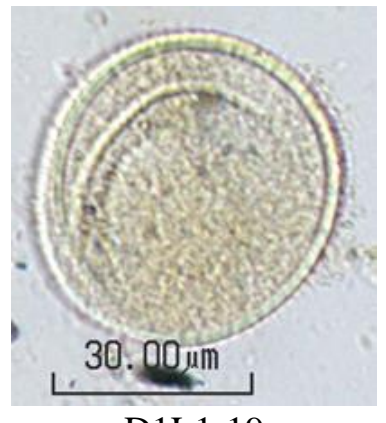

D1L1-19

Ch, D1L1 


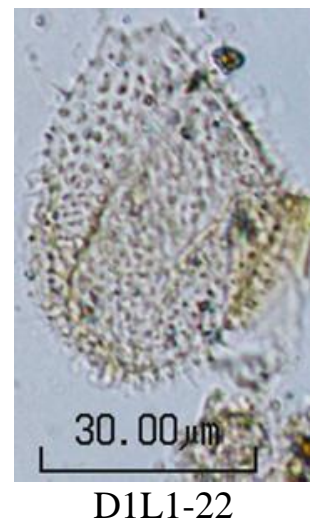

D1L1

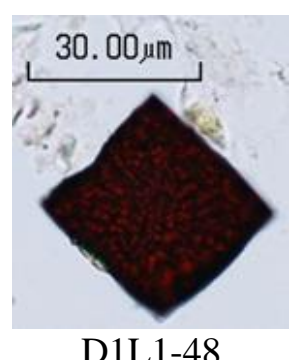

D1L1

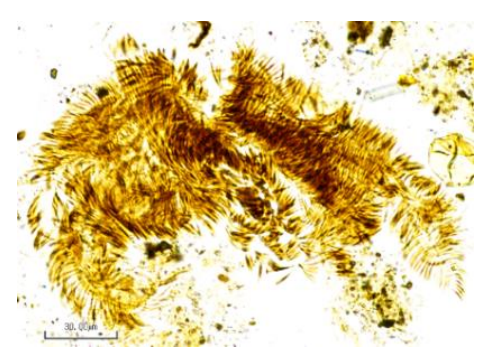

D3L6-31

D1L1, D3L6

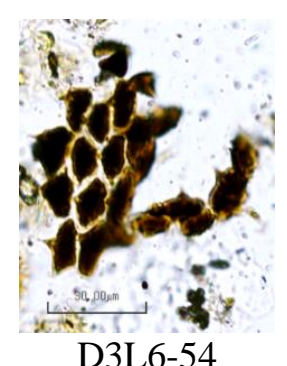

D3L6

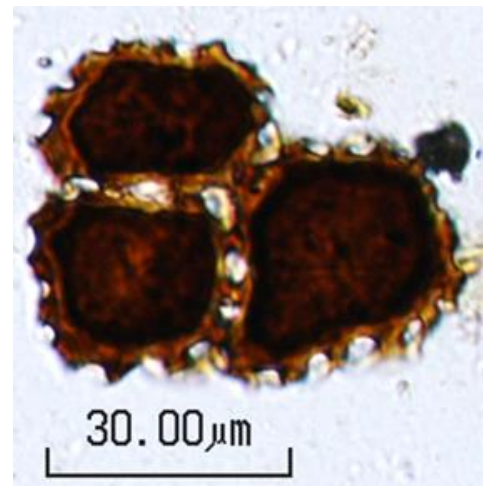

D1L1-33

Ch, D1L1

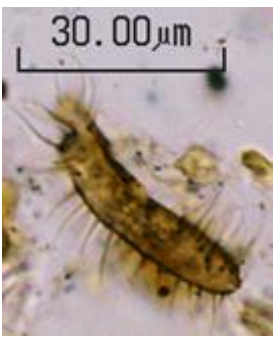

D1L1-57

D1L1

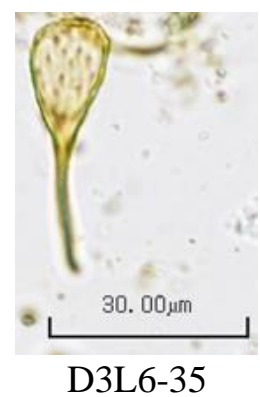

D3L6

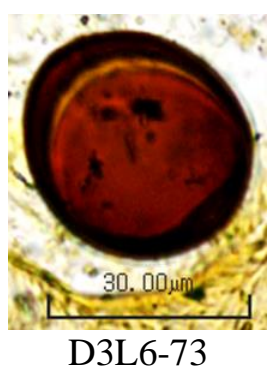

D3L6

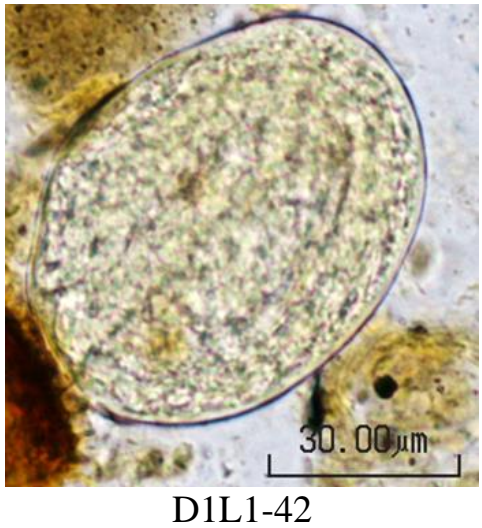

D1L1

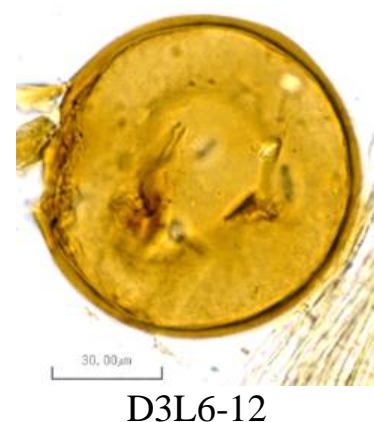

Ch, D1L1, D3L6

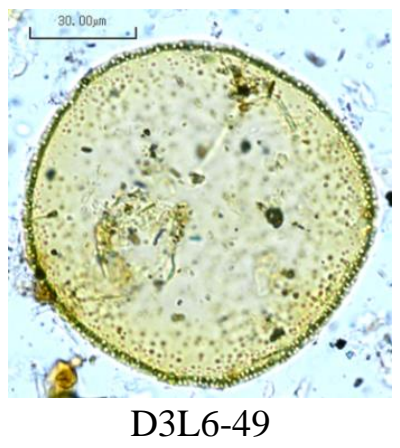

Ch, D1L1, D3L6

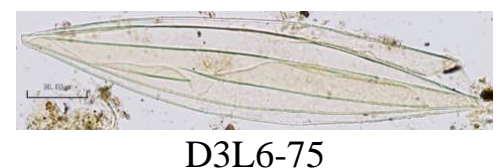

Ch, D1L1, D3L6 


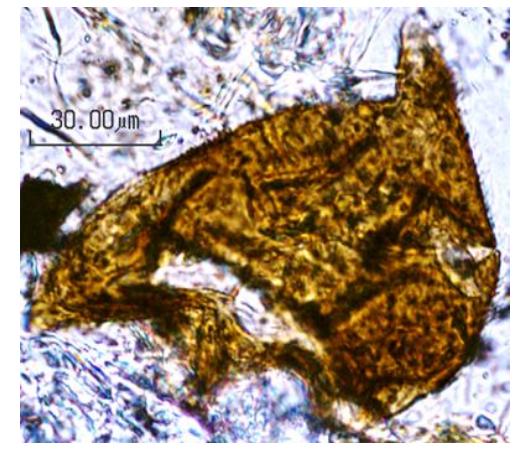

D3L6-79

D3L6

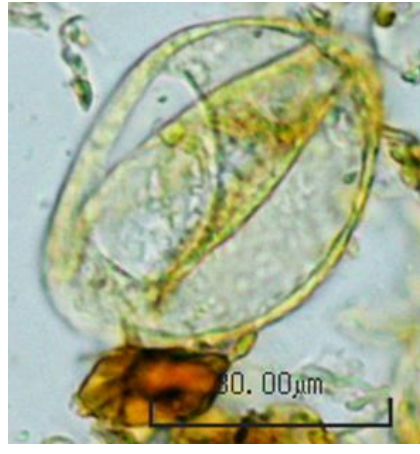

Tr5-2B-10

$\operatorname{Tr} 5-2 \mathrm{~B}$

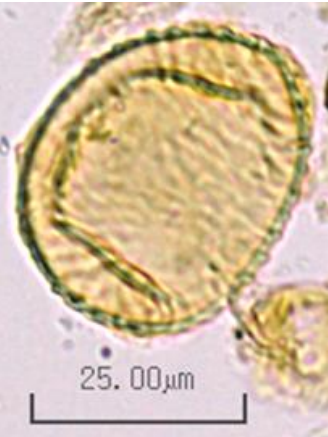

Tr5-2B-18

$\operatorname{Tr} 5-2 \mathrm{~B}$

(J) Testate Amoebae

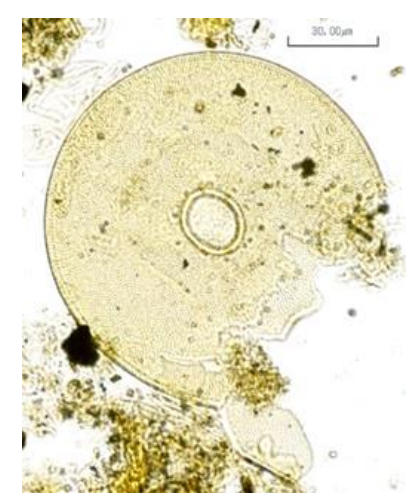

Arcella

HdV-352

Ch, D1L1, D3L6

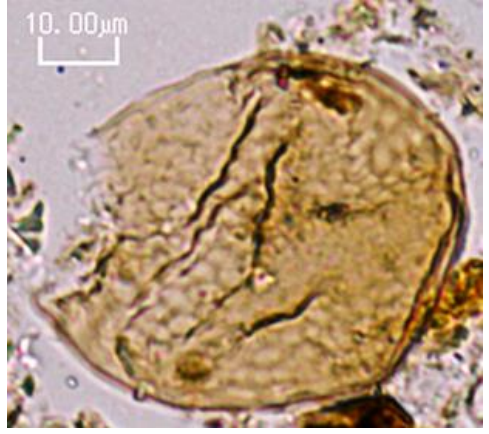

Assulina

HdV-32

$\operatorname{Tr} 5-2 \mathrm{~B}$

\section{(K) Plant remains}

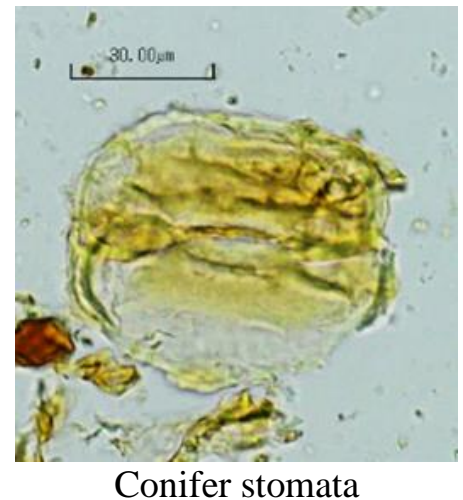

Ch, D1L1, D3L6, Tr5-2B

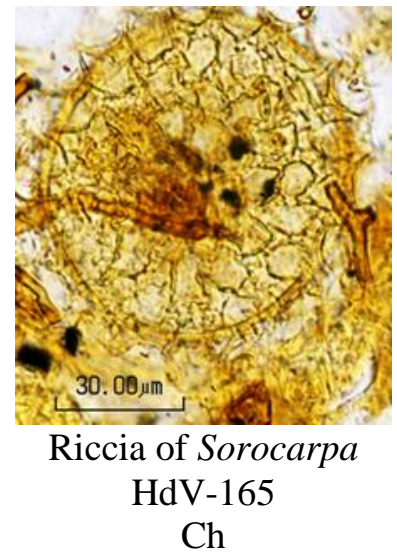

$\mathrm{Ch}$

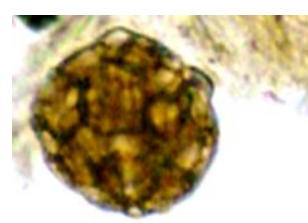

30. $00 \mu \mathrm{m}$

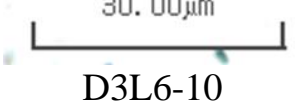

Ch, D1L1, D3L6 


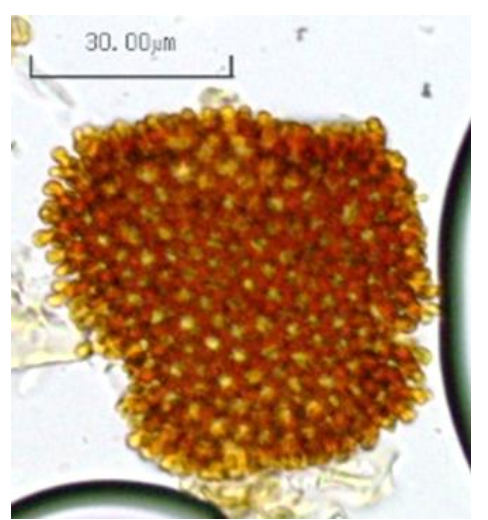

Tr5-2B-4

$\operatorname{Tr} 5-2 \mathrm{~B}$

\section{(L) Algae}
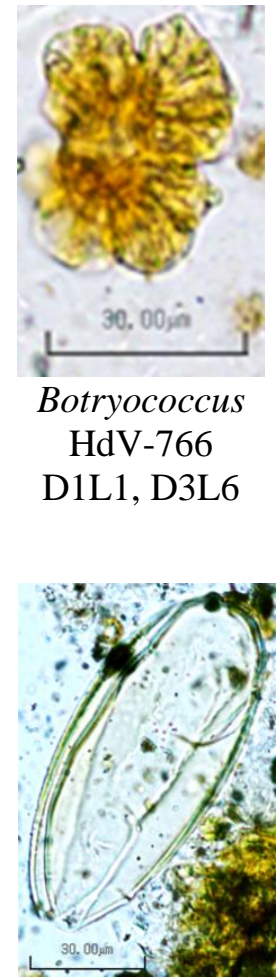

Spirogyra, type 1

HdV-130

D1L1, D3L6

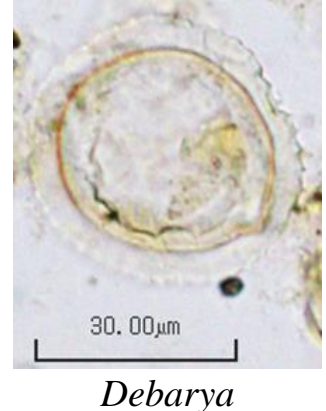

HdV-214

D1L1, D3L6

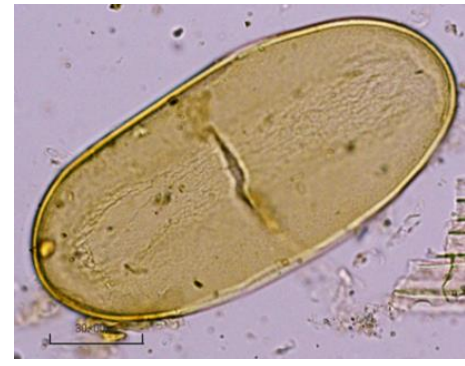

Spirogyra, type 2

HdV-132

D1L1, D3L6

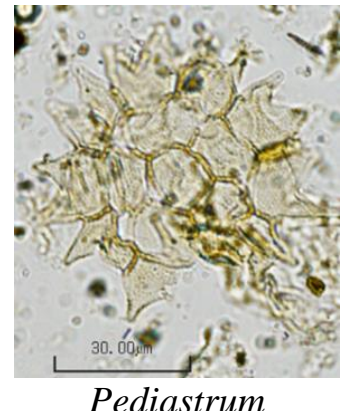

HdV-760

D1L1, D3L6

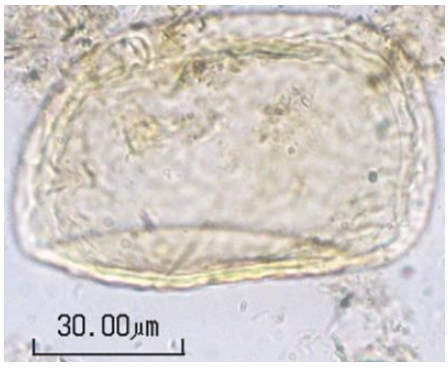

Spirogyra, type 3

HdV-210

D1L1, D3L6 


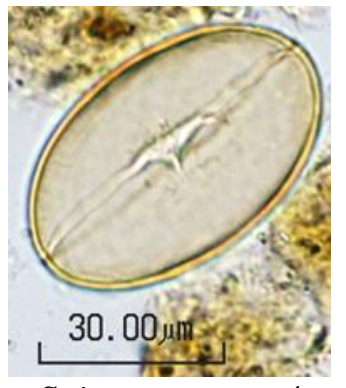

Spirogyra, type 4

HdV-417A

D1L1, D3L6

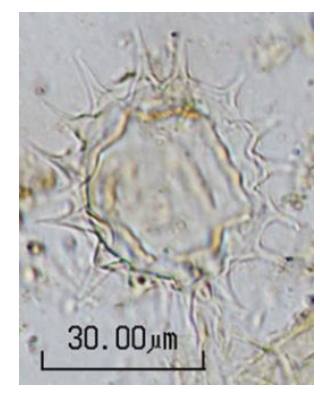

D1L1-23

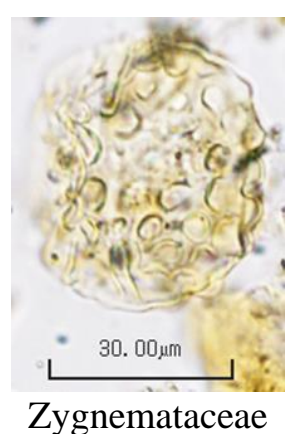

D1L1, D3L6

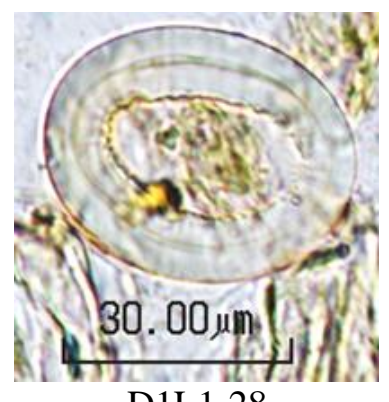

D1L1-28

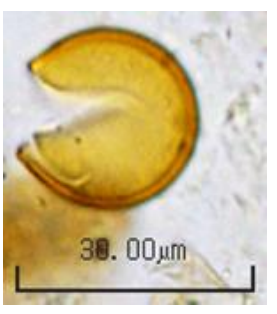

HdV-128

D1L1, D3L6

D1L1

D1L1 


\section{Appendix A3: Atlas of identified macro-charcoal morphotypes}

The atlas comprises all macro-charcoal morphotypes identified during the research in the Mongolian Altai. They are presented by name of type, pictures and morphological description. The atlas is divided into (A) wood-type macro-charcoal, (B) leaf-type macro-charcoal, (C) grass-type macrocharcoal and (D) other macro-charcoal types.

\section{(A) Wood-type macro charcoal}
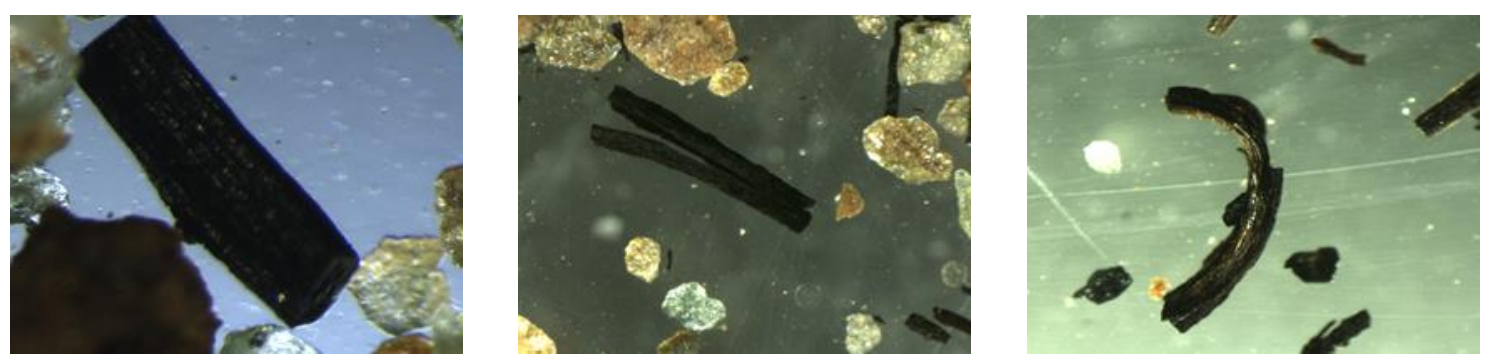

three-dimensional, larger particles

\section{(B) Leaf-type macro charcoal}
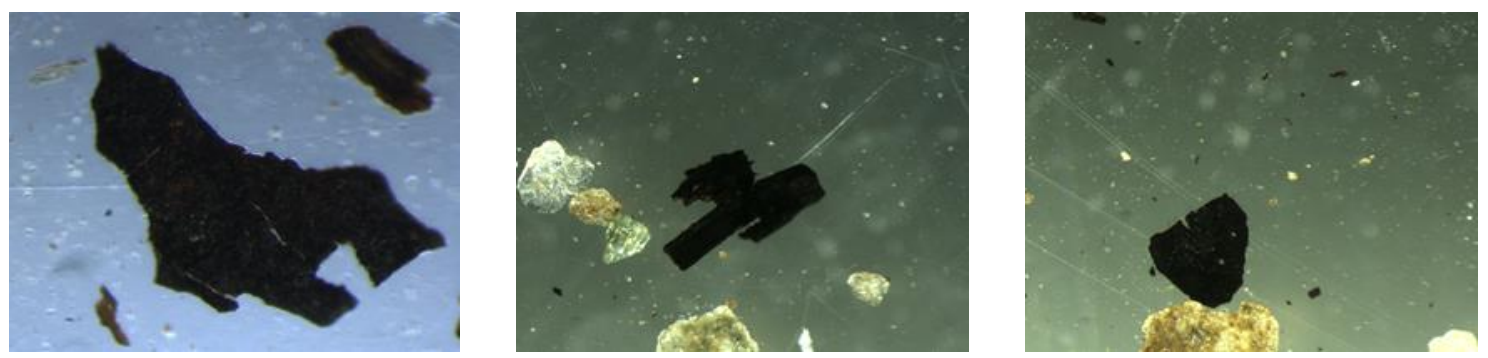

two-dimensional, irregularly shaped

\section{(C) Grass-type macro charcoal}
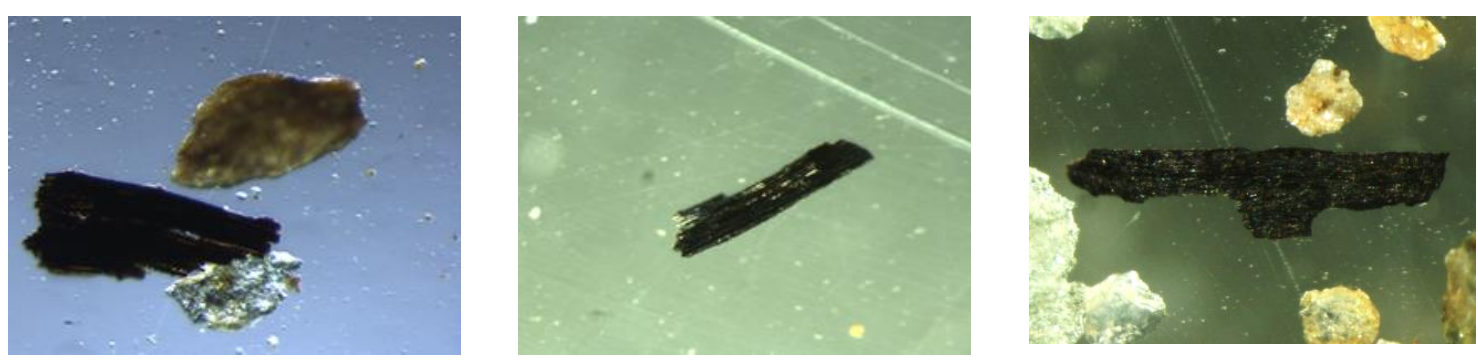

two-dimensional, elongated shape 
(D) Other macro charcoal types

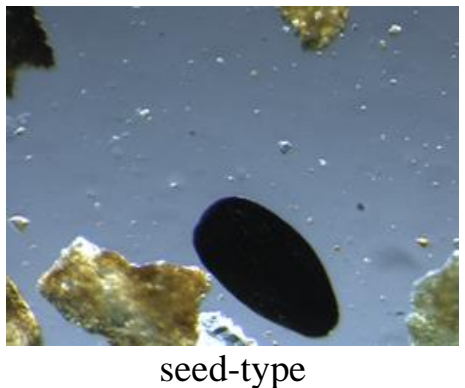

three-dimensional, rounded

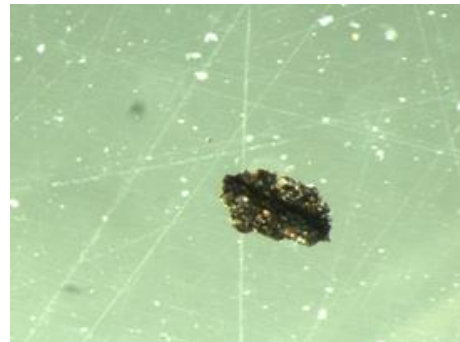

moss-type

three-dimensional, frayed edges

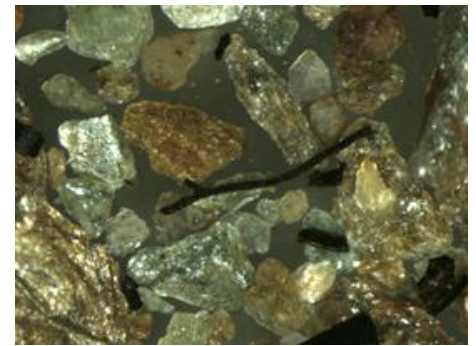

root-type

three-dimensional, long, thin 



\section{Appendix B}

\section{Detailed pollen and non-pollen palynomorph diagrams}

Appendix B1: Complete pollen percentage diagram of core G2-A, covering the last 3,880 cal yr BP (Manuscript 1)

Appendix B2: Complete pollen percentage diagram of core D3L6, covering the last 4,310 cal yr BP (Manuscript 2)

Appendix B3: Complete NPP percentage diagram of core D3L6, covering the last 4,310 cal yr BP (Manuscript 2)

Appendix B4: Complete pollen percentage diagram of core D1L1, covering the last 1,350 cal yr BP (Manuscript 3)

Appendix B5: Complete NPP percentage diagram of core D1L1, covering the last 1,350 cal yr BP (Manuscript 3)

Appendix B6: Complete diatom percentage diagram of core D1L1, covering the last 1,350 cal yr BP (Manuscript 3)

Appendix B7: Complete pollen percentage diagram of core $\mathrm{Ch}$, covering the last $320 \mathrm{cal}$ yr BP (Manuscript 4)

Appendix B8: Complete NPP percentage diagram of core $\mathrm{Ch}$, covering the last $320 \mathrm{cal} \mathrm{yr}$ BP (Manuscript 4)

Appendix B9: Complete pollen percentage diagram of core Tr5-2B, covering the last 1,350 cal yr BP (Manuscript 4)

Appendix B10:Complete NPP percentage diagram of core Tr5-2B, covering the last 1,350 cal yr BP (Manuscript 4) 
Appendix B1: Complete pollen percentage diagram of core G2-A, covering the last 3,880 cal yr BP (Manuscript 1) 


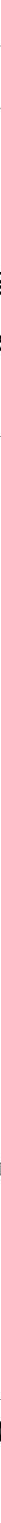




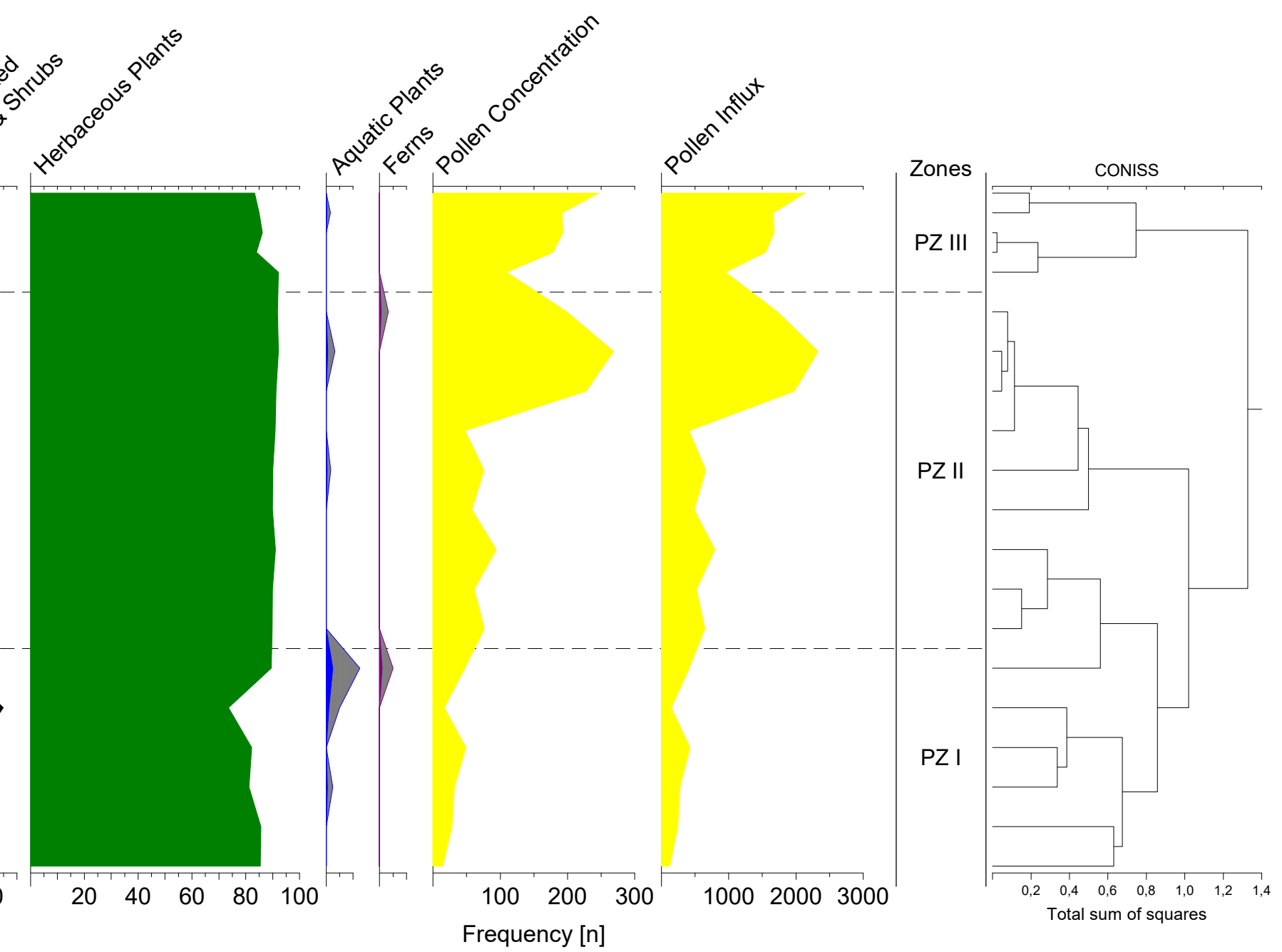


Appendix B2: Complete pollen percentage diagram of core D3L6, covering the last 4,310 cal yr BP (Manuscript 2) 


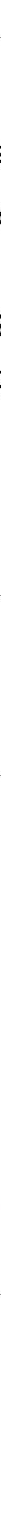




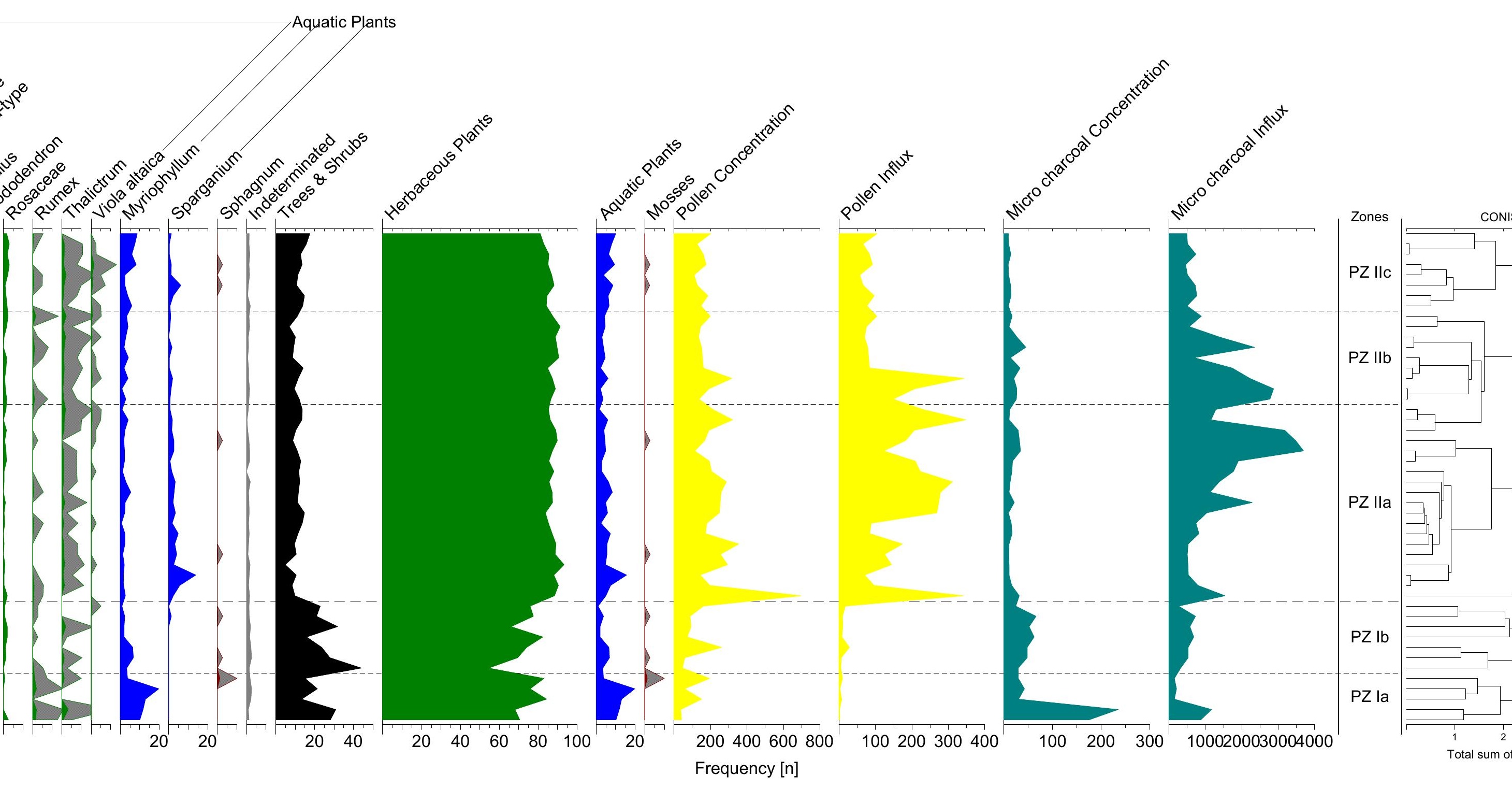


Appendix B3: Complete NPP percentage diagram of core D3L6, covering the last 4,310 cal yr BP (Manuscript 2) 


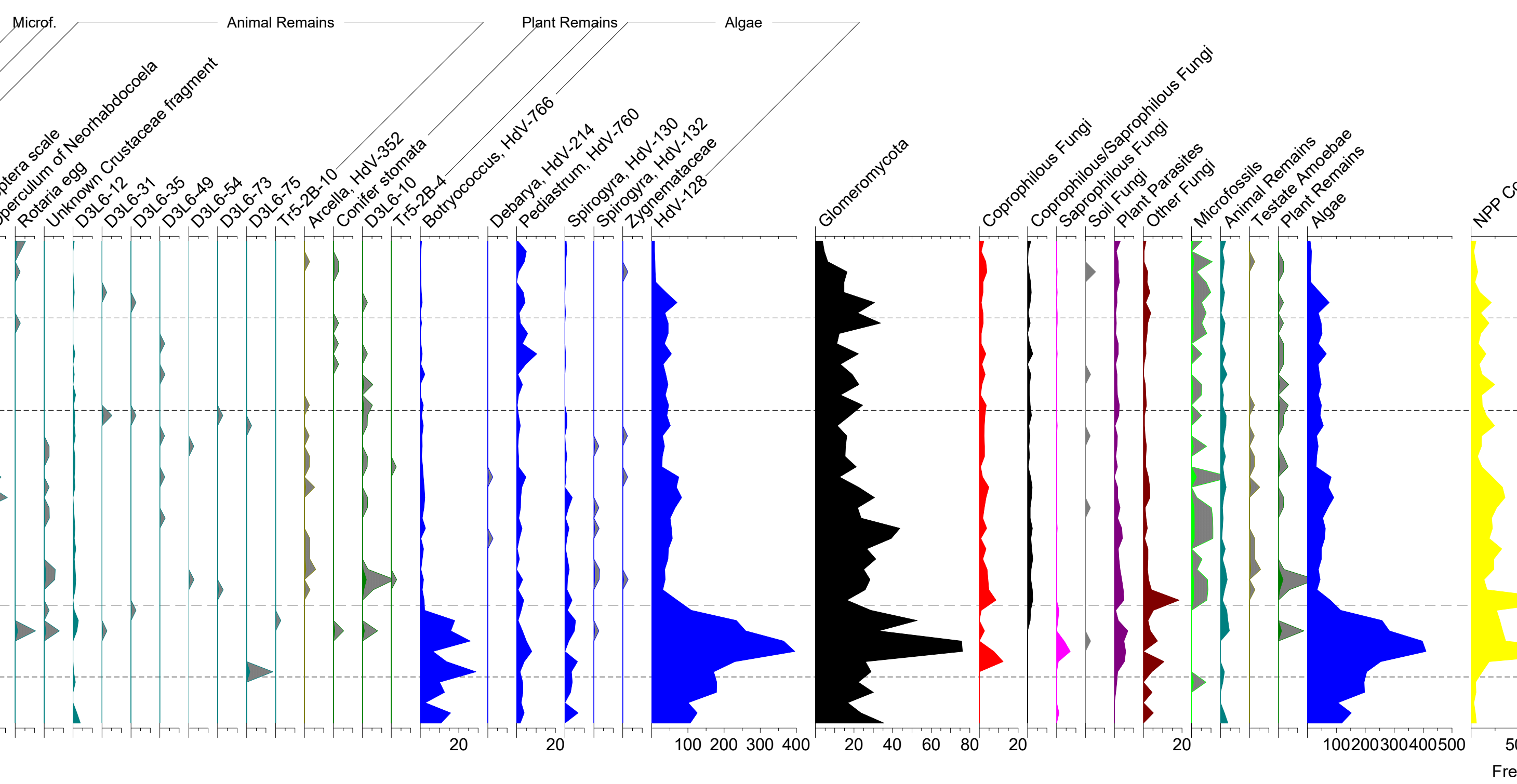


Zones

PZ IIc

PZ IIb

PZ Ila

PZ Ib

PZ la

$01000 \quad 1500$

quency [n] 
Appendix B4: Complete pollen percentage diagram of core D1L1, covering the last 1,350 cal yr BP (Manuscript 3) 


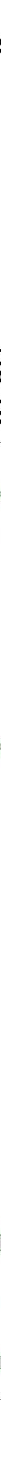

Frequency [\%] 


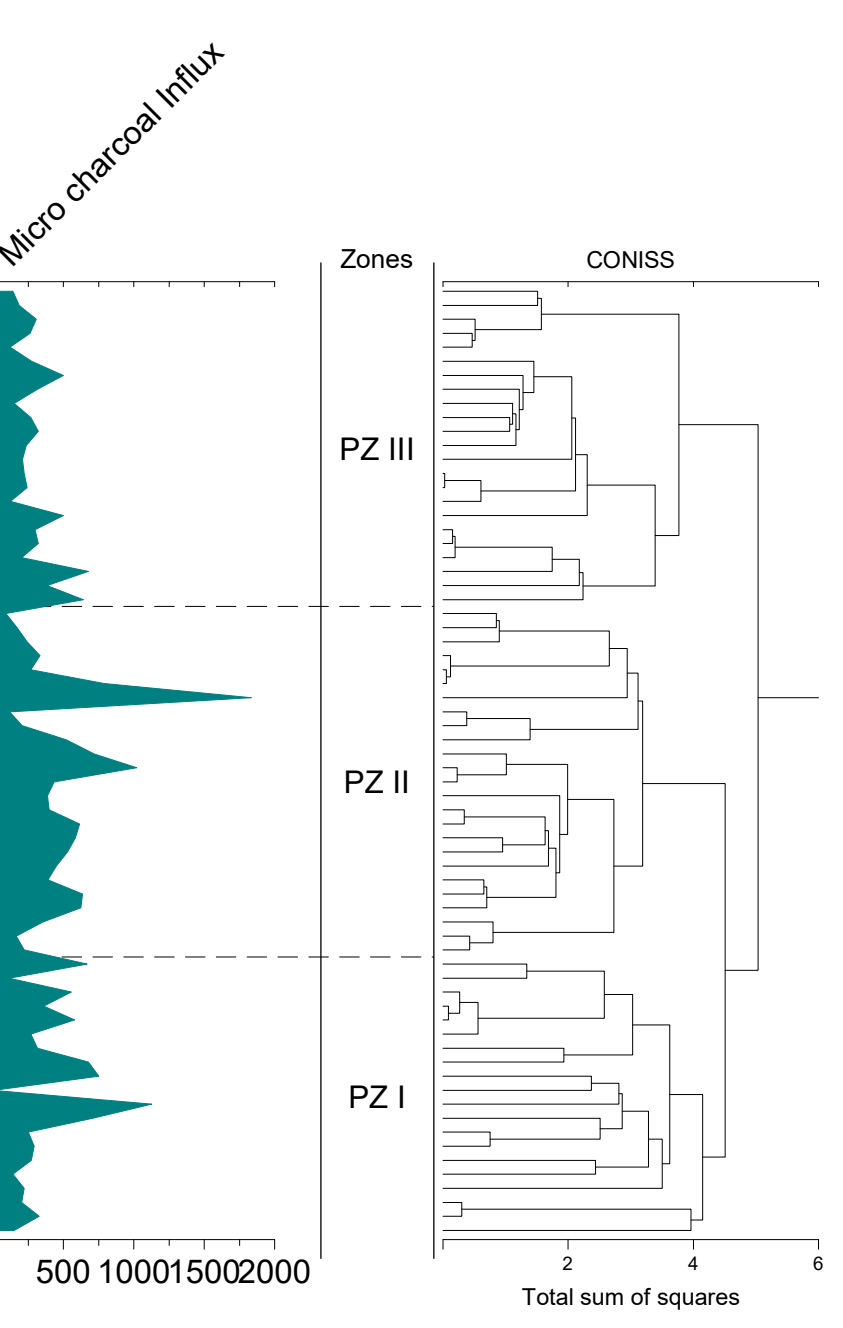


Appendix B5: Complete NPP percentage diagram of core D1L1, covering the last 1,350 cal yr BP (Manuscript 3) 


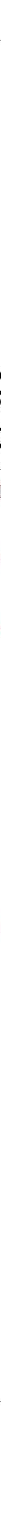




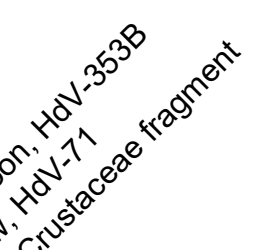

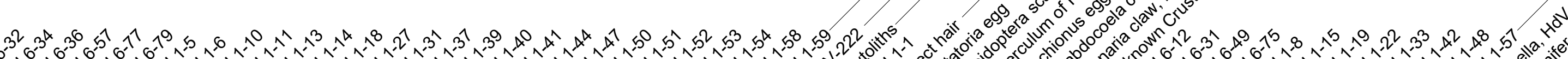

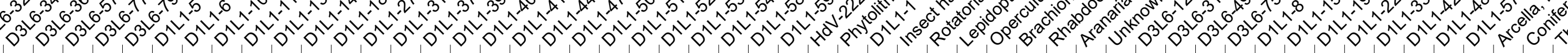

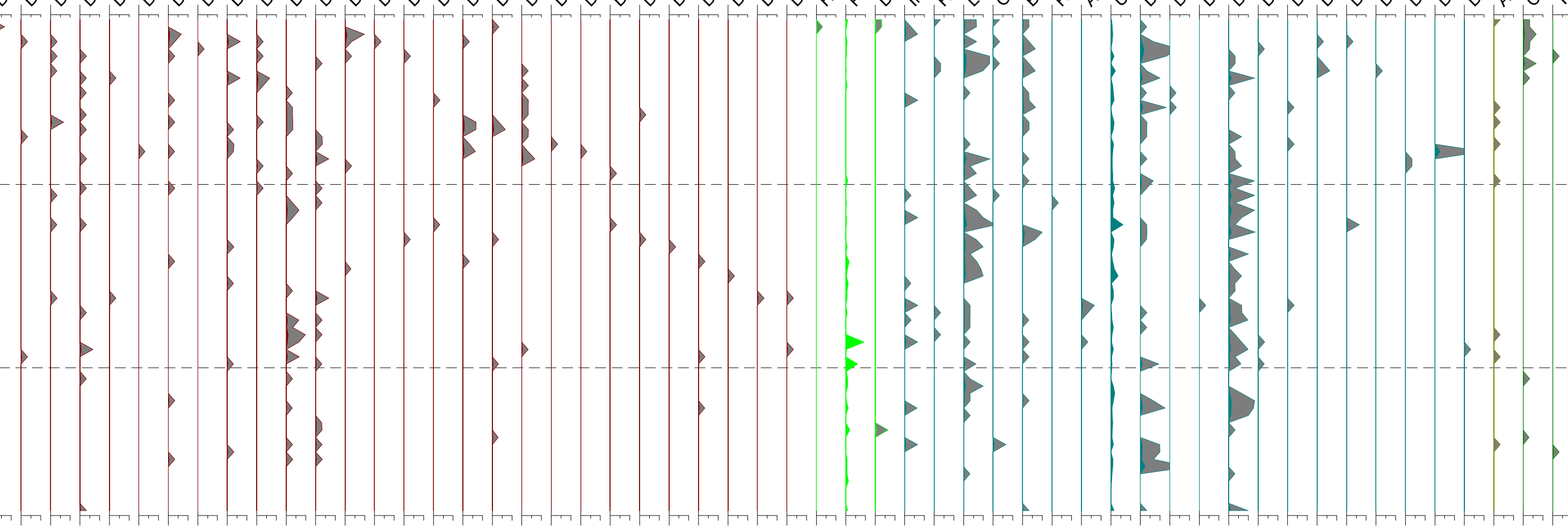




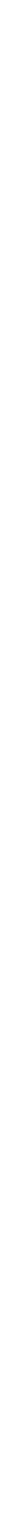



Appendix B6: Complete diatom percentage diagram of core D1L1, covering the last 1,350 cal yr BP (Manuscript 3) 


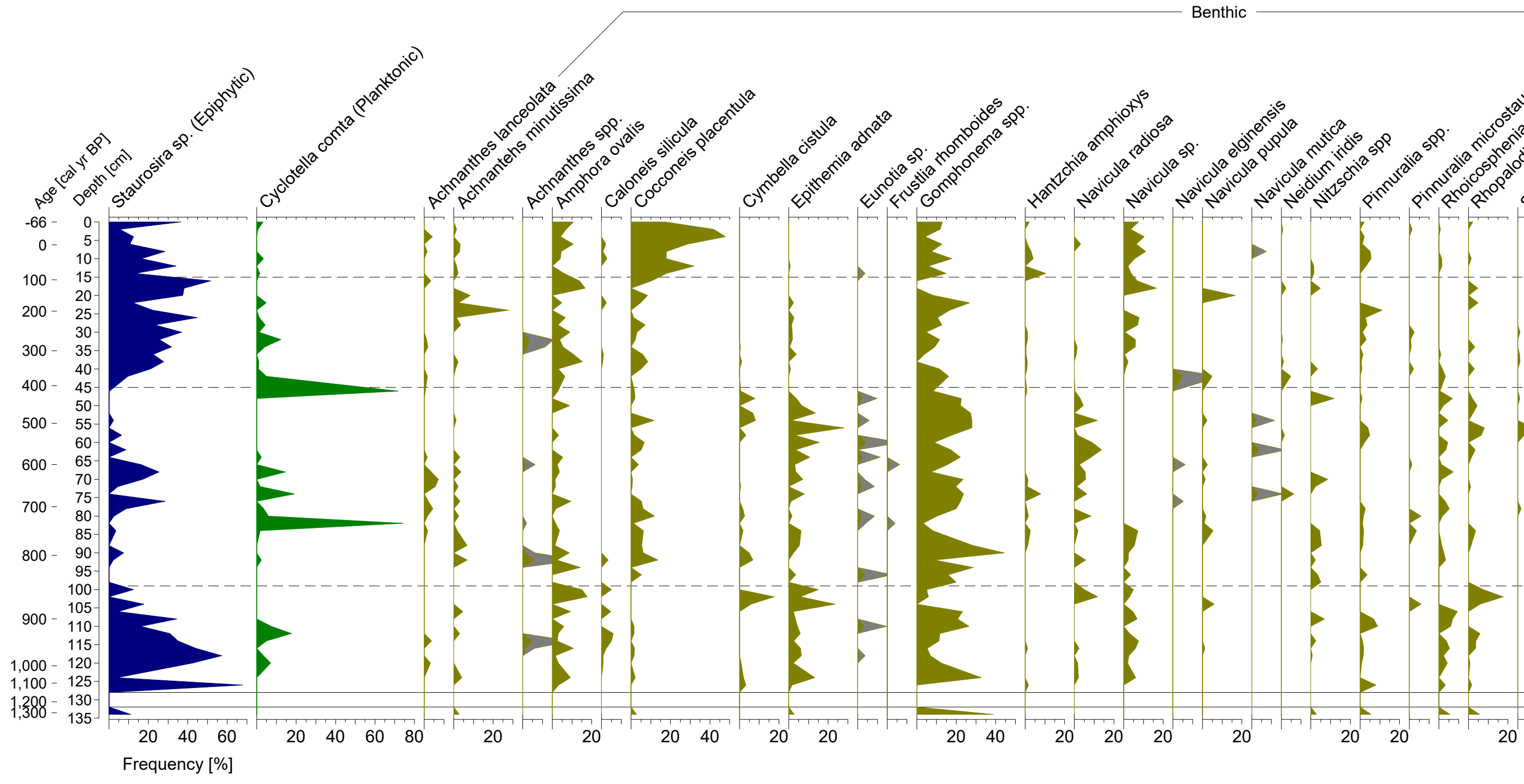




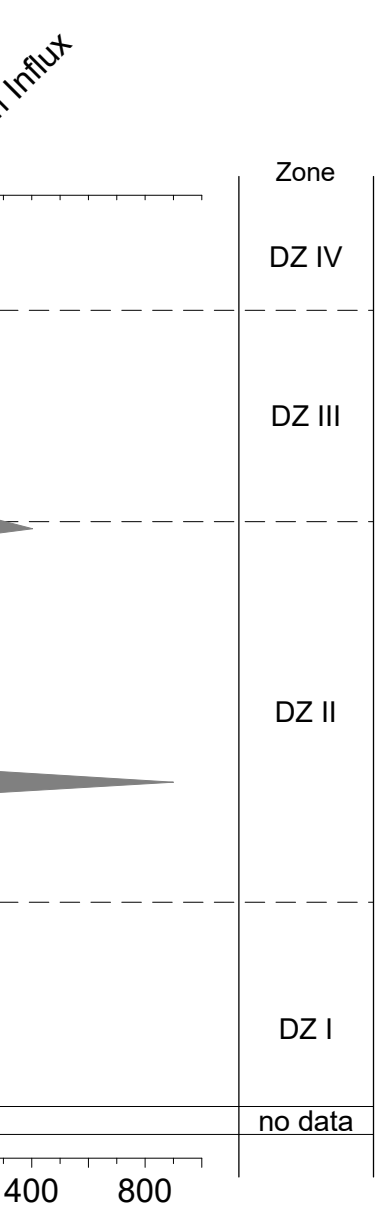


Appendix B7: Complete pollen percentage diagram of core $\mathrm{Ch}$, covering the last $320 \mathrm{cal} \mathrm{yr}$ BP (Manuscript 4) 


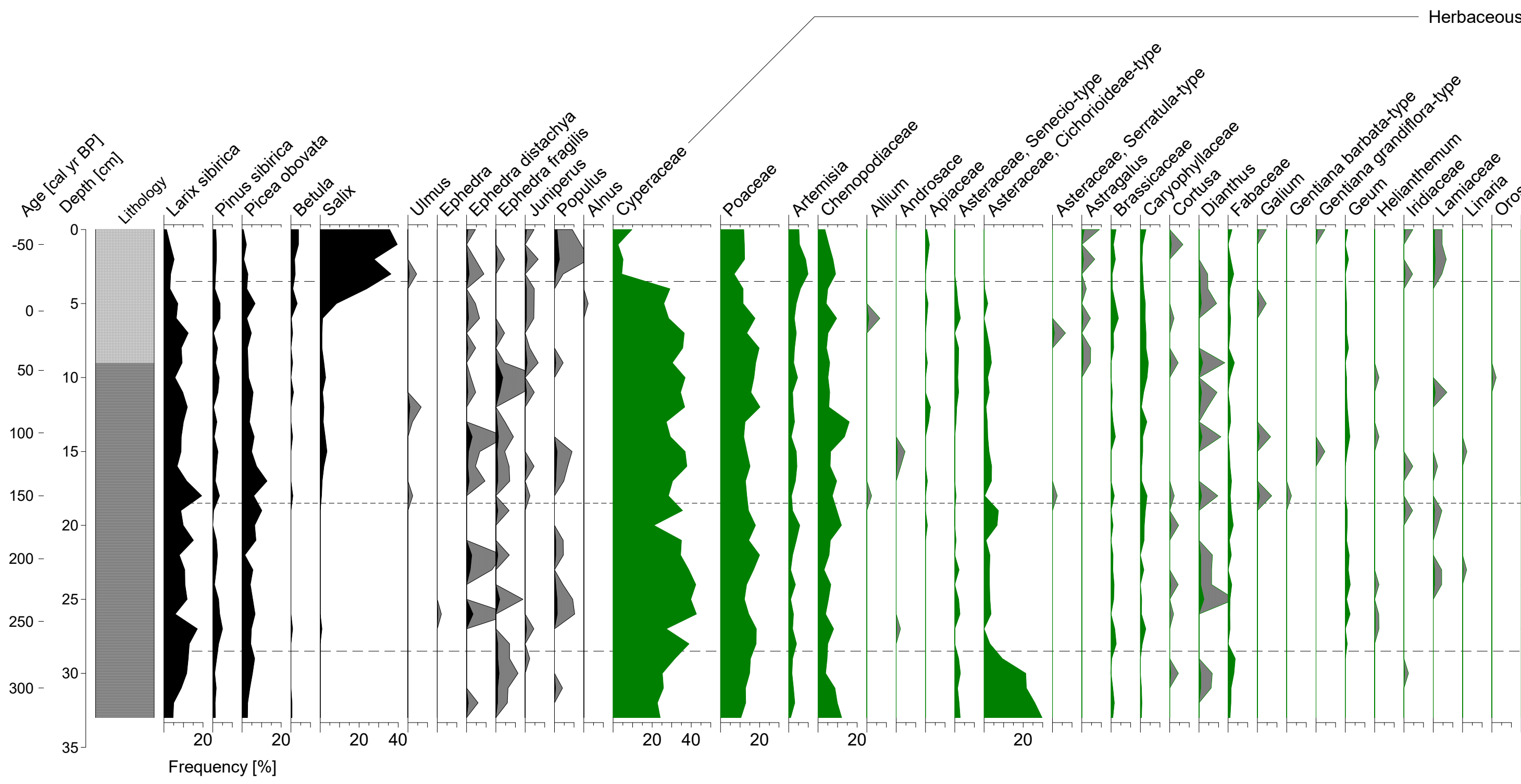




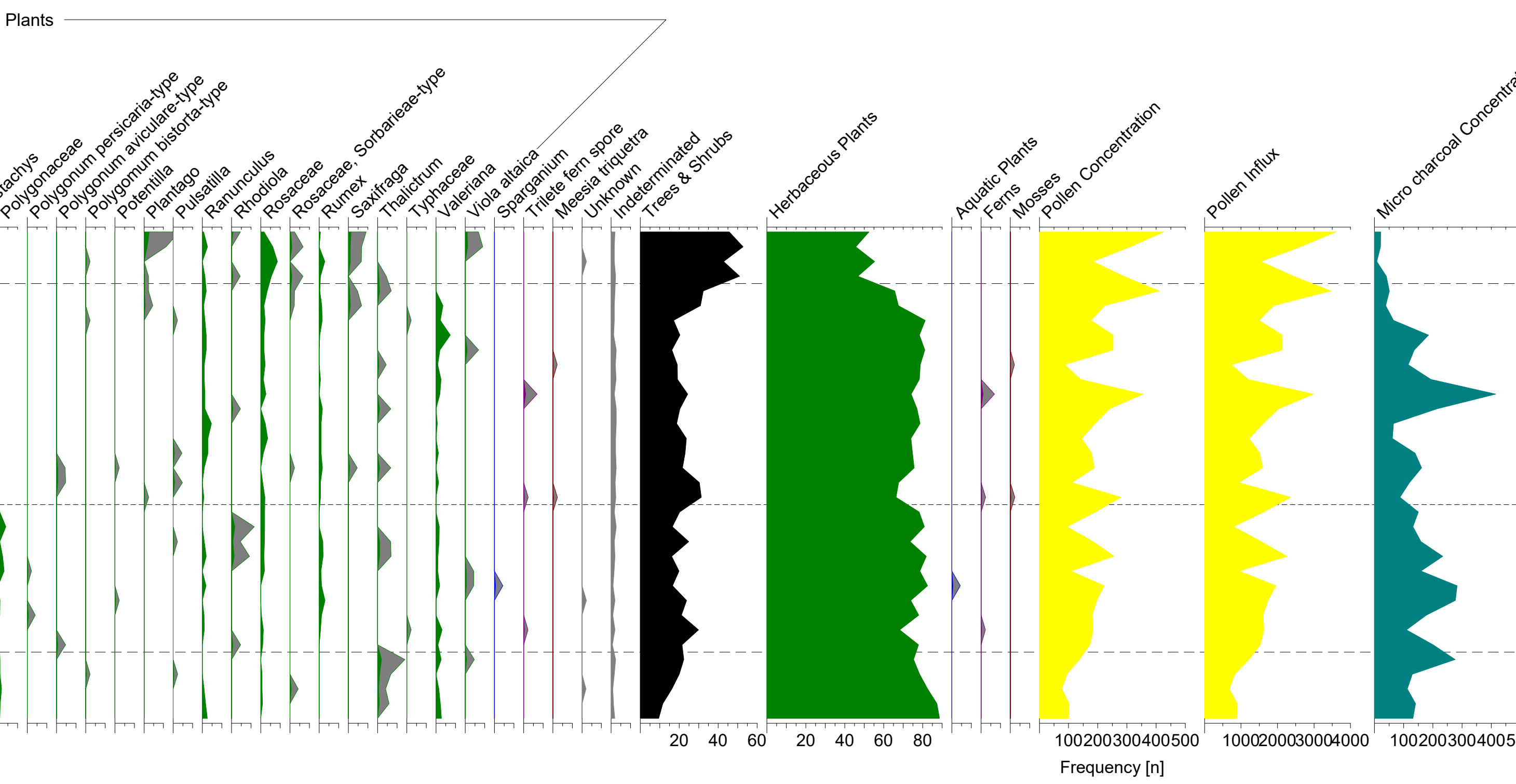




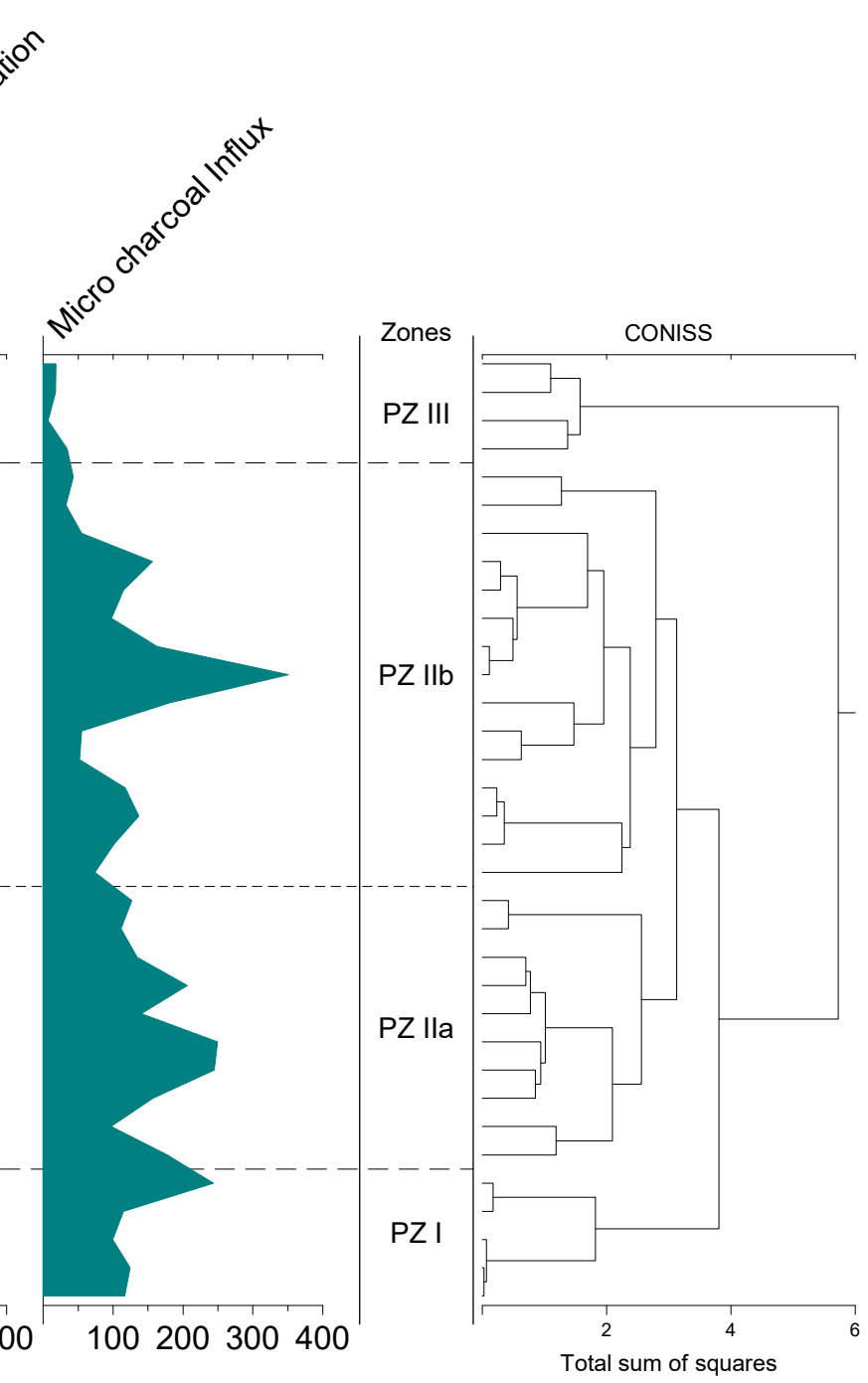


Appendix B8: Complete NPP percentage diagram of core Ch, covering the last $320 \mathrm{cal} \mathrm{yr}$ BP (Manuscript 4) 


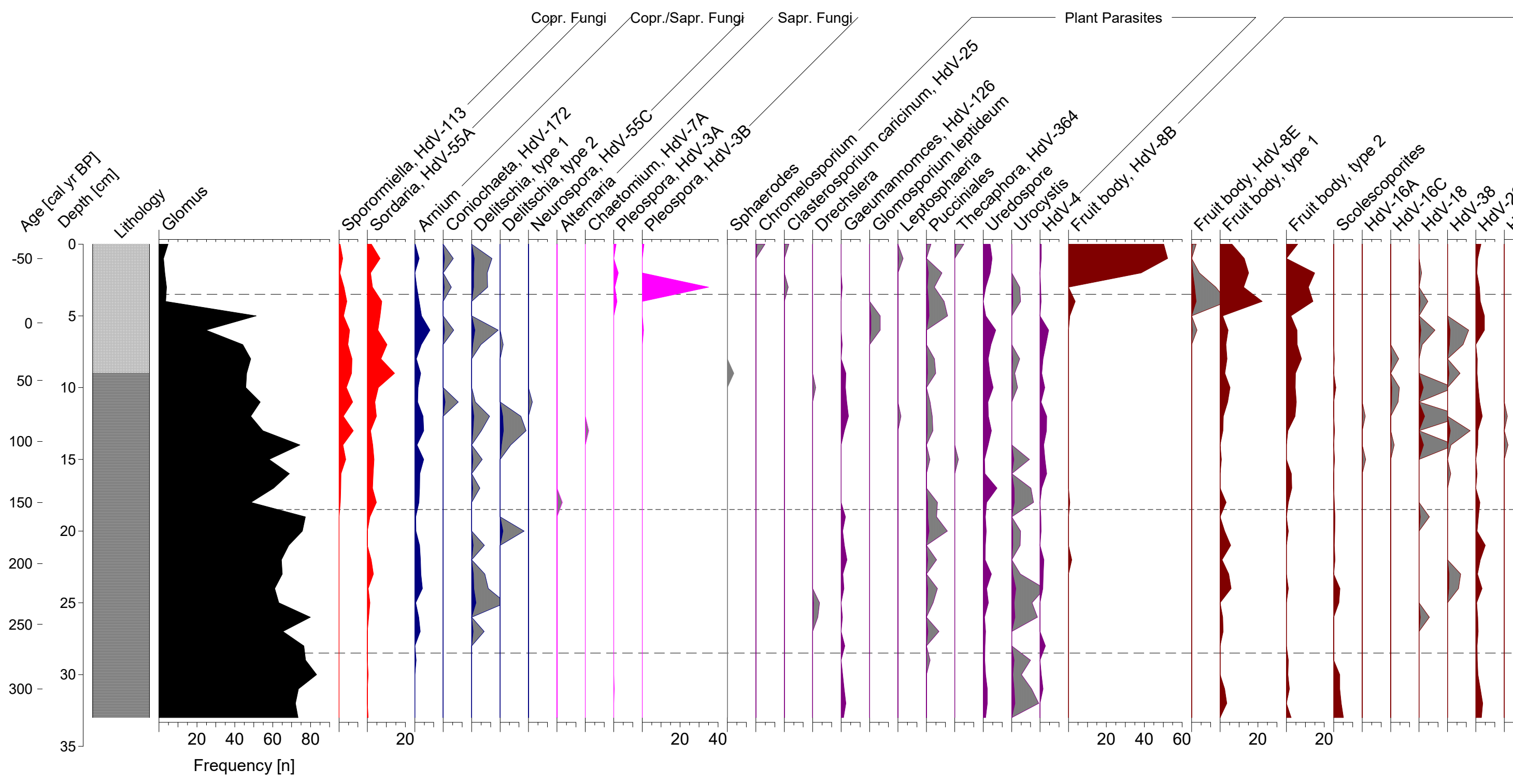




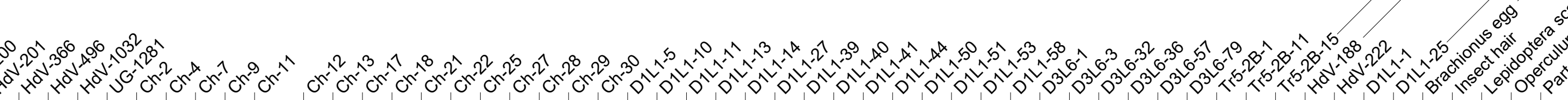

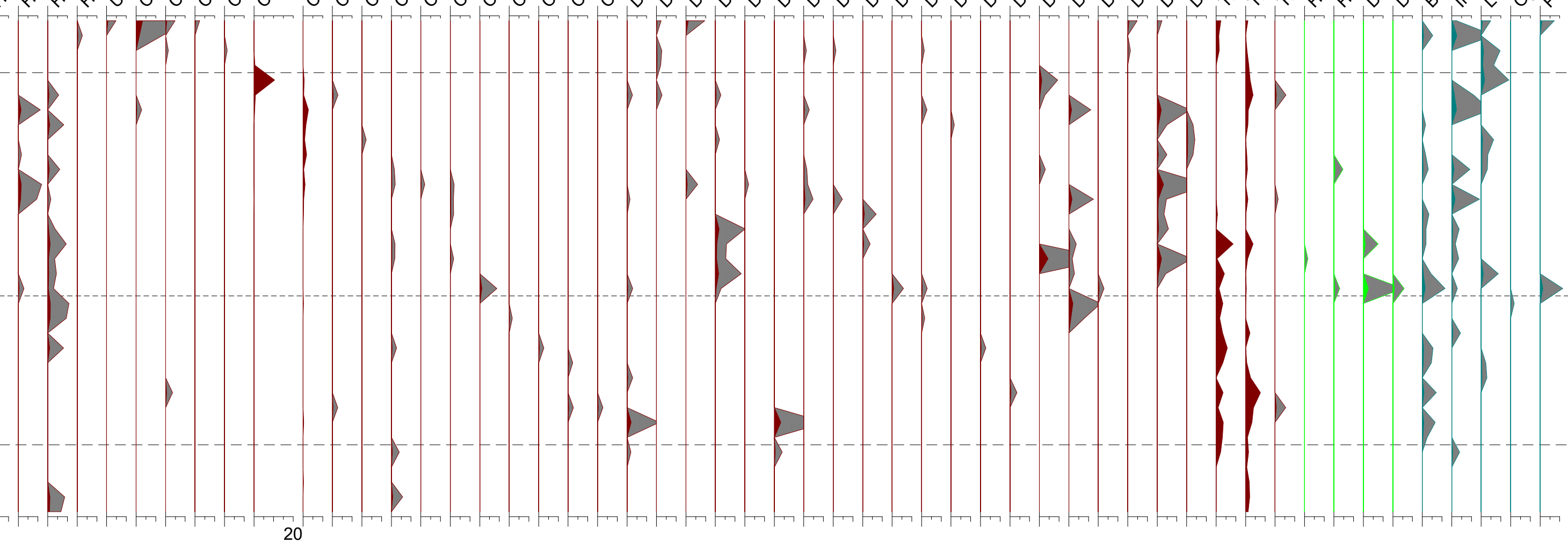




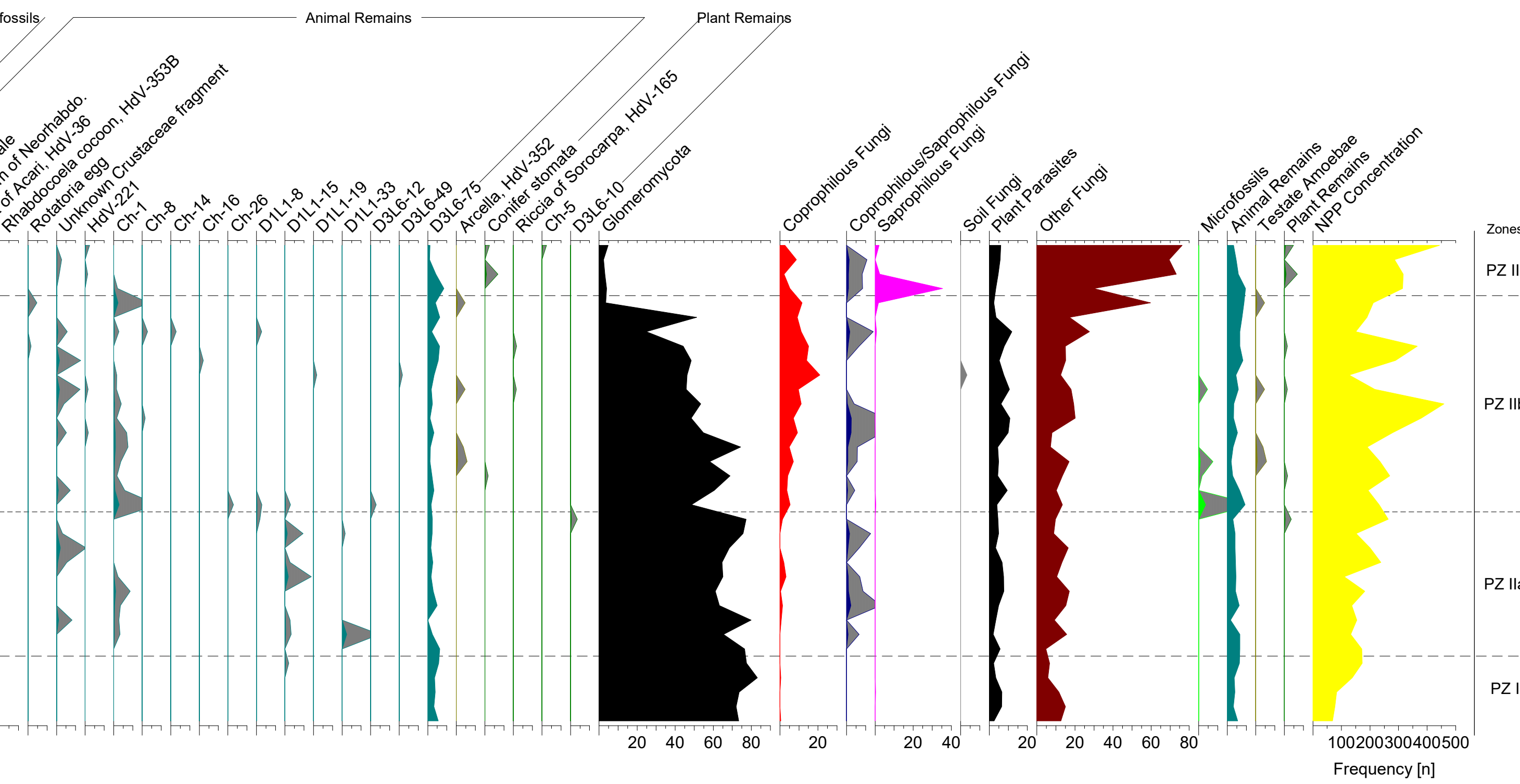



Appendix B9: Complete pollen percentage diagram of core $\operatorname{Tr} 5-2 \mathrm{~B}$, covering the last 1,350 cal yr BP (Manuscript 4) 


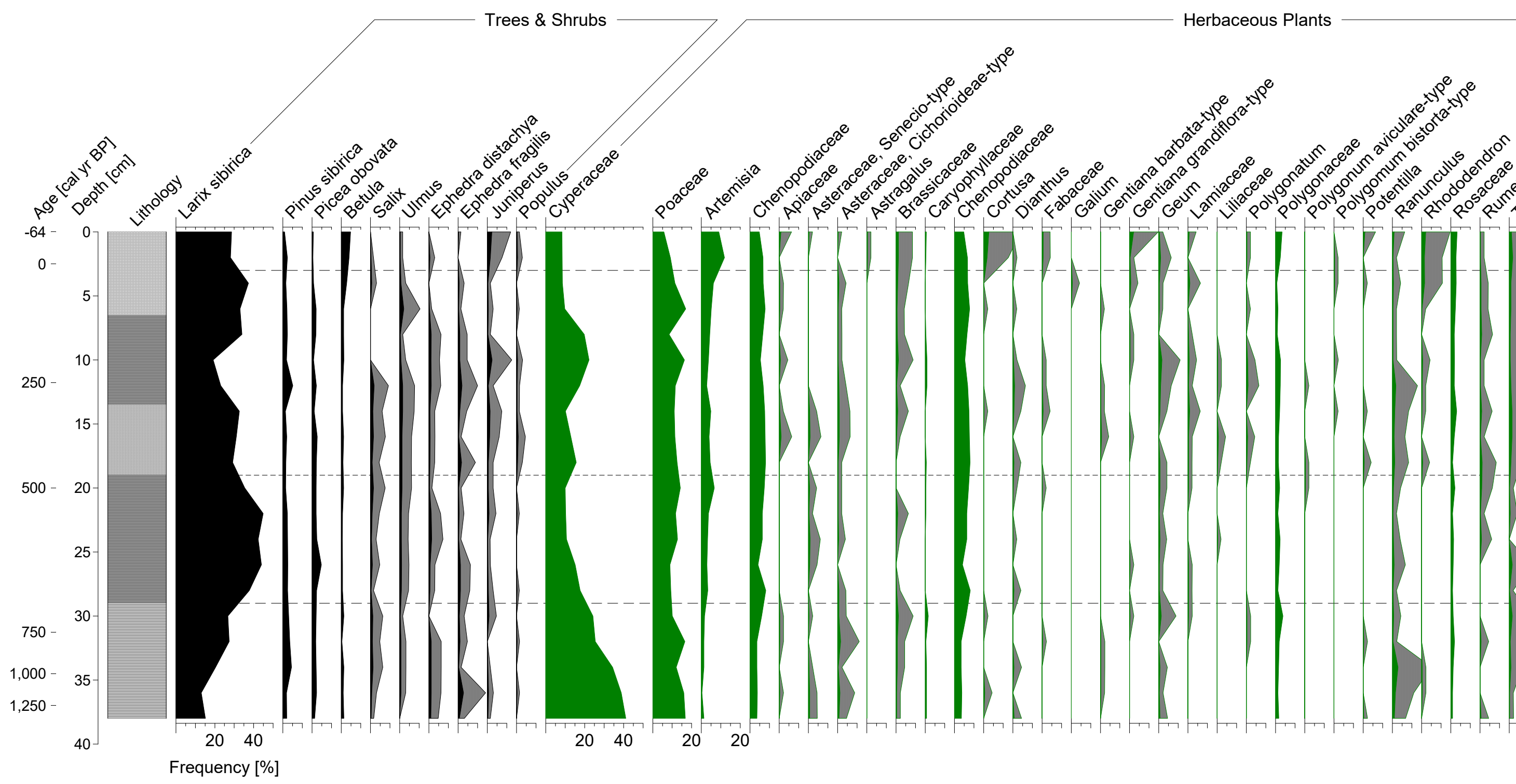




$$
\text { UIE }
$$


Appendix B10: Complete NPP percentage diagram of core Tr5-2B, covering the last 1,350 cal yr BP (Manuscript 4) 


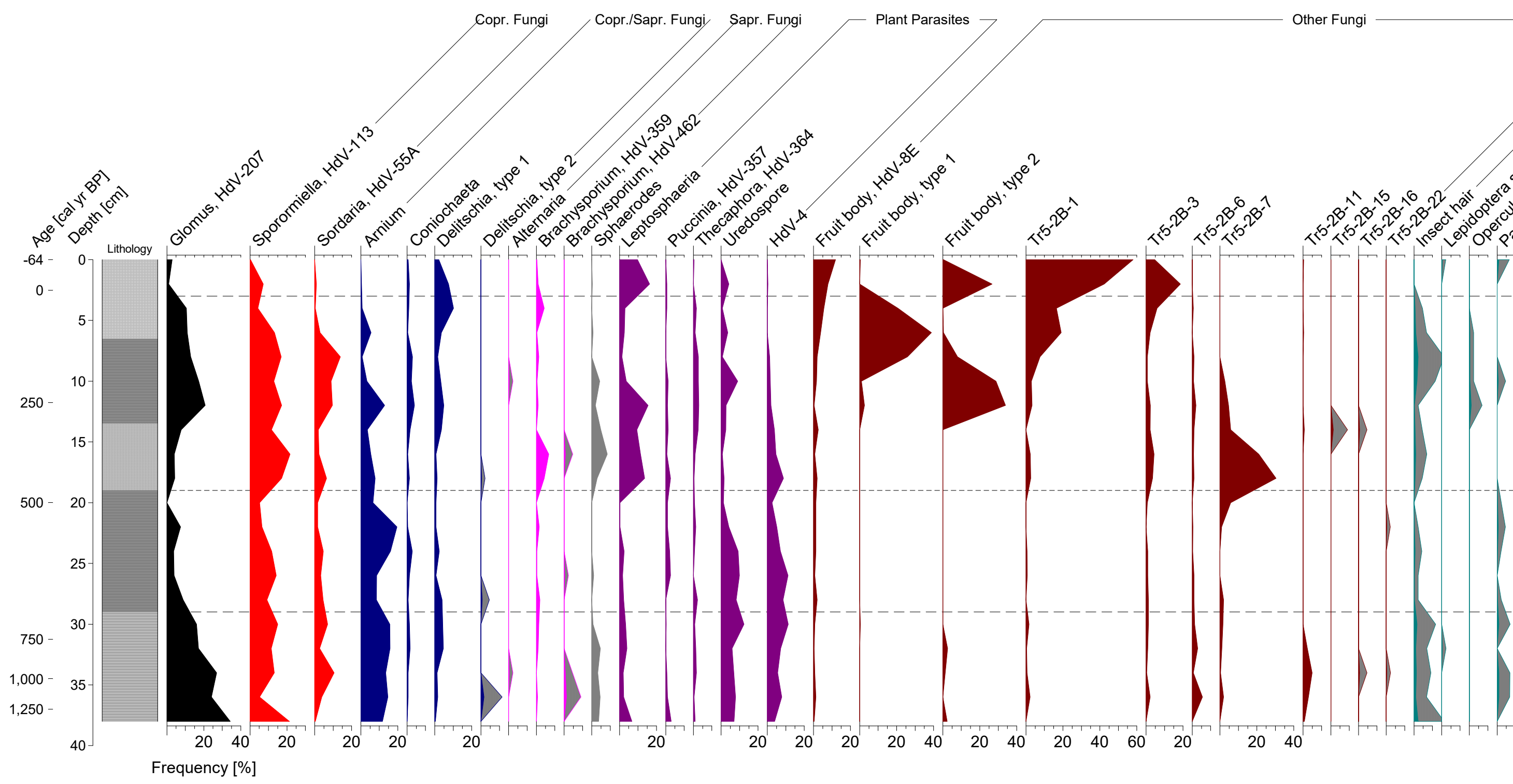




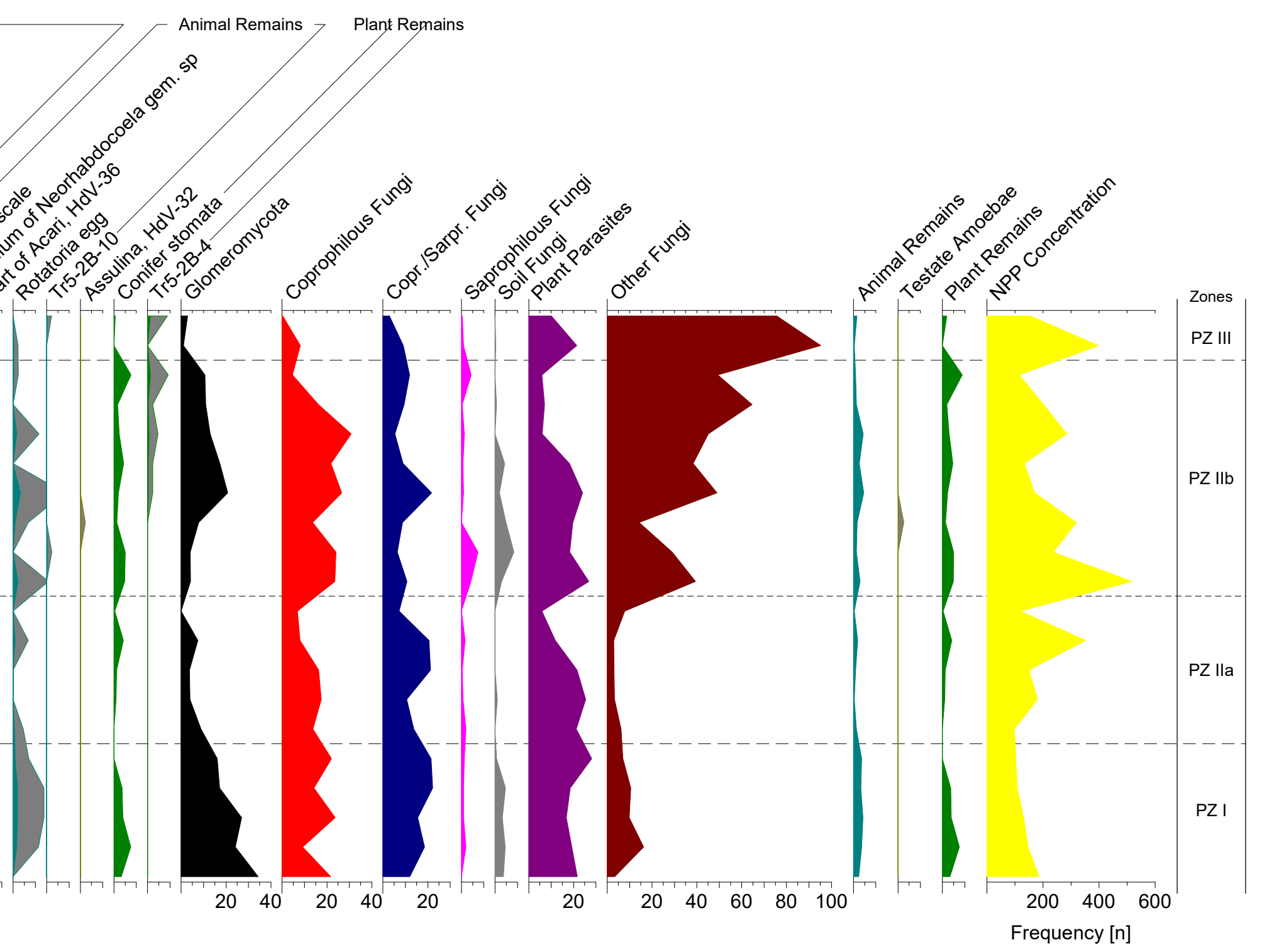

